\title{
Stochastic Analysis of Particle Movement over a Dune Bed
}

GEOLOGICAL SURVEY PROFESSIONAL PAPER 1040

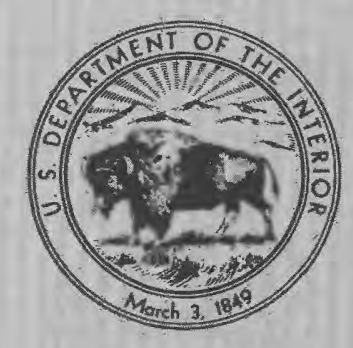





\section{Stochastic Analysis of \\ Particle Movement over a Dune Bed}

By BAUM K. LEE and HARVEY E. JOBSON

GEOLOGICAL SURVEY PROFESSIONAL PAPER 1040

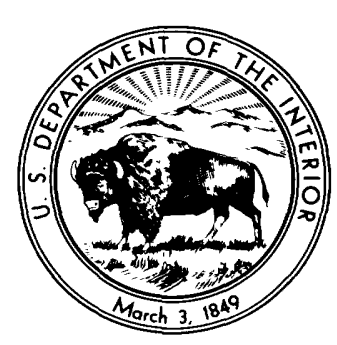

UNITED STATES GOVERNMENT PRINTING OFFIGE, WASHINGTON : 1977 


\title{
UNITED STATES DEPARTMENT OF THE INTERIOR
}

\section{CECIL D. ANDRUS, Secretary}

\section{GEOLOGICAL SURVEY}

\author{
V. E. McKelvey, Director
}

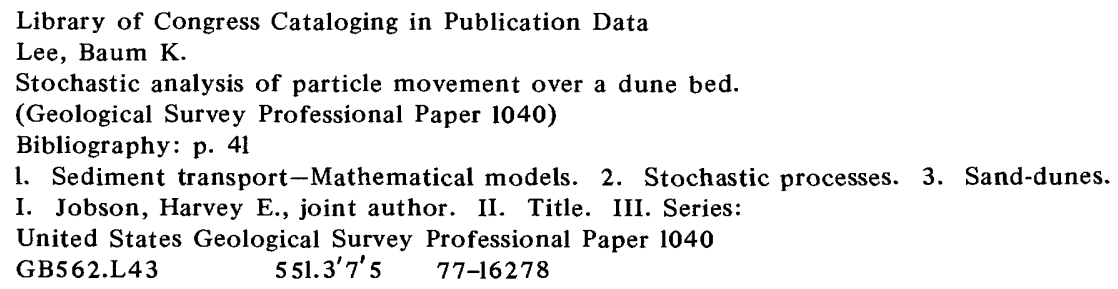

1. Sediment transport-Mathematical models. 2. Stochastic processes. 3. Sand-dunes.

I. Jobson, Harvey E., joint author. II. Title. III. Series:

United States Geological Survey Professional Paper 1040

$\begin{array}{lll}\text { GB562.L43 } & 551.3^{\prime} 7^{\prime} 5 & 77-16278\end{array}$

For sale by the Superintendent of Documents, U.S. Government Printing Office

Washington, D.C. 20402

Stock Number 024-001-03024-1 


\section{CONTENTS}

\begin{abstract}
Introduction

Acknowledgment

Background

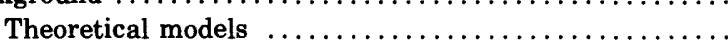

Experimental studies $\ldots \ldots \ldots \ldots \ldots \ldots \ldots \ldots \ldots$.

Remarks

Development of theory

Characteristics of particle movement over a dune bed ..

Estimation of the probability distributions of the elevations of deposition and erosion ..................

Estimation of the probability distributions of the rest periods

Estimation of the probability distributions of the step lengths

Bed-material transport equations
\end{abstract}

\begin{tabular}{r|r} 
Page \\
1 \\
1 \\
2 \\
2 \\
2 \\
4 \\
5 \\
5 \\
5 \\
6 \\
8 \\
8 \\
10 \\
14
\end{tabular}

Development of theory - Continued

General two-dimensional stochastic model for dispersion of bed-material sediment particles $\ldots \ldots \ldots \ldots \ldots \ldots$

Analysis and discussion of results $\ldots \ldots \ldots \ldots \ldots \ldots \ldots \ldots$

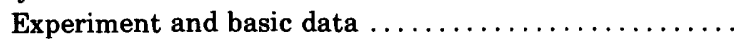

Probability distributions of the elevations of deposition

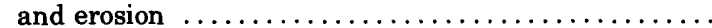

Rest period distributions $\ldots \ldots \ldots \ldots \ldots \ldots \ldots \ldots \ldots$

Step length distributions $\ldots \ldots \ldots \ldots \ldots \ldots \ldots \ldots \ldots$

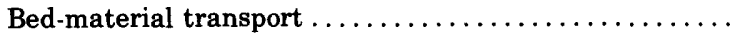

Variation of various statistics with flow conditions and a relation between the step length and the rest period

Two-dimensional stochastic model for dispersion of bedmaterial sediment particles $\ldots \ldots \ldots \ldots \ldots \ldots \ldots \ldots$

Summary and conclusions $\ldots \ldots \ldots \ldots \ldots \ldots \ldots \ldots \ldots \ldots$

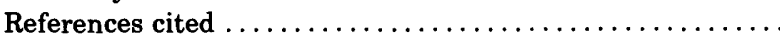

Page

18

22

22

23

25

30

36

39

39

40

\section{ILLUSTRATIONS}

Figures 1-20. Graphs showing:

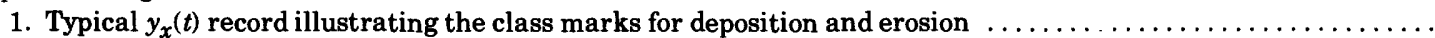

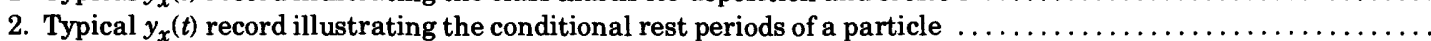

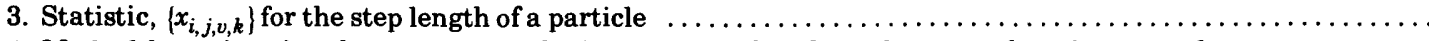

4. Method for estimating the percentage of volume occupied by dunes between elevations $\eta_{j}$ and $\eta_{j+1} \ldots \ldots \ldots \ldots$

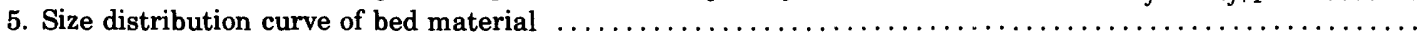

6. Frequency histograms, triangular density function, and truncated Gaussian density function for the elevation of deposition and erosion

7 -9. Sample probability mass functions of the conditional rest periods with fitted two-parameter gamma functions for:

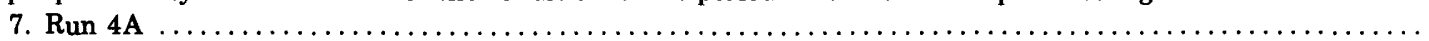

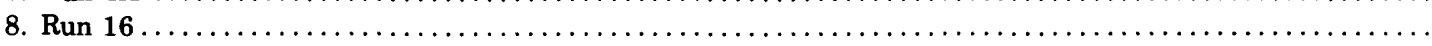

9. Run 17 .

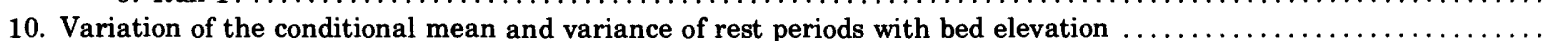

11. Frequency histograms for the marginal rest period and exponential fits $\ldots \ldots \ldots \ldots \ldots \ldots \ldots \ldots \ldots \ldots \ldots$

$12-14$. Sample probability mass functions of the conditional step lengths given the elevation of erosion is 0.0 with Gamma fits for:

12. Run $4 \mathrm{~A}$

13. Run 16

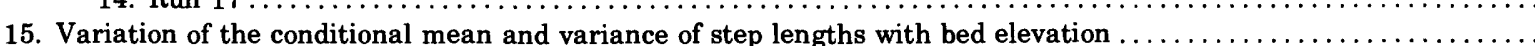

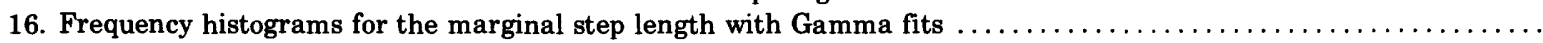

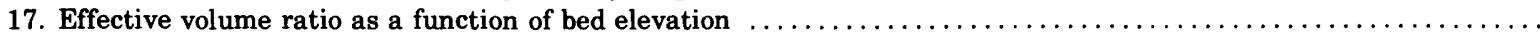

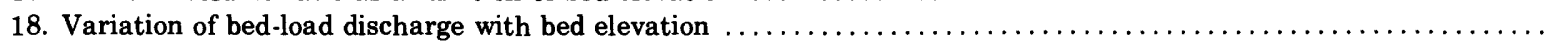

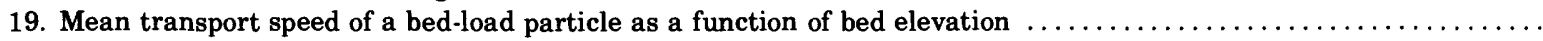

20. Ratio of the conditional variance of step lengths to the conditional variance of rest periods as a function of bed elevation 


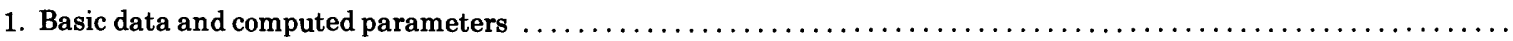

2. Sample probability mass functions of elevations of deposition and erosion $\ldots \ldots \ldots \ldots \ldots \ldots \ldots \ldots \ldots \ldots \ldots \ldots \ldots \ldots$

3 -5. Sample conditional probability mass function of rest periods, $p_{T \backslash Y_{D}}\left(t_{\alpha} \backslash y_{i}\right)$ for:

3. Run $4 \mathrm{~A}$

4. Run 16

5. Run 17 .

6. Variation of conditional mean and variance of rest periods with elevation of $\operatorname{deposition;} \hat{E}\left[T \backslash Y_{D}=y\right]$ and $V a \hat{n}$ $\left[T \backslash Y_{D}=y\right]$.

7. Estimates of parameters and the results of goodness of fit test for the conditional rest periods (two-parameter gamma)

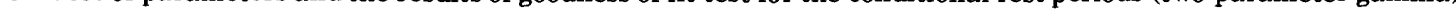

8 -10. Sample joint probability mass function of rest periods and elevation of deposition, $p_{T, Y_{D}}\left(t_{\alpha}, y_{i}\right)$ for:

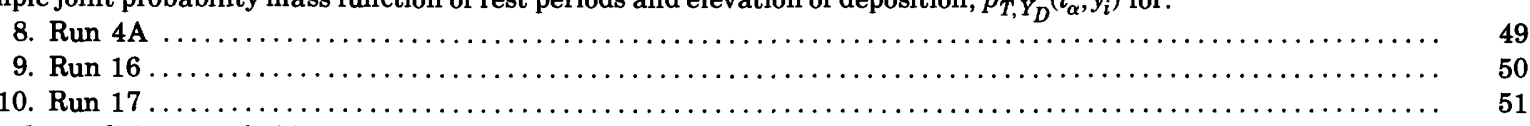

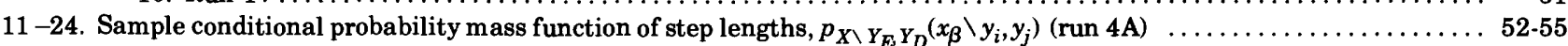

25 -42. Sample conditional probability mass function of step lengths, $p_{X \backslash Y_{E}, Y_{D}}\left(x_{\beta} \backslash y_{i}, y_{j}\right)($ run 16$) \ldots \ldots \ldots 5$. $\ldots . . \ldots 9$

43 -56. Sample conditional probability mass function of step lengths, $p_{X \backslash Y_{E}, Y_{D}}\left(x_{\beta} \backslash y_{i}, y_{j}\right)($ run 17$) \ldots \ldots$

57-59. Conditional means and variances of step lengths; $\hat{\mathrm{E}}\left[\bar{X} \backslash Y_{E}=y_{i}, Y_{D}=y_{j}\right]$ and

$\operatorname{Var}\left[X \backslash Y_{E}=y_{i}, Y_{D}=y_{j}\right]$ for:

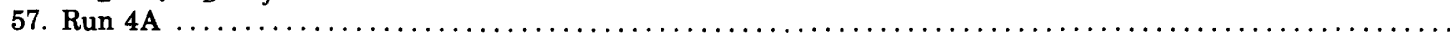

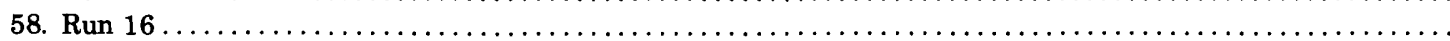

59. Run 17

$60-62$. Estimates of parameters describing two-parameter gamma distribution for conditional step lengths for:

60. Run 4A

61. Run 16

62. Run 17 .

$63-65$. Results of goodness of fit test for conditional step lengths for:

63. Run 4A

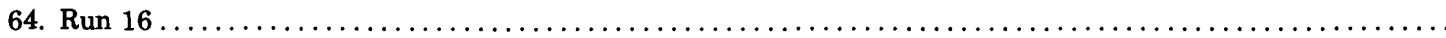

65. Run 17

66 -68. Sample conditional probability mass function of step lengths, $p_{X \backslash Y_{D}}\left(x_{\beta} \backslash y_{j}\right)$ for:

66. Run 4A

67. Run 16

69. Variation of conditional mean and variance of step lengths with elevation of deposition; $\mathrm{E}\left[X \backslash Y_{D}=y\right]$ and $\mathrm{Var}$

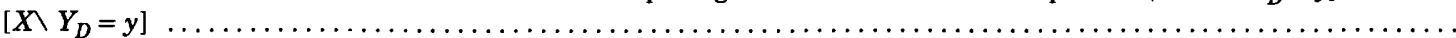

70-72. Sample joint probability mass function of step lengths and elevation of deposition, $p_{X, Y_{D}}\left(x_{\beta}, y_{j}\right)$ for:

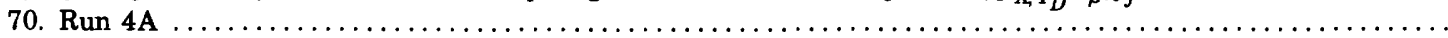

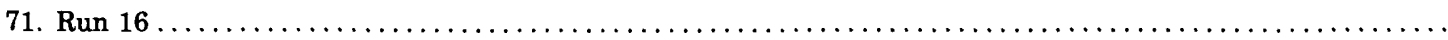

72. Run 17

73. Variation of various statistics with stream power

74. Comparison of the effective volume ratios at elevation $y_{j}$

75. Comparison of measured and computed total bed-material transport rates

\section{METRIC-ENGLISH EQUIVALENTS}

\begin{tabular}{ll}
\hline \multicolumn{1}{c}{ Metric unit } & \multicolumn{1}{c}{ English equivalent } \\
\hline Meter $(\mathrm{m})$ & $=3.28$ feet \\
Centimeter $(\mathrm{cm})$ & $=3.28 \times 10^{-2}$ foot \\
Tonne per day per meter $(\mathrm{t} / \mathrm{day} \cdot \mathrm{m})$ & $=.336$ ton per day per foot \\
Dyne per square centimeter $\left(\mathrm{d} / \mathrm{cm}^{2}\right)$ & $=2.09 \times 10^{-3}$ pound per square foot \\
Dyne per centimeter per second $(\mathrm{d} / \mathrm{cm} \cdot \mathrm{s})$ & $=6.85 \times 10^{-5}$ pound per foot per second \\
\hline
\end{tabular}




\section{SYMBOLS}

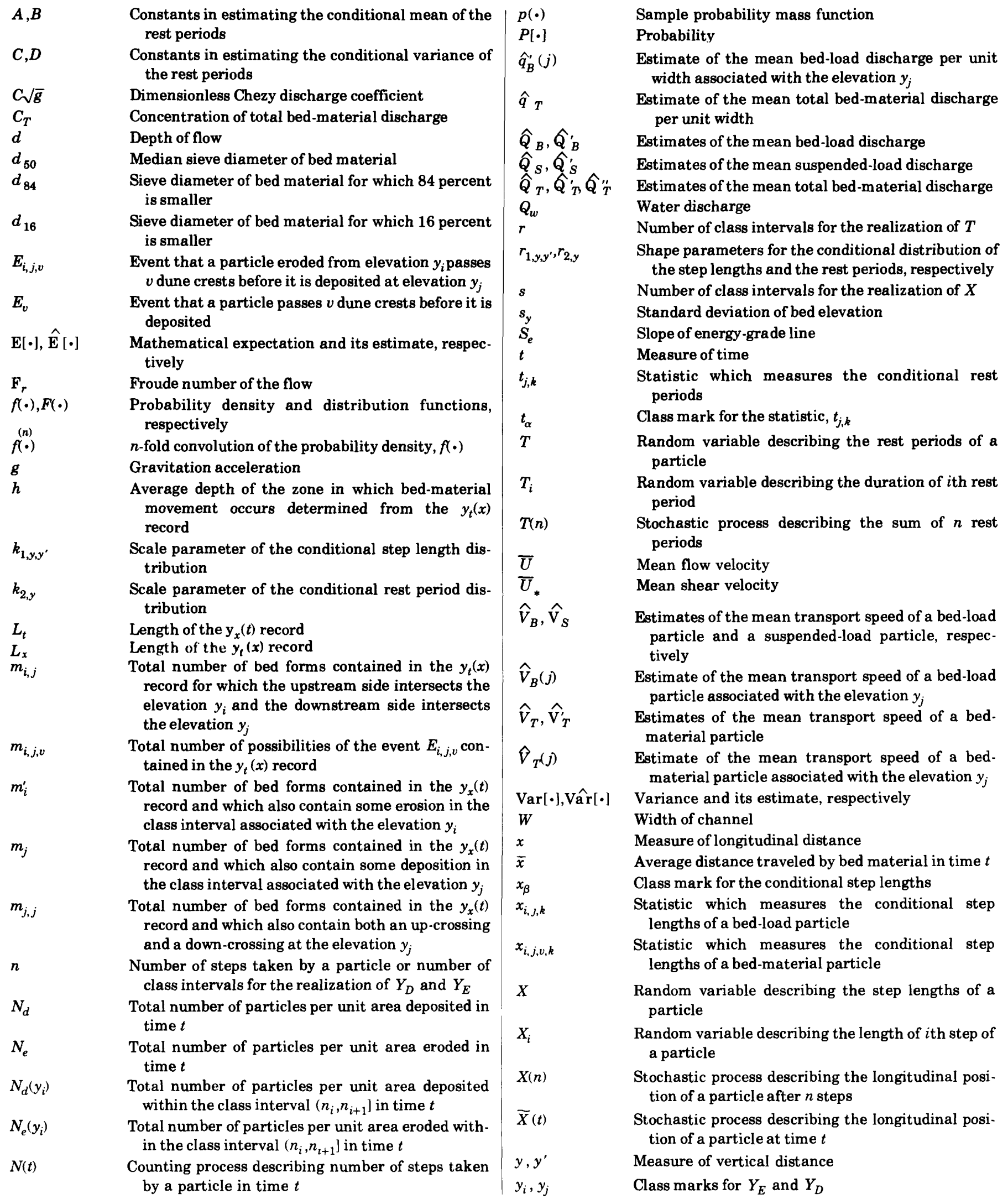


$y_{\max }, y_{\min }$

$\hat{y}_{\max }, \hat{y}_{\min }$

$y_{t}(x)$

$y_{x}(t)$

$Y_{D}, Y_{E}$

$Y_{D}(n)$

$\widetilde{y}(t)$

$\Delta \boldsymbol{y}_{j}$

$\Delta y_{j, k}^{+}$
Highest and lowest elevations, respectively, at which particles are deposited or eroded

Estimates of $y_{\max }$ and $y_{\min }$, respectively

Elevation of the bed, $y$, as a function of the Iongitudinal coordinates, $x$, at a given time, $t$

Elevation of the bed, $y$, as a function of time, $t$, at a fixed point, $x$

Random variables describing the elevation of particle deposition and erosion, respectively

Stochastic process describing the vertical position of a particle after $n$ steps

Stochastic process describing the vertical position of a particle at time $t$

Class width associated with $y_{j}$

Vertical rise of the bed in the class interval associated with $y_{j}$ for the $k$ th deposition period of the $y_{x}(t)$ record
Vertical fall of the bed in the class interval associated with $y_{i}$ for the $k$ th erosion period of the $y_{x}(t)$ record

Specific weight of bed material

Gamma function

Effective volume ratios

Lower and upper class limits for $y_{j}$, respectively

Bulk porosity of the bed material in place

Lower and upper class limits for $x_{\beta}$, respectively

Estimate of correlation coefficient

Geometric standard deviation of particle size

Mean bed shear stress

Lower and upper class limits for $t_{\alpha}$, respectively

Critical value of chi-square statistic

Number of particles per unit volume of the bed

Number of particles per unit volume of the bed associated with $y_{j}$ 


\title{
STOCHASTIC ANALYSIS OF PARTICLE MOVEMENT OVER A DUNE BED
}

\author{
By Baum K. LeE and HaRvey E. Jobson
}

\section{ABSTRACT}

Stochastic models are available that can be used to predict the transport and dispersion of bed-material sediment particles in an alluvial channel. These models are based on the proposition that the movement of a single bed-material sediment particle consists of a series of steps of random length separated by rest periods of random duration and, therefore, application of the models requires a knowledge of the probability distributions of the step lengths, the rest periods, the elevation of particle deposition, and the elevation of particle erosion. In the past, it has proven impossible to estimate these distributions except by use of tedious and time-consuming single particle experiments.

By considering a dune bed configuration which is composed of uniformly sized particles, the probability distributions of the rest period, the elevation of particle deposition, and the elevation of particle erosion are obtained from a record of the bed elevation at a fixed point as a continuous function of time. By restricting attention to a coarse sand, where the suspended load is negligible, the probability distribution of the step length is obtained from a series of "instantaneous" longitudinal bed profiles in addition to the above information. Using these probability distributions, three bed-material transport equations and a two-dimensional stochastic model for dispersion of bed-sediment particles are developed.

The procedure was tested by determining these distributions from bed profiles formed in a large laboratory flume with a coarse sand as the bed material. The elevation of particle deposition and the elevation of particle erosion can be considered to be identically dis. tributed, and their distribution can be described by either a "truncated Gaussian" or a "triangular" density function. The conditional probability distribution of the rest period given the elevation of particle deposition closely followed the two-parameter gamma distribution. The conditional probability distribution of the step length given the elevation of particle erosion and the elevation of particle deposition also closely followed the two-parameter gamma density function. For a given flow, the scale and shape parameters describing the gamma probability distributions can be expressed as functions of bed elevation.

The bed-material transport equations were tested for three flow conditions. The errors in the predicted mean total bed-material transport rates were $-3.0,+3.5$, and 80.1 percent for equation 55 , and $-1.7,+26.9$, and +64.1 percent for equation 63 . For the run with the large error, the mean total load concentration was small (8.9 milligrams per liter), and flow conditions were somewhat out of equilibrium.

\section{INTRODUCTION}

The movement of sediment in alluvial streams is so complex a process that it may never be subjected completely to a deterministic solution. It represents, in fact, an extreme degree of unsteady, nonuniform flow, since the streambed as well as the water surface may be continuously changing with time and position.

Numerous formulas and equations have been developed to predict sediment transport rates. Most of these developments ignore the actual nature of sediment movement and have assumed that the sediment transport rate can be described by a deterministic function of certain flow parameters. Unfortunately, after decades of searching, no universally accepted sediment transport equation has been found. The theories of probability, statistics, and stochastic processes have been used to describe the kinematics of a single bedsediment particle in an alluvial channel flow and to predict the dispersion characteristics of a group of such particles. These theories have clearly demonstrated a great potential for development of stochastic models of sediment transport and dispersion.

Most of the stochastic models (Shen and Todorovic, 1971; Grigg, 1969; Yang, 1968; Sayre and Conover, 1967; Hubbell and Sayre, 1964; Crickmore and Lean, 1962; Einstein, 1937) are based on the proposition that the movement of bed-sediment particles consists of a series of steps separated by rest periods, so that determination of the probability distributions for the step lengths and the rest periods of a bed-sediment particle plays the major role in quantifying the bed-sediment transport. While this movement concept can easily be verified through laboratory observations, Einstein (1937) was the first to use it. He developed a one-dimensional probabilistic model for bedload transport. More recently, Sayre and Conover (1967) derived a twodimensional stochastic model by introducing the prob- 
ability distribution of the elevation at which a bed-sediment particle is deposited.

The probability distributions of the step lengths and the rest periods of a bed-sediment particle have been estimated from single particle experiments (Grigg, 1969) or by using a group of tracer particles (Yang, 1968; Hubbell and Sayre, 1964; Crickmore and Lean, 1962). Because of the considerable effort required to conduct such experiments, it seems clear that some way must be found to estimate the probability distributions from more readily accessible data if significant further progress is to be expected. To apply the Sayre-Conover (1967) two-dimensional stochastic model, the probability distribution of the elevation at which a bed-sediment particle is deposited must be known. A method for estimating this distribution is developed in this report.

The objectives of this study are:

1. To present a method of estimating the following probability distributions for dune-bed conditions using only sounding records of the bed elevation - (a) probability distributions (note that there are two separate distributions) of the elevation at which a bed-sediment particle is eroded and deposited, and (b) conditional probability distributions of the step lengths of a bedsediment particle given the elevations at which the particle is eroded and deposited. A method estimating the conditional probability distribution of the rest periods of a bed-sediment particle given the elevation at which the particle is deposited has been presented by Sayre and Conover (1967).

2. To develop bed-material transport equations based on the above probability distributions and to compare the results with the experimentally measured values.

3. To derive a two-dimensional stochastic model for dispersion of bed-sediment particles as a function of the above probability distributions.

The probability distributions of the elevation at which a bed-sediment particle is eroded and deposited, and the probability distribution of the rest periods, conditioned on the elevation of deposition, will be obtained from a continuous record of the bed elevation at a particular point as a function of time. The probability distribution of the step lengths, conditioned on the elevation of erosion and the elevation of deposition, will be obtained from a series of "instantaneous" longitudinal bed profiles. With these distributions obtained, various related probability distributions of vital interest will be estimated, and a relation between the rest periods and the step lengths of a bed-sediment particle will be investigated.

Three experimental runs are analyzed and the relations between the statistics describing the postulated probability distributions and the hydraulic conditions are investigated. All data were obtained from a tilting recirculating flume of rectangular cross section $61 \mathrm{~m}$ long, $2.4 \mathrm{~m}$ wide, and $1.2 \mathrm{~m}$ deep. The bed material used in these experiments was screened river sand with a median sieve diameter equal to $1.13 \mathrm{~mm}$ and a geometric standard deviation equal to 1.51 .

\section{ACKNOWLEDGMENT}

The data contained herein are essentially the same as those contained in a dissertation by Lee (1973). The data were collected under the general supervision of the second author. Special thanks are due E. V. Richardson, D. B. Simons, C. F. Nordin, D. C. Boes, and R. P. Osborne.

\section{BACKGROUND \\ THEORETICAL MODELS}

Einstein (1937) treated the movement of a single sediment particle over an alluvial bed as a stochastic process described by an alternating sequence of two independent random variables, namely, step lengths and rest periods. Considering the particle movement in the distance-time plane on a Galton's board (Parzen, 1960), Einstein derived exponential probability density functions for the step lengths and the rest periods,

$$
f_{X}(x)=k_{1} e^{-k_{1} x}, x>0
$$

and

$$
f_{T}(t)=k_{2} e^{-k_{2} t}, t>0
$$

respectively, where

$X, T=$ random variables describing the step lengths and rest periods of a particle, respectively;

$x, t=$ distance and time, respectively;

$f_{X}(x), f_{T}(t)=$ common probability density functions of the step lengths and rest periods, respectively; and

$k_{1}, k_{2}=$ positive constants.

For a sediment particle introduced into the stream at distance $x=0$ in such a way that it takes its first step at time $t=0$, Einstein obtained the probability density function of the total distance traveled by the particle at time $t$ to be

$$
\begin{array}{r}
f(x ; t)=k_{1} e^{-k_{1} x-k_{2} t} \sum_{n=1}^{\infty} \frac{\left(k_{1} x\right)^{n-1}}{\Gamma(n)} \frac{\left(k_{2} t\right)^{n-1}}{\Gamma(n)} \\
x>0, t>0
\end{array}
$$

in which $\Gamma(\cdot)$ denotes the gamma function. Equation 3 also represents the concentration distribution of a group of identical sediment particles with respect to 
longitudinal position, $x$, as a function of time, $t$.

The probability density function for the case when the particle is initially $(t=0)$ at rest at $x=0$ also was obtained by a similar procedure,

$$
\begin{array}{r}
f(x ; t)=k_{1} e^{-k_{1} x-k_{2} t} \sum_{n=1}^{\infty} \frac{\left(k_{1} x\right)^{n-1}}{\Gamma(n)} \frac{\left(k_{2} t\right)^{n}}{\Gamma(n+1)} . \\
x>0, t>0 .
\end{array}
$$

It should be noted that equation 4 applies only to the particle that has taken at least one step.

Einstein (1950) also developed his well-known bedload equation by considering the dynamic lift force as a random variable. The idea is that the probability of a sediment particle being eroded from the bed surface is equal to the probability that the lift force exerted on the particle exceeds its submerged weight. He obtained

$$
p=1-\frac{1}{\sqrt{\pi}} \int_{-B_{\star} \Psi_{\star}-\frac{1}{\eta_{0}}}^{B_{*} \Psi_{*}-\frac{1}{\eta_{0}}} e^{-z^{2}} d z=\frac{A_{\star} \Phi_{\star}}{1+A_{\star} \Phi_{\star}},
$$

where

$p=$ probability of a sediment particle being eroded;

$\eta_{0}, A_{*}, B_{*}=$ constants;

$\Psi_{*}=$ intensity of shear for an individual particle size; and

$\Phi_{*}=$ intensity of transport for an individual particle size.

Solving equation 5 for $\Phi_{*}$, which is a function of the bedload transport rate, one obtains the bed-load discharge for individual particle sizes from hydraulic parameters and sediment properties.

Hubbell and Sayre (1964) presented a one-dimensional stochastic model for the longitudinal dispersion of bed-material particles in an alluvial channel. The results are identical to Einstein's (eqs. 1-4). The assumptions are: (1) the flow is in equilibrium (Simons and Richardson, 1966); (2) the particle always moves in a downstream direction with a series of alternate steps and rests; (3) the duration of movement is insignificant compared to the rest periods; and (4) the stochastic processes describing the number of steps taken by a particle in a distance interval and a time in. terval are independent of each other and both are homogeneous Poisson processes (Parzen, 1967). These assumptions are essentially the same as those of Einstein's (1937) although stated in a different way.

Based on the concept of continuity, Hubbell and Sayre (1964) proposed the transport equation for the bed material of a certain characteristic,

$$
\left(Q_{T}\right)_{C}=i_{C}\left(\gamma_{S}\right)_{C}(1-\theta) w h\left(\frac{\bar{x}}{t}\right)_{C} .
$$

where

$Q_{T}=$ bed-material discharge in weight per unit time;

$i_{c}=$ ratio of the volume of particles possessing the characteristic size to the volume of bedmaterial particles in the zone of particle movement;

$\gamma_{s}=$ specific weight of the bed material;

$\theta=$ bulk porosity of the bed in place;

$W=$ width of channel;

$h=$ average depth of the zone in which particle movement occurs;

$\bar{x}=$ average distance traveled by bed material in time $t$

$t=$ measure of time; and

$c=$ subscript that denotes terms associated with particles possessing a certain characteristic size.

Combining equation 6 with the result from the HubbellSayre one-dimensional stochastic model gives the total bed-material discharge for all particle sizes,

$$
Q_{T}=\sum_{c} i_{c}\left(\gamma_{s}\right)_{c}(1-\theta) w h\left(\frac{k_{2}}{k_{1}}\right)_{c},
$$

in which $k_{1}$ and $k_{2}$ are defined in equations 1 and 2, respectively.

Sayre and Conover (1967) extended the one-dimensional stochastic model derived by Hubbell and Sayre (1964) to two dimensions by introducing the vertical level at which particles are deposited. Their analysis led to the joint probability density function for the event that a particle has, at time $t$, traveled a distance equal to $x$ and is located at an elevation equal to $y$,

$f(x, y, t)$

$$
=f_{Y_{D}}(y) \sum_{n=1}^{\infty} f_{X}^{(n)}(x) \int_{0}^{t} f_{T}^{(n)}\left(t^{\prime}\right) \int_{t-t^{\prime}}^{\infty} f_{T \backslash Y_{D}}(\tau \backslash y) d \tau d t^{\prime},
$$

where

$f_{Y_{D}}(y)=$ probability density function for the (n) $(n) \quad$ elevation of particle deposition;

$f_{X}(x), f_{T}^{(n)}(t)=n$-fold convolutions of $f_{X}(x)$ and $f_{T}(t)$, respectively;

$f_{T \backslash Y_{D}}(t \backslash y)=$ conditional probability density function for the rest periods given the elevation at which the particle is deposited; and

$t^{\prime}=$ sum of the first $n$ rest periods.

If a group of identical sediment particles are released simultaneously at $x=0, y=y_{0}$, and $t=0$, equation 8 gives the concentration of the particles, which were initially at rest and have moved from their respective initial positions, with respect to longitudinal position, $x$, and vertical position, $y$, as a function of time, $t$. 
In order to apply equation 8 , the density functions, $f_{Y_{D}}(y), f_{T \backslash Y_{D}}(t \backslash y)$, and $f_{X}(x)$ must be specified. The unconditional density function, $f_{T}(t)$ is related to $f_{T \backslash Y_{D}}(t \backslash y)$ and $f_{Y_{D}}(y)$ by the relation

$$
f_{T}(t)=\int_{y_{\min }}^{y_{\max }} f_{T \backslash Y_{D}}(t \backslash y) f_{Y_{D}}(y) d y,
$$

in which $y_{\max }$ and $y_{\min }$ are the highest and lowest elevations at which particles can be deposited, respectively. The marginal case of equation 8 is

$$
\begin{array}{r}
f(x ; t)=\sum_{n=1}^{\infty} f_{X}^{(n)}(x) \int_{0}^{t}\left[\begin{array}{cc}
(n) & (n+1) \\
f_{T}^{(\tau)}-f_{T}^{(\tau)}
\end{array}\right] d \tau \\
=\sum_{n=1}^{\infty} f_{X}^{(n)}(x) \quad P[N(t)=n]
\end{array}
$$

in which $P[N(t)=n]$ denotes the probability that a particle takes $n$ steps in a time interval $t$. Equation 10 is a general one-dimensional stochastic model where only longitudinal dispersion is considered. One may note that the substitution of equations 1 and 2 into equation 10 reduces to equation 4 .

Yang (1968) assumed the step lengths are gamma distributed with a shape parameter, $r$, and the common density function,

$$
f_{X}(x)=\frac{k_{1}}{\Gamma(r)}\left(k_{1} x\right)^{r-1} e^{-k_{1} x}, x>0,
$$

and the rest periods are exponentially distributed with the common density function given in equation 2 . Substituting equations 2 and 11 into equation 10 , he obtained

$$
\begin{array}{r}
f(x ; t)=k_{1} e^{-k_{1} x-k_{2} t} \sum_{n=1}^{\infty} \frac{\frac{\left(k_{1} x\right)^{n r-1}}{\Gamma(n r)} \frac{\left(k_{2} t\right)^{n}}{\Gamma(n+1)}}{x>0, t>0} .
\end{array}
$$

Since the gamma distribution reduces to the exponential distribution when $r=1$, equation 4 is actually a special case of equation 12 .

Shen and Todorovic (1971) generalized the HubbellSayre one-dimensional model given in equations 1,2 , and 4 . The essential difference between the two models is that the former was based on the nonhomogeneous Poisson processes (Parzen, 1967), while the latter was based on the homogeneous Poisson processes. In the Shen-Todorovic model, the probability density functions of the step lengths and the rest periods are, respectively,

$$
f_{X}(x)=k_{1}(x) e^{-\int_{x_{0}}^{x} k_{1}(s) d s}, x>0,
$$

and

$$
f_{T}(t)=k_{2}(t) e^{-\int_{t_{0}}^{t} k_{2}(s) d s}, t>0,
$$

where

$k_{1}(x), k_{2}(t)=$ functions of $x$ and $t$, respectively; and

$x_{0}, t_{0}=$ initial position and time, respectively.

The probability density function of the total travel distance of a particle, which was initially at rest and has moved from its initial position, $x_{0}$, was found to be

$f(x ; t)=k_{1}(x) e$

$$
-\int_{x_{0}}^{x} k_{1}(s) d s-\int_{t_{0}}^{t} k_{2}(s) d s
$$

$\sum_{n=1}^{\infty} \frac{\left[\int_{x_{0}}^{x} k_{1}(s) d s\right]^{n-1}}{\Gamma(n)} \frac{\left[\int_{t_{0}}^{t} k_{2}(s) d s\right]^{n}}{\Gamma(n+1)}, x>0, t>0$.

It is seen from equations 13 and 14 that the mean number of steps taken by a particle in $\left(x_{0}, x\right]$ and $\left(t_{0}, t\right]$ are

$$
\int_{x_{0}}^{x} k_{1}(s) d s \text { and } \int_{t_{0}}^{t} k_{2}(s) d s
$$

respectively, whereas those of Hubbell-Sayre's model are $k_{1}\left(x-x_{0}\right)$ and $k_{2}\left(t-t_{0}\right)$, respectively. The HubbellSayre (1964) one-dimensional model is a special case of the Shen-Todorovic model.

\section{EXPERIMENTAL STUDIES}

Hubbell and Sayre (1964) conducted concentration distribution experiments both in the field and laboratory to evaluate the one-dimensional stochastic model given by equation 4 . The bed configurations in these experiments were large dunes in the field and ripples in the laboratory flume. Using radioactive tracer particles, a series of longitudinal concentration-distribution curves were obtained at different times for a given flow condition. The longitudinal concentration-distribution function, $\Phi(x ; t)$, is defined to be the weight of tracer particles per unit volume of bed material as a function of longitudinal distance and time and is related to $f(x ; t)$ by

$$
\Phi(x ; t)=\frac{W_{T}}{W h} f(x ; t),
$$

in which $W_{T}$ is the total weight of the tracer particles placed in the channel, $W$ is the channel width, $h$ is 
average depth of the zone of bed material movement, and $f(x ; t)$ is given by equation 4 . Based on equation 16 , the parameters $k_{1}$ and $k_{2}$ were estimated. With these estimates, Hubbell and Sayre reported that the theoretical and observed concentration-distribution functions agree reasonably well.

Yang (1968) carried out a set of experiments using radioactive tracer particles to verify the model given by equation 12. Experiments were performed with ripple and dune bed conditions in a laboratory flume $0.6 \mathrm{~m}$ wide by $18.3 \mathrm{~m}$ long. He reported that the shape of the experimental longitudinal dispersion curves are fairly well represented by equation 12 . Yang also made preliminary runs with a single plastic particle in a small flume and found that the step lengths very closely follow a gamma distribution with the parameter $r$ approximately equal to 2 and that the rest periods follow an exponential distribution very closely.

The first intensive experimental study on the movement of single particles was done by Grigg (1969). The experiments were conducted in a laboratory flume with two bed material sizes. The bed configurations were ripples and dunes. Using single radioactive tracer particles, he measured the step lengths and the rest periods directly and found the step lengths to be approximately gamma distributed and the rest periods to be approximately exponentially distributed as proposed by Yang.

Grigg found interesting correlations between: (1) Various properties of the step length distribution, the stream power (product of mean bed shear stress and mean flow velocity), and the distribution of bedform lengths; and (2) various properties of the rest period distribution and statistical properties derived from the variation of bed elevation with respect to time.

Based on an idea suggested by Hubbell and Sayre (1965), Grigg also made some progress toward experimentally testing the Sayre-Conover two-dimensional stochastic model. By analyzing a record of the bed elevation as a function of time, he showed that the conditional probability density function of the rest periods can be approximated by the exponential function,

$$
f_{T \backslash Y_{D}}(t \backslash y)=k_{3}(y) e^{-k_{3}(y) t} .
$$

and

$$
k_{3}(y)=\frac{1}{\alpha} e^{\beta y},
$$

in which $\alpha$ and $\beta$ are constants and $\gamma$ measures bed elevation in terms of the standard deviation about mean bed elevation.

\section{REMARKS}

Based on the review given in the previous sections, the following remarks are offered.
1. The Sayre-Conover model given by equation 10 is the most general one-dimensional model. The rest of the one-dimensional models, which were previously discussed, can be obtained from this model by proper substitutions. Therefore, it may be rated as the best existing one-dimensional model.

2. The Sayre-Conover model given by equation 8 is the only existing two-dimensional stochastic model. The derivation of - the Sayre-Conover model has been discussed by Lee (1973). To verify equation 8 , a method of estimating the probability distribution of the elevation at which particles are deposited must be known. One of the purposes of this report is to present such a method.

3. In order for the stochastic model to serve a prediction purpose, the relation between flow conditions and the parameters describing the probability distributions must be known. Without such knowledge the stochastic models cannot contribute much to the prediction problem.

4. A great deal of effort is required to perform dispersion and single particle experiments. If another method can be developed to estimate the necessary probability distributions from more readily accessible data, considerable savings would result. The methods developed in this report require only records of bed elevation.

\section{DEVELOPMENT OF THEORY}

\section{CHARACTERISTICS OF PARTICLE MOVEMENT OVER A DUNE BED}

Dunes are one of the most common bed forms in alluvial channels. Field observations by Simons and Richardson (1966) indicated that dunes may form in any alluvial channel, irrespective of the size of bed material, if the stream power is sufficiently large to cause general transport of the bed material without exceeding a Froude number of unity. The longitudinal profile of a dune is approximately triangular in shape with a gentle upstream slope and steep downstream slope. The upstream slope depends somewhat on flow conditions, whereas the downstream slope is more dependent on the angle of repose of the bed material. The length of a dune ranges from about $0.61 \mathrm{~m}$ to several hundred meters, depending on the scale of the flow system. The Chezy discharge coefficient, $C / \sqrt{g}$, ranges from 8 to 12 , and the total bed-material discharge concentration ranges from 100 to 1,200 milligrams per liter for dune flow conditions. For further information readers may refer to Simons and Richardson (1966).

For dune flow conditions, a record of the bed elevation as a function of time at a particular location reveals an alternating sequence of periods during which either erosion or deposition is occurring. This 
type of record is commonly obtained from the output of a depth sounder which is at a fixed location and hereafter will be referred to as the $y_{x}(t)$ record, that is, the elevation of the bed, $y$, positive upward, as a function of time, $t$, at a fixed location, $x$. When deposition occurs, $\left[d y_{x}(t) / d t\right]>0$, and when erosion occurs, $\left[d y_{x}(t) / d t\right]<0$, provided these derivatives exist. An instantaneous longitudinal bed profile may be characterized by an alternating series of erosion and deposition reaches. An instantaneous longitudinal profile can be obtained by mounting a depth sounder in a boat, provided that the speed of the boat is large relative to the speed of bed forms. These bed profiles will hereafter be referred to as the $y_{t}(x)$ records, that is, the elevation of the bed, $y$, positive upward, as a function of the longitudinal coordinates, $x$, at a given time, $t$. The longitudinal coordinate will be assumed to increase in the downstream direction; therefore, the reaches with positive slopes, $\left[d y_{t}(x) / d x\right]>0$, represent the upstream or stoss sides of the dunes, and the reaches with negative slopes, $\left[d y_{t}(x) / d x\right]<0$, represent the downstream or slip faces of the dunes. The dune crest is defined by a local maximum in the $y_{t}(x)$ record, and the dune trough is defined by a local minimum in the record.

Anyone who has an opportunity to observe closely the movement of sediment is aware that dunes move downstream owing to erosion from their. upstream face and deposition on their downstream face. That is, the bed forms migrate downstream because deposition occurs on the downstream face, where $\left[d y_{t}(x) / d x\right]<0$, and erosion occurs on the upstream face, where $\left[d y_{t}(x) / d x\right]>0$. It will be assumed throughout this report that no deposition occurs on the upstream sides of dunes and no erosion occurs on the downstream faces of dunes. This assumption is not strictly true physically but is necessary for the determination of the conditional step length distributions. If the assumption is true, each sediment particle on the stoss side of a dune must make a step in the downstream direction before it is deposited on the slip face of any dune. Once deposited it rests there until the dune has migrated downstream and it becomes reexposed on the stoss side. In other words, sediment particles are transported downstream in an alternating sequence of steps and rests of random length and duration. The frequencies and magnitudes of these steps and rests are of basic interest in understanding the nature of the movement of the sediments.

Because particles must be eroded from and deposited on the surface of the bed, the step length of a particular particle depends only on the elevation from which it is eroded, the elevation at which it is deposited, the number of dune crests which it passes before being deposited, and the scale and shape of the bed surface $\left(y_{t}(x)\right.$ record) during the time of its movement. Likewise the rest period of a particular particle depends on the scale and shape of the $y_{x}(t)$ record and on the elevation at which the particle is deposited. If the bed material size is not uniform, the elevation of deposition or erosion may also depend on the size of particles because of vertical sorting.

The intimate relationship between the bed-form shape, as measured by the $y_{x}(t)$ and $y_{t}(x)$ records, and the step lengths and rest periods of a bed-material particle allow the probability distributions of the step lengths and the rest periods to be estimated from the bed-form data. In the following three sections, a method of estimating the probability distributions of the rest periods, step lengths, and elevations at which a particle is deposited or eroded using the $y_{x}(t)$ and $y_{t}(x)$ records will be presented. In the last two sections the bedmaterial transport equations and a general two-dimensional bed-material dispersion equation will be derived as functions of these probability distributions. In the next chapter the transport equations will be tested using data from three flume runs and the results will be discussed.

\section{ESTIMATION OF THE PROBABILITY DISTRIBUTIONS OF THE ELEVATIONS OF DEPOSITION AND EROSION}

The probability that particles are deposited between the elevations $\eta_{j}$ and $\eta_{j+1}$ may be written as

$P\left[\eta_{j}<Y_{D} \leq \eta_{j+1}\right]$

$=\lim _{t \rightarrow \infty}\left\{\frac{\begin{array}{c}\text { number of particles deposited } \\ \text { within the interval }\left(\eta_{j}, \eta_{j}\right] \text { in time } t\end{array}}{\begin{array}{c}\text { number of particles deposited } \\ \text { over all intervals in time } t\end{array}}\right\}$

where

$P[\cdot]=$ probability;

$Y_{D}=$ random variable describing the elevations at which particles are deposited;

$\eta_{j}, \eta_{j+1}=$ lower and upper class limits associated with the class mark of the elevation $y_{j}$, respectively; and

$t=$ time during which the observations were made.

The elevation at which particles are deposited will hereafter simply be referred to as the elevation of deposition, $Y_{D}$.

If the number of particles per unit volume of the bed, $\Omega$, is constant, the flow is stationary (statistical sense), and both erosion and deposition cannot occur at the same point at the same time, the numerator and the denominator of equation 19 can be obtained from the $y_{x}(t)$ record. The total number of particles deposited per unit area within the class interval $\left(\eta_{j}, \eta_{j+1}\right]$ in time $t$, denoted by $N_{d}\left(y_{j}\right)$ is given by 


$$
N_{d}\left(y_{j}\right)=\Omega \sum_{k=1}^{m} \Delta y_{j, k^{i}}^{+} j=1,2, \ldots, n \text {, }
$$

where

$y_{j}=$ class mark for the realization of $Y_{D}$;

$n=$ number of class intervals for the realization of $Y_{D}$;

$\Delta y_{j, k}^{+}=$vertical rise of the bed in the class interval associated with $y_{j}$ for the $k$ th deposition period; and

$m_{j}=$ maximum number of bed forms contained in the $y_{x}(t)$ record and which also contain some deposition in the class interval associated with $y_{j}$.

Figure 1 illustrates the class marks, $y_{j}$, and the vertical rise of the bed, $\Delta y_{j, k}^{+}$, within the class intervals, $\Delta y_{j}$, for a typical $y_{x}(t)$ record. It is clear that $\Delta y_{j, k}^{+} \leqslant \Delta y_{j}=\eta_{j+1}-\eta_{j}$. The total number of particles per unit area deposited over all intervals, the denominator of equation 19 , is designated by $N_{d}$ and is obtained by summing equation 20 over all class marks:

$$
N_{d}=\sum_{j=1}^{n} N_{d}\left(y_{j}\right)=\Omega \sum_{j=1}^{n} \sum_{k=1}^{m_{j}} \Delta y_{j, k}^{+} .
$$

Equation 19 now becomes

$$
\begin{aligned}
P\left[\eta_{j}<Y_{D} \leq \eta_{j+1}\right]=\lim _{j} \rightarrow \infty & \frac{N_{d}\left(y_{j}\right)}{N_{d}} \\
& =\lim _{m_{j} \rightarrow \infty} \frac{\sum_{k=1}^{m_{j}} \Delta y_{j, k}^{+}}{\sum_{j=1}^{n} \sum_{k=1}^{m_{j}} \Delta y_{j, k}^{+}}
\end{aligned}
$$

Similarly an analysis of the erosion periods can be used to estimate the probability that particles are eroded between the elevations $\eta_{i}$ and $\eta_{i+1}$,

$$
\begin{aligned}
P\left[\eta_{i}<Y_{E} \leq \eta_{i+1}\right]=\lim _{m_{i}^{\prime} \rightarrow \infty} \frac{N_{e}\left(y_{i}\right)}{N_{e}} & \\
& =\lim _{m_{i}^{\prime} \rightarrow \infty} \frac{\sum_{k=1}^{m_{i}^{\prime}} \Delta \overline{y_{i, k}}}{\sum_{i=1}^{n} \sum_{k=1}^{m_{i}^{\prime}} \Delta \bar{y}_{i, k}},
\end{aligned}
$$

where

$Y_{E}=$ random variable describing the elevations at which particles are eroded;

$y_{i}=$ class mark for the realization of $Y_{E}$;

$\eta_{i}, \eta_{i+1}=$ lower and upper class limits of $y_{i}$, respectively;

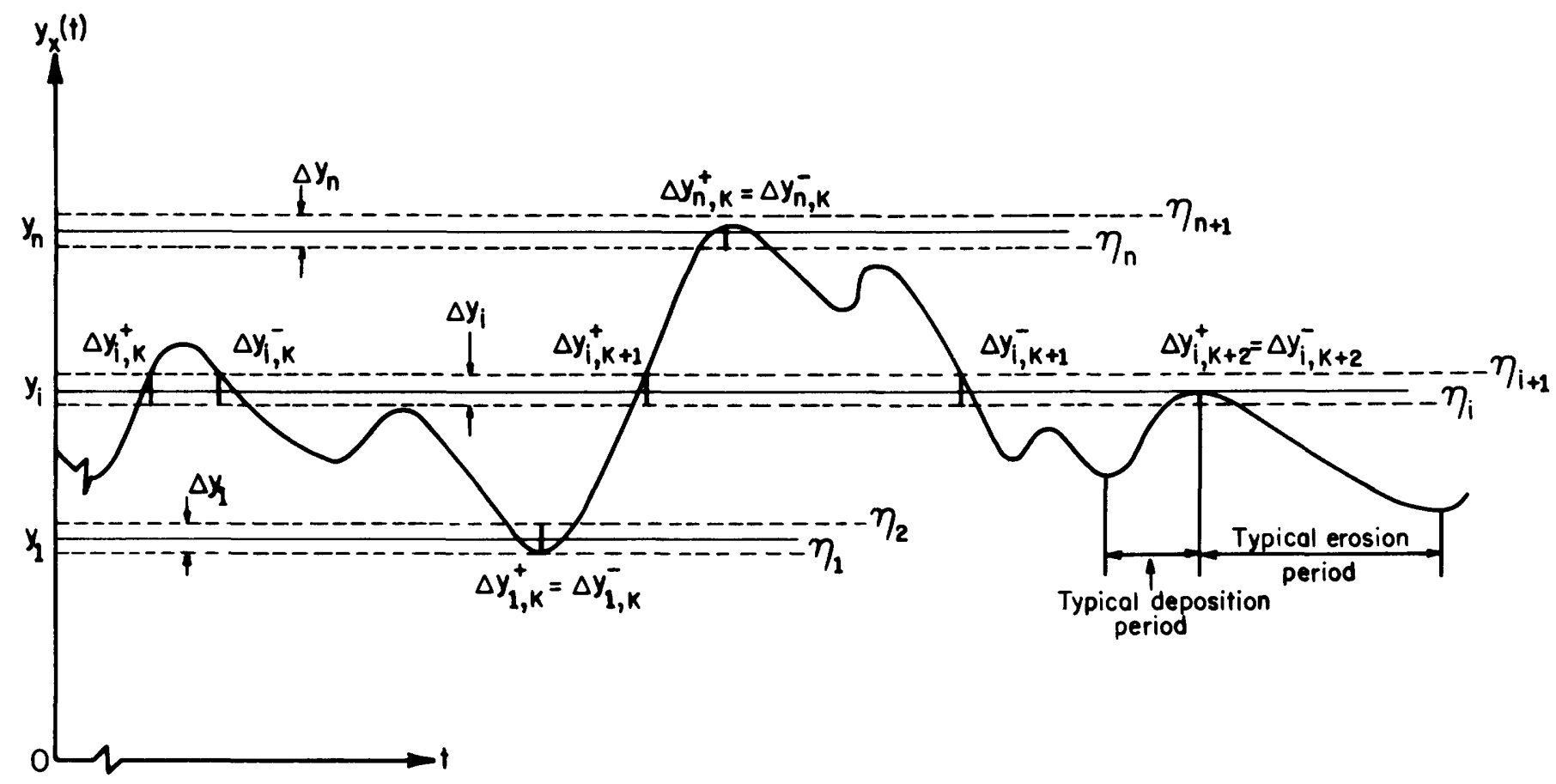

FIGURE 1. - Typical $y_{x}(t)$ record illustrating the class marks for deposition and erosion. 
$m_{i}^{\prime}=$ maximum number of bed forms contained in the $y_{x}(t)$ record and which also contain some erosion in the class interval associated with $y_{i}$;

$N_{e}\left(y_{i}\right)=$ total number of particles per unit area eroded from the interval $\left(\eta_{i}, \eta_{i+1}\right]$ centered at $y_{i}$;

$N_{e}=$ total number of particles per unit area eroded over all intervals;

$n=$ number of class intervals for $Y_{E}$; and

$\Delta y_{\bar{i}, k}=$ amount of erosion which occurred during the $k$ th erosion period in the vertical class interval associated with $y_{i}$ (fig. 1).

In the limit as $m_{j}$ and $m_{i}^{\prime}$ approach infinity for a stationary record, the distributions of $P\left[\eta_{j}<Y_{D} \leqslant \eta_{j+1}\right]$ and $P\left[\eta_{i}<Y_{E} \leqslant \eta_{i+1}\right]$ must be identical. The elevation at which particles are eroded will hereafter simply be referred to as the elevation of erosion, $Y_{E}$.

To repeat, the following assumptions are necessary for equations 22 and 23 to be valid: (1) Flow is in equilibrium such that both deposition and erosion processes are stationary with respect to time $t ;(2)$ both erosion and deposition do not occur at the same point during the same time period; and (3) the number of particles per unit volume of the bed is constant.

If the measuring equipment were sensitive enough to detect the movement of single particles, the second assumption would not be necessary because it would be physically impossible for one particle to be eroded and another to be deposited at the same point and at the same time. For $y_{x}(t)$ records obtained from less sensitive equipment, of course, the assumption may not be strictly true. When the bed material is not uniform in size, equations 20 through 23 are not strictly true because the number of particles per unit volume of the bed, $\Omega$, is a function of elevation due to a vertical sorting. However, equations 22 and 23 should serve as first approximations to the true probabilities, $P\left[\eta_{j}<Y_{D} \leqslant \eta_{J+1}\right]$ and $P\left[\eta_{i}<Y_{E} \leqslant \eta_{i+1}\right]$, even for the nonuniform bed material.

If the number of particles per unit volume were known as a function of elevation, $y$, assumption (3) could be dropped. In this case, the counterpart of equation 22 is

$$
\begin{aligned}
& P\left[\eta_{j}<Y_{D} \leq \eta_{j+1}\right] \\
& =\lim _{m_{j} \rightarrow \infty} \frac{\Omega_{j} \sum_{k=1}^{m_{j}} \Delta y_{j, k}^{+}}{\sum_{j=1}^{n} \Omega_{j} \sum_{k=1}^{m_{j}} \Delta y_{j, k}^{+}},
\end{aligned}
$$

in which $\Omega_{j}$ is the number of particles per unit volume of the bed associated with $y_{j}$. The counterpart of equation 23 would be similar. The value of $\Omega_{j}$ could be obtained from core-sample segments taken from different elevations within the bed. In the next section, $\Omega$ will be assumed to be a constant in estimation of $P\left[\eta_{j}<Y_{D} \leqslant \eta_{j+1}\right]$ and $P\left[\eta_{i}<Y_{E} \leqslant \eta_{i+1}\right]$. Because the bed material was very uniform in size, however, the assumption should have been very good.

Equations 22 and 23 are estimated by use of the sample probability mass functions which are defined to be

$$
\begin{aligned}
p_{Y_{D}}\left(y_{j}\right)= & \frac{N_{d}\left(y_{j}\right)}{N_{d}} \\
& \approx P\left[\eta_{j}<Y_{D} \leq \eta_{j}+1 \text { for a large } m_{j},\right.
\end{aligned}
$$

and

$$
\begin{aligned}
p_{Y_{E}}\left(y_{i}\right)= & \frac{\stackrel{N}{e}_{e}\left(y_{i}\right)}{N_{e}} \\
& \simeq P\left[\eta_{i}<Y_{E} \leq \eta_{i+1}\right] \text { for a large } m_{i} .
\end{aligned}
$$

in which $P_{Y_{D}}\left(y_{j}\right)$ is used to estimate equation 22 and $P_{Y_{E}}\left(y_{i}\right)$ is used to estimate equation 23. Estimates of the mean and variance of the elevation of deposition are respectively

$$
\hat{E}\left[Y_{D}\right]=\sum_{j=1}^{n} y_{j} p_{Y_{D}}\left(y_{j}\right),
$$

and

$$
\operatorname{Vâr}\left[Y_{D}\right]=\left[\sum_{j=1}^{n} y_{j}^{2} p_{Y_{D}}\left(y_{j}\right)\right]-\left[\sum_{j=1}^{n} y_{j} p_{Y_{D}}\left(y_{j}\right)\right]^{2}
$$

in which $\hat{E}[\cdot]$ and $\operatorname{Var}[\cdot]$ denote estimates of the expected value and variance, respectively. Replacing the $D$ 's with $E$ 's and the $j$ 's with $i$ 's in equation 27 gives the estimates for the mean and variance of the elevation of erosion.

The probability density functions for the elevations of deposition and erosion $\left[f_{Y_{D}}(y)\right.$ and $\left.f_{Y_{E}}(y)\right]$ may be inferred from the probability mass functions $\left[p_{Y_{D}}\left(y_{i}\right)\right.$ and $\left.p_{Y_{E}}\left(y_{i}\right)\right]$ by means of a statistical fitting procedure. This will be discussed later.

\section{ESTIMATION OF THE PROBABILITY DISTRIBUTIONS OF THE REST PERIODS}

In this study the rest period of a particle is defined as the time lapse between the burial and reexposure of 
the particle. This definition is consistent with the assumption that erosion and deposition do not occur at the same point during the same time period, and it is also necessary in analyzing single particle measurements because the measurement techniques cannot detect momentary rests by the particle. Using the burial definition, the $y_{x}(t)$ record provides a means of estimating the probability density functions of particle rest periods conditioned on the elevations of deposition. The method is illustrated schematically in figure 2 , where the statistic $\left\{t_{j, k} ; j=1,2, \ldots, n ; k=1,2, \ldots\right.$, $m_{j, j}$ \}measures the conditional rest period, the index $k$ signifies a particular bed form. The term $m_{j, j}$ designates the maximum number of bed forms which are contained in the $y_{x}(t)$ record and which also contain both an up-crossing and a down-crossing at the elevation $y_{j}$. This use of the $y_{x}(t)$ record was first suggested by Hubbell and Sayre (1965) and was partly evaluated by Grigg (1969).

A relative frequency analysis of the statistic $\left\{t_{j, k}\right\}$ leads to a sample conditional probability mass function of the rest periods which is defined to be

$$
\begin{array}{r}
p_{T \backslash Y_{D}}\left(t_{\alpha} \backslash y_{j}\right)=P\left[\tau_{\alpha}<T \leq \tau_{\alpha+1} \backslash \eta_{j}<Y_{D} \leq \eta_{j+1}\right] ; \\
j=1,2, \ldots, n ; \alpha=1,2, \ldots, r,
\end{array}
$$

where

$$
\begin{aligned}
& T=\text { random variable describing the rest } \\
& \text { periods; }
\end{aligned}
$$

$t_{\alpha}, y_{j}=$ class marks for $T$ and $Y_{D}$, respectively;

$\tau_{\alpha}, \tau_{\alpha+1}=$ lower and upper class limits of $t_{\alpha}$, respectively; and

$r=$ number of class intervals for $T$.

Equation 25 can be used to release the condition on equation 28 and to obtain the marginal sample probability mass function for the rest periods,

$$
\begin{array}{r}
p_{T}\left(t_{\alpha}\right)=P\left[\tau_{\alpha}<T \leq \tau_{\alpha+1}\right]=\sum_{j=1}^{n} p_{T \backslash Y_{D}}\left(t_{\alpha} \backslash y_{j}\right) p_{Y_{D}}\left(y_{j}\right) ; \\
\alpha=1,2, \ldots, r .
\end{array}
$$

From equations 28 and 29 the corresponding probability density functions for the conditional rest periods, $f_{T \backslash Y_{D}}(t \backslash y)$, and for the marginal rest periods, $f_{T}(t)$, may be approximated by means of a statistical fitting procedure.

The mean and variance of the conditional rest periods are estimated from the sample moments

and

$$
\hat{E}\left[T \backslash Y_{D}=y_{j}\right]=\frac{1}{m_{j, j}} \sum_{k=1}^{m_{j, j}} t_{j, k} .
$$

$$
\left.\begin{array}{l}
\operatorname{Var}\left[T \backslash Y_{D}=y_{j}\right] \\
=\frac{1}{m_{j, j}}\left[\sum_{k=1}^{m_{j, j}}\left(t_{j, k}\right)^{2}\right]-\left[\frac{1}{m_{j, j}} \sum_{k=1}^{m_{j, j}} t_{j, k}\right]^{2}
\end{array}\right\}
$$

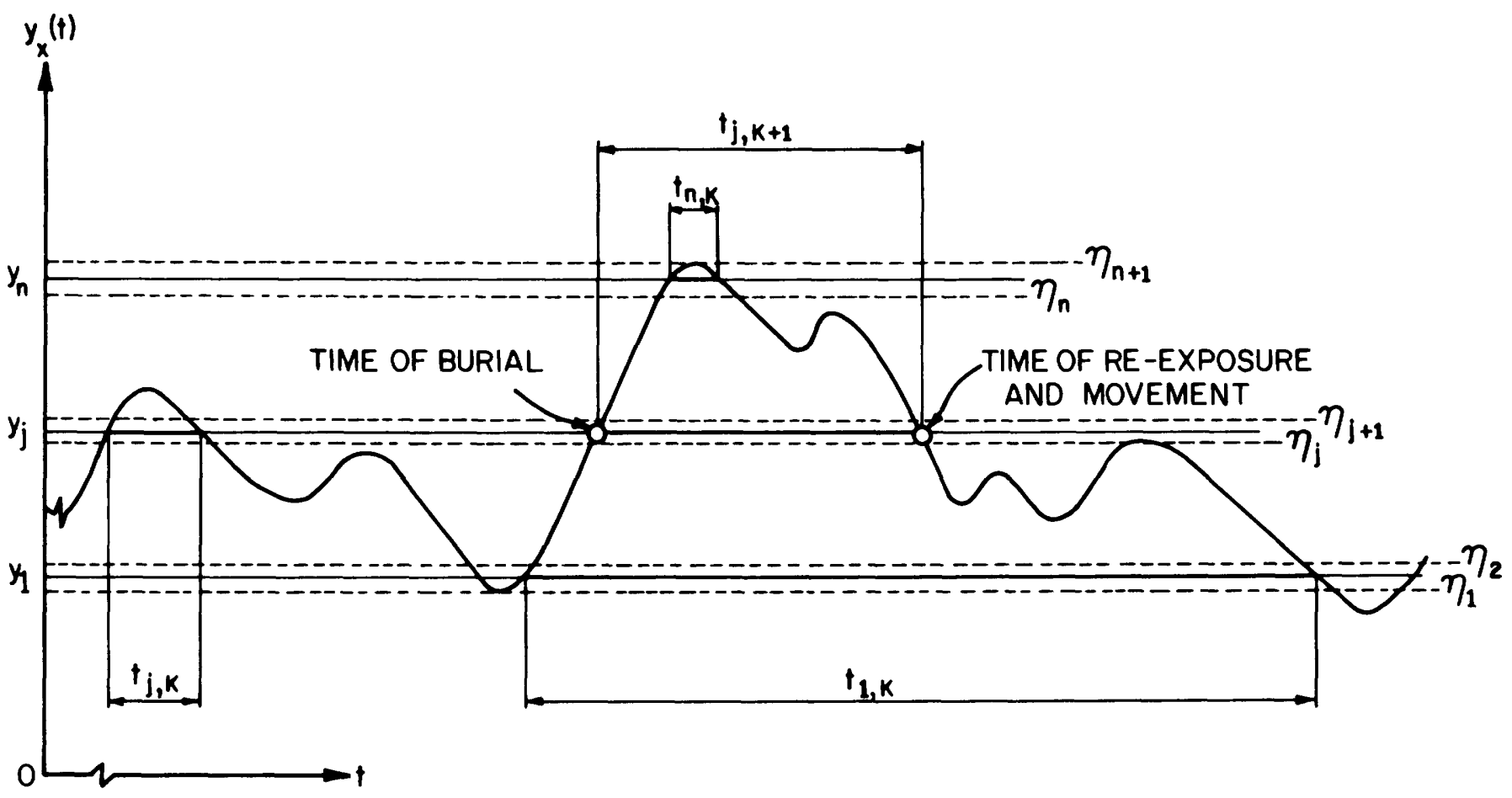

FIGURE 2. - Typical $y_{x}(t)$ record illustrating the conditional rest periods of a particle. 
Estimates of the mean and variance of the marginal rest periods are respectively

$$
\left.\begin{array}{c}
\hat{E}[T]=\sum_{j=1}^{n} \hat{E}\left[T \backslash Y_{D}=y_{j}\right] p_{Y_{D}}\left(y_{j}\right), \\
\operatorname{Var}[T]=\hat{E}\left[T^{2}\right]-(\hat{E}[T])^{2},
\end{array}\right\}
$$

and

in which

$$
\begin{aligned}
\hat{E}\left[T^{2}\right]=\sum_{j=1}^{n} \hat{E}\left[T^{2} \backslash Y_{D}\right. & \left.=y_{j}\right] p_{Y_{D}}\left(y_{j}\right) \\
& =\frac{1}{m_{j, j}} \sum_{k=1}^{m_{j, j}}\left(t_{j, k}\right)^{2} p_{Y_{D}}\left(y_{j}\right)
\end{aligned}
$$

The joint probability density function of $T$ and $Y_{D}$, denoted by $f_{T, Y_{D}}(t, y)$ is estimated from the sample joint probability mass function defined to be

$$
p_{T, Y_{D}}\left(t_{\alpha}, y_{j}\right)=P\left[\tau_{\alpha}<T \leq \tau_{\alpha+1}, \eta_{j}<Y_{D} \leq \eta_{j+1}\right],
$$

where $j=1,2, \ldots, n$ and $a=1,2, \ldots, r$. From equations 25 and $28, P_{T, Y_{D}}\left(t_{\alpha}, y_{j}\right)$ is completely determined such that

$$
p_{T, Y_{D}}\left(t_{\alpha}, y_{j}\right)=p_{T \backslash Y_{D}}\left(t_{\alpha} \backslash y_{j}\right) p_{Y_{D}}\left(y_{j}\right)
$$

Finally the correlation coefficient between $T$ and $Y_{D}$ is estimated to be

$$
\hat{\rho}_{T, Y_{D}}=\frac{\hat{E}\left[T Y_{D}\right]-\hat{E}[T] \hat{E}\left[Y_{D}\right]}{\sqrt{\operatorname{Var}[T]} \sqrt{\operatorname{Var}\left[Y_{D}\right]}},
$$

in which

$$
\hat{E}\left[T Y_{D}\right]=\sum_{\alpha=1}^{r} \sum_{j=1}^{n} t_{\alpha} y_{j} p_{T, Y_{D}}\left(t_{\alpha}, y_{j}\right),
$$

$\widehat{\mathrm{E}}\left[Y_{D}\right]$ and $\operatorname{Var}\left[Y_{D}\right]$ are given in equation 27 , and $\hat{\mathrm{E}}[T]$ and Vâr $[T]$ are given in equation 31 . The joint distribution expresses the relation between the rest period and the elevation of deposition and the correlation coefficient measures a degree of linear association between the rest period and the elevation of deposition.

If the shape of the $y_{x}(t)$ record is dependent on the flow conditions and bed-material properties, then the rest period statistics as determined by equations 28 through 34 are also functions of flow conditions and bed-material properties.

In summary, the probability distribution for the marginal rest period of a sediment particle, the rest period conditioned on the elevation of deposition, and the elevation of particle deposition and erosion can all be obtained from a continuous record of the bed elevation at a single point as a function of time. The only assumptions that are needed are: (1) Both erosion and deposition do not occur at the same point at the same time; (2) bed elevation is stationary (in the statistical sense); and (3) the number of particles per unit volume of the bed is constant. These assumptions are not severely restrictive, and the results are equally applicable to both field and laboratory analysis.

\section{ESTIMATION OF THE PROBABILITY DISTRIBUTIONS OF THE STEP LENGTHS}

The $y_{x}(t)$ record contained the information necessary to estimate the probability distributions of the rest periods. Both the $y_{x}(t)$ and the $y_{t}(x)$ records are necessary to determine the step length statistics. Unfortunately, more assumptions are also necessary and these assumptions may be considerably more restrictive than the ones made up to this time.

As previously mentioned, it will be assumed that each sediment particle on the stoss side of a dune makes a step in the downstream direction before it is deposited on the slip face of any dune. Once deposited it rests there until it is reexposed on the stoss side. Let $E_{i, j, v}$ be the event that a particle, eroded from elevation, $y_{i}$, of the stoss side of a dune, passes $v$ dune crests before it is deposited at elevation, $y_{j}$. Then the statistic $\left\{x_{i, j, v, k}\right.$; $\left.i, j=1,2, \ldots, n ; v=1,2, \ldots ; k=1,2, \ldots, m_{i, j, v}\right\}$ (fig. 3 ) is the measure of the conditional step length of the event, $E_{i, j, v}$. The term $m_{i, j, v}$ represents the total number of possibilities of the event $E_{i, j, v}$ contained in the $y_{t}(x)$ record and the index $k$ specifies a particular possibility. In general, the term $m_{i, j, v}$ will be different for each combination of values $i, j$, and $v$.

A frequency analysis of the statistic $\left\{x_{i, j, v, k}\right\}$ gives a sample conditional probability mass function which is defined to be

$$
\begin{aligned}
& p_{X \backslash Y_{E}, Y_{D}, E_{v}\left(x_{\beta} \backslash y_{i}, y_{j}, v\right)} \\
& =P\left[\lambda_{\beta}<X \leq \lambda_{\beta+1} \backslash \eta_{i}<Y_{E} \leq \eta_{i+1}, \eta_{j}<Y_{D} \leq \eta_{j}+1, E_{v}\right] \\
& \beta=1,2, \ldots, s ; i, j,=1,2, \ldots, n ; v=1,2, \ldots,
\end{aligned}
$$

where

$X=$ random variable describing the step lengths;

$x_{\beta}=$ class mark for the realizations of $X$;

$\lambda_{\beta}, \lambda_{\beta+1}=$ lower and upper class limits of $x_{\beta}$, respectively;

$s=$ number of class intervals for the realizations of $X$; and 


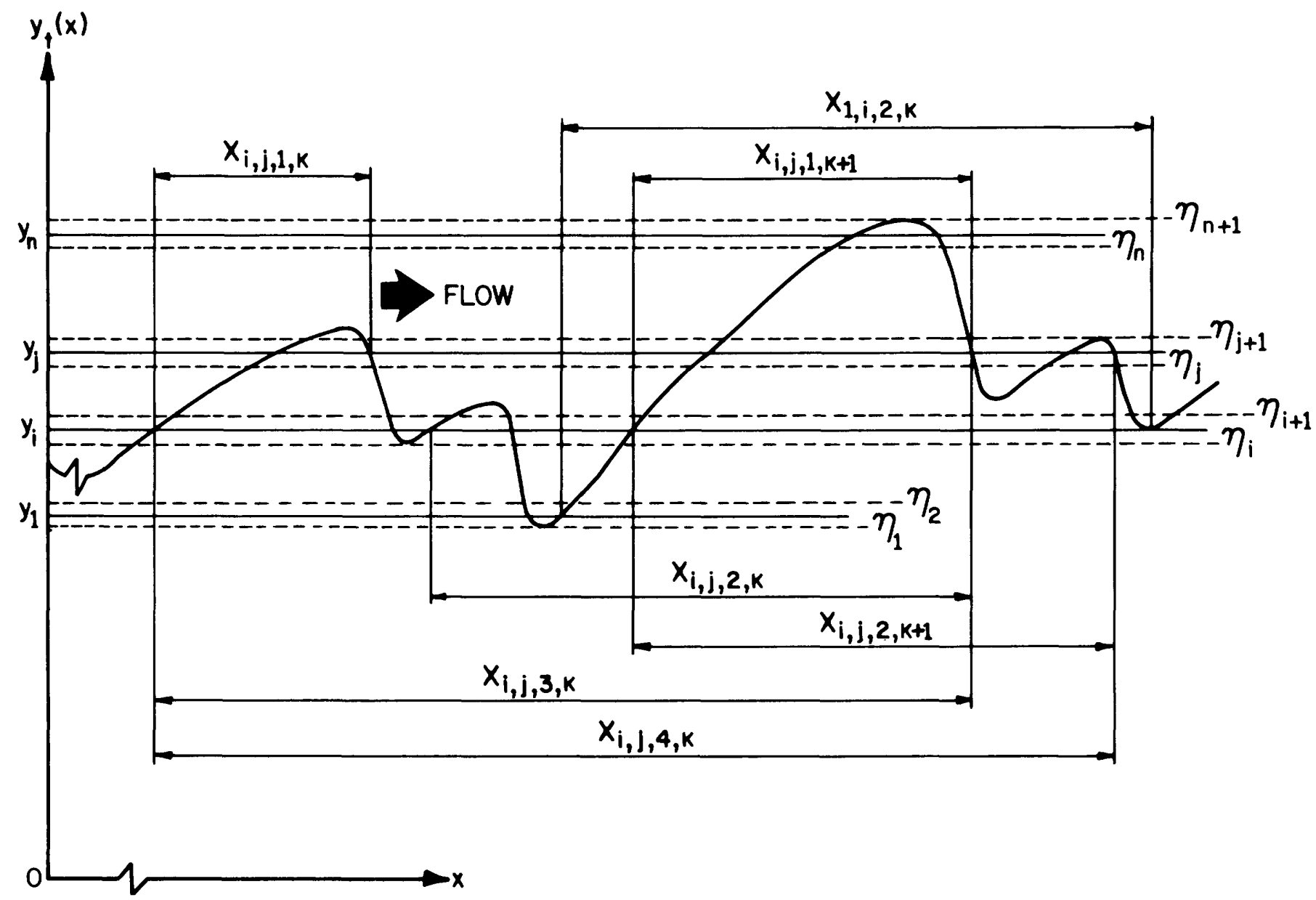

FIgURE 3. - Statistic, $\left\{x_{i, j, v, k} ; i, j=1,2, \ldots, n ; v=1,2, \ldots ; k=1,2, \ldots, m_{i, j, v}\right\}$, for the step length of a particle.

$E_{v}=$ event that a particle passes $v$ dune crests before it is deposited (fig. 3 ).

The corresponding probability density function,

$$
f_{X \backslash Y_{E}, Y_{D}, E_{v}}\left(x \backslash y^{\prime}, y, v\right),
$$

may be determined from

$$
p_{X \backslash Y_{E}, Y_{D}, E_{v}}\left(x_{\beta} \backslash y_{i}, y_{j}, v\right) \text {, }
$$

and its mean and variance are estimated to be

$\hat{E}\left[X \backslash Y_{E}=y_{i}, Y_{D}=y_{j}, E_{v}\right]=\frac{1}{m_{i, j, v}} \sum_{k=1}^{m_{i, j, v}} x_{i, j, v, k}$

and

$\operatorname{Var}\left[X \backslash Y_{E}=y_{i}, Y_{D}=y_{j}, E_{v}\right]$

$=\frac{1}{m_{i, j, v}} \sum_{k=1}^{m_{i, j, v}}\left(x_{i, j, v, k}\right)^{2}-\left[\frac{1}{m_{i, j, v}} \sum_{k=1}^{m_{i, j, v}} x_{i, j, v, k}\right]^{2}$ in which

$\frac{1}{m_{i, j, v}} \sum_{k=1}^{m_{i, j, v}}\left(x_{i, j, v, k}\right)^{2}=\hat{E}\left[X^{2} \backslash Y_{E}=y_{i}, y_{D}=y_{j}, E_{v}\right]$.

If $Y_{E}, Y_{D}$, and $E_{v}$ are mutually independent (it seems to be reasonable that after a particle passes the crest of a dune it has probably lost track of where it came from), the density function $\left[f_{X \backslash Y_{D}, E_{v}}(x \backslash y, v)\right]$ of the step lengths given that a particle is deposited at elevation $y$ after passing $v$ dune crests is estimated from the sample conditional mass function which is given by

$$
\begin{aligned}
p_{X \backslash Y_{D}, E_{v}}\left(x_{\beta} \backslash y_{j}, v\right) \\
=P\left[\lambda_{\beta}<X \leq \lambda_{\beta}+1 \backslash \eta_{j}<Y_{D} \leq \eta_{j}+1, E_{v}\right] \\
=\sum_{i=1}^{n} p_{X \backslash Y_{E}, Y_{D^{\prime}} E_{v}\left(x_{\beta} \backslash y_{i}, y_{j}, v\right) p_{Y_{E}}\left(y_{i}\right)}
\end{aligned}
$$

in which $p_{Y_{E}}\left(y_{i}\right)$ is given by equation 26 . The mean and 
variance of the step lengths of a particle which is deposited at $y_{j}$ after passing $v$ dune crests are estimated to be

$$
\begin{aligned}
\hat{E}\left[X \backslash Y_{D}\right. & \left.=y_{j^{\prime}} E_{v}\right] \\
& =\sum_{i=1}^{n} \hat{E}\left[X \backslash Y_{E}=y_{i}, Y_{D}=y_{j}, E_{v}\right] p_{Y_{E}}\left(y_{i}\right),
\end{aligned}
$$

and

$$
\begin{aligned}
\operatorname{Vâr}[ & {\left[X \backslash Y_{D}=y_{j}, E_{v}\right] } \\
& =\hat{E}\left[X^{2} \backslash Y_{D}=y_{j}, E_{v}\right]-\left(\hat{E}\left[X \backslash Y_{D}=y_{j}, E_{v}\right]\right)^{2},
\end{aligned}
$$

in which

$$
\begin{aligned}
\hat{\mathrm{E}}\left[X^{2} \backslash Y_{D}\right. & \left.=y_{j}, E_{v}\right] \\
& =\sum_{i=1}^{n} \hat{E}\left[X^{2} \backslash Y_{E}=y_{i}, Y_{D}=y_{j}, E_{v}\right] p_{Y_{E}}\left(y_{i}\right) .
\end{aligned}
$$

Likewise, the following sample probability mass functions and corresponding means and variances are obtained;

$$
\begin{aligned}
& p_{X \backslash Y_{D}}\left(x_{\beta} \backslash y_{j}\right) \\
& =P\left[\lambda_{\beta}<X \leq \lambda_{\beta+1} \backslash \eta_{j}<Y_{D} \leq \eta_{j+1}\right] \\
& =\sum_{\nu=1}^{\infty} p_{X \backslash Y_{D^{\prime}}, E_{\nu}}\left(x_{\beta} \backslash y_{j^{\prime}}, \nu\right) P\left[E_{\nu}\right] \\
& \hat{E}\left[X \backslash Y_{D}=y_{j}\right]=\sum_{v=1}^{\infty} \hat{E}\left[X \backslash Y Y_{D}=y_{j}, E_{v}\right] P\left[E_{v}\right] \\
& \operatorname{Vâr}\left[X \backslash Y_{D}=y_{j}\right] \\
& =\left[\sum_{v=1}^{\infty} \hat{E}\left[X^{2} \backslash Y_{D}=y_{j}, E_{v}\right] P\left[E_{v}\right]\right]-\left(\hat{E}\left[X \backslash Y_{D}=y_{j}\right]\right)^{2} ; \\
& p_{X \backslash E_{\nu}}\left(x_{\beta} \backslash \nu\right)=P\left[\lambda_{\beta}<X \leq \lambda_{\beta+1} \backslash E_{\nu}\right] \\
& =\sum_{j=1}^{n} p_{X \backslash Y_{D}, E_{v}}\left(x_{\beta} \backslash y_{j}, v\right) p_{Y_{D}}\left(y_{j}\right) \\
& \hat{E}\left[X \backslash E_{v}\right]=\sum_{j=1}^{n} \hat{E}\left[X \backslash Y_{D}=y_{j}, E_{v}\right] p_{Y_{D}}\left(y_{j}\right) \\
& \operatorname{Var}\left[X \backslash E_{v}\right] \\
& =\left[\sum_{j=1}^{n} \hat{E}\left[X^{2} \backslash Y_{D}=y_{j^{\prime}} E_{v}\right] p_{Y_{D}}\left(y_{j}\right)\right]-\left(\hat{E}\left[X \backslash E_{v}\right]\right)^{2} ;
\end{aligned}
$$

and

$$
\left.\begin{array}{r}
p_{X}\left(x_{\beta}\right)=P\left[\lambda_{\beta}<X \leq \lambda_{\beta+1}\right] \\
=\sum_{\nu=1}^{\infty} p_{X \backslash E_{\nu}}\left(x_{\beta} \backslash \nu\right) P\left[E_{v}\right] \\
\hat{E}[X]=\sum_{\nu=1}^{\infty} \hat{E}\left[X \backslash E_{\nu}\right] P\left[E_{\nu}\right] \\
\operatorname{Var}[X]=\left[\sum_{\nu=1}^{\infty} \hat{E}\left[X^{2} \backslash E_{\nu}\right] P\left[E_{\nu}\right]\right]-(\hat{E}[X])^{2} \cdot
\end{array}\right\}
$$

The density functions, $f_{X \backslash Y_{D}}(x \backslash y), f_{X \backslash E_{v}}(x \backslash v)$, and $f_{X}(x)$ are estimated from equation sets 39,40 , and 41 , respectively.

The joint probability density function of $X$ and $Y_{D}$, conditioned on the event $E_{v},\left[f_{X, Y_{D} \backslash E_{v}}(x, y \backslash v)\right]$ can be estimated from a sample joint probability mass function,

$$
\begin{aligned}
p_{X, Y_{D} \backslash E_{\nu}}\left(x_{\beta^{\prime}} y_{j} \backslash v\right) \\
\quad=P\left[\lambda_{\beta}<X \leq \lambda_{\beta+1}, \eta_{j}<Y_{D} \leq \eta_{j+1} \backslash E_{\nu}\right]
\end{aligned}
$$

and

$$
\begin{aligned}
p_{X, Y_{D} \backslash E_{\nu}}\left(x_{\beta} \backslash y_{j}, v\right) & =p_{X \backslash Y_{D}, E_{\nu}}\left(x_{\beta} \backslash y_{j}, v\right) p_{Y_{D} \backslash E_{\nu}}\left(y_{j} \backslash v\right) \\
& =p_{X \backslash Y_{D}, E_{\nu}}\left(x_{\beta} \backslash y_{j}, v\right) p_{Y_{D}}\left(y_{j}\right)
\end{aligned}
$$

Note that $p_{Y_{D} \backslash E_{v}}\left(y_{j} \backslash v\right)=p_{Y_{D}}\left(y_{j}\right)$ because $Y_{D}$ and $E_{v}$ were assumed to be independent. The correlation coefficient of $X$ and $Y_{D}$, conditioned on the event $E_{v}$, is then estimated to be

$$
\hat{\rho}_{X, Y_{D} \backslash E_{v}}=\frac{\hat{E}\left[X Y_{D} \backslash E_{v}\right]-\hat{E}\left[X \backslash E_{v}\right] \hat{E}\left[Y_{D}\right]}{\sqrt{\operatorname{Var}\left[X \backslash E_{v}\right]} \sqrt{\operatorname{Var}\left[Y_{D}\right]}},
$$

in which

$\hat{\mathrm{E}}\left[X Y_{D} \backslash E_{v}\right]$

$=\sum_{\beta=1}^{s} x_{\beta}\left\{\sum_{j=1}^{n} y_{j} p_{X \backslash Y_{D^{\prime}} E_{\nu}}\left(x_{\beta} \backslash y_{j}, v\right) p_{Y_{D}}\left(y_{j}\right)\right\}$, and

$\hat{\mathrm{E}}\left[Y_{D}\right], \operatorname{Var}\left[Y_{D}\right], \hat{\mathrm{E}}\left[X \backslash E_{v}\right]$, and $\operatorname{Vâ}\left[X \backslash E_{v}\right]$ are given by equation sets 27 and 40 . Similarly, the joint probability density function of $X$ and $Y_{D},\left[f_{X, Y_{D}}(x, y)\right]$ and the 
corresponding correlation coefficient, $\rho_{X, Y_{D}}$, are estimated to be

and

$$
p_{X, Y_{D}}\left(x_{\beta}, y_{j}\right)=p_{X \backslash Y_{D}}\left(x_{\beta} \backslash y_{j}\right) p_{Y_{D}}\left(y_{j}\right)
$$

$$
\hat{p}_{X, Y_{D}}=\frac{\hat{E}\left[X Y_{D}\right]-\hat{E}[X] \hat{E}\left[Y_{D}\right]}{\sqrt{\operatorname{Var}[X]} \sqrt{\operatorname{Var}\left[Y_{D}\right]}},
$$

in which

$$
\hat{E}\left[X Y_{D}\right]=\sum_{\beta=1}^{s} x_{\beta}\left\{\sum_{i=1}^{n} y_{j} p_{X \backslash Y_{D}}\left(x_{\beta} \backslash y_{j}\right) p_{Y_{D}}\left(y_{j}\right)\right\} \text {. }
$$

The joint distributions (eqs. 43 and 45 ) express the relation between the step length and the elevation of deposition, and the correlation coefficients (eqs. 44 and 46) measure the degree of linear association between the step length and the elevation of deposition.

The American Society of Civil Engineers (Task Committee on Preparation of Sedimentation Manual, 1962) defines bedload as that material moving on or near the bed. Accepting this general definition, it would appear consistent to count any sediment particle which was able to skip across a dune trough as suspended load, since it would be extremely unlikely that a particle would be able to pass the trough while moving on or near the bed. A very precise, and admittedly restrictive, definition of bedload is used for the purpose of this report. For the purposes of this report, bed load is defined as that part of bed material which is deposited on the downstream face of the dune from which it is eroded. Then the suspended load must be that material which is not deposited on the downstream face of the dune from which it is eroded, that is, all sediment particles which pass two or more dune crests before being deposited. The same particle could be counted as bedload during one step but as suspended load during the next step. By definition then, it follows that $P\left[E_{1}\right]=$ probability that a particle is transported as the bedload; and

$$
1-P\left[E_{1}\right] \equiv \sum_{v=2}^{\infty} P\left[E_{v}\right]=
$$

probability that a particle is transported as the suspended load during any step. The probability distributions and moments for the step lengths of a bed-load particle may be obtained by putting $v=1$ in the sets of equations 35 through 40 and 42 through 48 .

For a bed material composed of coarse sand it seems reasonable to assume that all particles are transported as bed load, that is, all particles eroded from the stoss side of a dune will be deposited on the downstream side of the same dune; and therefore, $P\left[E_{1}\right] \equiv 1$, and $P\left[E_{v}\right] \equiv 0$ for $v \geqslant 2$. For this case, a frequency analysis of the statistic $\left\{x_{i, j, v, k} ; i, j=1,2, \ldots, n ; k=1,2, \ldots\right.$, $\left.m_{i, j, v} ; v=1\right\}$ gives a sample conditional probability mass function which is defined to be

$$
\begin{aligned}
& p_{X \backslash Y_{E}, Y_{D}}\left(x_{\beta} \backslash y_{i}, y_{j}\right) \\
& =P\left[\lambda_{\beta}<X \leq \lambda_{\beta+1} \backslash \eta_{i}<Y_{E} \leq \eta_{i+1}, \eta_{j}<Y_{D} \leq \eta_{j}+1\right] \\
& \quad \beta=1,2, \ldots, s ; i, j=1,2, \ldots, n .
\end{aligned}
$$

The corresponding probability density function, $f_{X \backslash Y_{E}, Y_{D}}\left(x \backslash y^{\prime}, y\right)$, may be approximated from $p_{X \backslash Y_{E}, Y_{D}}\left(x_{\beta} \backslash y_{i}, y_{j}\right)$. Denoting the statistic $\left\{x_{i, j, v, k}\right.$; $\left.i, j=1,2, \ldots ; k=1,2, \ldots, m_{i, j, v} ; v=1\right\}$ simply as $\left\{x_{i, j, k}\right.$; $\left.i, j=1,2, \ldots, n ; k=1,2, \ldots, m_{i, j}\right\}$ (fig. 3), the corresponding mean and variances are estimated to be

$$
\begin{aligned}
& \hat{E}\left[X \backslash Y_{E}=y_{i^{\prime}} \quad Y_{D}=y_{j}\right]=\frac{1}{m_{i, j}} \sum_{k=1}^{m_{i, j}} x_{i, j, k}, \\
& \text { and } \\
& \text { Vâr }\left[X \backslash Y_{E}=y_{i}, \quad Y_{D}=y_{j}\right] \\
& \quad=\left(\frac{1}{m_{i, j}} \sum_{k=1}^{m_{i, j}}\left(x_{i, j, k}\right)^{2}\right)-\left(\frac{1}{m_{i, j}} \sum_{k=1}^{m_{i, j}} x_{i, j, k}\right)^{2} .
\end{aligned}
$$

The term $m_{i, j}$ represents the total number of bed forms in the sample for which the upstream side intersects the elevation $y_{j}$ and the downstream side intersects the elevation $y_{i}$. In general, the term $m_{i, j}$ will be different for each combination of values of $i$ and $j$ (fig. 3).

Based on the statistic $\left\{x_{i, j, k}\right\}$ and assuming that $Y_{E}$ and $Y_{D}$ are mutually independent, the probability density functions, $f_{X \backslash Y_{D}}(x \backslash y), f_{X}(x)$, and $f_{X, Y_{D}}(x, y)$ as well as the corresponding moments are estimated by setting $P\left[E_{1}\right]=1$ in equation sets $37,38,39,40,42$, and 44 .

Since the bed-form shape and rate of movement are dependent on the flow condition and bed material properties, it should be clear that equations 35 through 48 are also functions of the flow condition and bed material properties. The statistic $\left\{x_{i, j, k}\right\}$ will be analyzed later to estimate the various probability distributions of the step lengths for a coarse sand for three different flow conditions.

Summarizing this section, the step length distributions can be estimated by combining the information contained in the $y_{x}(t)$ and $y_{t}(x)$ records. Additional assumptions are required however. These are: (1) No deposition occurs on the upstream sides of dunes, and no erosion occurs on the downstream faces of dunes; and (2) the elevation of particle erosion, $Y_{E}$, the eleva- 
tion of particle deposition, $Y_{D}$, and the event that a particle passes $v$ dune crests before it is deposited, $E_{v}$, are mutually independent. The first assumption may not be strictly true especially, due to flow separation, in the neighborhood of dune trough where both deposition and erosion may occur at the same point. For dune flow conditions, however, laboratory observation shows that such an area is small enough that the results should be applicable without an appreciable error. The second assumption seems to be reasonable because as a sediment particle passes a dune crest it likely loses the memory of where it came from. Estimation of $P\left[E_{v}\right]$ would not appear to be a simple task. However, for a bed material composed of coarse sand, the assumption that all particles which are eroded from the stoss side of a dune will be deposited on the downstream side of the same dune seems to be reasonable.

\section{BED-MATERIAL TRANSPORT EQUATIONS}

The mean transport speed of a bed material particle, $V_{T}$, is estimated to be

$\hat{V}_{T}=\frac{\text { Total distance traveled by a particle after } m \text { steps }}{\text { Total time required for a particle to make } m \text { steps }}$

$$
\begin{aligned}
= & \frac{m \hat{E}[X]}{m \hat{E}[T]}=\frac{\hat{E}[X]}{\hat{E}[T]} \\
= & \frac{\sum_{j=1}^{n} \hat{E}\left[X \backslash Y_{D}=y_{j}\right] p_{Y_{D}}\left(y_{j}\right)}{n} \text { for a large } m \\
& \sum_{j=1} \hat{E}\left[T \backslash Y_{D}=y_{j}\right] p_{Y_{D}}\left(y_{j}\right)
\end{aligned}
$$

in which $\hat{V}_{T}$ denotes an estimate of the mean transport speed, $V_{T}$,

$$
\hat{E}[X]=\sum_{v=1}^{\infty} \sum_{j=1}^{n} \sum_{i=1}^{n}\left[\frac{1}{m_{i, j, v}} \sum_{k=1}^{m_{i, j, v}} x_{i, j, v, k}\right]
$$

and

$$
\hat{E}[T]=\sum_{j=1}^{n}\left[\frac{1}{m_{j, j}} \sum_{k=1}^{m_{j, j}} t_{j, k}\right] p_{Y_{D}}\left(y_{j}\right)
$$

In equation 49 , the duration of particle movement is assumed to be negligible compared to the rest period. This assumption will be used throughout this section.
The mean transport speed could also be estimated to be

$$
\hat{V}_{T}^{\prime}=\sum_{j=1}^{n} \frac{\hat{E}\left[X \backslash Y_{D}=y_{j}\right]}{\hat{E}\left[T \backslash Y_{D}=y_{j}\right]} p_{Y_{D}}\left(y_{j}\right)
$$

where $\hat{V}_{T}^{\prime}$ also estimates the mean transport speed of a bed material particle. In general it can be shown that $\hat{V}_{T} \neq \hat{V}_{T}^{\prime}$ and the results of this study will indicate that $\widehat{V}_{T} \leqslant \widehat{V}_{T}^{\prime}$. Now the question is: Which one will give the better estimate of the mean bed material transport rate? The difference between the two equations is the manner in which the events are averaged or weighted. So, in order to answer the question, one must depend upon physical arguments and reasoning. In equation 50, the average speed of a particle at each elevation is weighted by the number of particles with this speed. Equation 50 gives the best estimate of the arithmetic mean of individual particle speeds. On the other hand, equation 49 computes the estimate of the mean particle speed as the total distance traveled by a number of particles divided by the amount of time required to transport the same number of particles. In other words, the center of mass of a group of particles is translated through a distance,

$$
\sum_{j=1}^{n} \hat{\mathrm{E}}\left[X \backslash Y_{D}=y_{j}\right] p_{Y_{D}}\left(y_{j}\right)
$$

in time,

$$
\sum_{j=1}^{n} \hat{\mathrm{E}}\left[T \backslash Y_{D}=y_{j}\right] p_{Y_{D}}\left(y_{j}\right)
$$

Equation 49 will be used in this section because it is based on a mass flux concept and it gives an unbiased estimate of the mean sediment transport rate. The mean particle speed given by equation 50 will be useful in the study of bed material dispersion because it is based on individual particle speeds.

Defining the bed load and suspended load as given in the previous section, the mean transport speed of a bedload particle, $V_{B}$, is estimated to be

$$
\hat{V}_{B}=\frac{\hat{E}\left[X \backslash E_{1}\right]}{\hat{E}[T]},
$$

where $\hat{V}_{B}$ is an estimate of $V_{B}$ and

$$
\hat{E}\left[X \backslash E_{1}\right]=\sum_{j=1}^{n} \sum_{i=1}^{n}\left[\frac{1}{m_{i, j}} \sum_{k=1}^{m_{i, j}} x_{i, j, k}\right] p_{p_{E}\left(y_{i}\right) p_{Y_{D}}\left(y_{j}\right)}
$$

Similarly, the mean transport speed of a suspended load particle, $V_{S}$, is estimated to be 


$$
\hat{V}_{S}=\frac{\hat{E}\left[X \mid \bigcup_{\nu=2}^{\infty} E_{v}\right]}{\hat{E}[T]}=\frac{\sum_{v=2}^{\infty} \hat{E}\left[X \backslash E_{v}\right] P\left[E_{v}\right]}{\hat{E}[T] \sum_{\nu=2}^{\infty} P\left[E_{v}\right]},
$$

where

$$
\begin{aligned}
\hat{V}_{S} & =\text { estimate of } V_{s} \\
\bigcup_{v=2} & E_{v}=\text { union of event, } E_{v}, \text { for } v \geqslant 2 .
\end{aligned}
$$

$\widehat{\mathrm{E}}\left[X \backslash E_{v}\right]$ is given in equation 40 . Note that

$$
P\left[\bigcup_{v=1}^{\infty} E_{v}\right]=\sum_{v=1}^{\infty} P\left[E_{v}\right]=1
$$

and

$$
\hat{E}\left[X \mid \bigcup_{v=2}^{\infty} E_{v}\right]=\frac{\sum_{v=2}^{\infty} \hat{E}\left[X \backslash E_{v}\right] P\left[E_{v}\right]}{\sum_{v=2}^{\infty} P\left[E_{v}\right]}
$$

Using equations 49,51, 52, and 53,

$$
\begin{aligned}
\hat{V}_{T}=\frac{\hat{E}\left[X \backslash E_{1}\right]}{\hat{E}[T]} P\left[E_{1}\right]+\frac{\sum_{v=2}^{\infty} \hat{E}\left[X \backslash E_{v}\right] P\left[E_{v}\right]}{\hat{E}[T]} \\
=\hat{V}_{B} P\left[E_{1}\right]+\hat{V}_{S} \sum_{\nu=2}^{\infty} P\left[E_{v}\right] \\
=\hat{V}_{B} P\left[E_{1}\right]+\hat{V}_{S}\left(1-P\left[E_{l}\right]\right) .
\end{aligned}
$$

If all bed material particles have identical transport characteristics, which is reasonable for uniformly sized bed material, the mean total bed material discharge is obtained by use of the continuity concept,

$$
\hat{Q}_{T}=\gamma_{S}(1-\theta) W h \hat{V}_{T} \text {. }
$$

where

$\hat{\mathbf{Q}}_{T}=$ estimate of the mean total bed material discharge in weight per unit time;

$\gamma_{s}=$ specific weight of the bed material;

$\Theta=$ porosity of the bed;

$W=$ width of the channel;

$h=$ average depth of the zone in which bed material movement occurs; and $\hat{V}_{T}$ is given in equation 49.
Similarly, estimates of the mean bed-load discharge and suspended load discharge are, respectively,

$$
\hat{Q}_{B}=\gamma_{S}(1-\theta) W h \hat{V}_{B} P\left[E_{1}\right] \text {, }
$$

and

$$
\hat{Q}_{S}=\gamma_{S}(1-\theta) W h \hat{V}_{S}\left(1-P\left[E_{1}\right]\right) \text {, }
$$

where $\hat{V}_{B}$ and $\hat{V}_{S}$ are given in equations 51 and 52 , respectively. From equations 54 through 57,

$$
\hat{Q}_{T}=\hat{Q}_{B}+\hat{Q}_{S} \text {. }
$$

Although equations 55, 56, and 57 have the form of a continuity equation, the concept of continuity applies only in a statistical sense, because particles move only when they are exposed on the stoss side of a dune or when they are in suspension. Hubbell and Sayre (1964) proposed that the average depth of the zone of bed material movement, $h$, be estimated from the $y_{t}(x)$ record. For this method, the length of the reach for which $h$ is to be determined is divided into sections. Starting from the upstream end, each section of length $f_{i}$ extends from the dune trough at which the section begins to the first trough downstream that is deeper relative to a line parallel to the plane of the mean bed surface. After sectioning, a mean depth of sand above the projected line for each section, $h_{i}$ is determined, and the $h$ for the total reach, $L_{x}$, is computed as the weighted average of the $h_{i}$ 's for each section. Expressed mathematically,

$$
h=\frac{1}{L_{x}} \sum_{i=1}^{m} \ell_{i} h_{i} .
$$

The reasoning behind the procedure is based upon the assumption that although the individual dunes may change shape as they progress downstream, a statistical constancy of form exists over a long reach. Hence, quantitatively the particles subject to movement are those that would move if the entire profile were to progress downstream without changing form, and the depth of bed material movement is defined by lines that are parallel to the mean bed surface and extend downstream from the deepest trough.

If all bed material particles are assumed to be transported as the bedload,

$$
\hat{Q}_{T}=\hat{Q}_{B}=\gamma_{S}(1-\theta) W h \hat{V}_{B}
$$

where $\hat{V}_{B}$ is determined from equation 51 . For coarse sand $P\left[E_{1}\right]$ is expected to be very close to unity because the suspended load is negligible compared to the bed load. For a fine sand for which $P\left[E_{1}\right] \neq 1$, equation 60 would give only an approximation to the total load. 
Equations 55, 56, and 57 can be used with measured $y_{x}(t)$ and $y_{t}(x)$ records to compute the various transport rates. However, in order to apply the equations to the prediction of the bed material transport rate where the $y_{x}(t)$ and $y_{t}(x)$ records are not available, the relations, $\widehat{E}\left[X \backslash Y_{E}=y_{i}, Y_{D}=y_{j}, E_{v}\right]$,

$\widehat{E}\left[T \backslash Y_{D}=y_{j}\right], P\left[E_{v}\right], p_{Y_{D}}\left(\mathrm{y}_{\mathrm{j}}\right), p_{Y_{E}}\left(y_{i}\right)$, and $h$, to pertinent hydraulic and sediment parameters must be established.

The mean transport speed of bed material particles deposited at elevation $y_{j}$, which is denoted by $V_{T}(j)$, (more precisely, deposited between the elevations $\eta_{j}$ and $\eta_{j+1}$, centered at $y_{j}$ ) may be estimated

$$
\hat{V}_{T}(j)=\frac{\hat{E}\left[X \backslash Y_{D}=y_{j}\right]}{\hat{E}\left[T \backslash Y_{D}=y_{j}\right]},
$$

where $\hat{V}_{T}(j)$ estimates $V_{T}(j)$,

$$
\begin{aligned}
& \hat{\mathrm{E}}\left[X, Y_{D}=y_{j}\right] \\
& =\sum_{v=1}^{\infty} \sum_{i=1}^{n}\left[\frac{1}{m_{i, j, v}} \sum_{k=1}^{m_{i, j, v}} x_{i, j, v, k}\right] p_{Y_{E}}\left(y_{i}\right) P\left[E_{v}\right] .
\end{aligned}
$$

and

$$
\hat{E}\left[T \backslash Y_{D}=y_{j}\right]=\frac{1}{m_{j, j}} \sum_{k=1}^{m_{j, j}} t_{j, k} .
$$

Based on equation 61 , another transport equation can be developed as follows. Let $\xi_{j}$ denote the percentage of volume between elevations $\eta_{j}$ and $\eta_{j+1}$ occupied by dunes over a given reach; then, $\xi_{j}$ can be estimated from the $y_{t}(x)$ record (fig. 4 ),

$$
\xi_{j}=\frac{1}{L_{x}} \sum_{k} \lambda_{j, k}
$$

where $L_{x}$ is the total length of $y_{t}(x)$ record, and $\lambda_{j, k}$ is defined in figure 4. Applying equations 61 and 62 , the mean total bed material discharge can be expressed as

$$
\begin{aligned}
Q_{T}^{\prime}=\gamma_{s}(1-\theta) w & \sum_{j=1}^{n} \hat{V}_{T}(j) \Delta y_{j} \xi_{j} \\
& =\gamma_{s}(1-\theta) w \sum_{j=1}^{n} \frac{\hat{E}\left[X \backslash Y_{D}=y_{j}\right]}{\hat{E}\left[T \backslash Y_{D}=y_{j}\right]} \Delta y_{j} \xi_{j}
\end{aligned}
$$

where

$\hat{\mathbf{Q}}_{T}^{\prime}=$ estimate of mean total bed material discharge; and

$\Delta y_{j}=$ nonstandardized class width associated with elevation $y_{j}\left(\Delta y_{j}=\eta_{j+1}-\eta_{j}\right)$.

Equation 63 takes into account the local variation of the depth of the zone of bed material movement with respect to the elevation of deposition, and demonstrates to what extent each elevation contributes to the total transport rate. Similarly, the mean transport speed of a bed-load particle deposited at elevation $y_{j}$, which is denoted by $V_{B}(j)$, can be estimated from equation 61 by considering $P\left[E_{1}\right]=1$ and $P\left[E_{v}\right] \equiv 0$ for $v \geqslant 2$. It can be shown, of course, that equations 54,56 , and 57 also apply at each elevation $j$ as well as to depth-averaged values.

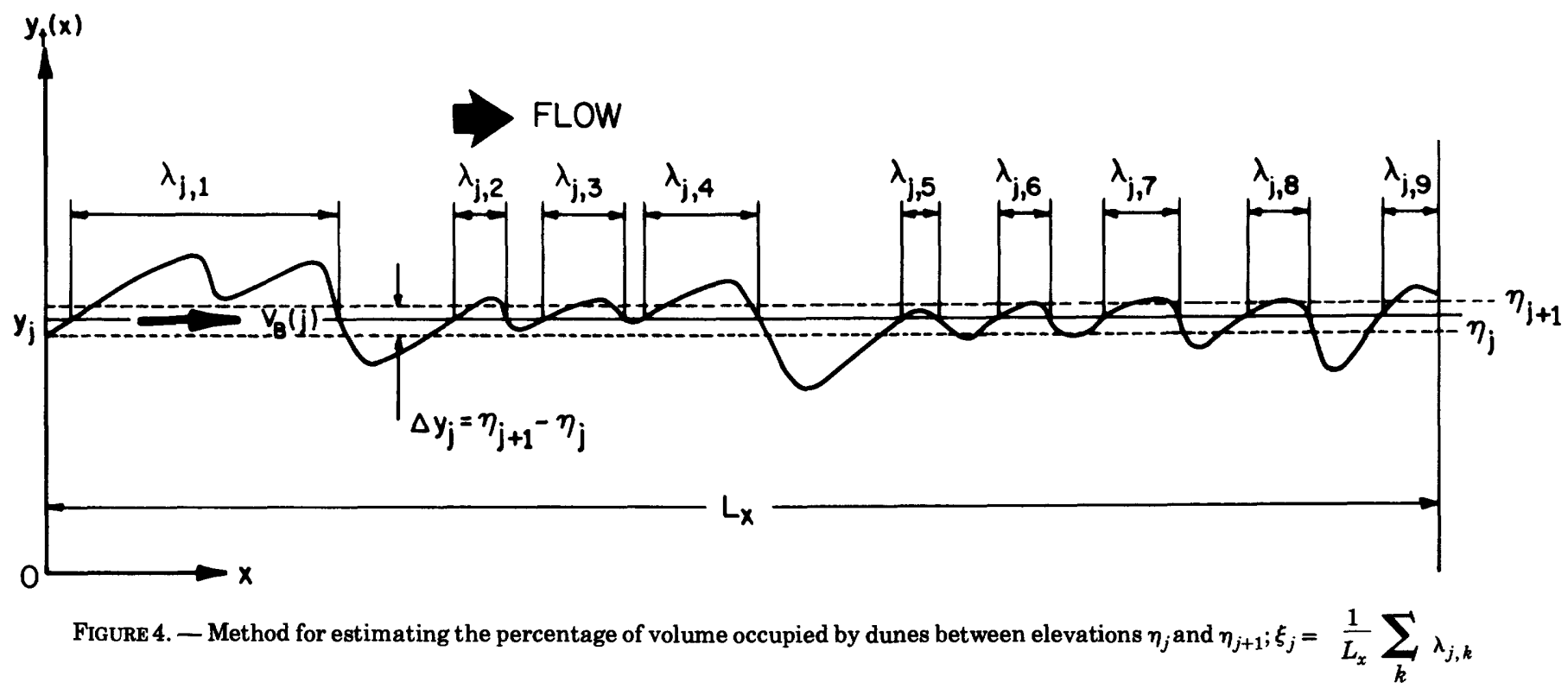


The third method to compute the mean total bed material discharge is based on the following reasoning:

$$
\begin{array}{r}
Q_{T}=\left[\begin{array}{c}
\text { Number of particles } \\
\text { deposited per } \\
\text { unit time and area }
\end{array}\right] \times\left[\begin{array}{c}
\text { Weight } \\
\text { per } \\
\text { particle }
\end{array}\right] \\
\times\left[\begin{array}{c}
\text { Mean distance } \\
\text { traveled by } \\
\text { a particle }
\end{array}\right] \times\left[\begin{array}{c}
\text { Width } \\
\text { of } \\
\text { channel }
\end{array}\right]
\end{array}
$$

where $Q_{T}$ is the mean total bed material discharge in weight per unit time. Restricting the attention to elevation $y_{j}$, the terms in equation 64 are estimated as follows:

$$
\begin{aligned}
& {\left[\begin{array}{c}
\text { Number of particles deposited per } \\
\text { unit time and area at } y_{j}
\end{array}\right]_{m}} \\
& =\frac{\Omega_{j} \sum_{k=1}^{m_{j}} \Delta \dot{y}_{j, k}}{L_{t}} \\
& {\left[\begin{array}{c}
\text { Weight per particle } \\
\text { at } y_{j}
\end{array}\right]=\frac{\gamma_{s}(1-\theta)}{\Omega_{j}} \text {, and }} \\
& =\hat{\mathrm{E}}\left[X \backslash Y_{D}=y_{j}\right],
\end{aligned}
$$

where $L_{t}$ is the total length of $y_{x}(t)$ record, and all other symbols have been defined previously. Summing the product of the terms in equation 65 over all elevations,

$\hat{Q}_{T}^{\prime \prime}=\frac{\gamma_{s}(1-\theta) W}{L_{t}} \sum_{j=1}^{n}\left\{\hat{E}\left[X \backslash Y_{D}=y_{j}\right] \sum_{k=1}^{m_{j}} \dot{y}_{j, k}^{+}\right\}$

where

$$
\begin{aligned}
& \hat{Q}_{T}^{\prime \prime}=\text { estimate of mean total bed-material discharge; } \\
& \text { and } \\
& W=\text { width of channel. }
\end{aligned}
$$

Equation 66 also illustrates the contribution of each elevation to the total transport, but its primary distinction is that the transport rate is computed from the sounding records with a minimum number of computations.

The relationship between the three transport equations, 55, 63, and 66 , will now be demonstrated. First, the comparison of equations 55 and 66 is demonstrated. Combining equations 22,25 , and 66 ,

$$
\begin{array}{r}
\hat{Q}_{T}^{\prime \prime}=\frac{\gamma_{s}(1-\theta) W}{L_{t}} \sum_{j=1}^{n}\left\{\hat{E}\left[X, Y_{D}=y_{j}\right] p_{Y_{D}}\left(y_{j}\right) \frac{N_{d}}{\Omega}\right\} \\
=\frac{\gamma_{s}(1-\theta) W N_{d}}{\Omega L_{t}} \hat{\mathrm{E}}[X] .
\end{array}
$$

Multiplying and dividing by the marginal rest period and utilizing equations $20,21,25,30$, and 31 ,

$$
\begin{aligned}
\hat{Q}_{T}^{\prime \prime}=\frac{\gamma_{s}(1-\theta) W N_{d}}{\Omega L_{t}} \frac{\hat{\mathrm{E}}[X]}{\hat{\mathrm{E}}[T]} & \\
& \sum_{j=1}^{n}\left\{\left(\frac{1}{m_{j j}} \sum_{k=1}^{m_{j j}} t_{j, k}\right)\left(\frac{\Omega}{N_{d}} \sum_{k=1}^{m_{j}} \Delta \dot{y}_{j, k}\right)\right\} \ldots
\end{aligned}
$$

As the value of $\Delta y$ decreases the value of the last term can be approximated without appreciable error, as

$$
\sum_{k=1}^{m_{j}} \Delta y_{j, k}^{+} \cong m_{j} \Delta y_{j} \ldots
$$

Strictly speaking $m_{j} \Delta y_{j}$ is equal to or slightly greater than the term

$$
\sum_{k=1}^{m_{j}} \Delta y_{j, k}^{+}
$$

(fig. 1). Assuming a long record with small vertical class intervals such that equation 69 is valid and such that $m_{j}=m_{j j}$, equation 68 reduces to

$$
\hat{Q}_{T}^{\prime \prime}=\gamma_{s}(1-\theta) w \frac{\hat{E}[X]}{\hat{E}[T]} \sum_{j=1}^{n} \frac{\Delta y_{j}}{L_{t}} \sum_{k=1}^{m_{j}} t_{j, k} \ldots
$$

which would be equivalent to equation 55 provided that the average depth of the zone in which bed-material movement occurs, $h^{\prime}$ is defined by

$$
n^{\prime}=\frac{1}{L_{t}} \sum_{j=1}^{n}\left(\Delta y_{j} \sum_{k=1}^{m_{j}} t_{j, k}\right) \ldots
$$

Equation 71, is similar to equation 59 except that it is based on the time record of depth, $y_{x}(t)$, while equation 59 is based on the longitudinal profile, $y_{t}(x)$.

To investigate the relation between equations 63 and 66 , we proceed as follows. The last term of equation 66 can be approximated without an appreciable error, as $m_{j} \Delta y_{j}$ using equation 69 . Replacing the last term by its approximate value, and multiplying equation 66 by the 
right-hand side of equation 30 while dividing by the left-hand side,

$\hat{Q}_{T}^{\prime \prime}=\gamma_{s}(1-\theta) W$

$$
\sum_{j=1}^{n}\left\{\frac{\hat{E}\left[X \backslash Y_{D}=y_{j}\right]}{\hat{E}\left[T \backslash Y_{D}=y_{j}\right]} \frac{m_{j}}{m_{j j}} \frac{\Delta y_{j}}{L_{t}}\right\} \sum_{k=1}^{m_{j j}} t_{j, k} \ldots
$$

The number of bed forms contained in the $y_{x}(t)$ record and which also contains some deposition in the class interval, $m_{j}$, should be almost equal to the total number of bed forms with both an upcrossing and a downcrossing in the interval, $m_{j j}$. Assuming $m_{j}=m_{j j}$, equation 72 is identical to equation 63 except that the percentage of the volume in the class interval occupied by dunes is computed from the $y_{x}(t)$ record instead of from equation 62 which is based on the $y_{t}(x)$ record.

In summary, three transport equations have been presented, equations 55, 63, and 66. Although the equations appear quite different in form, they are all based on similar assumptions. As the record length becomes long and the class intervals reduce to zero in the limit, the three equations would become identical provided that either the $y_{x}(t)$ record or the $y_{t}(x)$ record could be used to determine the active depth. (This should be true for equilibrium flow.) In the following section, the total load will be computed for three flow conditions using all three equations, and the results will be compared.

\section{GENERAL TWO-DIMENSIONAL STOCHASTIC MODEL FOR DISPERSION OF BED-MATERIAL SEDIMENT PARTICLES}

Let us define the following stochastic processes:

$$
\widetilde{X}(t)=\sum_{i=0}^{N(t)} X_{i}=\begin{aligned}
& \text { longitudinal position of a bed- } \\
& \text { material sediment particle at } \\
& \text { time } t \text { in which } \widetilde{X}(0)=X_{0}=0 .
\end{aligned}
$$

$N(t)=$ counting process describing number of steps taken by a bed-material sediment particle in time $t$.

$X_{i}=$ length of $i$ th step of a bed-material sediment particle.
$X(n)=\sum_{i=1}^{n} X_{i}=\begin{aligned} & \text { longitudinal position of a bed- } \\ & \text { material sediment particle after }\end{aligned}$ $n$ steps.

$\widetilde{Y}(t)=$ vertical position of a bed-material sediment particle at time $t$.

$Y_{D}(n)=$ elevation at which a bed-material sediment particle is deposited after $n$ steps.
The probability that the particle has, at time $t$, traveled a distance equal to or less than $x$ and that it is located at an elevation equal to or less than $y$ may now be expressed as the joint distribution function

$$
\begin{aligned}
F(x, y ; t) & =P[\tilde{X}(t) \leq x, \tilde{Y}(t) \leq y] \\
& =\sum_{n=0}^{\infty} P[\tilde{X}(t) \leq x, \tilde{Y}(t) \leq y, N(t)=n] .
\end{aligned}
$$

Using the definition of conditional probability and assuming that the duration of the particle movement is negligible, equation 73 can be restated as

$$
\begin{aligned}
& F(x, y ; t)=\sum_{n=0}^{\infty} P\left[X(n) \leq x, Y_{D}(n) \leq y, N(t)=n\right] \\
& =\sum_{n=0}^{\infty} P\left[X(n) \leq x, N(t)=n \backslash Y_{D}(n) \leq y\right] P\left[Y_{D}(n) \leq y\right] \\
& =\int_{y_{\min }}^{y} \sum_{n=0}^{\infty} P[X(n) \leq x, N(t) \\
& \left.=n \backslash Y_{D}(n)=y^{\prime}\right] f_{Y_{D}(n)}\left(y^{\prime}\right) d y^{\prime}
\end{aligned}
$$

where

$y_{\min }=$ lowest elevation of deposition; and

$f_{Y_{U^{(n)}}}(y)=$ probability density function of $Y_{D}(n)$.

The event, $\{N(t)=n\}$, can be expressed in terms of the rest period of a bed-material sediment particle

$$
\{N(t)=n\}=\{T(n) \leq t\} \bigcap\{T(n+1)>t\}
$$

where

$\{\cdot\}=$ events;

$\bigcap=$ intersection of events;

$$
T(n)=\sum_{i=1}^{n} T_{i} ; \text { and }
$$

$T_{i}=$ random variable describing the duration of $i$ th rest period of a bed-material sediment particle.

By virtue of equation 75 , it follows that

$$
\begin{aligned}
P[N(t)=n]=P[T(n) & \leq t, T(n+1)>t] \\
& =P\left[T(n) \leq t, T_{n+1}>t-T(n)\right] .
\end{aligned}
$$

For further simplification of equation 74, the following assumptions are made: (1) $X(n)$ and $N(t)$ are mutually independent for every $n$. (2) $X_{i}$ for $i \geqslant 1$ are independently and identically distributed according to the probability density function $f_{X}(x)$, where 
$0 \leqslant x<\infty$. Outside this range, $f_{X}(x)=0$. (3) $X_{i}$ is independent of $Y_{D}(j)$ for $i \neq j$. (4) $Y_{D}(i)$ for $i \geqslant 1$ are independently and identically distributed according to the probability density function $f_{Y_{D}}(y)$, where $y_{\min } \leqslant y \leqslant y_{\max }$. Outside this range, $f_{Y_{D}}(y)=0$. (5) $T_{i}$ for $i \geqslant 1$ are independently and identically distributed according to the probability density function $f_{T}(t)$, where $0 \leqslant t<\infty$. Outside this range, $f_{T}(t)=0$. (6) $T_{i}$ is independent of $Y_{D}(j-1)$ for $i \neq j$. In other words, assumption 1 states that the total distance $X(n)$ traveled by a sediment particle after $n$ steps should not depend on which time interval within $[0, t]$ that these $n$ steps occurred. The step lengths are always positive so that the particle always moves in downstream direction (part of assumption 2). Each step length depends on the elevation at which the particle is deposited at the end of that step (assumption $3)$. The elevation at which the particle is deposited at the end of any step does not depend on the elevation at which it was deposited at the end of any previous step (assumption 4). Finally, the duration of each rest period depends on the elevation at which the particle was deposited at the end of the previous step (assumption 5).

Utilizing assumption 1 , equation 74 becomes

$$
\begin{aligned}
F(x, y ; t) & =\int_{y_{\min }}^{y} \sum_{n=0}^{\infty}\left\{P\left[X(n) \leq x \backslash Y_{D}(n)=y^{\prime}\right]\right. \\
& \left.\cdot P\left[N(t)=n \backslash Y_{D}(n)=y^{\prime}\right] f_{Y_{D}(n)}\left(y^{\prime}\right)\right\} d y^{\prime} \\
& =\int_{y_{\min }}^{y} P\left[X(0) \leq x \backslash Y_{D}(0)=y^{\prime}\right] \\
& \cdot P\left[N(t)=0 \backslash Y_{D}(0)=y^{\prime}\right] f_{Y_{D}(0)}\left(y^{\prime}\right) d y^{\prime} \\
& +\int_{y}^{y} \sum_{n=1}^{\infty}\left\{P\left[X(n) \leq x \backslash Y_{D}(n)=y^{\prime}\right]\right. \\
& \left.\cdot P\left[N(t)=n \backslash Y_{D}(n)=y^{\prime}\right] f_{Y_{D}}(n)\left(y^{\prime}\right)\right\} d y^{\prime}
\end{aligned}
$$

Under assumptions 2, 3, and 4, and using the concepts of joint and conditional probability,

$$
\begin{aligned}
P[X(n) & \left.\leq x \backslash Y_{D}(n)=y^{\prime}\right] \\
& =P\left[X(n-1)+X_{n} \leq x \backslash Y_{D}(n)=y^{\prime}\right] \\
& =\int_{0}^{x} f_{X(n-1)+X_{n} \backslash Y_{D}(n)\left(x^{\prime} \backslash y^{\prime}\right) d x^{\prime}} \\
& =\int_{0}^{x} d x^{\prime} \int_{0}^{x^{\prime}} f_{X(n-1), X_{n} \backslash Y_{D}(n)}\left(\zeta, x^{\prime}-\zeta \backslash y^{\prime}\right) d \zeta
\end{aligned}
$$

and using assumptions 3 and 4 ,

$P\left[X(n) \leq x \backslash Y_{D}(n)=y^{\prime}\right]$

$$
\begin{aligned}
& =\int_{0}^{x} d x^{\prime} \int_{0}^{x^{\prime}} f_{X(n-1)}(\zeta) f_{X \backslash Y_{D}}\left(x^{\prime}-\zeta \backslash y^{\prime}\right) d \zeta \\
& =\int_{0}^{x} d x^{\prime} \int_{0}^{x^{\prime}} f_{X}^{(n-1)} f_{X \backslash Y_{D}}\left(x^{\prime}-\zeta \backslash y^{\prime}\right) d \zeta
\end{aligned}
$$

in which

$$
\begin{aligned}
X(n-1)=\sum_{i=0}^{n-1} X_{i}, X_{0}=0, \\
f_{X(n-1)}(\zeta)=f_{X}^{(n-1)}(\zeta) \\
=\int_{0}^{\zeta} f_{X}^{(n-2)}(\theta) f_{X}(\zeta-\theta) d \theta ; n=3,4,5, \ldots
\end{aligned}
$$

and

$$
\stackrel{(n)}{f_{X}(\zeta)}=f_{X}(x) ; n=2
$$

In equations 78 and $79, f_{X(n-1)}, X_{n} \backslash Y_{D^{(n)}}\left(\zeta, x^{\prime}-\zeta \backslash y^{\prime}\right)$ denotes the joint probability density function of $X(n-1)$ and $X_{n}$, conditioned on $Y_{D}(n), f_{X}^{(n-1)}(\zeta)$ is the $(n-1)$-fold convolution of the probability density function for the length of a single step, and it is equal to the probability density function for the distance traveled by the particle in $(n-1)$ steps, and $f_{X \backslash Y_{D}}(x \backslash y)$ is the conditional probability density function for a single step length given that the particle is deposited at elevation $y$.

Turning now to the other part of equation 77 and using equation 76 and assumptions 4,5 , and 6 ,

$$
\begin{aligned}
& P\left[N(t)=n \backslash Y_{D}(n)=y^{\prime}\right] \\
& =P\left[T(n) \leq t, T_{n+1}>t-T(n) \backslash Y_{D}(n)=y^{\prime}\right] \\
& =\int_{0}^{t} \int_{t-t^{\prime}}^{\infty} f_{T(n), T_{n+1} \backslash Y_{D}(n)}\left(t^{\prime}, \tau \backslash y^{\prime}\right) d \tau d t^{\prime} \\
& =\int_{0}^{t} \int_{t-t^{\prime}}^{\infty} f_{T(n)}\left(t^{\prime}\right) f_{T_{n+1} \backslash Y_{D}(n)}\left(\tau \backslash y^{\prime}\right) d \tau d t^{\prime} \\
& =\int_{0}^{t} f_{T}^{(n)}\left(t^{\prime}\right) d t^{\prime} \int_{t-t^{\prime}}^{\infty} f_{T \backslash Y_{D}}\left(\tau \backslash y^{\prime}\right) d \tau
\end{aligned}
$$


in which

$T(n)=\sum_{i=1}^{n} T_{i}$

$$
\begin{array}{r}
f_{T(n)}\left(t^{\prime}\right)=f_{T}^{(n)}\left(t^{\prime}\right)=\int_{0}^{t^{\prime}} f_{T}^{(n-1)} f_{T}\left(t^{\prime}-\theta\right) d \theta ; \\
n=2,3,4, \ldots .
\end{array}
$$

and

$$
\stackrel{(n)}{f_{T}\left(t^{\prime}\right)}=f_{T}(t) ; n=1
$$

$(n)$

In the above, $T_{n+1}$ is the random variable describing the duration of the $(n+1)$ th rest period of a particle, $f_{T(n), T_{n+1} \backslash Y_{D}^{(n)}}\left(t^{\prime}, \tau \backslash y^{\prime}\right)$ is the joint probability density function of $T(n)$ and $T_{n+1}$, conditioned on $Y_{D}(n)$, $f_{T \backslash \mathrm{Y}_{\mathrm{D}}}(t \backslash y)$ is the conditional probability density function for the duration of a rest period given that the particle was deposited at elevation $y$, and $f_{T}^{(n)}(t)$ is the $n$-fold convolution of the probability density function, $f_{T}(t)$, for the duration of a single rest period and is equal to the probability density function for the duration of $n$ successive rest periods.

Similarly, the terms for $n=0$ in equation 77 become:

$$
P\left[X(0) \leq x \backslash Y_{D}(0)=y^{\prime}\right]=1
$$

because $X(0)=X_{0}=0$ and $0 \leqslant x<\infty$, and

$$
\begin{aligned}
P\left[N(t)=0 \backslash Y_{D}(0)=y^{\prime}\right]= & P\left[T_{1}>t \backslash Y_{D}(0)=y^{\prime}\right] \\
& =\int_{t}^{\infty} f_{T \backslash Y_{D}}\left(t^{\prime} \backslash y^{\prime}\right) d t^{\prime} .
\end{aligned}
$$

where $T_{1}$ is the random variable describing the duration of the first rest period in time $t$. It is important to note that the initial condition, $X(0)=X_{0}=0$, implies that the particle starts its first rest period at $t=0$.

Introducing equations $78,80,82$, and 83 into equation 77 ,

$$
\begin{aligned}
& F(x, y ; t)=\int_{y_{\min }}^{y} f_{Y_{D}}\left(y^{\prime}\right) d y^{\prime} \int_{t}^{\infty} f_{T \backslash Y_{D}}\left(t^{\prime} \backslash y^{\prime}\right) d t^{\prime} \\
& +\int_{y_{\min }}^{y} f_{Y_{D}}\left(y^{\prime}\right) d y^{\prime} \sum_{n=1}^{\infty}\left(\int_{0}^{x} d x^{\prime} \int_{0}^{x^{\prime}} f_{X}(\zeta)\right. \\
& \left.f_{X \backslash Y_{D}}\left(x^{\prime}-\zeta \backslash y^{\prime}\right) d \zeta \cdot \int_{0}^{t} f_{T}^{(n)}\left(t^{\prime}\right) d t^{\prime} \int_{t-t^{\prime}}^{\infty} f_{T \backslash Y_{D}}\left(\tau \backslash y^{\prime}\right) d \tau\right)
\end{aligned}
$$

The first term of equation 84 represents the joint probability that the particle has not moved from its initial position and that its initial elevation is equal to or less than $y$, and it is not a function of $x$. Hence,

$$
\begin{aligned}
\left.\frac{\partial^{2}}{\partial x \partial y}[F(x, y ; t)]\right|_{n=0}=\frac{\partial^{2}}{\partial x \partial y} & \int_{y_{\min }}^{y} f_{Y_{D}}\left(y^{\prime}\right) d y^{\prime} \\
& \int_{t}^{\infty} f_{T \backslash Y_{D}}\left(t^{\prime} \backslash y^{\prime}\right) d t^{\prime} \equiv 0 .
\end{aligned}
$$

The corresponding density function is therefore

$$
\begin{aligned}
f(x, y ; t)= & \frac{\partial^{2}}{\partial x \partial y} F(x, y ; t) \\
= & f_{Y_{D}}(y) \sum_{n=1}^{\infty}\left(\int_{0}^{x} f_{X}^{(n-1)} f_{X \backslash Y_{D}}(x-\zeta \backslash y) d \zeta\right. \\
& \left.\cdot \int_{0}^{t} f_{T}^{(n)}\left(t^{\prime}\right) d t^{\prime} \int_{t-t^{\prime}}^{\infty} f_{T \backslash Y_{D}}(\tau i y) d \tau\right)
\end{aligned}
$$

If a large number of identical particles are initially at rest at $x=0, y=y_{0}$, equation 85 expresses the longitudinal and vertical distribution at time $t$ of the particles which have moved from their respective initial positions. It should be noted here that $f(x, y ; t)$ is not a true probability density function because

$$
\int_{0}^{\infty} d x \int_{y_{\min }}^{y_{\max }} f(x, y ; t) d y=1-P[N(t)=0]<1 .
$$

That is to say, equation 85 applies only after the particle has moved from its initial position. The expression $f(x, y ; t)$ does not exist for $x=0$.

If we assume that $X_{i}$ is independent of $Y_{D}(j)$ for all $i$ and $j$ and drop assumption 3 , equation 85 reduces to equation 8 ,

$f(x, y ; t)$

$$
=f_{Y_{D}}(y) \sum_{n=1}^{\infty} f_{X}^{(n)}(x) \int_{0}^{t} f_{T}^{(n)}\left(t^{\prime}\right) d t^{\prime} \int_{t-t^{\prime}}^{\infty} f_{T \backslash Y_{D}}(\tau \backslash y) d \tau,
$$

which is the Sayre-Conover (1967) two-dimensional stochastic model. The difference between equations 85 and 8 is that equation 85 takes some of the dependence between $X$ and $Y_{D}$ into account whereas equation 8 is based on the independence of $X$ and $Y_{D}$. Hence, the Sayre-Conover model is a special case of equation 85 . 
The marginal case of equation 85 gives the longitudinal distribution at time $t$ of the particles which have moved from their initial positions. Integrating equation 85 over $y$,

$f(x ; t)=\int_{y_{\min }}^{y_{\max }} f(x, y ; t) d y=\sum_{n=1}^{\infty} \int_{0}^{x} f_{X}^{(n-1)}(\zeta) d \zeta \int_{0}^{t} f_{T}^{(n)}\left(t^{\prime}\right) d t^{\prime}$

$\int_{t-t^{\prime}}^{\infty} d \tau\left[\int_{y_{\min }}^{y_{\max }} f_{X \backslash Y_{D}}\left(x-\zeta \backslash y^{\prime}\right) f_{T \backslash Y_{D}}{ }^{\left(\tau \backslash y^{\prime}\right) f_{Y_{D}}\left(y^{\prime}\right) d y^{\prime}}\right]$

By virtue of assumption 1,

$$
\begin{aligned}
& \int_{y_{\min }}^{y_{\max }} f_{X \backslash Y_{D}}\left(x-\zeta \backslash y^{\prime}\right) f_{T \backslash Y_{D}}\left(\tau \backslash y^{\prime}\right) f_{Y_{D}}\left(y^{\prime}\right) d y^{\prime} \\
&=\int_{y_{\min }}^{y_{\max }} f_{X, T \backslash Y_{D}}\left(x-\zeta, \tau i y^{\prime}\right) f_{Y_{D}}\left(y^{\prime}\right) d y^{\prime} \\
&=f_{X, T}(x-\zeta, \tau)=f_{X}(x-\zeta) f_{T}(\tau)
\end{aligned}
$$

Substituting equation 88 into equation 87 and rearranging terms,

$$
\begin{aligned}
f(x ; t)=\sum_{n=1}^{\infty} \int_{0}^{x} f_{X}^{(n-1)}(\zeta) f_{X}(x-\zeta) d \zeta & t \int_{0}^{t} f_{T}^{(n)}\left(t^{\prime}\right) d t^{\prime} \int_{t-t^{\prime}}^{\infty} f_{T}(\tau) d \tau
\end{aligned}
$$

Because

$$
\int_{0}^{x} f_{X}^{(\zeta)-1)} f_{X}(x-\zeta) d \zeta=f_{X}^{(n)}(x)
$$

and from equation 76 ,

$$
P[N(t)=n]=\int_{0}^{t} f_{T}^{(n)}\left(t^{\prime}\right) d t^{\prime} \int_{t-t^{\prime}}^{\infty} f_{T}(\tau) d \tau
$$

Meanwhile, equation 75 can be restated as

$$
\begin{aligned}
\{N(t)=n\}=\{T(n) \leq t\} \bigcap & \{T(n+1)>t\} \\
= & \{T(n) \leq t\}-\{T(n+1)>t\} \\
= & \{T(n) \leq t\}-\{T(n+1) \leq t\}
\end{aligned}
$$

where $\{T(n+1)>t\}^{c}$ denotes the complement of the event $\{T(n+1)>t\}$. Because $\{T(n+1) \leqslant t\}$ is a subevent of $\{T(n) \leqslant t\}$, it follows that

$$
\begin{aligned}
P[N(t)=n]=P[T(n) & \leq t]-P[T(n+1) \leq t] \\
& =\int_{0}^{t} f_{T}^{(n)}\left(t^{\prime}\right) d t^{\prime}-\int_{0}^{t}(n+1)
\end{aligned}
$$

From equations 89 and 90 , we have the marginal probability density function,

$$
\begin{aligned}
f(x ; t) & =\sum_{n=1}^{\infty} f_{X}^{(n)}(x) P[N(t)=n] \\
& =\sum_{n=1}^{\infty} f_{X}^{(n)}(x) \int_{0}^{t}\left[\begin{array}{cc}
(n) & (n+1) \\
f_{T}^{\left(t^{\prime}\right)}-f_{T}^{\left(t^{\prime}\right)}
\end{array}\right] d t^{\prime}
\end{aligned}
$$

Equation 91 is identical to the Sayre-Conover (1967) one-dimensional stochastic model which is given in equation 10 . As with equation 85 , here also $f(x ; t)$ is not a true probability density function because

$$
\int_{0}^{\infty} f(x ; t) d x=1-P[N(t)=0]<1 .
$$

where $P[N(t)=0]$ is the probability that the particle has not moved from its initial position.

In order to apply equations 84 or 85 , the probability density functions $f_{Y_{D}}(y), f_{T \backslash Y_{D}}(t \backslash y)$, and $f_{X \backslash Y_{D}}(x \backslash y)$ must be known. These density functions are estimated from equations 25,28 , and 39 . The probability density functions $f_{T}(t)$ and $f_{X}(x)$ are determined by the relations

$$
f_{T}(t)=\int_{y_{\min }}^{y_{\max }} f_{T \backslash Y_{D}}(t \backslash y) f_{Y_{D}}(y) d y
$$

and

$$
f_{X}(x)=\int_{y_{\min }}^{y_{\max }} f_{X \backslash Y_{D}}(x \nmid y) f_{Y_{D}}(y) d y
$$

where $y_{\min }$ and $y_{\max }$ are estimated from the $y_{x}(t)$ record. Equations 92 and 93 are the continuous forms corresponding to equations 29 and 40 (or 41 ), respectively. With $f_{T}(t)$ and $f_{X}(x)$ determined, the corresponding convolutions, $f_{T}^{(n)}(t)$ and $f_{X}^{(n-1)}(x)$ are determined from equations 81 and 79 , respectively. 


\section{ANALYSIS AND DISCUSSION OF RESULTS}

\section{EXPERIMENT AND BASIC DATA}

Three dune runs were made in a tilting recirculating flume of rectangular cross section, $61 \mathrm{~m}$ long, $2.4 \mathrm{~m}$ wide, and $1.2 \mathrm{~m}$ deep. The flume has been described in detail by Williams (1971).

The bed material used in these experiments was a screened river sand (Cherry Creek sand), with a median sieve diameter, $d_{50}=1.13 \mathrm{~mm}$, and a geometric standard deviation, $\sigma_{g}=1.51$. The size distribution, shown in figure 5 , was obtained by a sieve analysis of 3,000 grams of bed material.
After an equilibrium flow, as defined by Simons and Richardson (1966), was established, the $y_{x}(t)$ and $y_{t}(x)$ records, the total bed-material discharge, and the hydraulic properties of interest were measured. The methods and procedures of the measurements have been described in detail by Lee (1969). The summary of measured and derived data is given in table 1 . The values of the water discharge, depth, energy slope, bed shape, and total bed-material concentration presented in table 1 are the average of several individual measurements. The sampled load was measured by a DH-48 sampler. The number of measurements was the same as the number of $y_{t}(x)$ charts.

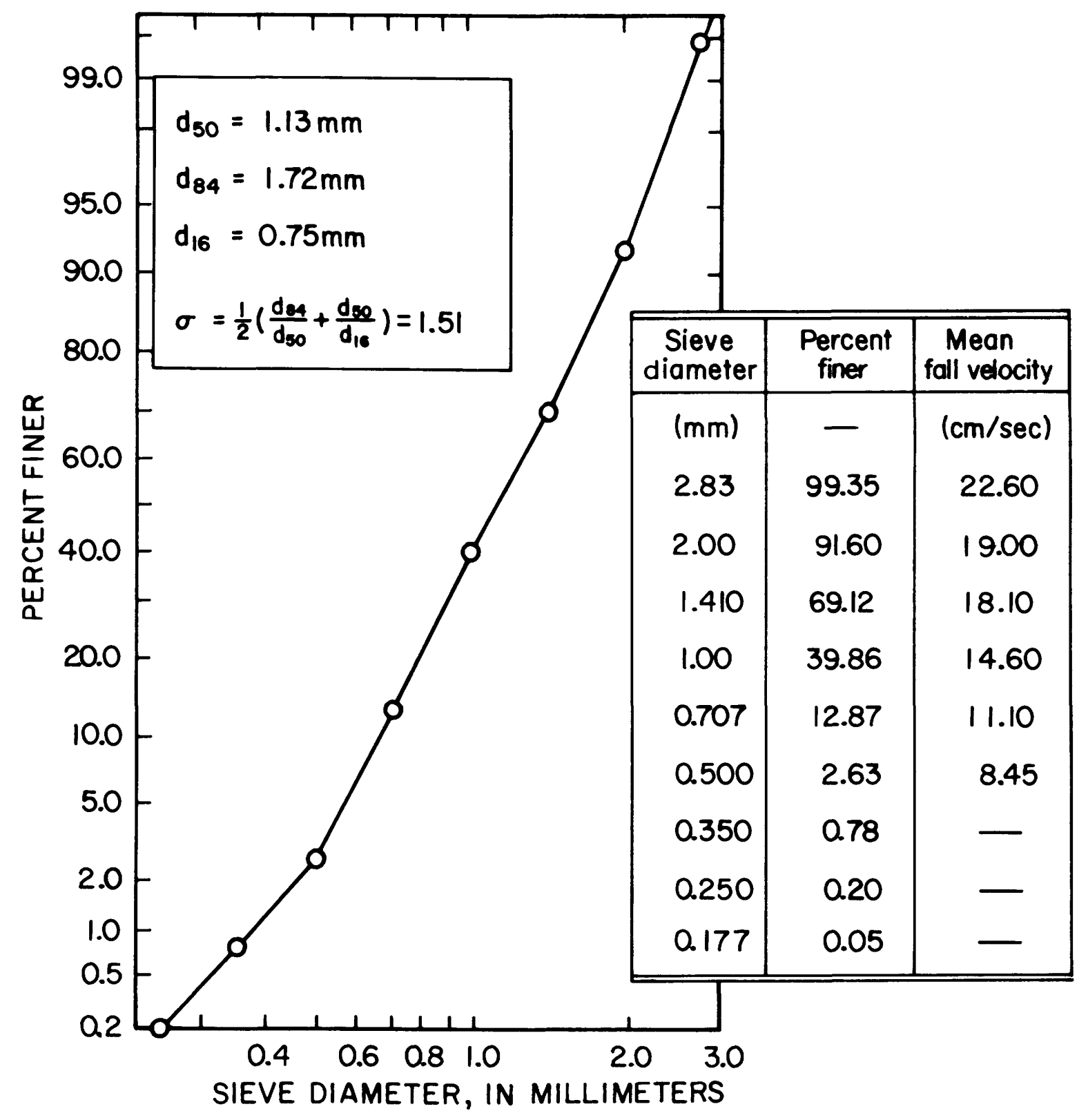

FIGURE 5. - Size distribution curve of bed material. 
TABLE 1. - Basic data and computed parameters

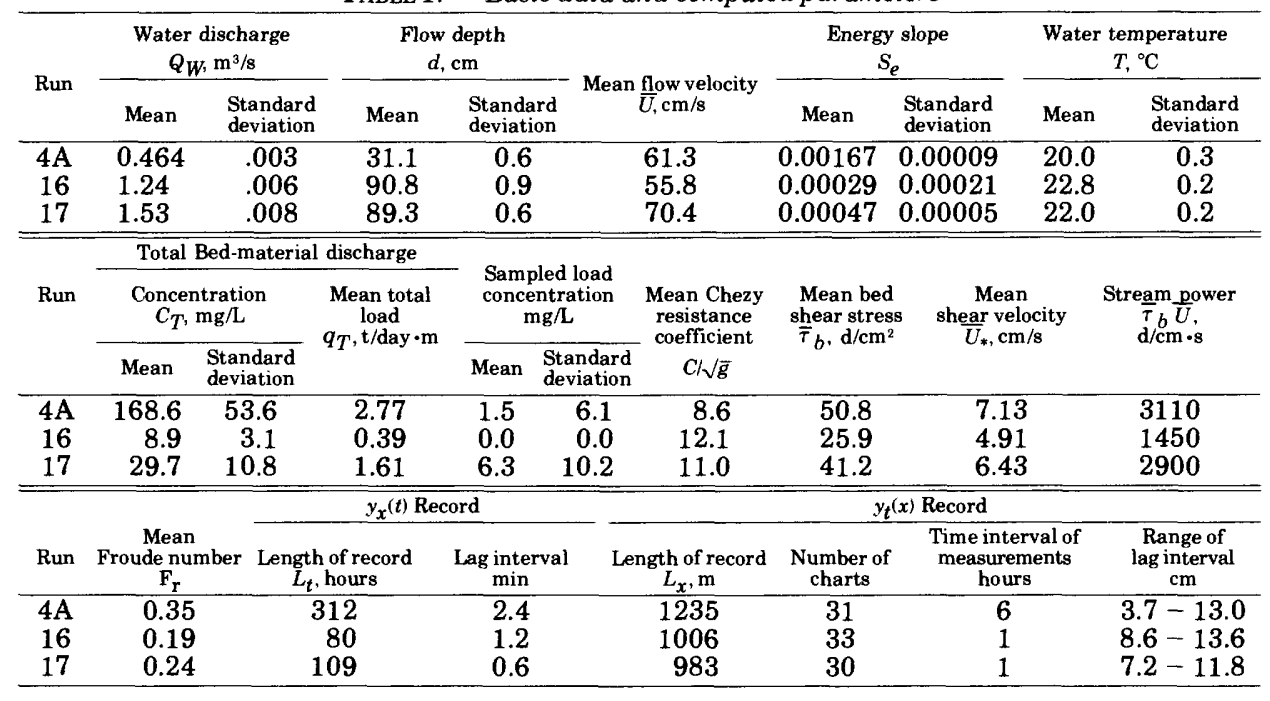

The $y_{t}(x)$ charts were obtained by mounting a sonic depth sounder on the instrument carriage and traversing it along the centerline of the flume in the upstream direction. The sonic depth sounder has been described by Karaki, Gray, and Collins (1961). Although the duration of traverse was approximately 5 minutes, the $y_{t}(x)$ record was considered to be instantaneous. The $y_{x}(t)$ record was obtained by locating a sonic depth sounder at the centerline of the flume $42.1 \mathrm{~m}$ downstream of the headbox. Both the $y_{t}(x)$ and $y_{x}(t)$ records were digitized with an analog-to-digital converter at the lag intervals shown in table 1 . The lag in terval on the $y_{t}(x)$ charts were not constant because the speed of the carriage was somewhat different for each chart. The output of the converter was to computer cards so that all statistics could be processed on the digital computer.

\section{PROBABILITY DISTRIBUTIONS OF THE ELEVATIONS OF DEPOSITION AND EROSION}

The sample probability mass functions for the elevation of deposition and erosion were computed using equations 25 and 26 and the $y_{x}(t)$ records. The results of calculations for the three flume runs are presented in table 2.

The $y_{x}(t)$ record of each run was standardized so that the class mark, $y_{i}$, measures the elevation of deposition or erosion in terms of the standard deviation about the mean bed elevation. The class width of 0.4 was used for all class marks. The frequency histograms for the elevation of deposition and erosion are plotted in figure 6 .

The truncated Gaussian probability density function, defined by

$$
\left.\begin{array}{c}
f_{Y_{D}}(y)=f_{Y_{E}}(y) \\
=\frac{\frac{1}{\sqrt{2 \pi}} e^{-\frac{1}{2} y^{2}}}{\frac{1}{\sqrt{2 \pi}} \int_{-2.4}^{2.4} e^{-\frac{1}{2} y^{2}} d y}=1.017 \frac{1}{\sqrt{2 \pi}} e^{-\frac{1}{2} y^{2}} \\
\text { for }-2.4 \leq y \leq 2.4 \\
f_{Y_{D}}(y)=f_{Y_{E}}(y)=0 \text { otherwise }
\end{array}\right\}
$$

appears to fit the data reasonably well. A symmetric triangular density function defined by

$$
\left.\begin{array}{r}
f_{Y_{D}}(y)=f_{Y_{E}}(y)=-\frac{1}{2.4^{2}} y+\frac{1}{2.4} \text { for } 0 \leq y \leq 2.4 \\
f_{Y_{D}}(y)=f_{Y_{E}}(y)=\frac{1}{2.4^{2}} y+\frac{1}{2.4} \text { for }-2.4 \leq y \leq 00 \\
f_{Y_{D}}(y)=f_{Y_{E}}(y)=0 \text { otherwise },
\end{array}\right\}
$$

also appears to fit the data reasonably well. Equations 94 and 95 are both plotted in figure 6 . In equations 94 and $95, f_{Y_{D}}(y)$ and $f_{Y_{E}}(y)$ are the probability density functions of the elevation of deposition and erosion, respectively, and $y$ is the standardized elevation.

Both distributions assume nonzero values only for $-2.4 \leqslant y \leqslant 2.4$ and the two models postulate that $Y_{D}$ and $Y_{E}$ are identically distributed. The truncation limits on these distributions are rather arbitrary. 


\section{Run 4A}
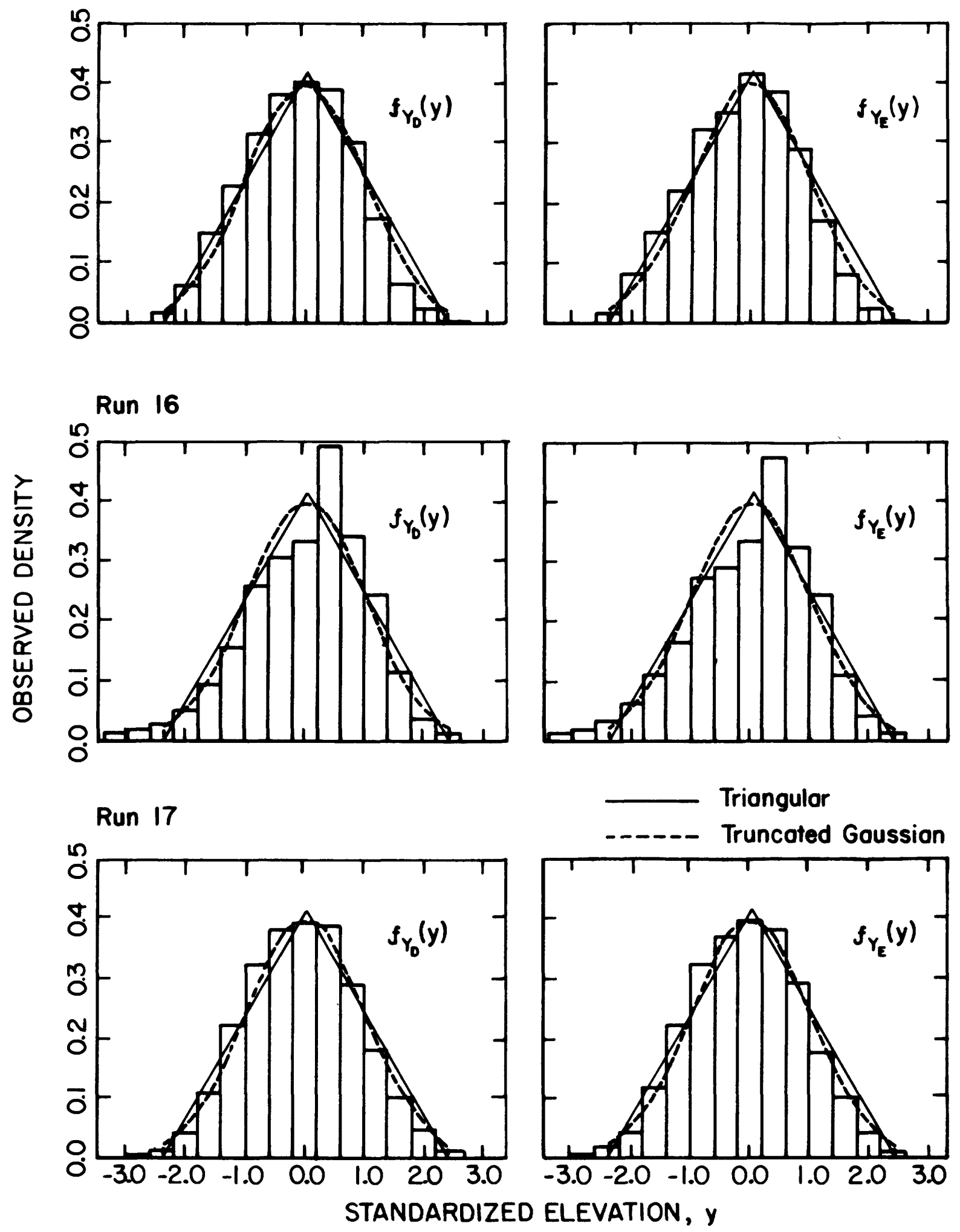

FIGURE 6. - Frequency histograms, triangular density function, and truncated Gaussian density function for the elevation of deposition and erosion. 
The mean and variance for the truncated Gaussian density are

and

$$
E\left[Y_{D}\right]=E\left[Y_{E}\right]=0 \text {, }
$$

$$
\left.\begin{array}{rl}
\operatorname{Var}\left[Y_{D}\right] & =\operatorname{Var}\left[Y_{E}\right]=E\left[Y_{D}^{2}\right] \\
& =E\left[Y_{E}^{2}\right] \approx 1.017 \int_{-2.4}^{2.4} y^{2} g(y) d y=0.891
\end{array}\right\}
$$

where $g(y)=\frac{1}{\sqrt{2 \pi}} e^{-\frac{1}{2} y^{2}}$. For the triangular density

$$
\left.\begin{array}{l}
\qquad\left[Y_{D}\right]=E\left[Y_{E}\right]=0 \\
\text { and } \\
\operatorname{Var}\left[Y_{D}\right]=\operatorname{Var}\left[Y_{E}\right]=E\left[Y_{D}^{2}\right] \\
\\
=E\left[Y_{E}^{2}\right]=\frac{2.4^{2}}{6}=0.960
\end{array}\right\}
$$

The variances of these distributions are quite sensitive to the assumed truncation limits.

A goodness of fit test using the chi-square statistic indicated that neither model would be rejected for runs 16 and 17 at a significance level of 0.05 . For run $4 \mathrm{~A}$, however, both models were rejected at the same level of significance. As seen in figure 6, the truncated Gaussian density appears to give a slightly better approximation to $f_{Y_{D}}(y)$ and $f_{Y_{E}}(y)$; but, the triangular density is much easier to handle in analytical treatments. The variance of the triangular distribution is even more sensitive to the assumed limits than is the variance of the truncated Gaussian distribution. Therefore, the triangular distribution probably should not be used in predicting the variance.

For stationary processes, continuity requires that the probability of erosion equal the probability of deposition for all elevations. Therefore, the density functions for the elevations of deposition and erosion must be identical. The mean and variance of sample histograms as well as the total number of points available for analysis, $\Sigma m_{i}$, are shown in table 2. Little data were available for run 16 , only 134 crossings compared to 2,167 for run $4 \mathrm{~A}$ and 708 for run 17. Although run 16 was continued for 33 hours, the very low transport rate (table 1 ) and slow movement of the bed forms limited the number of crossings available for analysis. It should also be pointed out that equilibrium flow was never attained for this flow which was barely above the initiation of motion stage.

\section{REST PERIOD DISTRIBUTIONS}

The sample conditional probability mass function of the rest periods were computed by determining the difference betweeen the time of reexposure and movement and the time of burial of the center of each class mark for each crossing event, $m_{j, j}$, that occurred in the $y_{x}(t)$ record (fig. 2). The results of the measurements are presented in tables 3 through 5 , and examples of the mass functions are presented in figures 7,8 , and 9. The standardized $y_{x}(t)$ record was used and the class width of the elevation was taken to be the same as that used in determining the probability distribution for the elevation of deposition, 0.4 .

The mean and variance of the conditional rest periods were computed using equation 30 , and the results are presented in table 6 . These results are also plotted as a function of bed elevation in figure 10. As can be seen from figure 10, both the conditional mean and variance of the rest periods decrease with increasing elevation of deposition. Inspection of figure 2 indicates that the conditional mean should decrease with increasing elevation of deposition. However, the decrease of the variance is not so obvious. Because the mean value is decreasing with increasing elevation, the decrease in the variance is not too meaningful. The coefficient of variation (standard deviation/mean) is probably a better measure of the variability of the rest periods. Restricting our attention to runs $4 \mathrm{~A}$ and 17 , for reasons to be discussed later, the coefficient of variation remained roughly constant in the range of 0.6-0.75 for elevations above the mean bed elevation, and it increased with decreasing elevation to a value of about 1.5 at 2.4 standard deviations below the mean bed elevation. Thus the variability of the rest period, as measured relative to its mean, also decreases with increasing elevation at least up to the mean bed elevation.

As seen from figure 10 , both the mean and variance of the conditional rest periods may be approximated by an expression of the form,

and

$$
\hat{E}\left[T \backslash Y_{D}=y\right]=A e^{-B y}
$$

$$
\operatorname{Vâr}\left[T \backslash Y_{D}=y\right]=C e^{-D y}
$$

The constants $A, B, C$, and $D$ in equation 98 were determined by a regression analysis of the data plotted in figure 10 , and the resulting values are presented in the figure. The values $A$ and $C$ represent measures of the mean and variance of the rest period, respectively, for the mean bed elevation. The values of $B$ and $D$ are measures of the rate of change of the mean and variance of the rest period with bed elevation, respectively.

The distributions of the conditional rest periods were approximated by the two-parameter gamma probability 

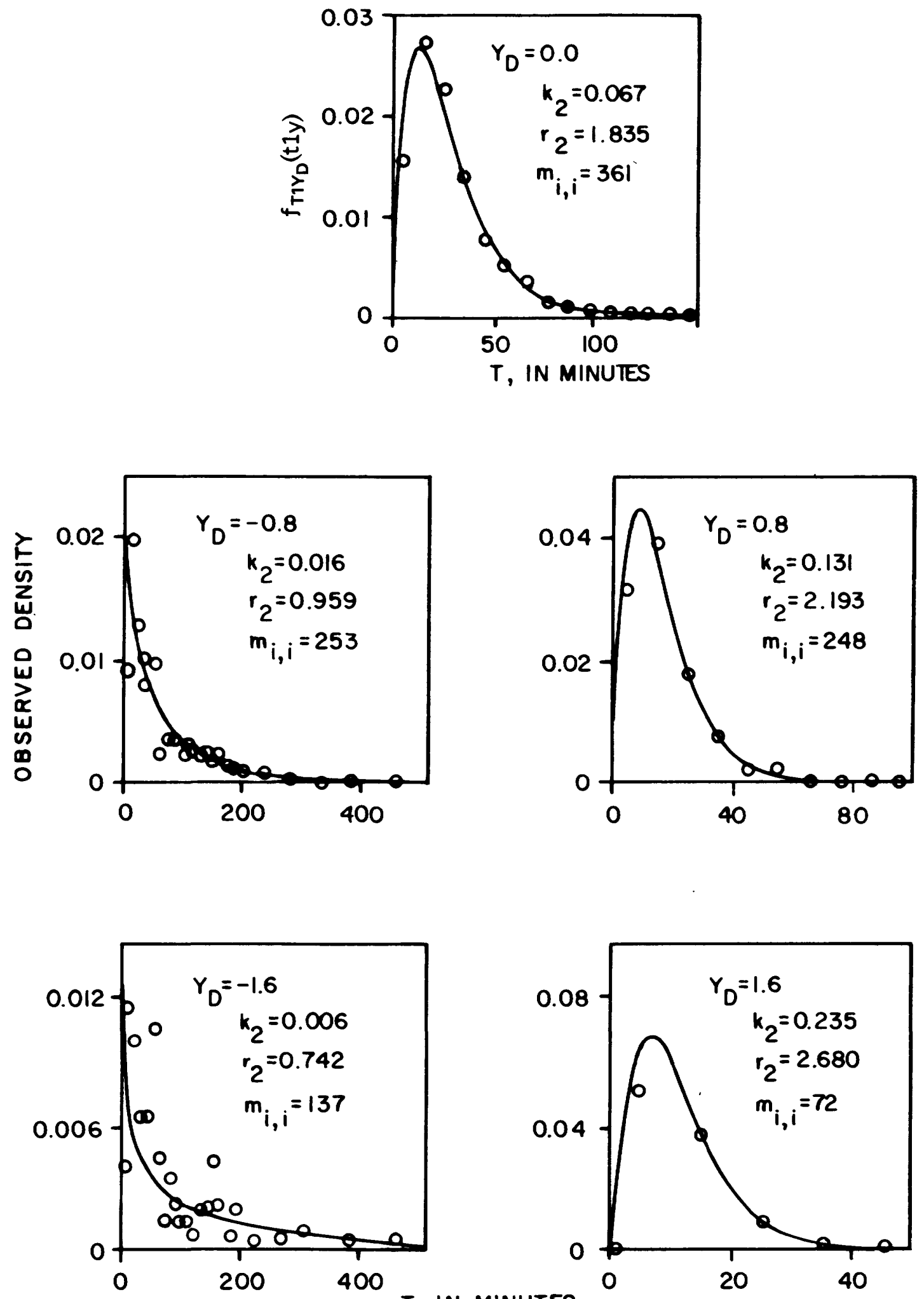

FIGURE 7. - Sample probability mass functions of the conditional rest periods with fitted two-parameter gamma functions (run 4A). 

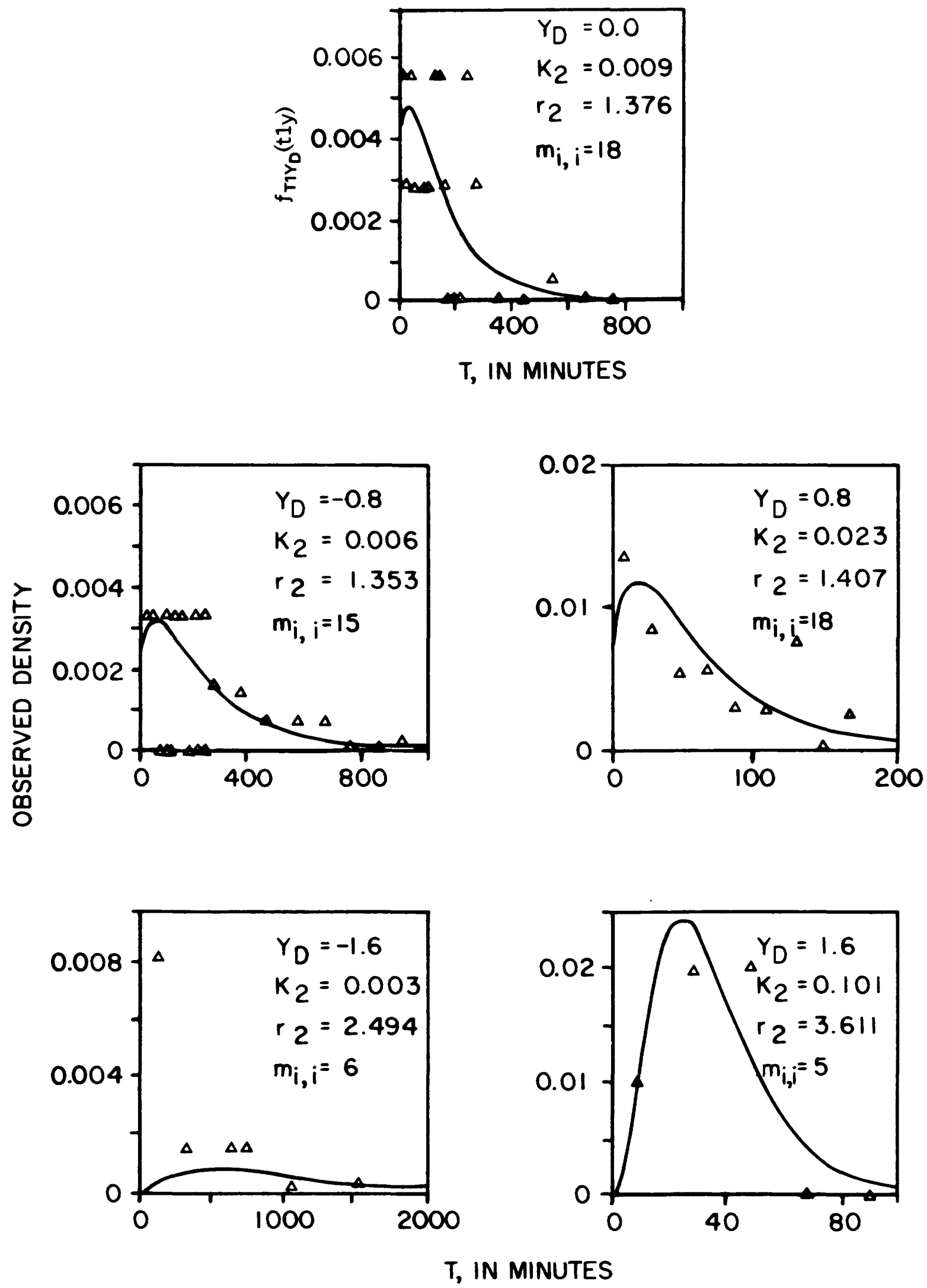

FIGURE 8. - Sample probability mass functions of the conditional rest periods with fitted two-parameter gamma functions (run 16). 

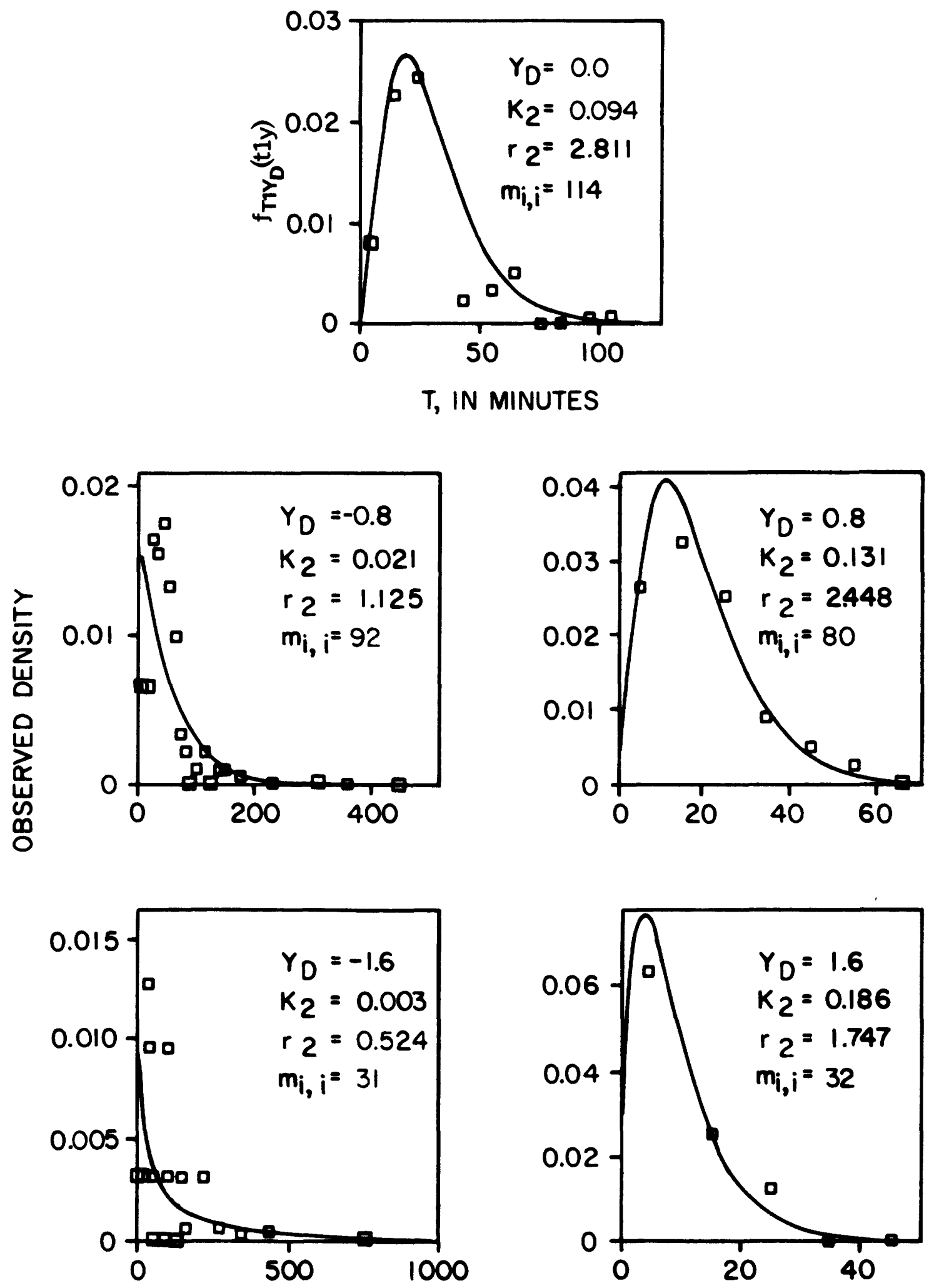

T, IN MINUTES

FIGURE 9. - Sample probability mass functions of the conditional rest periods with fitted two-parameter gamma functions (run 17). 

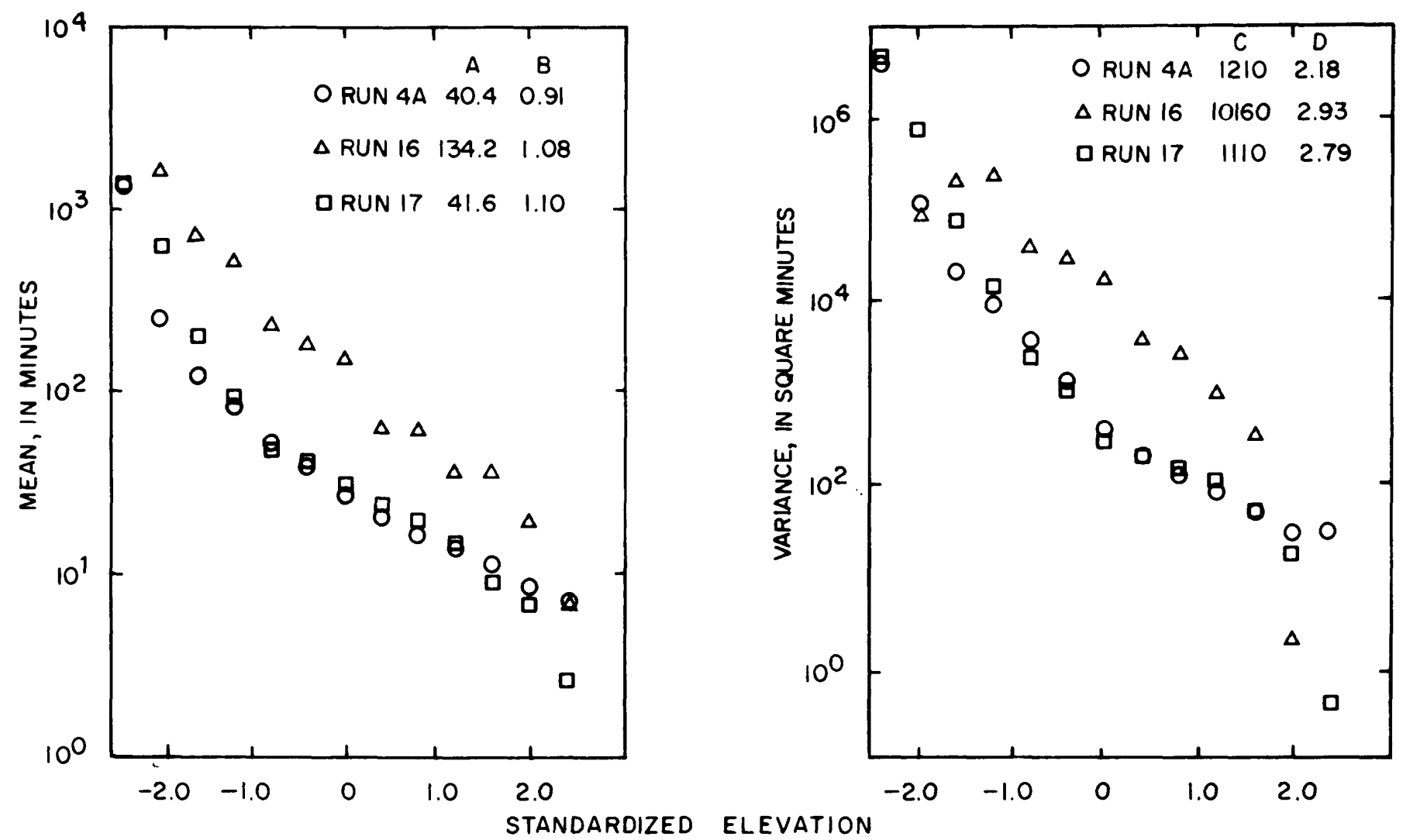

FigURE 10. - Variation of the conditional mean and variance of rest periods with bed elevation.

density function which has the form,

$$
f_{T \backslash Y_{D}}(t \backslash y)=\frac{k_{2, y}}{\Gamma\left(r_{2, y}\right)}\left(k_{2, y^{t)}}{ }^{r} 2, y^{-1} e^{-\left(k_{2}, y^{\prime t}\right.}\right.
$$

where

$$
\Gamma(\bullet)=\text { gamma function; and }
$$

$$
k_{2, y}, r_{2, y}=\text { scale and shape parameters, respectively. }
$$

The scale and shape parameters were estimated by using the method of moments,

$$
k_{2, y}=\frac{\hat{E}\left[T \backslash Y_{D}=y\right]}{\operatorname{Vâr}\left[T \backslash Y_{D}=y\right]}
$$

and

$$
\left.r_{2, y}=\frac{\left(\hat{E}\left[T \backslash Y_{D}=y\right]\right)^{2}}{\operatorname{Vâr}\left[T \backslash Y_{D}=y\right]}=k_{2, y} \hat{E}\left[T \backslash Y_{D}=y\right]\right\}
$$

$(100)$

and the data contained in table 6 . The variation of $k_{2, y}$ and $r_{2, y}$ with bed elevation are presented in table 7 along with the results of a chi-square goodness of fit test. The ability of the two-parameter gamma distribution to fit the measured mass functions is illustrated in figures 7,8 , and 9 .
From table 7, as well as from figures 7,8 , and 9, both the scale and shape parameters increase with increasing bed elevation, with a few exceptions for the shape parameter. The shape of the conditional density of the rest periods (figs. $7,8,9$ ) approaches a $J$-shape and becomes more peaked as bed elevation decreases. Therefore, the exponential density might fit better than the two-parameter gamma density below the mean bed elevation $(y<0)$. The exponential density function is a special case of the gamma density with $r_{2, y}=1$. The better fit of the exponential density seems to be consistent with the fact that all rejections of the chi-square test ( 6 rejections out of 22 at a significant level of 0.05 ) occurred below the mean bed elevation (table 7). It would appear that the exponential form for the conditional rest period as proposed by Grigg (1969) is only valid for elevations below the mean bed elevation.

A major factor in determining the degree of fit between the measured density functions and the fitted curves in figures 7,8 , and 9 appears to be the number of points available from which the distribution was constructed. In general, if more than 100 points were available, $m_{i, i}$, the fit is pretty good. The weakness of the data for run 16 is very apparent. Even at the mean bed elevation, only 18 crossing events were observed. 
Combining equations 98 and 100 , the scale and shape parameters can be estimated using only the constants $A, B, C$, and $D$.

$$
\left.\begin{array}{c}
k_{2, y}=\frac{A e^{D y}}{C e^{B y}} \\
r_{2, y}=\frac{A^{2} e^{D y}}{C e^{2 B y}}=k_{2, y} A e^{-B y}
\end{array}\right\}
$$

and

The sample joint probability mass functions of the rest period and the elevation of deposition were computed from equation 33 using the results presented in tables 2 through 5 . The results of these computations are presented in tables 8,9 , and 10 . The correlation coefficients were computed by using equation 34 , along with the data contained in tables $2,6,8,9$, and 10 . The values of the correlation coefficients were $-0.27,-0.53$, and -0.26 for runs $4 \mathrm{~A}, 16$, and 17 , respectively. The rest period and the elevation of deposition are negatively correlated, but the degree of their linear association is not strong.

The sample marginal probability mass functions, $p_{T}\left(t_{a}\right)$, were computed by use of equation 29 and the data contained in tables $2,3,4$, and 5 . The results of these computations are also presented in tables 8,9 , and 10. The sample frequency histograms for the marginal rest periods are plotted in figure 11 . The mean and variance of the marginal rest periods were computed by use of equation 31 . These results are also presented in figure 11. The variance values appear to be extremely large. For example, the standard deviation for run $4 \mathrm{~A}$ is almost four times the mean value. The computed variance values are extremely dependent on the long rest periods, the extreme events generally occur at low bed elevations. For example, by ignoring rest periods of greater than 2,000 minutes, which have a probability of occurrence of only 0.0015 , the variance is reduced from 42,000 to 12,000 .

Also shown in figure 11 are exponential density functions with a mean equal to the computed marginal mean. The exponential density function fits the data reasonably well; however, there would appear to be room for improvement. A gamma density fitted by the method of moments would be an extremely poor fit of the data. A gamma distribution, estimated by the maximum likelihood method may fit the data reasonably well.

The marginal distribution of the rest periods could also be estimated by

$$
f_{T}(t)=\int_{-2.4}^{2.4} f_{T \backslash Y_{D}}(t \backslash y) f_{Y_{D}}(y) d y
$$

where $f_{T \backslash Y_{D}}(t \backslash y)$ is the two-parameter gamma density (eq. 101) with parameters given by equation 101 , and $f_{Y_{D}}(y)$ is given by equation 94 , or it could be obtained by fitting the frequency histograms contained in figure 11 with some assumed distribution.

\section{STEP LENGTH DISTRIBUTIONS}

The $y_{t}(x)$ record was standardized after removing a straight line trend. The trend determined by the method of least squares accounted for the possibility that the sand bed in the flume was not parallel to the instrument carriage rails supporting the sonic sounder. In standardizing the $y_{t}(x)$ record, the standard deviation obtained from the $y_{x}(t)$ record was used. With these standardized data, the statistic $\left\{x_{i, j, k}\right\}$ was analyzed (fig. 3) to estimate various probability distributions of the step lengths.

The sample probability mass functions given the elevations of deposition and erosion were computed by using equation 47 , and the results are presented in tables 11 through 56. Examples of these mass functions are shown in figures 12,13 , and 14 . The corresponding means and variances were estimated by equation 48 and summarized in tables 57, 58, and 59.

It can be seen from tables 57,58 , and 59 , as well as in figures 12,13 , and 14 , that the conditional mean of the step length decreases with an increase in either the elevation of deposition or of erosion. This result could be expected simply from the typical shape of the dunes. Likewise the conditional variance of the step length tends to decrease with an increase in the elevation of either deposition or erosion. The above statements essentially imply that longer step lengths are associated with lower elevations at which a sediment particle is eroded and deposited, and vice versa.

The distribution of conditional step lengths were approximated by the two parameter gamma probability density functions,

$$
\begin{aligned}
& f_{X \backslash Y_{E} Y_{D}\left(x \backslash y, y^{\prime}\right)} \\
& =\frac{k_{1, y, y^{\prime}}}{\Gamma\left(r_{1, y, y^{\prime}}\right)}\left(x k_{1, y, y^{\prime}}\right)^{\left(-1+r_{1, y, y^{\prime}}\right)-\left(k_{1}, y, y^{\prime}\right) x}
\end{aligned}
$$

where

$$
\begin{aligned}
y \text { and } y^{\prime}= & \underset{\quad}{\operatorname{arguments} \text { of }} Y_{E} \text { and } Y_{D} \text { respec- } \\
k_{1, y, y^{\prime}} \text { and } r_{1, y, y^{\prime}}= & \begin{array}{l}
\text { scale and shape parameters, } \\
\text { respectively. }
\end{array}
\end{aligned}
$$

The parameters $k_{1, y, y}$ and $r_{1, y, y}$, were estimated by the 

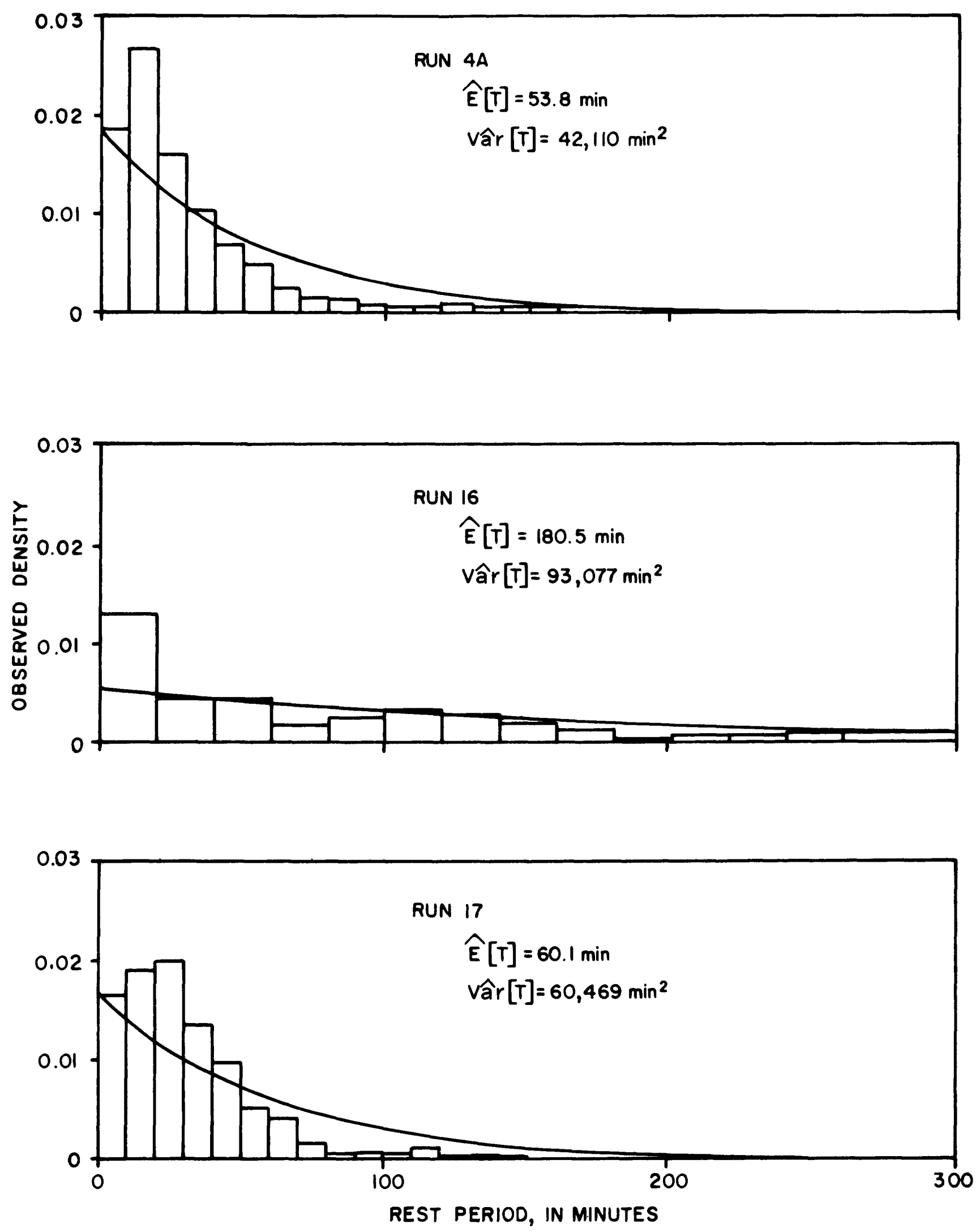

FigURE 11. - Frequency histograms for the marginal rest period and exponential fits. 

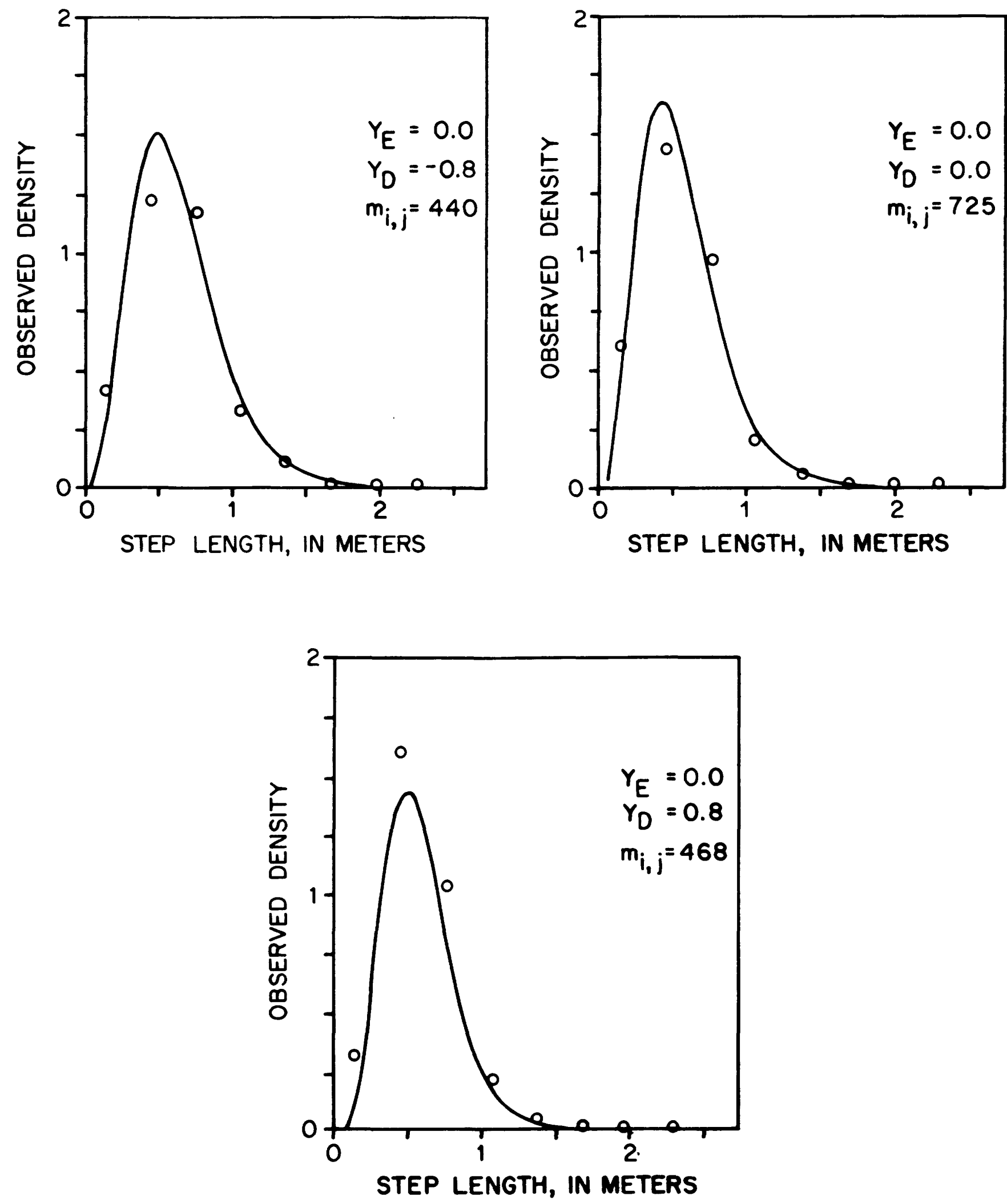

FIGURE 12. - Sample probability mass functions of the conditional step lengths given the elevation of erosion is 0.0 with Gamma fits (run $4 \mathrm{~A}$ ). 

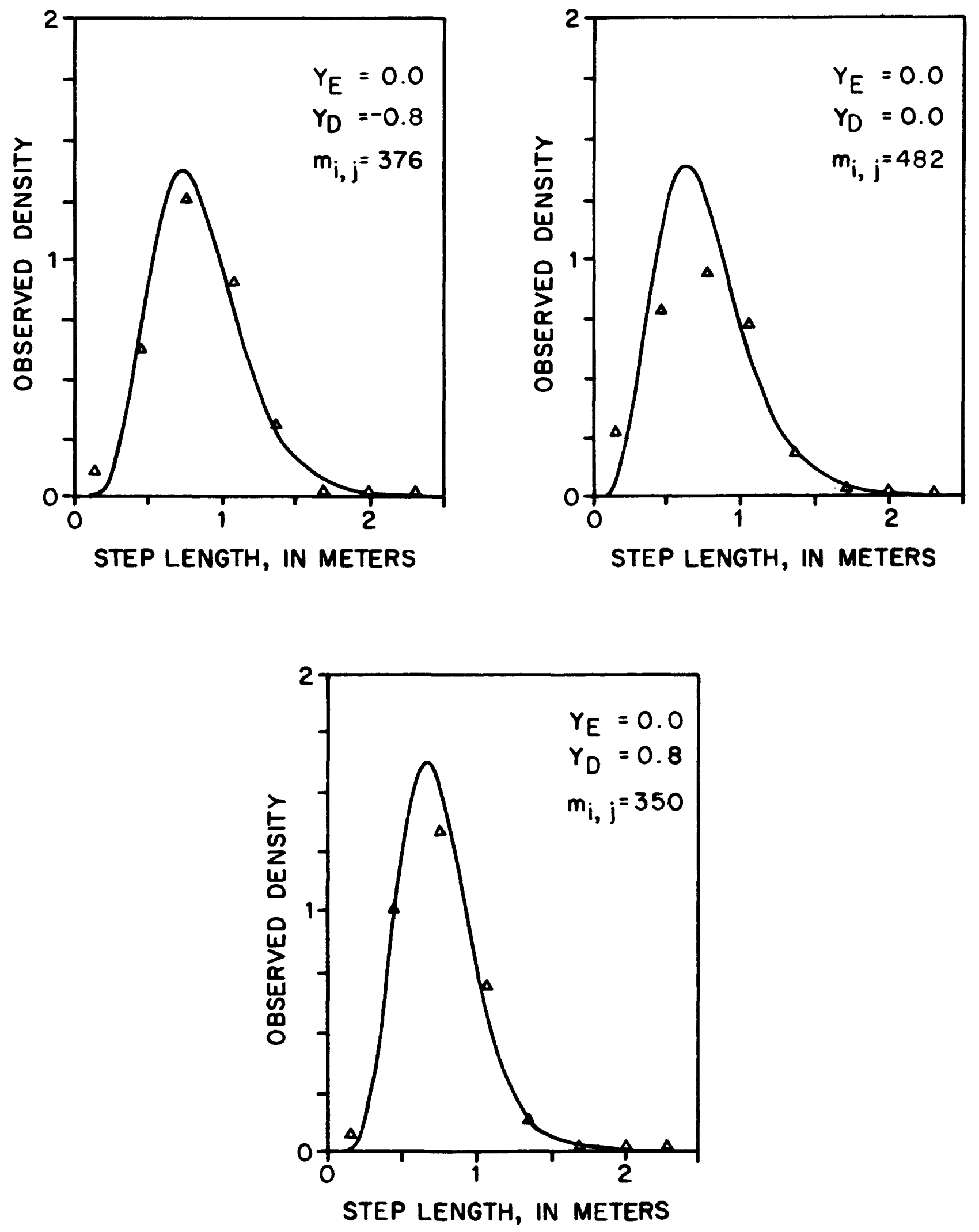

- FIGURE 13. - Sample probability mass functions of the conditional step lengths given the elevation of emosion is 0.0 with Gamma fits (run 16 ). 

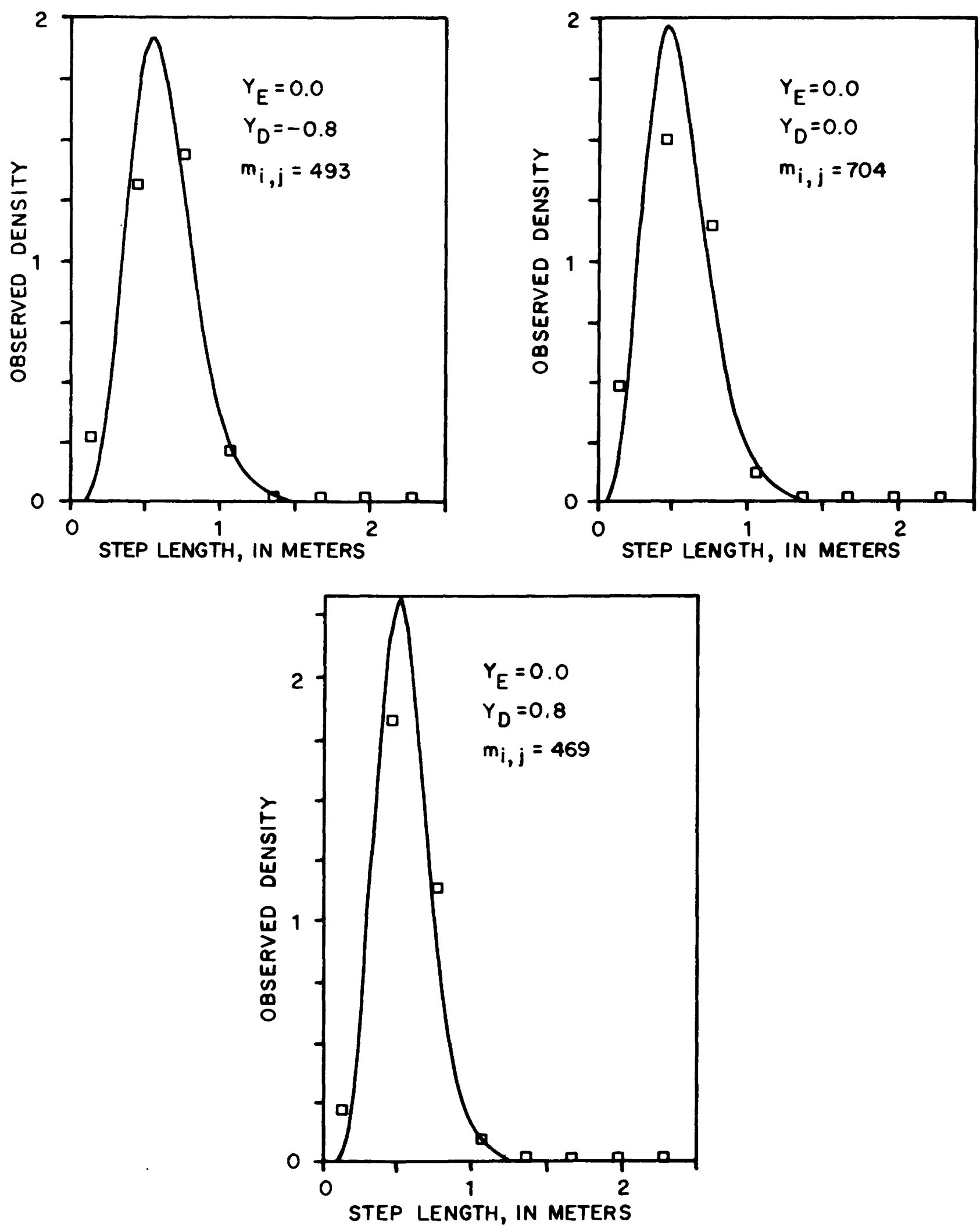

FIGURE 14. - Sample probability mass functions of the conditional step lengths given the elevation of erosion is 0.0 with Gamma fits (run 17). 
method of moments, using data contained in tables 57 , 58 , and 59 and the expressions

and

$$
k_{1, y, y^{\prime}}=\frac{\hat{E}\left[X \backslash Y_{E}=y, Y_{D}=y^{\prime}\right]}{\operatorname{Var}\left[X \backslash Y_{E}=y, Y_{D}=y^{\prime}\right]}
$$

$$
\left.\begin{array}{r}
r_{1, y, y^{\prime}}=\frac{\left(\hat{E}\left[X \backslash Y_{E}=y, Y_{D}=y^{\prime}\right]\right)^{2}}{\operatorname{Vâr}\left[X \backslash Y_{E}=y, Y_{D}=y^{\prime}\right]} \\
=\hat{E}\left[X \backslash Y_{E}=y, Y_{D}=y^{\prime}\right] k_{1, y, y^{\prime}}
\end{array}\right\}
$$

The variation of $k_{1, y, y}$ and $r_{1, y, y}$, with the elevations of erosion and deposition are shown in tables 60,61 , and 62. These approximations are also shown in figures 12 , 13 , and 14.

The chi-square test for goodness of fit was used to test these gamma approximations. The results of these tests are summarized in tables 63,64 , and 65 . None of the 81 distributions tested could be rejected at the 0.05 level of significance. In other words, there is no good statistical reason to reject the hypothesis that the probability density functions for the step lengths, given the elevation of deposition and erosion, are distributed according to the two-parameter gamma distribution. The

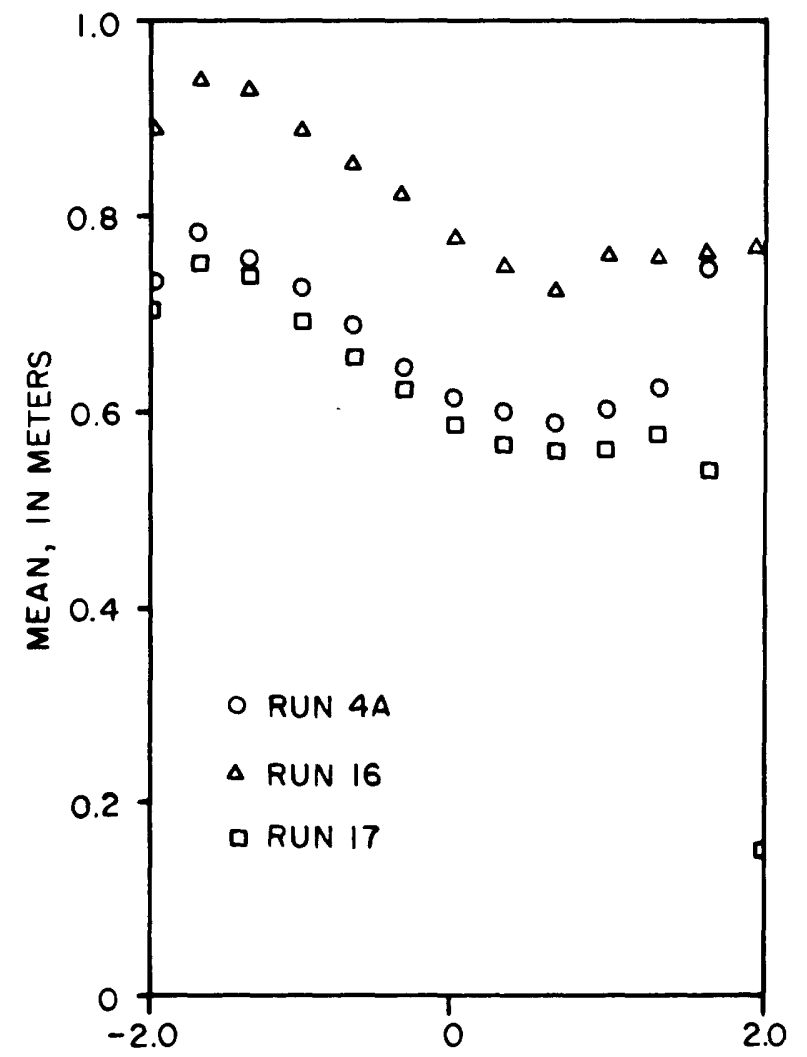

fitted gamma distributions are also plotted and the example mass functions presented in figures 12,13 , and 14. These figures also help to illustrate the ability of the two-parameter gamma distributions to fit the measured conditional step length distributions.

The sample conditional mass functions, given the elevation of deposition, were computed based on equation 37 and the data contained in tables 2 and 11-56. These mass functions are presented in tables 66, 67, and 68. The corresponding conditional means and variances were computed using equation 38 and are presented in table 69 as well as being plotted in figure 15. Again, the general decrease in the expected value of the step length with an increase in the elevation of deposition is apparent.

The sample joint probability mass function of the step length and the elevation of deposition was computed by equation 43 , and the results are shown in tables 70, 71, and 72. The correlation coefficients were computed by equation 44 , and their values were -0.15 , -0.15 , and -0.20 for runs $4 A, 16$, and 17 , respectively, indicating that the step length and the elevation of deposition are negatively correlated, but the degree of their linear associations is not strong. The sample marginal probability mass functions, $p_{X}\left(x_{\beta}\right)$, computed using equation 40 , are also shown in tables 70,71 , and 72 . The

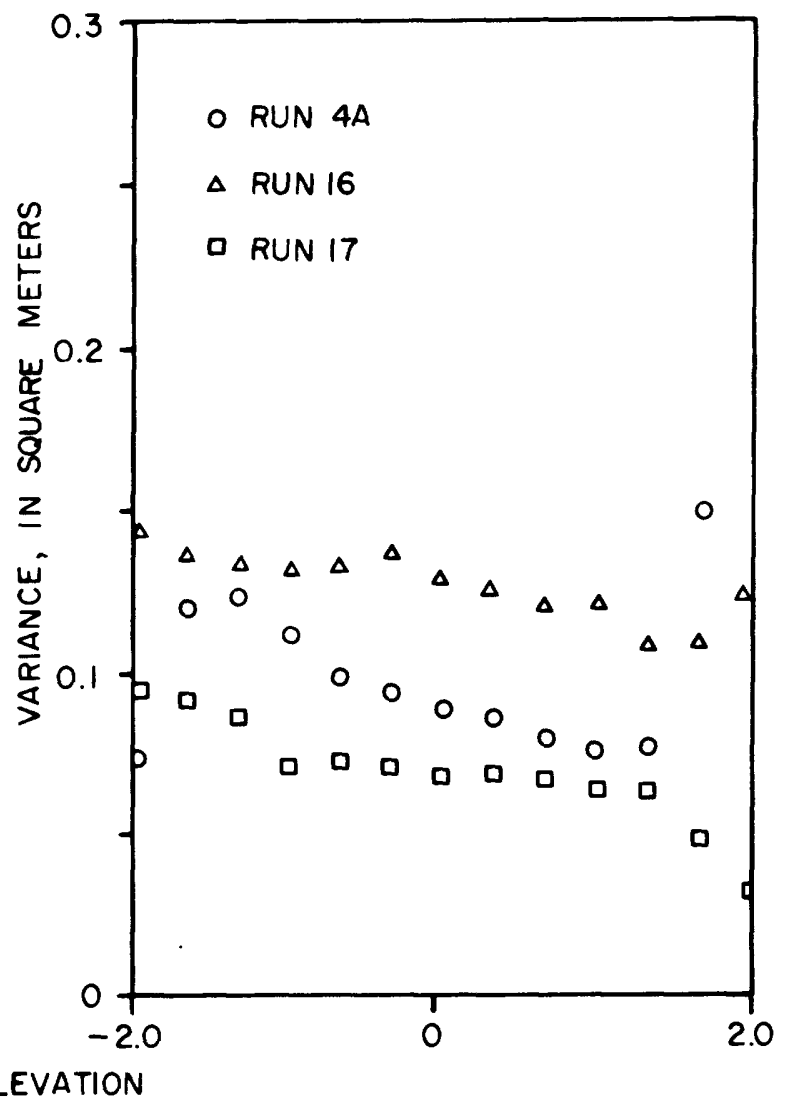

FIGURE 15. - Variation of the conditional mean and variance of step lengths with bed elevation; $\hat{E}\left[X \backslash Y_{D}=y\right]$. 
sample frequency histograms for the marginal rest periods are plotted in figure 16 . The mean and variance of the marginal rest periods were computed by use of equation 41 . These results are also presented in figure 16 . The range of the means is fairly small, only 0.610 to $0.799 \mathrm{~m}$. The mean dune lengths, as measured by the distance between trough points, for the three runs were $1.19,1.66$, and $1.23 \mathrm{~m}$ respectively for runs $4 \mathrm{~A}, 16$, and 17. The mean step lengths were, therefore, 54,48 , and 49 percent of the mean dune lengths. Grigg (1969) found the mean step lengths of single tagged particles to be about 60 percent of the mean dune length. Of course, Grigg was working with a much finer sand, .33 to $.45 \mathrm{~mm}$, as compared to $1.15 \mathrm{~mm}$ for this study. Also shown in figure 16 are gamma density functions for which the parameters $k$ and $r$ were determined from the mean and variance shown in the figure. The gamma functions appear to fit the data very well for all three runs. The value of the parameter $r$ ranged from 4.05 for run $4 \mathrm{~A}$ to 4.59 for run 17 . This is slightly more than twice the value estimated by Yang (1968) from the step length distribution of a single plastic particle.

\section{BED-MATERIAL TRANSPORT}

The following assumptions and conditions were used to estimate the mean total bed-material transport rate by equations 55, 63, and 66: (1) Because the bed material was coarse sand (fig. 5), all sediment par ;icles are assumed to be transported as bed load. Expressed mathematically, $P\left[E_{1}\right]=1$. (2) $\gamma_{s}(1-\theta)=1602 \mathrm{~kg} / \mathrm{m}^{3}$. (3) $\Delta y_{j}=0.4 s_{y}$ everywhere. By virtue of item 1 , it follows that $\widehat{V}_{T}=\hat{V}_{B}, \widehat{V}_{T}(j)=\widehat{V}_{B}(j)$, and $\hat{Q}_{T}=\hat{Q}_{B}$. In item $3, s_{y}$ is the standard deviation of the bed elevation computed from the $y_{x}(t)$ record.

All parameters and statistics which are required by equations 55, 63, and 66 are summarized in tables 73 and 74. The average depth of the zone of bed material movement, $h$, was determined by equation 59 . It was found that one chart of the $y_{t}(x)$ record (about $34 \mathrm{~m}$ ) is sufficient to obtain a reliable value of $h$, although over 30 charts of the $y_{t}(x)$ record were used in this study. Each chart contained about ten dunes. Using equation $62, \xi_{j}$, the percentage of volume between elevations $\eta_{i}$ and $\eta_{j+1}$ occupied by dunes (hereafter will be referred to as the effective volume ratio) was obtained from the $y_{t}(x)$ record. The results are presented in table 74 and plotted in figure 17. As shown in figure $17 \xi_{j}$ is nearly independent of flow condition. As long as the bed forms are dunes, $\xi_{j}$ does not change appreciably. It is also shown in figure 17 that $\xi_{j}$ is nearly unity and zero at $y_{j}=-2.4$ and $y_{j}=+2.4$, respectively. This is partial justification for the upper and lower limits of the elevations of erosion and deposition used in equations 94 and 95.
Another effective volume ratio can be obtained from the $y_{x}(t)$ record. Denoting this ratio by $\zeta_{j}$,

$$
\zeta_{j}=\frac{1}{L_{t}} \sum_{k=1}^{m_{j}} t_{j, k}
$$

where

$L_{t}=$ total length of $y_{x}(t)$ record;

$m_{j}=$ maximum number of bed forms contained in the $y_{x}(t)$ record which also contains some deposition at elevation $y_{j}$; and

$t_{j, k}=$ measurement of the conditional rest period.

There is no significant difference between $\xi_{j}$ and $\zeta_{j}$ (table 74) except for depths greater or less than 2.0 standard deviations from the mean. The longitudinal profiles $\left(y_{t}(x)\right.$ records) appear to contain a larger number of extreme events than the time record at a given point (the $y_{x}(t)$ ). The explanation for this is probably that the flow was fairly stationary but that it was not longitudinally uniform.

A comparison of measured and computed total bedmaterial transport rates is shown in table 75. It is seen that:

1. For run $4 \mathrm{~A}$, all three equations provide excellent estimates to the observed mean total bed-material discharges.

2. Equation 55 provided an excellent estimate to the mean total bed-material discharge for run 17 . However, the other two equations overestimated the discharge by more than 25 percent. The reason for the differences in the equations is not understood.

3. None of the equations gave good estimates of the mean total bed-material discharge for run 16 . The consistently overestimated discharge ranged from 64 percent for equation 63 to 80 percent for equation 55 . It should be remembered, however, that the mean total bed-material discharge was less than $9 \mathrm{mg} / \mathrm{L}$ during this run, that the flow was not in equilibrium as illustrated by the large variation of energy slope (table 1), and that very few rest period statistics were available for analysis (fig. 8).

Taken as a whole, the results are very encouraging. Although equation 55 gave the most accurate results for run 17, it should be noted that equations 63 and 66 gave very consistent results for all runs when they are compared one with the other. The discharge predicted by equation 66 was $8.3,8.4$, and 8.5 percent larger than that predicted by equation 63 for runs $4 \mathrm{~A}, 16$, and 17 , respectively. Although equation 66 is probably simpler to evaluate than equation 63 , it appears that some accuracy has been sacrificed. The main difference between equations 63 and 66 is the way in which the effective depth or effective volume ratio (eq. 62,71 ) is 

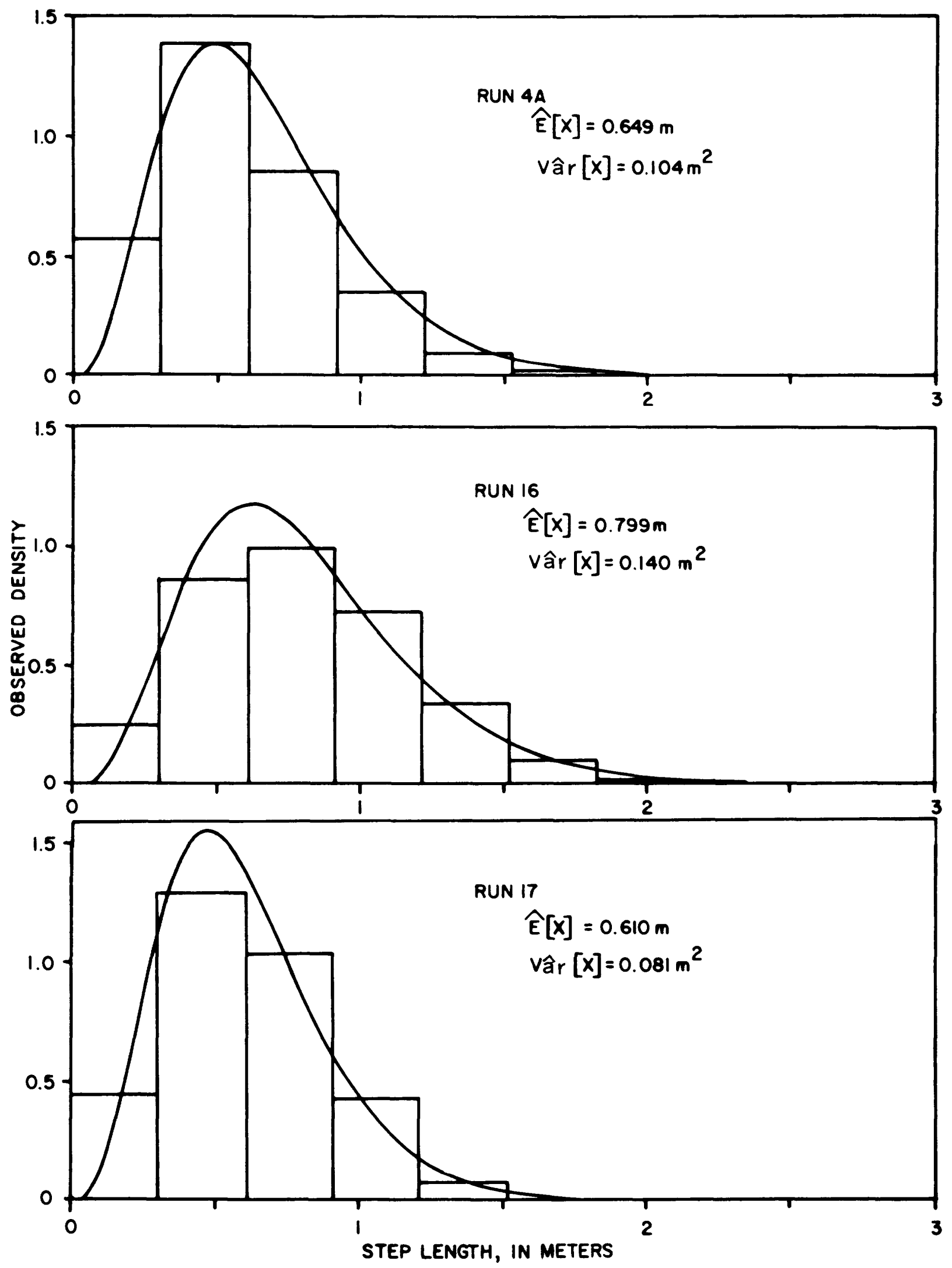

FIGURE 16. - Frequency histograms for the marginal step length with Gamma fits. 
TABLE 73. - Variation of various statistics with stream power

\begin{tabular}{lccccccccc}
\hline Run & $\begin{array}{c}\bar{\tau}_{b} \bar{U} \\
(\mathrm{~d} / \mathrm{cm} \cdot \mathrm{s})\end{array}$ & $\begin{array}{c}\hat{\mathrm{E}}[\mathrm{X}] \\
(\mathrm{m})\end{array}$ & $\begin{array}{c}\mathrm{Vâr}[X] \\
\left(\mathrm{m}^{2}\right)\end{array}$ & $\begin{array}{c}\hat{\mathrm{E}}[T] \\
(\mathrm{min})\end{array}$ & $\begin{array}{c}\mathrm{Var}[T] \\
\left(\mathrm{min}^{2}\right)\end{array}$ & $\begin{array}{c}\hat{V}_{T}=\frac{\hat{\mathrm{E}}[X]}{\hat{\mathrm{E}}[T]} \\
(\mathrm{cm} / \mathrm{s})\end{array}$ & $\begin{array}{c}\hat{V}_{T}^{\prime} \\
(\mathrm{cm} / \mathrm{s})\end{array}$ & $\begin{array}{c}n \\
(\mathrm{~cm})\end{array}$ & $\begin{array}{c}s_{y} \\
(\mathrm{~cm})\end{array}$ \\
\hline $4 \mathrm{~A}$ & 3,110 & 0.649 & 0.104 & 53.8 & 42,110 & 0.0201 & 0.0378 & 9.66 & 4.26 \\
16 & 1.450 & 0.799 & 0.140 & 180.5 & 93,077 & 0.0073 & 0.0166 & 6.89 & 3.01 \\
17 & 2,900 & 0.610 & 0.081 & 60.1 & 60,469 & 0.0169 & 0.0372 & 7.13 & 3.61
\end{tabular}

TABLE 74. - Comparison of the effective volume ratios at elevation $y_{j}$; $\xi_{j}$, from $y_{t}(x)$ record and $\zeta_{j}$, from $y_{x}(t)$ record

\begin{tabular}{|c|c|c|c|c|c|c|}
\hline \multirow{2}{*}{$Y_{D}=y_{j}$} & \multicolumn{2}{|c|}{ Run $4 \mathrm{~A}$} & \multicolumn{2}{|c|}{ Run 16} & \multicolumn{2}{|c|}{ Run 17} \\
\hline & ${ }^{\xi} j$ & $\zeta_{j}$ & ${ }^{\xi} j$ & $s_{j}$ & ${ }^{\xi} j$ & $\zeta_{j}$ \\
\hline-2.8 & 0.968 & $\ldots$ & 1.000 & -... & 1.000 & -... \\
\hline-2.4 & .963 & .... & .995 & $\ldots$ & .998 & -.... \\
\hline-2.0 & .949 & 0.903 & .975 & -...- & .989 & $\ldots$ \\
\hline-1.6 & .925 & .883 & .935 & 0.890 & .964 & 0.943 \\
\hline-1.2 & .877 & .865 & .865 & .840 & .900 & .867 \\
\hline-0.8 & .791 & .787 & .778 & .719 & .801 & .756 \\
\hline-0.4 & .668 & .675 & .670 & .656 & .669 & .645 \\
\hline 0.0 & .512 & .529 & .535 & .567 & .522 & .522 \\
\hline 0.4 & .344 & .379 & .385 & .388 & .364 & .380 \\
\hline 0.8 & .189 & .222 & .230 & .230 & .202 & .234 \\
\hline 1.2 & .078 & .112 & .103 & .097 & .079 & .120 \\
\hline 1.6 & .015 & .044 & .036 & .037 & .020 & .046 \\
\hline 2.0 & .001 & .009 & .012 & .008 & .002 & .013 \\
\hline 2.4 & .000 & $\ldots$ & .004 & .001 & .000 & .001 \\
\hline 2.8 & $\ldots$ & $\ldots$ & .001 & .... & .000 & $\cdots$ \\
\hline
\end{tabular}

computed, and these functions were similar (table 74); therefore, the consistency of their final result was expected. Equation 55 had the lowest average absolute error for all three runs; however, equation 63 gave the most accurate result on two out of three runs. Because of the similarity of equations 55 and 63 , it would be difficult to say one was more accurate than the other. Their relative accuracy probably depends on chance occurrence of extreme events in one or the other records of bed elevation.

In table $75, \hat{q}_{T}$ is the mean total bed-material discharge in weight per width and time, and it was obtained by dividing equations 55,63 , and 66 by the width of the channel, $W$.

If we define $q_{B}^{\prime}(j)$ as the mean bed-load discharge associated with elevation $y_{j}$, then based on equation 63 ,

$$
\hat{q}_{B}^{\prime}(j)=\gamma_{s}(1-\theta) \hat{V}_{B}(j) \xi_{j} \Delta y_{j}
$$

where $\hat{q}_{B}(j)$ estimates $q_{B}^{\prime}(j)$ and $\hat{V}_{B}(j)$ is an estimate of the mean transport speed of a bed-load particle at elevation $y_{j}$. The mean transport speed, $\widehat{V}_{B}(j)$, is given by equation 61 provided that the suspended load is negligible. With equation 106 , the variation of bed-load discharge with bed elevation may be investigated. This variation is shown in figure 18 for all three runs. It is seen that the maximum bed-load discharge is associated with the mean bed elevation and that an insignificant portion of the bed-load movement appears to occur for $y_{j} \leqslant-2.4$ and $y_{j} \geqslant+2.4$.

TABLE 75. - Comparison of measured and computed total bed-material transport rates

\begin{tabular}{|c|c|c|c|c|c|c|}
\hline \multirow{2}{*}{ Run } & \multicolumn{6}{|c|}{ Measured total bed-material discharge $(\mathrm{t} / \mathrm{ddy} \cdot \mathrm{m})$} \\
\hline & $\begin{array}{l}\text { Number of } \\
\text { measurements }\end{array}$ & & Maxımum & Minimum & $\begin{array}{l}\text { Standard } \\
\text { deviation }\end{array}$ & Mean \\
\hline $4 \mathrm{~A}$ & 54 & & 5.30 & 0.91 & 0.88 & 2.77 \\
\hline 16 & 32 & & 0.72 & 0.18 & 0.14 & 0.40 \\
\hline 17 & 32 & & 3.04 & 0.59 & 0.59 & 1.61 \\
\hline \multirow{2}{*}{ Run } & \multicolumn{3}{|c|}{ Computed mean, $\hat{q}_{T}(\mathrm{t} / \mathrm{day} \cdot \mathrm{m})$} & \multicolumn{3}{|c|}{ Computed mean/measured mean } \\
\hline & Eq. 55 & Eq. 63 & Eq. 66 & Eq. 55 & Eq. 63 & Eq. 66 \\
\hline $4 \mathrm{~A}$ & 2.68 & 2.72 & 2.94 & 0.970 & 0.983 & 1.066 \\
\hline 16 & 0.70 & 0.64 & 0.67 & 1.801 & 1.641 & 1.725 \\
\hline 17 & 1.67 & 2.05 & 2.18 & 1.035 & 1.269 & 1.354 \\
\hline
\end{tabular}




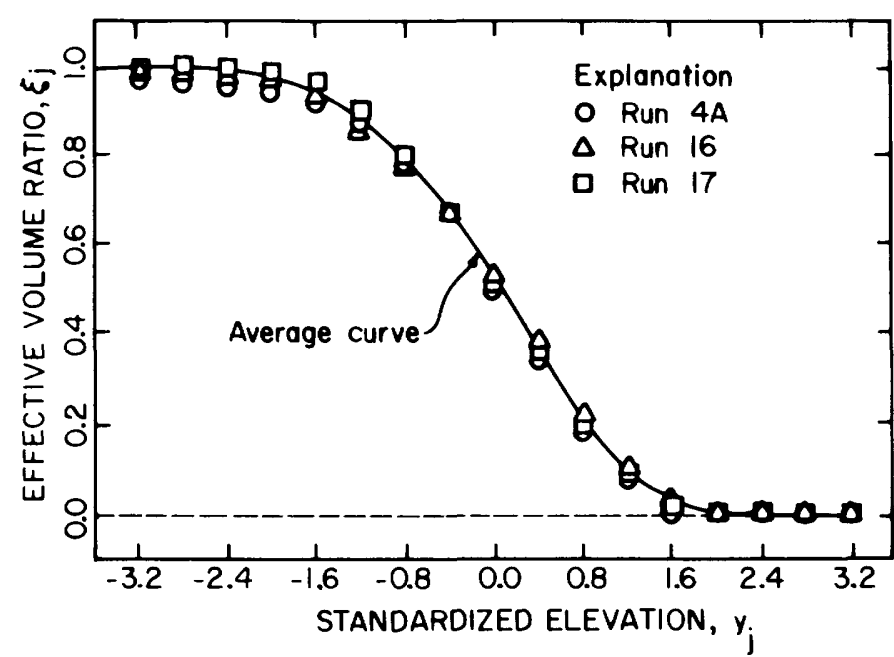

FIGURE 17. - Effective volume ratio as a function of bed elevation, $\boldsymbol{y}_{j}$; $\xi_{j}=\left(\sum_{k} \lambda_{j, k} / L_{x}\right)$.

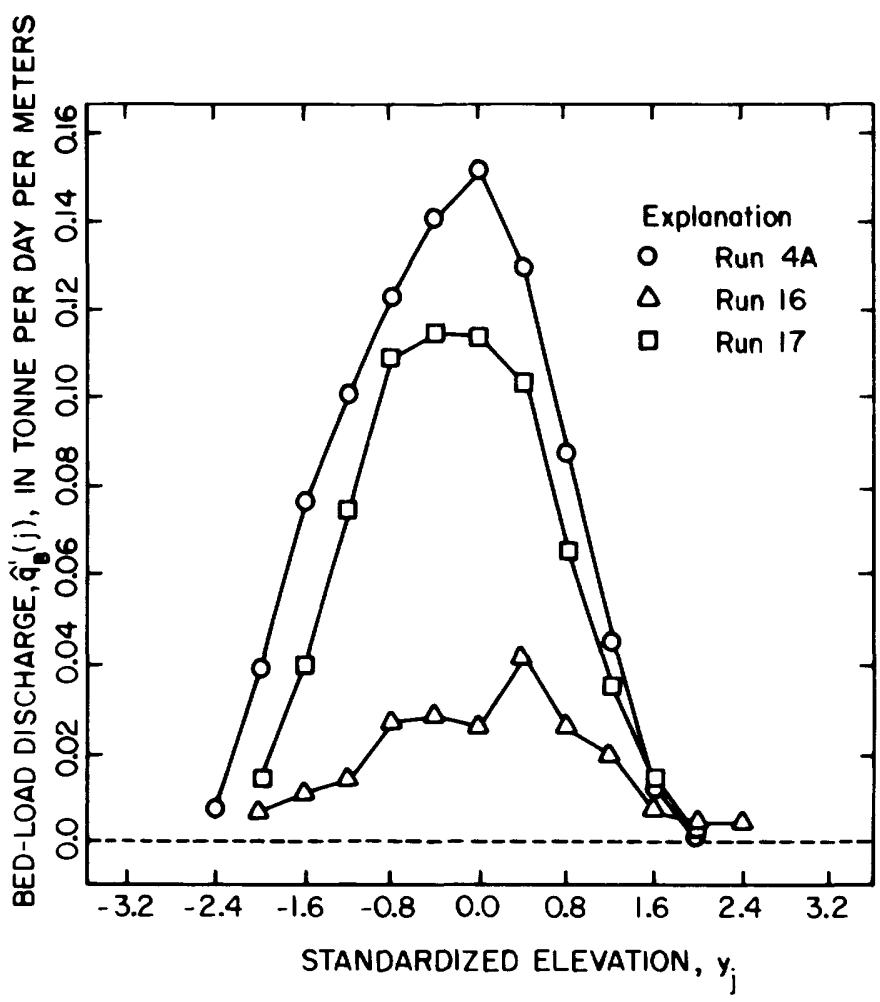

FIGURE 18. - Variation of bed-load discharge with bed elevation.

\section{VARIATION OF VARIOUS STATISTICS WITH FLOW CONDITIONS AND A RELATION BETWEEN THE STEP LENGTH AND THE REST PERIODS}

Although three flume runs are not sufficient to establish a reliable relation between the various statistics and flow conditions, some qualitative trends can be determined from table 73 . The stream power (product of mean bed shear stress and mean flow velocity) was used as a measure of the flow conditions. From table 73 , it is seen that:

1. The mean transport speed of a bed-material particle $\left(\hat{V}_{T}, \hat{V}_{T}^{\prime}\right)$, the average depth of the zone in which bed material movement occurs $(h)$, and the standard deviation of the bed $\left(s_{y}\right)$, appear to increase with increasing stream power $\left(\bar{\tau}_{b} \bar{U}\right)$.

2. The marginal mean of the step lengths $(E[X])$, the marginal variance of the step lengths $(\operatorname{Var}[X])$, the marginal mean of the rest periods $(\hat{\mathrm{E}}[T])$, and the marginal variance of the rest periods ( $\operatorname{Var}[T]$ ), appear to decrease with increasing stream power within the range of stream power investigated here.

The variation of the ratios of the conditional mean step length to the conditional mean rest period

$$
\left(\hat{V}_{B}(y)=\left(\hat{E}\left[X \backslash Y_{D}=y\right]\right) /\left(\hat{E}\left[T \backslash Y_{D}=y\right]\right)\right)
$$

and of the conditional variance of the step length to the conditional variance of the rest period

$$
\left(\operatorname{Var}\left[X \backslash Y_{D}=y\right] / \operatorname{Var}\left[T \backslash Y_{D}=y\right]\right)
$$

with bed elevation, $y$, is shown in figures 19 and 20 . From these figures it is seen that both ratios increase with increasing bed elevation.

\section{TWO-DIMENSIONAL STOCHASTIC MODEL FOR DISPERSION OF

BED-MATERIAL SEDIMENT PARTICLES

A two-dimensional stochastic model for dispersion of bed-material sediment particles was derived earlier and was given by equation 85 ,

$$
\begin{aligned}
f(x, y ; t)= & f_{Y_{D}}(y) \sum_{n=1}^{\infty}\left(\int_{0}^{x} f_{X}^{(n-1)} f_{X \backslash Y_{D}}(x-\zeta \backslash y) d \zeta\right. \\
& \left.\cdot \int_{0}^{t} f_{T}^{(n)}\left(t^{\prime}\right) d t^{\prime} \int_{t-t^{\prime}}^{\infty} f_{T \backslash Y_{D}}(\tau \backslash y) d \tau\right)
\end{aligned}
$$

The one-dimensional model as a marginal case of equation 85 was

$$
f(x ; t)=\sum_{n=1}^{\infty} f_{X}^{(n)}(x) \int_{0}^{t}\left[\begin{array}{cc}
(n) & (n+1) \\
f_{T}\left(t^{\prime}\right)-f_{T}\left(t^{\prime}\right)
\end{array}\right] d t^{\prime} .
$$

Note that $y$ is the standardized elevation. In order to apply equations 85 and 91 , the probability density functions,

$f_{Y_{D}}(y), f_{T \backslash Y_{D}}(t \backslash y), f_{T}(t), \stackrel{(n)}{(n)} \stackrel{(n+1)}{(t)}, f_{T}^{(t)}, f_{X \backslash Y_{D}}(x \backslash y), f_{X}(x)$, $f_{X}^{(n-1)}(x)$, and $f_{X}^{(n)}(x)$ must be specified.

Although probability density functions for all these distributions have not been determined in this report, the measured probability mass functions have been presented in tables $2,3-5,8-10$, and $66-68$, respec- 


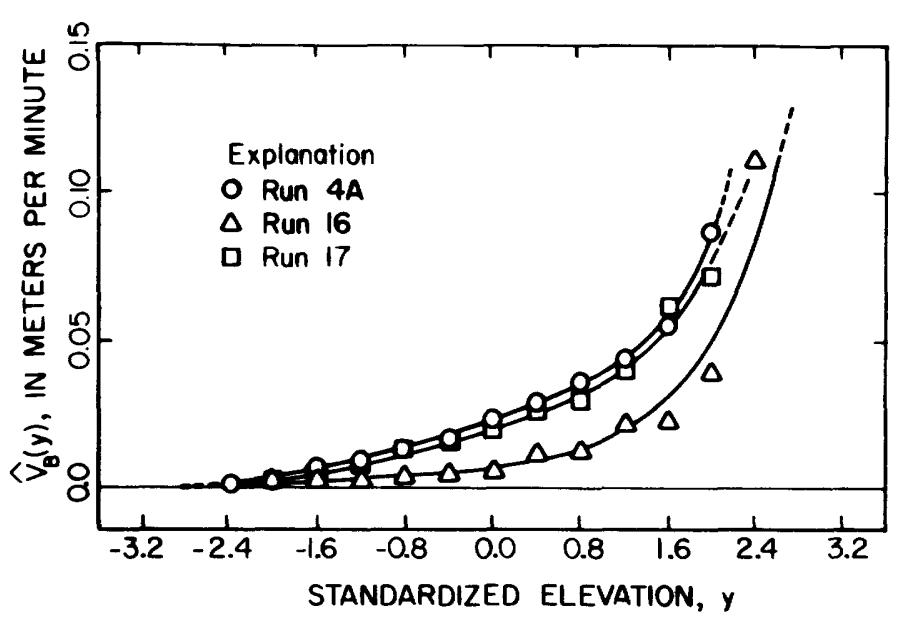

FIGURE 19. - Mean transport speed of a bed-load particle as a function of bed elevation, $y$.

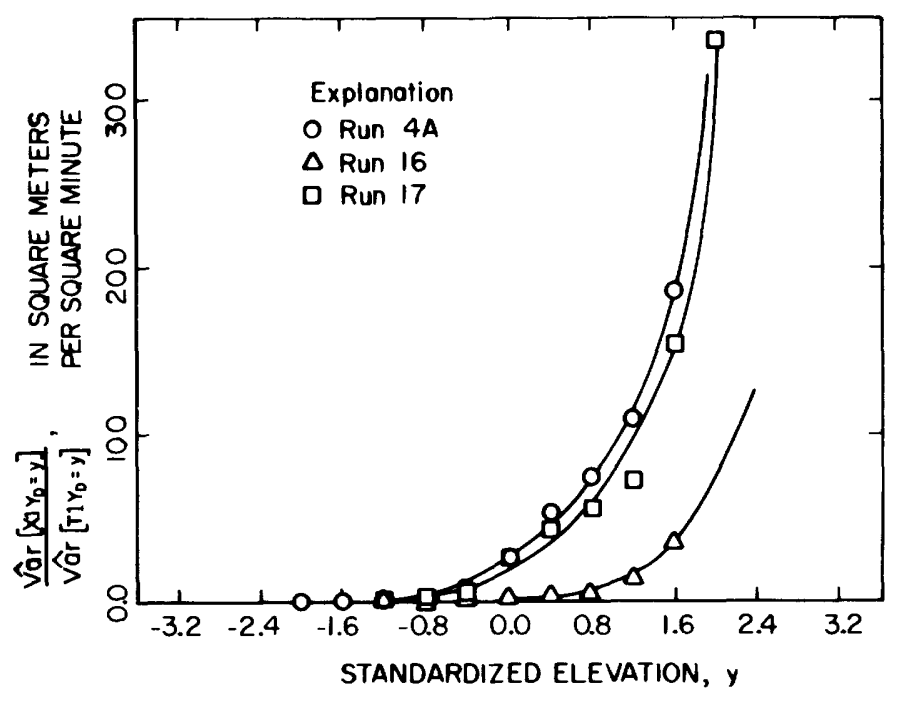

FIGURE 20. - Ratio of the conditional variance of step lengths to the conditional variance of rest periods as a function of bed elevation.

tively. Equations for determining the $n$-fold convolutions of $p_{T}(t)$ and $p_{X}(x)$ can be obtained from equations 82 and 79 with proper substitutions (Parzen, 1967). Further progress in the solution of either equation 85 or 91 could proceed along either of two lines. First, all probability density functions could be replaced with the corresponding sample probability mass functions, the integrals approximated by summations, and the solutions obtained numerically. Alternately, the mass functions could be fitted by density functions of some assumed form and an analytical solution attempted. Lee (1973) used various fitting procedures to obtain all the probability density functions required to solve equation 85 , but the integration of the equation appears quite formidable.

\section{SUMMARY AND CONCLUSIONS}

Stochastic models were developed which can be used to predict the transport and dispersion of bed-material sediment particles in an alluvial channel. These models are based on the proposition that the movement of bedmaterial sediment particles consists of a series of steps separated by rest periods and, therefore, their application requires a knowledge of the probability distributions of the step lengths, the rest periods, and the elevation of particle deposition and erosion.

The probability distribution of the rest periods, conditioned un the elevation of particle deposition and the probability distributions of the elevation of particle erosion and deposition, were obtained from a record of the bed elevation at a fixed point as a continuous function of time $\left[y_{x}(t)\right.$ record]. The necessary assumptions were: (1) Equilibrium flow; (2) both erosion and deposition do not occur at the same point during the same time period; and (3) the number of particles per unit volume of the bed is constant.

The probability distribution of the step lengths, conditioned on the elevation of particle erosion and the elevation of particle deposition, was obtained from a series of instantaneous longitudinal bed profiles $\left[y_{t}(x)\right.$ record]. The required assumptions were: (1) All bedmaterial sediment particles which are eroded from the upstream face of a dune will be deposited on the downstream side of the same dune; and (2) no deposition occurs on the upstream sides of dunes, and no erosion occurs on the downstream faces of dunes. These assumptions appeared to be reasonable at least for a dune-covered bed composed of a coarse sand.

Introducing an additional assumption that the elevation of particle erosion and the elevation of particle deposition are mutually independent, various related probability distributions were obtained. These distributions included: (1) The marginal distributions of the rest periods and the step lengths; (2) the joint distribution of the rest periods and the elevation of particle deposition; and (3) the joint distribution of the step lengths and the elevation of particle deposition.

A two-dimensional stochastic model for dispersion of bed-sediment particles was then derived (eq. 85). In order to apply the model, the probability distributions of (1) the step lengths given the elevation of particle deposition; (2) the rest periods given the elevation of particle deposition; and (3) the elevation of particle deposition, must be known. The mass functions of these distributions were estimated; however, the integrations required by the model remained unsolved.

Applying the concept of continuity, three bedmaterial transport models were presented. Application of these models requires the estimation of: (1) The con- 
ditional means of the rest periods and the step lengths; (2) the probability distribution of the elevation of deposition; (3) the average depth of the zone of bedmaterial movement; and (4) the effective volume ratio. These were all obtained from the $y_{x}(t)$ and $y_{t}(x)$ records. In the derivation of the models, the bed load was defined as that part of bed material which is deposited on the downstream face of the dune from which it is eroded, and the suspended load was defined as that part of bed material which passes two or more dune crests before being deposited. These definitions are very precise compared to the definitions prepared by the Task Committee on Preparation of Sedimentation Manual (1962).

Based on flume experiments with a coarse sand, the following conclusions were drawn:

1. The elevation of particle erosion and the elevation of particle deposition can be considered to be identically distributed, and their distribution can be approximated by either a truncated Gaussian density function or a symmetric triangular density function. In general, the truncated Gaussian density provides slightly better results; although the triangular density is much easier to handle analytically.

2. The conditional probability distribution of the rest periods, given the elevation of deposition, can be well described by the two-parameter gamma density function. The shape of the conditional density approaches a $\mathrm{J}$-shape and becomes more peaked as bed elevation decreases.

A. Both the conditional mean and variance of the rest periods increase with decreasing bed elevation. These relations can be expressed by exponential functions.

B. Both the scale and shape parameters for the conditional distribution of the rest periods increase with increasing bed elevation, and they can be described by exponential functions of bed elevation.

C. The correlation coefficient between the rest periods and the elevation of deposition indicated that the rest periods and the elevation of deposition are negatively correlated, but the degree of their linear association is not strong.

3. The conditional probability distribution of the step lengths, given the elevation of deposition and the elevation of erosion, can be approximated by the twoparameter gamma distribution. The shape of the conditional density is strongly dependent on the elevation of deposition and erosion.

A. For a fixed elevation of deposition, both the double conditional mean and variance of the step lengths increase with decreasing elevation of ero- sion. In other words, longer step lengths are associated with lower elevation at which a sediment particle is eroded or deposited and vice versa.

B. The correlation coefficient between the step lengths and the elevation of deposition indicates that they are negatively correlated, but the degree of their linear association is not strong.

4. All three bed-material transport models are found to be quite satisfactory except for run 16 .

A. The effective volume ratio can be obtained from either the $y_{t}(x)$ record or the $y_{x}(t)$ record, and it appears to be rearly independent of flow condition.

B. The maximum bed-load movement is associated with mean bed elevation, and little movement occurs for $y \leqslant-2.4$ and $y \geqslant+2.4$.

5. The mean transport speed of a bed-material particle, the average depth of the zone of bed material movement, and the standard deviation of bed elevation increased with increasing stream power, whereas the marginal means and variances of the rest periods and the step lengths decreased with increasing stream power.

Figures 10 and 15 suggest that the step lengths and the rest periods are positively correlated in an average sense, but the degree of linear association was not strong.

\section{REFERENCES GITED}

Crickmore, M. J., and Lean, G. H., 1962, The measurement of sand transport by means of radioactive tracers: Proc. Royal Soc. of London, ser. A, v. 266, p. 402-421.

Einstein, H. A., 1937, Der Geschiebetrieb als Wahrscheinlichkeitsproblem [The bed-load movement as a probability problem]: Mitteilung der Verschsanstalt für Wasserbau, an der Eidgenössische Technische Hochschule in Zürich, Verlag Rascher and Co., $110 \mathrm{p}$. 1950, The bed load function for sediment transportation in open channel flows: U.S. Dept. Agriculture Tech. Bull., no. 1026, $70 \mathrm{p}$.

Grigg, N. S., 1969, Motion of single particles in sand channels: $\mathrm{Ph} . \mathrm{D}$. dissert., Colorado State Univ., Fort Collins, $162 \mathrm{p}$.

Hubbell, D. W., and Sayre, W. W., 1964, Sand transport studies with radioactive tracers: Am. Soc. Civil Engineers Proc., v. 90, no. HY3, p. 39-68.

1965, Closure to: Sand transport studies with radioactive tracers: Am. Soc. Civil Engineers Proc., v. 91, no. HY5, p. 139-149.

Karaki, S. S., Gray, E. E., and Collins, J., 1961, Dual channel stream monitor: Am. Soc. Civil Engineers Proc., v. 87, no. HY6, p. 1-16.

Lee, B. K., 1969, Laboratory study of an alluvial stream at one-foot depth: M.S. thesis, Colorado State Univ., Fort Collins, Civil Eng. Dept., $57 \mathrm{p}$.

1973, Stochastic analysis of particle movement over a dune bed; Ph. D. dissert., Colorado State Univ., Fort Collins, 220 p.

Parzen, E., 1960, Modern probability theory and its applications: New York, John Wiley and Sons, Inc., $464 \mathrm{p}$.

1967, Stochastic processes: San Francisco, Holden-Day, Inc., $324 \mathrm{p}$. 
Sayre, W. W., and Conover, W. J., 1967, General two-dimensional stochastic model for the transport and dispersion of bedmaterial sediment particles: Internat. Assoc. Hydraulic Research, 12th Cong., Fort Collins, Colo., Proc., v. 2, p. 88-95.

Shen, H. W., and Todorovic, P. N., 1971, A general stochastic model for the transport of sediment bed material: 1st Internat. Symposium on Stochastic Hydraulics, ed. Chao-Lin Chiu, Proc., Pittsburgh, Penn., 1. 426-448.

Simons, D. B., and Richardson, E. V., 1966, Resistance to flow in alluvial channels: U.S. Geol. Survey Prof. Paper 422-J, 61 p.

Task Committee on Preparation of Sedimentation Manual, Committee on Sedimentation, 1962, Sediment transportation mechanics: Introduction and properties of sediment: Am. Soc. Civil Engineers Proc., v. 88, no. HY6, pt. 1, p. 78.

Williams, G. P., 1971, Aids in designing laboratory flumes: U.S. Geol. Survey open-file report, $294 \mathrm{p}$.

Yang, T., 1968, Sand dispersion in a laboratory flume: Ph.D. dissert., Colorado State Univ., Fort Collins, 162 p. 


\section{SUPPLEMENTAL DATA \\ TABLES 2-72}


Table 2. Somple probability mass fronctions of elevations of deposition and erosion

\begin{tabular}{|c|c|c|c|c|c|c|c|c|}
\hline \multirow{2}{*}{$\begin{array}{c}\text { Elevation } \\
y_{i}\end{array}$} & \multicolumn{2}{|c|}{ Run $4 \mathrm{~A}$} & \multicolumn{2}{|c|}{ Run 16} & \multicolumn{2}{|c|}{ Run 17} & \multirow{2}{*}{$\begin{array}{l}\text { Triangular } \\
\text { Density }\end{array}$} & \multirow{2}{*}{$\begin{array}{l}\text { Truncated } \\
\text { Gaussian }\end{array}$} \\
\hline & $p_{Y_{D}}\left(y_{i}\right)$ & $p_{Y_{E}}\left(y_{i}\right)$ & $p_{Y_{D}}\left(y_{i}\right)$ & $p_{Y_{E}}\left(y_{i}\right)$ & $p_{Y_{D}}\left(y_{i}\right)$ & $p_{Y_{E}}\left(y_{i}\right)$ & & \\
\hline-3.6 & 0.000 & 0.000 & 0.000 & 0.000 & 0.000 & 0.000 & $-\cdots$ & -..- \\
\hline-3.2 & .000 & .000 & .006 & .006 & .000 & .000 & ---- & -...- \\
\hline-2.8 & .000 & .000 & .007 & .007 & .001 & .002 & -.... & -...- \\
\hline-2.4 & .006 & .006 & .011 & .013 & .005 & .006 & 0.004 & 0.006 \\
\hline-2.0 & .025 & .032 & .019 & .025 & .017 & .017 & .028 & .022 \\
\hline-1.6 & .060 & .060 & .038 & .044 & .044 & .047 & $.0,56$ & .046 \\
\hline-1.2 & .091 & .088 & .062 & .065 & .089 & .089 & .083 & .079 \\
\hline-0.8 & .125 & .129 & .104 & .109 & .129 & .129 & .111 & .118 \\
\hline-0.4 & .152 & .140 & .122 & .116 & .153 & .148 & .139 & .148 \\
\hline 0.0 & .160 & .166 & .133 & .134 & .154 & .157 & .158 & .162 \\
\hline 0.4 & .156 & .154 & .197 & .189 & .154 & .153 & .139 & .148 \\
\hline 0.8 & .120 & .116 & .137 & .130 & .117 & .118 & .111 & .118 \\
\hline 1.2 & .070 & .068 & .097 & .097 & .073 & .072 & .083 & .079 \\
\hline 1.6 & .025 & .032 & .046 & .044 & .041 & .041 & .056 & .046 \\
\hline 2.0 & .009 & .009 & .016 & .016 & .019 & .017 & .028 & .022 \\
\hline 2.4 & .001 & .001 & .005 & .005 & .004 & .004 & .004 & .006 \\
\hline 2.8 & .000 & .000 & .000 & .000 & .000 & .000 & --.- & $-\cdots$ \\
\hline$\sum_{i} m_{i}$ or $\sum_{i} m_{i}^{\prime}$ & 2,167 & 2,167 & 134 & 134 & 708 & 708 & -..- & -.... \\
\hline$\hat{\mathrm{E}}\left[Y_{D}\right]$ or $\hat{\mathrm{E}}\left[y_{E}\right]$ & -.130 & -.133 & .055 & .006 & -.039 & -.043 & ----- & $\ldots$ \\
\hline$\widehat{\operatorname{Var}}\left[Y_{D}\right]$ or $\widehat{\operatorname{Var}}\left[Y_{E}\right]$ & .813 & .850 & .999 & 1.046 & .863 & .870 & -..-- & $-\cdots$ \\
\hline
\end{tabular}

Note: $m_{i}$ is the total number of bed forms contained in the $y_{x}(t)$ record and which also contain some deposition in the class interval associated with the elevation $y_{i}$.

$m_{i}^{\prime}$ is the total number of bed forms contained in the $y_{x}(t)$ record and which also contain some erosion in the class interval associated with the elevation $y_{i}$. 
SUPPLEMENTAL DATA TABLES

Table 3. Sample conditional probability mass function of rest periods, $p_{T} \mid Y_{D}\left(t_{\alpha} \mid y_{i}\right)$ (Run 4A)

\begin{tabular}{|c|c|c|c|c|c|c|c|c|c|c|c|c|c|c|c|c|}
\hline \multirow{3}{*}{\multicolumn{2}{|c|}{$\begin{array}{l}\tau_{\alpha} \\
\tau_{\alpha+1} \\
t_{\alpha}\end{array}$}} & 0 & 10 & 20 & 30 & 40 & 50 & 60 & 70 & 80 & 90 & 100 & 110 & 120 & 130 & 140 \\
\hline & & 10 & 20 & 30 & 40 & 50 & 60 & 70 & 80 & 90 & 100 & 110 & 120 & 130 & 140 & 150 \\
\hline & & 5 & 15 & 25 & 35 & 45 & 55 & 65 & 75 & 85 & 95 & 105 & 115 & 125 & 135 & 145 \\
\hline \multirow{15}{*}{ 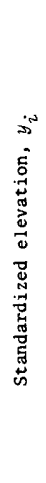 } & -2.8 & 0 & 0 & 0 & 0 & 0 & 0 & 0 & 0 & 0 & 0 & 0 & 0 & 0 & 0 & 0 \\
\hline & -2.4 & 0 & 0 & 0 & 0 & 0 & 0 & 0 & 0 & 0 & 0 & 0 & 0 & 0 & .0909 & 0 \\
\hline & -2.0 & .0448 & .0746 & .1045 & .0896 & .0448 & .0298 & .0149 & .0298 & .0298 & .0149 & 0 & .0298 & .0149 & .0149 & .0149 \\
\hline & -1.6 & .0411 & .1241 & .1022 & .0657 & .0657 & .1095 & .0438 & .0146 & .0365 & .0219 & .0146 & .0146 & .0073 & .0219 & .0219 \\
\hline & -1.2 & .1031 & .1443 & .1186 & .0723 & .0979 & .0670 & .0412 & .0258 & .0361 & .0103 & .0154 & .0052 & .0309 & .0206 & .0361 \\
\hline & -0.8 & .0909 & .2016 & .1265 & .0988 & .0830 & .0988 & .0237 & .0316 & .0316 & .0237 & .0277 & .0237 & .0198 & .0158 & .0158 \\
\hline & -0.4 & .1019 & .2229 & .1337 & .1752 & .1178 & .0637 & .0478 & .0350 & .0223 & .0159 & .0127 & .0096 & .0159 & .0064 & .0032 \\
\hline & 0.0 & .1579 & .2742 & .2271 & .1385 & .0803 & .0499 & .0360 & .0111 & .0083 & .0054 & 0 & .0028 & .0083 & 0 & 0 \\
\hline & 0.4 & .2189 & .3639 & .2041 & .1036 & .0710 & .0148 & .0177 & .0059 & 0 & 0 & 0 & 0 & 0 & 0 & 0 \\
\hline & 0.8 & .3145 & .3952 & .1694 & .0766 & .0202 & .0242 & 0 & 0 & 0 & 0 & 0 & 0 & 0 & 0 & 0 \\
\hline & 1.2 & .4067 & .3533 & .1867 & .0467 & .0067 & 0 & 0 & 0 & 0 & 0 & 0 & 0 & 0 & 0 & 0 \\
\hline & 1.6 & .5139 & .3750 & .0833 & .0278 & 0 & 0 & 0 & 0 & 0 & 0 & 0 & 0 & 0 & 0 & 0 \\
\hline & 2.0 & .7368 & .2105 & .0526 & 0 & 0 & 0 & 0 & 0 & 0 & 0 & 0 & 0 & 0 & 0 & 0 \\
\hline & 2.4 & .6667 & .3333 & 0 & 0 & 0 & 0 & 0 & 0 & 0 & 0 & 0 & 0 & 0 & 0 & 0 \\
\hline & 2.8 & 0 & 0 & 0 & 0 & 0 & 0 & 0 & 0 & 0 & 0 & 0 & 0 & 0 & 0 & 0 \\
\hline \multirow{3}{*}{\multicolumn{2}{|c|}{$\begin{array}{l}\tau_{\alpha} \\
\tau_{\alpha+1} \\
t_{\alpha}\end{array}$}} & 150 & 160 & 170 & 180 & 190 & 200 & 250 & 300 & 350 & 400 & 500 & 600 & 1,000 & 2,000 & \multirow{3}{*}{$m_{i, i}$} \\
\hline & & 160 & 170 & 180 & 190 & 200 & 250 & 300 & 350 & 400 & 500 & 600 & 1,000 & 2,000 & 8,000 & \\
\hline & & 155 & 165 & 175 & 185 & 195 & 225 & 275 & 325 & 375 & 450 & 550 & 800 & 1,500 & 5,000 & \\
\hline \multirow{15}{*}{ 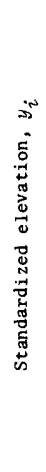 } & -2.8 & 0 & 0 & 0 & 0 & 0 & 0 & 0 & 0 & 0 & 0 & 0 & 0 & 0 & 0 & 0 \\
\hline & -2.4 & 0 & 0 & 0 & 0 & 0 & .2727 & .0909 & 0 & 0 & .0909 & 0 & .0909 & .0909 & .2727 & 11 \\
\hline & -2.0 & 0 & 0 & .0149 & .0448 & 0 & .0746 & .0597 & .0149 & .0298 & .0298 & .0448 & .0896 & .0448 & 0 & 67 \\
\hline & -1.6 & .0438 & .0219 & .0146 & .0073 & .0219 & .0219 & .0219 & .0438 & .0219 & .0292 & .019 & .0146 & 0 & 0 & 137 \\
\hline & -1.2 & .0258 & .0052 & .0052 & .0103 & .0155 & .0309 & .0464 & .0155 & .0052 & .0154 & 0 & 0 & 0 & 0 & 194 \\
\hline & -0.8 & .0158 & .0198 & .0079 & .0079 & .0039 & .0198 & .0079 & 0 & 0 & .0039 & 0 & 0 & 0 & 0 & 253 \\
\hline & -0.4 & .0032 & .0032 & .0032 & 0 & 0 & .0032 & .0032 & 0 & 0 & 0 & 0 & 0 & 0 & 0 & 314 \\
\hline & 0.0 & 0 & 0 & 0 & 0 & 0 & 0 & 0 & 0 & 0 & 0 & 0 & 0 & 0 & 0 & 361 \\
\hline & 0.4 & 0 & 0 & 0 & 0 & 0 & 0 & 0 & 0 & 0 & 0 & 0 & 0 & 0 & 0 & 338 \\
\hline & 0.8 & 0 & 0 & 0 & 0 & 0 & 0 & 0 & 0 & 0 & 0 & 0 & 0 & 0 & 0 & 248 \\
\hline & 1.2 & 0 & 0 & 0 & 0 & 0 & 0 & 0 & 0 & 0 & 0 & 0 & 0 & 0 & 0 & 150 \\
\hline & 1.6 & 0 & 0 & 0 & 0 & 0 & 0 & 0 & 0 & 0 & 0 & 0 & 0 & 0 & 0 & 72 \\
\hline & 2.0 & 0 & 0 & 0 & 0 & 0 & 0 & 0 & 0 & 0 & 0 & 0 & 0 & 0 & 0 & 19 \\
\hline & 2.4 & 0 & 0 & 0 & 0 & 0 & 0 & 0 & 0 & 0 & 0 & 0 & 0 & 0 & 0 & 3 \\
\hline & 2.8 & 0 & 0 & 0 & 0 & 0 & 0 & 0 & 0 & 0 & 0 & 0 & 0 & 0 & 0 & 0 \\
\hline
\end{tabular}

Note: $\tau_{\alpha}, \tau_{\alpha+1}$, and $t_{\alpha}$ are in minutes.

$m_{i, i}$ is the total number of bed forms contained in the $y_{x}(t)$ record and which also contain both an up-crossing and a down-crossing at the elevation $y_{i}$. 
Table 4. Sample conditional probability mass function of rest periods, $p_{T \mid Y_{D}}\left(t_{\alpha} \mid y_{i}\right)$ (Run 16)

\begin{tabular}{|c|c|c|c|c|c|c|c|c|c|c|c|c|}
\hline \multirow{3}{*}{\multicolumn{2}{|c|}{$\begin{array}{l}\tau_{\alpha} \\
\tau_{\alpha+1} \\
t_{\alpha}\end{array}$}} & 0 & 20 & 40 & 60 & 80 & 100 & 120 & 140 & 160 & 180 & 200 \\
\hline & & 20 & 40 & 60 & 80 & 100 & 120 & 140 & 160 & 180 & 200 & 220 \\
\hline & & 10 & 30 & 50 & 70 & 90 & 110 & 130 & 150 & 170 & 190 & 210 \\
\hline \multirow{15}{*}{ 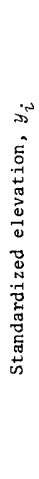 } & -2.8 & 0 & 0 & 0 & 0 & 0 & 0 & 0 & 0 & 0 & 0 & 0 \\
\hline & -2.4 & 0 & 0 & 0 & 0 & 0 & 0 & 0 & 0 & 0 & 0 & 0 \\
\hline & -2.0 & 0 & 0 & 0 & 0 & 0 & 0 & 0 & 0 & 0 & 0 & 0 \\
\hline & -1.6 & 0 & 0 & 0 & 0 & 0 & 0 & 0 & .1667 & 0 & 0 & 0 \\
\hline & -1.2 & .2500 & 0 & 0 & 0 & 0 & 0 & 0 & .1250 & 0 & 0 & 0 \\
\hline & -0.8 & .1333 & .0667 & .0667 & 0 & 0 & .0667 & .0667 & .0667 & 0 & 0 & .0666 \\
\hline & -0.4 & .1765 & .0588 & 0 & .0588 & .0588 & .0588 & .0588 & .0588 & .0588 & 0 & .0588 \\
\hline & 0.0 & .1111 & .0556 & .1111 & .0556 & .0556 & .0556 & .1111 & .1111 & .0555 & 0 & 0 \\
\hline & 0.4 & .4138 & .1034 & .0690 & .0345 & .0345 & .2069 & .0345 & 0 & .0345 & .0345 & 0 \\
\hline & 0.8 & .2778 & .1667 & .1111 & .1111 & .0556 & .0556 & .1666 & 0 & .0556 & 0 & 0 \\
\hline & 1.2 & .5385 & 0 & .2308 & 0 & .2308 & 0 & 0 & 0 & 0 & 0 & 0 \\
\hline & 1.6 & .2000 & .4000 & .4000 & 0 & 0 & 0 & 0 & 0 & 0 & 0 & 0 \\
\hline & 2.0 & .5000 & .5000 & 0 & 0 & 0 & 0 & 0 & 0 & 0 & 0 & 0 \\
\hline & 2.4 & 1.0000 & 0 & 0 & 0 & 0 & 0 & 0 & 0 & 0 & 0 & 0 \\
\hline & 2.8 & 0 & 0 & 0 & 0 & 0 & 0 & 0 & 0 & 0 & 0 & 0 \\
\hline \multicolumn{2}{|c|}{${ }^{\tau} \alpha$} & 220 & 240 & 260 & 300 & 400 & 500 & 600 & 700 & 800 & 1,300 & \\
\hline \multicolumn{2}{|c|}{$\tau_{\alpha+1}$} & 240 & 260 & 300 & 400 & 500 & 600 & 700 & 800 & 1,300 & 1,800 & $m_{i, i}$ \\
\hline \multicolumn{2}{|c|}{$t_{\alpha}$} & 230 & 250 & 280 & 350 & 450 & 550 & 650 & 750 & 1,050 & 1,550 & \\
\hline \multirow{15}{*}{ 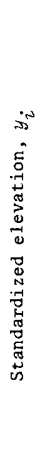 } & -2.8 & 0 & 0 & 0 & 0 & 0 & 0 & 0 & 0 & 0 & 0 & 0 \\
\hline & -2.4 & 0 & 0 & 0 & 0 & 0 & 0 & 0 & 0 & 0 & 0 & 0 \\
\hline & -2.0 & 0 & 0 & 0 & 0 & 0 & 0 & 0 & 0 & 0 & 1.0000 & 2 \\
\hline & -1.6 & 0 & 0 & 0 & .1667 & 0 & 0 & .1667 & .1667 & .1666 & .1666 & 6 \\
\hline & -1.2 & 0 & 0 & .1250 & 0 & .1250 & 0 & 0 & .1250 & .1250 & .1250 & 8 \\
\hline & -0.8 & .0666 & 0 & .0666 & .1333 & .0667 & .0667 & .0667 & 0 & 0 & 0 & 15 \\
\hline & -0.4 & 0 & .0588 & .1176 & .0588 & .0588 & 0 & .0588 & 0 & 0 & 0 & 17 \\
\hline & 0.0 & 0 & .1111 & .1111 & 0 & 0 & .0555 & 0 & 0 & 0 & 0 & 18 \\
\hline & 0.4 & .0345 & 0 & 0 & 0 & 0 & 0 & 0 & 0 & 0 & 0 & 29 \\
\hline & 0.8 & 0 & 0 & 0 & 0 & 0 & 0 & 0 & 0 & 0 & 0 & 18 \\
\hline & 1.2 & 0 & 0 & 0 & 0 & 0 & 0 & 0 & 0 & 0 & 0 & 13 \\
\hline & 1.6 & 0 & 0 & 0 & 0 & 0 & 0 & 0 & 0 & 0 & 0 & 5 \\
\hline & 2,0 & 0 & 0 & 0 & 0 & 0 & 0 & 0 & 0 & 0 & 0 & 2 \\
\hline & 2.4 & 0 & 0 & 0 & 0 & 0 & 0 & 0 & 0 & 0 & 0 & 1 \\
\hline & 2.8 & 0 & 0 & 0 & 0 & 0 & 0 & 0 & 0 & 0 & 0 & 0 \\
\hline
\end{tabular}

Note: $\tau_{\alpha}, \tau_{\alpha+1}$, and $t_{\alpha}$ are in minutes.

$m_{i, i}$ is the total number of bed forms contained in the $y_{x}(t)$ record and which also contain both an up-crossing and a down-crossing at the elevation $y_{i}$ 
SUPPLEMENTAL DATA TABLES

Table 5. Scmple conditional probability mass function of rest periods, $p_{T \mid Y_{D}}\left(t_{\alpha} \mid y_{i}\right)$ (Run 17)

\begin{tabular}{|c|c|c|c|c|c|c|c|c|c|c|c|c|c|c|}
\hline & & 0 & 10 & 20 & 30 & 40 & 50 & 60 & 70 & 80 & 90 & 100 & 110 & 120 \\
\hline & $\alpha+1$ & 10 & 20 & 30 & 40 & 50 & 60 & 70 & 80 & 90 & 100 & 110 & 120 & 130 \\
\hline & $\alpha$ & 5 & 15 & 25 & 35 & 45 & 55 & 65 & 75 & 85 & 95 & 105 & 115 & 125 \\
\hline & -2.8 & 0 & 0 & 0 & 0 & 0 & 0 & 0 & 0 & 0 & 0 & 0 & 0 & 0 \\
\hline & -2.4 & 0 & 0 & 0 & 0 & 0 & 0 & 0 & 0 & 0 & 0 & 0 & 0 & 0 \\
\hline & -2.0 & 0 & 0 & 0 & 0 & .1000 & .1000 & 0 & 0 & 0 & 0 & 0 & .1000 & .1000 \\
\hline$i^{2}$ & -1.6 & .0322 & .0322 & .0322 & .1290 & .0968 & .0322 & 0 & .0322 & 0 & .0323 & .0323 & .0968 & 0 \\
\hline$\therefore$ & -1.2 & .0328 & .0164 & .1311 & .0984 & .1639 & .0492 & .1639 & .0656 & .0328 & .0328 & .0328 & .0164 & .0164 \\
\hline$\because$ & -0.8 & .0652 & .0652 & .1630 & .1522 & .1739 & .1304 & .0978 & .0326 & .0217 & 0 & .0109 & .0217 & 0 \\
\hline 2 & -0.4 & .0385 & .1442 & .2404 & .2115 & .1250 & .1058 & .0288 & .0385 & .0096 & .0192 & .0096 & 0 & 0 \\
\hline$\overline{0}$ & 0.0 & .0789 & .2281 & .2544 & .2105 & .1228 & .0351 & .0526 & 0 & 0 & .0088 & .0088 & 0 & 0 \\
\hline$\underset{N}{\mathbb{B}}$ & 0.4 & .1892 & .3063 & .2703 & .1261 & .0531 & .0270 & .0180 & 0 & 0 & 0 & 0 & 0 & 0 \\
\hline t. & 0.8 & .2625 & .3250 & .2500 & .0875 & .0500 & .0250 & 0 & 0 & 0 & 0 & 0 & 0 & 0 \\
\hline एँ & 1.2 & .4286 & .2857 & .1786 & .0893 & .0179 & 0 & 0 & 0 & 0 & 0 & 0 & 0 & 0 \\
\hline$\ddot{\Delta}$ & 1.6 & .6250 & .2500 & .1250 & 0 & 0 & 0 & 0 & 0 & 0 & 0 & 0 & 0 & 0 \\
\hline & 2.0 & .7273 & .2727 & 0 & 0 & 0 & 0 & 0 & 0 & 0 & 0 & 0 & 0 & 0 \\
\hline & 2.4 & 1.0000 & 0 & 0 & 0 & 0 & 0 & 0 & 0 & 0 & 0 & 0 & 0 & 0 \\
\hline & 2.8 & 0 & 0 & 0 & 0 & 0 & 0 & 0 & 0 & 0 & 0 & 0 & 0 & 0 \\
\hline & & 130 & 140 & 150 & 200 & 250 & 300 & 400 & 500 & 1,000 & 2,000 & 3,000 & & \\
\hline & $\alpha+1$ & 140 & 150 & 200 & 250 & 300 & 400 & 500 & 1,000 & 2,000 & 3,000 & 4,000 & & $m_{i, i}$ \\
\hline & & 135 & 145 & 175 & 225 & 275 & 350 & 450 & 750 & 1,500 & 2,500 & 3,500 & & \\
\hline & -2.8 & 0 & 0 & 0 & 0 & 0 & 0 & 0 & 0 & 0 & 0 & 0 & & 0 \\
\hline & -2.4 & 0 & .3333 & 0 & .3334 & 0 & 0 & 0 & 0 & 0 & 0 & .3333 & & 3 \\
\hline & -2.0 & .1000 & 0 & 0 & 0 & .1000 & 0 & .1000 & .1000 & .1000 & .1000 & 0 & & 10 \\
\hline s & -1.6 & .0322 & .0322 & .0322 & .1613 & .0322 & .0322 & .0645 & .0645 & 0 & 0 & 0 & & 31 \\
\hline$=$ & -1.2 & .0164 & 0 & .0328 & .0328 & 0 & .0328 & .0164 & .0164 & 0 & 0 & 0 & & 61 \\
\hline$\stackrel{\overbrace{}}{\pi}$ & -0.8 & .0109 & .0109 & .0217 & 0 & .0109 & .0109 & 0 & 0 & 0 & 0 & 0 & & 92 \\
\hline$\stackrel{\infty}{2}$ & -0.4 & 0 & 0 & 0 & 0 & .0096 & 0 & 0 & 0 & 0 & 0 & 0 & & 104 \\
\hline $\overrightarrow{0}$ & 0.0 & 0 & 0 & 0 & 0 & 0 & 0 & 0 & 0 & 0 & 0 & 0 & & 114 \\
\hline d & 0.4 & 0 & 0 & 0 & 0 & 0 & 0 & 0 & 0 & 0 & 0 & 0 & & 111 \\
\hline $\overrightarrow{0}$ & 0.8 & 0 & 0 & 0 & 0 & 0 & 0 & 0 & 0 & 0 & 0 & 0 & & 80 \\
\hline ]్ & 1.2 & 0 & 0 & 0 & 0 & 0 & 0 & 0 & 0 & 0 & 0 & 0 & & 56 \\
\hline 莕 & 1.6 & 0 & 0 & 0 & 0 & 0 & 0 & 0 & 0 & 0 & 0 & 0 & & 32 \\
\hline & 2.0 & 0 & 0 & 0 & 0 & 0 & 0 & 0 & 0 & 0 & 0 & 0 & & 11 \\
\hline & 2.4 & 0 & 0 & 0 & 0 & 0 & 0 & 0 & 0 & 0 & 0 & 0 & & 3 \\
\hline & 2.8 & 0 & 0 & 0 & 0 & 0 & 0 & 0 & 0 & 0 & 0 & 0 & & 0 \\
\hline
\end{tabular}

Note: $\tau_{\alpha}, \tau_{\alpha+1}$, and $t_{\alpha}$ are in minutes

$m_{i, i}$ is the total number of bed forms contained in the $y_{x}(t)$ record and which also contain $i, i$ both an up-crossing and a down-crossing at the elevation $y_{i}$. 
Table 6. Variation of conditional mean and variance of rest periods with elevation of dsposition; $\hat{\mathrm{E}}\left[T \mid Y_{D}=y\right]$ and $\operatorname{Var}\left[T \mid Y_{D}=y\right]$

\begin{tabular}{|c|c|c|c|c|c|c|}
\hline \multirow{2}{*}{$\begin{array}{c}\text { Standardized } \\
\text { Elevation } \\
y_{i}\end{array}$} & \multicolumn{3}{|c|}{$\hat{\mathrm{E}}\left[T \mid Y_{D}=y_{i}\right], \min$} & \multicolumn{3}{|c|}{$\widehat{\operatorname{Var}}\left[T \mid Y_{D}=y_{i}\right], \min ^{2}$} \\
\hline & Run $4 \mathrm{~A}$ & Run 16 & Run 17 & Run $4 \mathrm{~A}$ & Run 16 & Run 17 \\
\hline-2.8 & ( & -....... & -....... & ( & -...... & ................ \\
\hline-2.4 & $1,400.8$ & -.....- & $1,443.7$ & $4,179,378$ & -..-..-- & $4,671,616$ \\
\hline-2.0 & 252.2 & $1,550.3$ & 610.6 & 109,148 & 84,679 & 762,079 \\
\hline-1.6 & 120.5 & 714.8 & 198.0 & 19,552 & 204,840 & 74,793 \\
\hline-1.2 & 83.4 & 505.6 & 92.5 & 8,696 & 246,658 & 14,193 \\
\hline-0.8 & 58.2 & 230.9 & 53.5 & 3,529 & 39,416 & 2,548 \\
\hline-0.4 & 40.2 & 185.8 & 40.4 & 1,288 & 28,686 & 1,129 \\
\hline 0.0 & 27.4 & 151.7 & 29.8 & 409 & 16,715 & 316 \\
\hline 0.4 & 21.0 & 64.5 & 22.3 & 193 & 4,030 & 188 \\
\hline 0.8 & 16.7 & 61.5 & 19.0 & 127 & 2,691 & 145 \\
\hline 1.2 & 13.9 & 36.0 & 14.0 & 82 & 1,039 & 107 \\
\hline 1.6 & 11.4 & 35.6 & 9.4 & 49 & 351 & 50 \\
\hline 2.0 & 8.5 & 19.8 & 7.5 & 30 & 2 & 18 \\
\hline 2.4 & 7.1 & 6.9 & 2.6 & 29 & $\ldots$ & 0.4 \\
\hline 2.8 & $\ldots$ & -...-. & - - & 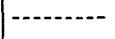 & -........ & $\cdots$ \\
\hline$\hat{\mathrm{E}}[T]$ & 53.8 & 180.5 & 60.1 & -- & $-\cdots$ & \\
\hline$\widehat{\operatorname{var}}[T]$ & - & -.....- & - & 42,110 & 93,077 & 60,469 \\
\hline$\sum_{i} m_{i, i}$ & 2,167 & 134 & 708 & 2,167 & 134 & 708 \\
\hline
\end{tabular}

Table 7. Estimates of parameters and the results of goodness of fit test for tinc conditional rest periods (two-parameter ganma)

\begin{tabular}{|c|c|c|c|c|c|c|c|c|c|c|c|c|}
\hline \multirow{2}{*}{$\begin{array}{c}\text { Elevation } \\
y_{i}\end{array}$} & \multicolumn{4}{|c|}{ Run $4 \mathrm{~A}$} & \multicolumn{4}{|c|}{ Run 16} & \multicolumn{4}{|c|}{ Run 17} \\
\hline & $k_{2, y^{1 /}}$ & $r_{2, y^{2}}$ & $m_{i, i}$ & $\begin{array}{l}\text { Goodness } \\
\text { of } \\
\text { Fit Test }\end{array}$ & $\begin{array}{l}k_{2, y} \\
\min ^{-1}\end{array}$ & $r_{2, y}$ & $m_{i, i}$ & $\begin{array}{l}\text { Goodness } \\
\text { of } \\
\text { Fit Test }\end{array}$ & $\begin{array}{l}k_{2, y} \\
\min ^{-1}\end{array}$ & $r_{2, y}$ & $m_{i, i}$ & $\begin{array}{l}\text { Goodness } \\
\text { of } \\
\text { Fit Test }\end{array}$ \\
\hline-2.4 & 0.0003 & 0.470 & 11 & ......- & -...- & ---- & 0 & $\cdots$ & -.--- &.--- & 3 & -- \\
\hline-2.0 & .0023 & .583 & 67 & -.--.- & -.-- & -... & 2 & ....... & 0.0008 & 0.489 & 10 & -....- \\
\hline-1.6 & .006 & .742 & 137 & $x^{2}>x_{c}^{2}$ & 0.003 & 2.494 & 6 & $\cdots$ & .003 & .524 & 31 & $x^{2}<x_{c}^{2}$ \\
\hline-1.2 & .010 & .800 & 194 & $x^{2}>x_{c}^{2}$ & .002 & 1.036 & 8 & $\cdots$ & .007 & .604 & 61 & $x^{2}>x_{c}^{2}$ \\
\hline-0.8 & .016 & .959 & 253 & $x^{2}<x_{c}^{2}$ & .006 & 1.353 & 15 & -...-- & .021 & 1.125 & 92 & $x^{2}>x_{c}^{2}$ \\
\hline-0.4 & .031 & 1.255 & 314 & $x^{2}>x_{c}^{2}$ & .006 & 1.204 & 17 & $x^{2}<x_{c}^{2}$ & .036 & 1.444 & 104 & $x^{2}>x_{c}^{2}$ \\
\hline 0.0 & .067 & 1.835 & 361 & $x^{2}<x_{c}^{2}$ & .009 & 1.376 & 18 & $x^{2}<x_{c}^{2}$ & .094 & 2.811 & 114 & $x^{2}<x_{c}^{2}$ \\
\hline 0.4 & .109 & 2.276 & 338 & $x^{2}<x_{c}^{2}$ & .016 & 1.031 & 29 & $x^{2}<x_{c}^{2}$ & .118 & 2.638 & 111 & $x^{2}<x_{c}^{2}$ \\
\hline 0.8 & .131 & 2.193 & 248 & $x^{2}<x_{c}^{2}$ & .023 & 1.407 & 18 & $x^{2}<x_{c}^{2}$ & .131 & 2.488 & 80 & $x^{2}<x_{c}^{2}$ \\
\hline 1.2 & .157 & 2.361 & 150 & $x^{2}<x_{c}^{2}$ & .035 & 1.247 & 13 & - & .131 & 1.827 & 56 & $x^{2}<x_{c}^{2}$ \\
\hline 1.6 & .235 & 2.680 & 72 & $x^{2}<x_{c}^{2}$ & .101 & 3.611 & 5 & ......... & .186 & 1.747 & 32 & $x^{2}<x_{c}^{2}$ \\
\hline 2.0 & .283 & 2.408 & 19 & -........ & -...- & -.... & 2 & $\cdots$ & .417 & 3.125 & 11 & -....... \\
\hline 2.4 & -----. & ----- & 3 & -..... & ..... & --..- & 1 & -- & ------ & -..- & 3 & --- \\
\hline
\end{tabular}


SUPPLEMENTAL DATA TABLES

Table 8. Sample joint probability mass function of rest periods and elevation of deposition, $p_{T, y_{D}}\left(t_{\alpha}, y_{i}\right)$ (Run $\left.4 \mathrm{~A}\right)$

\begin{tabular}{|c|c|c|c|c|c|c|c|c|c|c|c|c|c|c|c|c|}
\hline \multirow{3}{*}{\multicolumn{2}{|c|}{$\begin{array}{l}\tau_{\alpha} \\
\tau_{\alpha+1} \\
t_{\alpha}\end{array}$}} & 0 & 10 & 20 & 30 & 40 & 50 & 60 & 70 & 80 & 90 & 100 & 110 & 120 & 130 & 140 \\
\hline & & 10 & 20 & 30 & 40 & 50 & 60 & 70 & 80 & 90 & 200 & 110 & 120 & 130 & 140 & 150 \\
\hline & & 5 & 15 & 25 & 35 & 45 & 55 & 65 & 75 & 85 & 95 & 105 & 115 & 125 & 135 & 145 \\
\hline \multirow{15}{*}{ 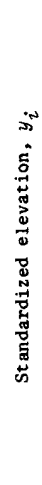 } & -2.8 & 0 & 0 & 0 & 0 & 0 & 0 & 0 & 0 & 0 & 0 & 0 & 0 & 0 & 0 & 0 \\
\hline & -2.4 & 0 & 0 & 0 & 0 & 0 & 0 & 0 & 0 & 0 & 0 & 0 & 0 & 0 & .0005 & 0 \\
\hline & -2.0 & .0011 & .0019 & .0027 & .0023 & .0011 & .0008 & .0004 & .0008 & .0008 & .0004 & 0 & .0008 & .0004 & .0004 & .0004 \\
\hline & -1.6 & .0025 & .0075 & .0062 & .0040 & .0040 & .0066 & .0026 & .0009 & .0022 & .0013 & .0009 & .0009 & .0004 & .0013 & .0013 \\
\hline & -1.2 & .0093 & .0131 & .0107 & .0065 & .0089 & .0061 & .0037 & .0023 & .0033 & .0009 & .0014 & .0005 & .0028 & .0019 & .0033 \\
\hline & -0.8 & .0114 & .0253 & .0158 & .0124 & .0104 & .0124 & .0030 & .0040 & .0040 & .0030 & .0035 & .0030 & .0025 & .0020 & .0020 \\
\hline & -0.4 & .0155 & .0338 & 0203 & .0266 & .0179 & .0097 & .0072 & .0053 & .0034 & .0024 & .0019 & .0014 & .0024 & .0010 & .0005 \\
\hline & 0.0 & .0253 & .0440 & .0365 & .0222 & .0129 & .0080 & .0058 & .0018 & .0013 & .0009 & 0 & .0004 & .0013 & 0 & 0 \\
\hline & 0.4 & .0341 & .0567 & .0318 & .0161 & .0111 & .0023 & .0028 & .0009 & 0 & 0 & 0 & 0 & 0 & 0 & 0 \\
\hline & 0.8 & .0377 & .0473 & .0203 & .0092 & .0024 & .0029 & 0 & 0 & 0 & 0 & 0 & 0 & 0 & 0 & 0 \\
\hline & 1.2 & .0286 & .0248 & .0131 & .0033 & .0005 & 0 & 0 & 0 & 0 & 0 & 0 & 0 & 0 & 0 & 0 \\
\hline & 1.6 & .0127 & .0093 & .0021 & .0007 & 0 & 0 & 0 & 0 & 0 & 0 & 0 & 0 & 0 & 0 & 0 \\
\hline & 2.0 & .0064 & .0018 & .0004 & 0 & 0 & 0 & 0 & 0 & 0 & 0 & 0 & 0 & 0 & 0 & 0 \\
\hline & 2.4 & .0005 & .0003 & 0 & 0 & 0 & 0 & 0 & 0 & 0 & 0 & 0 & 0 & 0 & 0 & 0 \\
\hline & 2.8 & 0 & 0 & 0 & 0 & 0 & 0 & 0 & 0 & 0 & 0 & 0 & 0 & 0 & 0 & 0 \\
\hline \multicolumn{2}{|c|}{$p_{T}\left(t_{\alpha}\right)$} & .1857 & .2658 & .1600 & .1033 & .0691 & .0487 & .0255 & .0160 & .0150 & .0089 & .0077 & .0070 & .0098 & .0070 & .0074 \\
\hline \multirow{3}{*}{\multicolumn{2}{|c|}{$\begin{array}{l}\tau_{\alpha} \\
\tau_{\alpha+1} \\
t_{\alpha}\end{array}$}} & 150 & 160 & 170 & 180 & 190 & 200 & 250 & 300 & 350 & 400 & 500 & 600 & 1,000 & 2,000 & \\
\hline & & 160 & 170 & 180 & 190 & 200 & 250 & 300 & 350 & 400 & 500 & 600 & 1,000 & 2,000 & 8,000 & \\
\hline & & 155 & 165 & 175 & 185 & 195 & 225 & 275 & 325 & 375 & 450 & 550 & 800 & 1,500 & 5,000 & \\
\hline \multirow{15}{*}{ 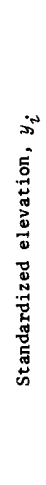 } & -2.8 & 0 & 0 & 0 & 0 & 0 & 0 & 0 & 0 & 0 & 0 & 0 & 0 & 0 & 0 & \\
\hline & -2.4 & 0 & 0 & 0 & 0 & 0 & .0015 & .0005 & 0 & 0 & .0005 & 0 & .0005 & .0005 & .0015 & \\
\hline & -2.0 & 0 & 0 & .0004 & .0011 & 0 & .0019 & .0015 & .0004 & .0008 & .0008 & .0011 & .0023 & .0011 & 0 & \\
\hline & -1.6 & .0026 & .0013 & .0009 & .0004 & .0013 & .0013 & .0013 & .0026 & .0013 & .0018 & .0013 & .0009 & 0 & 0 & \\
\hline & -1.2 & .0023 & .0005 & .0005 & .0009 & .0014 & .0028 & .0043 & .0014 & .0005 & .0014 & 0 & 0 & 0 & 0 & \\
\hline & -0.8 & .0020 & .0025 & .0010 & .0010 & .0005 & .0025 & .0010 & 0 & 0 & 0 & 0 & 0 & 0 & 0 & \\
\hline & -0.4 & .0005 & .0005 & .0005 & 0 & 0 & .0005 & .0005 & 0 & 0 & .0005 & 0 & 0 & 0 & 0 & \\
\hline & 0.0 & 0 & 0 & 0 & 0 & 0 & 0 & 0 & 0 & 0 & 0 & 0 & 0 & 0 & 0 & \\
\hline & 0.4 & 0 & 0 & 0 & 0 & 0 & 0 & 0 & 0 & 0 & 0 & 0 & 0 & 0 & 0 & \\
\hline & 0.8 & 0 & 0 & 0 & 0 & 0 & 0 & 0 & 0 & 0 & 0 & 0 & 0 & 0 & 0 & \\
\hline & 1.2 & 0 & 0 & 0 & 0 & 0 & 0 & 0 & 0 & 0 & 0 & 0 & 0 & 0 & 0 & \\
\hline & 1.6 & 0 & 0 & 0 & 0 & 0 & 0 & 0 & 0 & 0 & 0 & 0 & 0 & 0 & 0 & \\
\hline & 2.0 & 0 & 0 & 0 & 0 & 0 & 0 & 0 & 0 & 0 & 0 & 0 & 0 & 0 & 0 & \\
\hline & 2.4 & 0 & 0 & 0 & 0 & 0 & 0 & 0 & 0 & 0 & 0 & 0 & 0 & 0 & 0 & \\
\hline & 2.8 & 0 & 0 & 0 & 0 & 0 & 0 & 0 & 0 & 0 & 0 & 0 & 0 & 0 & 0 & \\
\hline \multicolumn{2}{|c|}{$p_{T}\left(t_{\alpha}\right)$} & .0074 & .0048 & .0032 & .0035 & .0032 & .0105 & .0090 & .0044 & .0026 & .0049 & .0024 & .0037 & .0017 & .0015 & \\
\hline
\end{tabular}

Note: $\tau_{\alpha}, \tau_{\alpha+1}$, and $t_{\alpha}$ are in minutes. 
Table 9. Sample joint probability mass function of rest periods and elevation of deposition, $p_{T, Y_{D}}\left(t_{\alpha}, y_{i}\right)($ Run 16)

\begin{tabular}{|c|c|c|c|c|c|c|c|c|c|c|c|c|}
\hline \multirow{3}{*}{\multicolumn{2}{|c|}{$\begin{array}{l}\tau_{\alpha} \\
\tau_{\alpha+1} \\
t_{\alpha}\end{array}$}} & 0 & 20 & 40 & 60 & 80 & 100 & 120 & 140 & 160 & 180 & 200 \\
\hline & & 20 & 40 & 60 & 80 & 100 & 120 & 140 & 160 & 180 & 200 & 220 \\
\hline & & 110 & 30 & 50 & 70 & 90 & 110 & 130 & 150 & 170 & 190 & 210 \\
\hline \multirow{15}{*}{ 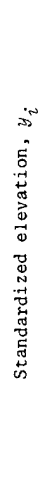 } & -2.8 & 0 & 0 & 0 & 0 & 0 & 0 & 0 & 0 & 0 & 0 & 0 \\
\hline & -2.4 & 0 & 0 & 0 & 0 & 0 & 0 & 0 & 0 & 0 & 0 & 0 \\
\hline & -2.0 & 0 & 0 & 0 & 0 & 0 & 0 & 0 & 0 & 0 & 0 & 0 \\
\hline & -1.6 & 0 & 0 & 0 & 0 & 0 & 0 & 0 & .0063 & 0 & 0 & 0 \\
\hline & -1.2 & .0151 & 0 & 0 & 0 & 0 & 0 & 0 & .0075 & 0 & 0 & 0 \\
\hline & -0.8 & .0138 & .0069 & .0069 & 0 & 0 & .0069 & .0069 & .0069 & 0 & 0 & .0069 \\
\hline & -0.4 & .0216 & .0072 & 0 & .0072 & .0072 & .0072 & .0072 & .0072 & .0072 & 0 & .0072 \\
\hline & 0.0 & .0148 & .0074 & .0148 & .0074 & .0074 & .0074 & .0148 & .0148 & .0074 & 0 & 0 \\
\hline & 0.4 & .0817 & .0204 & .0136 & .0068 & .0068 & .0409 & .0068 & 0 & .0068 & .0068 & 0 \\
\hline & 0.8 & .0381 & .0229 & .0153 & .0153 & .0076 & .0076 & .0229 & 0 & .0076 & 0 & 0 \\
\hline & 1.2 & .0524 & 0 & .0225 & 0 & .0225 & 0 & 0 & 0 & 0 & 0 & 0 \\
\hline & 1.6 & .0093 & .0185 & .0185 & 0 & 0 & 0 & 0 & 0 & 0 & 0 & 0 \\
\hline & 2.0 & .0082 & .0082 & 0 & 0 & 0 & 0 & 0 & 0 & 0 & 0 & 0 \\
\hline & 2.4 & .0048 & 0 & 0 & 0 & 0 & 0 & 0 & 0 & 0 & 0 & 0 \\
\hline & 2.8 & 0 & 0 & 0 & 0 & 0 & 0 & 0 & 0 & 0 & 0 & 0 \\
\hline \multicolumn{2}{|c|}{$F_{T}\left(t_{\alpha}\right)$} & .2598 & .0915 & .0916 & .0367 & .0515 & .0700 & .0586 & .0427 & .0290 & .0068 & .0141 \\
\hline \multirow{3}{*}{\multicolumn{2}{|c|}{$\begin{array}{l}\tau_{\alpha} \\
\tau_{\alpha+1} \\
t_{\alpha}\end{array}$}} & 220 & 240 & 260 & 300 & 400 & 500 & 600 & 700 & 800 & 1,300 & \\
\hline & & 240 & 260 & 300 & 400 & 500 & 600 & 700 & 800 & 1,300 & 1,800 & \\
\hline & & 230 & 250 & 280 & 350 & 450 & 550 & 650 & 750 & 1,050 & 1,550 & \\
\hline \multirow{15}{*}{ 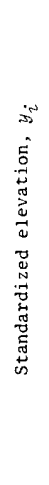 } & -2.8 & 0 & 0 & 0 & 0 & 0 & 0 & 0 & 0 & 0 & 0 & \\
\hline & -2.4 & 0 & 0 & 0 & 0 & 0 & 0 & 0 & 0 & 0 & 0 & \\
\hline & -2.0 & 0 & .0 & 0 & 0 & 0 & 0 & 0 & 0 & 0 & .0191 & \\
\hline & -1.6 & 0 & 0 & 0 & .0063 & 0 & 0 & .0063 & .0063 & .0063 & .0063 & \\
\hline & -1.2 & 0 & 0 & .0075 & 0 & .0075 & 0 & 0 & .0075 & .0075 & .0075 & \\
\hline & -0.8 & .0069 & 0 & .0069 & .0138 & .0069 & .0069 & .0069 & 0 & 0 & 0 & \\
\hline & -0.4 & 0 & .0072 & .0144 & .0072 & .0072 & 0 & .0072 & 0 & 0 & 0 & \\
\hline & 0.0 & 0 & .0148 & .0148 & 0 & 0 & .0074 & 0 & 0 & 0 & 0 & \\
\hline & 0.4 & .0068 & 0 & 0 & 0 & 0 & 0 & 0 & 0 & 0 & 0 & \\
\hline & 0.8 & 0 & 0 & 0 & 0 & 0 & 0 & 0 & 0 & 0 & 0 & \\
\hline & 1.2 & 0 & 0 & 0 & 0 & 0 & 0 & 0 & 0 & 0 & 0 & \\
\hline & 1.6 & 0 & 0 & 0 & 0 & 0 & 0 & 0 & 0 & 0 & 0 & \\
\hline & 2.0 & 0 & 0 & 0 & 0 & 0 & 0 & 0 & 0 & 0 & 0 & \\
\hline & 2.4 & 0 & 0 & 0 & 0 & 0 & 0 & 0 & 0 & 0 & 0 & \\
\hline & 2,8 & 0 & 0 & 0 & 0 & 0 & 0 & 0 & 0 & 0 & 0 & \\
\hline \multicolumn{2}{|c|}{$p_{T}\left(t_{\alpha}\right)$} & .0137 & .0220 & .0436 & .0273 & .0216 & .0143 & .0204 & .0138 & .0138 & .0329 & \\
\hline
\end{tabular}




\section{SUPPLEMENTAL DATA TABLES}

Table 10. Sample joint probabilits mass function of rest periods and elevation of deposition, $p_{T, Y_{D}}\left(t_{\alpha}, y_{i}\right)$ (Run 17)

\begin{tabular}{|c|c|c|c|c|c|c|c|c|c|c|c|c|c|}
\hline \multirow{3}{*}{\multicolumn{2}{|c|}{$\begin{array}{l}\tau_{\alpha} \\
\tau_{\alpha+1} \\
t_{\alpha}\end{array}$}} & 0 & 10 & 20 & 30 & 40 & 50 & 60 & 70 & 80 & 90 & 100 & 110 \\
\hline & & 10 & 20 & 30 & 40 & 50 & 60 & 70 & 80 & 90 & 100 & 110 & 120 \\
\hline & & 5 & 15 & 25 & 35 & 45 & 55 & 65 & 75 & 85 & 95 & 105 & 115 \\
\hline \multirow{15}{*}{ 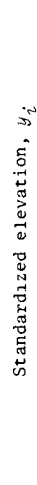 } & -2.8 & 0 & 0 & 0 & 0 & 0 & 0 & 0 & 0 & 0 & 0 & 0 & 0 \\
\hline & -2.4 & 0 & 0 & 0 & 0 & 0 & 0 & 0 & 0 & 0 & 0 & 0 & 0 \\
\hline & -2.0 & 0 & 0 & 0 & 0 & .0017 & .0017 & 0 & 0 & 0 & 0 & 0 & .0017 \\
\hline & -1.6 & .0014 & .0014 & .0014 & .0056 & .0042 & .0014 & 0 & .0014 & 0 & .0014 & .0014 & .0042 \\
\hline & -1.2 & .0029 & .0015 & .0017 & .0088 & .0146 & .0044 & .0146 & .0058 & .0029 & .0029 & .0029 & .0015 \\
\hline & -0.8 & .0085 & .0085 & .0211 & .0197 & .0226 & .0169 & .0127 & .0042 & .0028 & 0 & .0014 & .0028 \\
\hline & -0.4 & .0059 & .0220 & .0367 & .0323 & .0191 & .0162 & .0044 & .0059 & .0015 & .0029 & 0 & .0029 \\
\hline & 0.0 & .0121 & .0351 & .0392 & .0324 & .0189 & .0054 & .0081 & 0. & 0 & .0013 & .0013 & 0 \\
\hline & 0.4 & .0294 & .0476 & .0420 & .0196 & .0098 & .0042 & .0028 & 0 & 0 & 0 & 0 & 0 \\
\hline & 0.8 & .0309 & .0382 & .0294 & .0103 & .0059 & .0029 & 0 & 0 & 0 & 0 & 0 & 0 \\
\hline & 1.2 & .0312 & .0208 & .0130 & .0065 & .0013 & 0 & 0 & 0 & 0 & 0 & 0 & 0 \\
\hline & 1.6 & .0256 & .0102 & .0051 & 0 & 0 & 0 & 0 & 0 & 0 & 0 & 0 & 0 \\
\hline & 2.0 & .0137 & .0051 & 0 & 0 & 0 & 0 & 0 & 0 & 0 & 0 & 0 & 0 \\
\hline & 2.4 & .0035 & 0 & 0 & 0 & 0 & 0 & 0 & 0 & 0 & 0 & 0 & 0 \\
\hline & 2.8 & 0 & 0 & 0 & 0 & 0 & 0 & 0 & 0 & 0 & 0 & 0 & 0 \\
\hline \multicolumn{2}{|c|}{$p_{T}\left(t_{\alpha}\right)$} & .1651 & .1904 & .1996 & .1352 & .0981 & .0531 & .0426 & .0173 & .0072 & .0085 & .0070 & .0131 \\
\hline \multicolumn{2}{|c|}{$\tau_{\alpha}$} & 120 & 130 & 140 & 150 & 200 & 250 & 300 & 400 & 500 & 1,000 & 2,000 & 3,000 \\
\hline \multicolumn{2}{|c|}{$\tau_{\alpha+1}$} & 130 & 140 & 150 & 200 & 250 & 300 & 400 & 500 & 1,000 & 2,000 & 3,000 & 4,000 \\
\hline \multicolumn{2}{|c|}{$t_{\alpha}$} & 125 & 135 & 145 & 175 & 225 & 275 & 350 & 450 & 750 & 1,500 & 2,500 & 3,500 \\
\hline \multirow{15}{*}{ 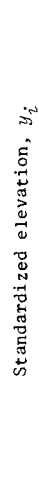 } & -2.8 & 0 & 0 & 0 & 0 & 0 & 0 & 0 & 0 & 0 & 0 & 0 & 0 \\
\hline & -2.4 & 0 & 0 & .0018 & 0 & .0018 & 0 & 0 & 0 & 0 & 0 & 0 & .0018 \\
\hline & -2.0 & .0017 & .0017 & 0 & 0 & 0 & .0017 & 0 & .0017 & .0017 & .0017 & .0017 & 0 \\
\hline & -1.6 & 0 & .0014 & .0014 & .0014 & .0070 & .0014 & .0014 & .0028 & .0028 & 0 & 0 & 0 \\
\hline & -1.2 & .0015 & .0015 & 0 & .0029 & .0029 & 0 & .0029 & .0015 & .0015 & 0 & 0 & 0 \\
\hline & -0.8 & 0 & .0014 & .0014 & .0028 & 0 & .0014 & .0014 & 0 & 0 & 0 & 0 & 0 \\
\hline & -0.4 & .0015 & 0 & 0 & 0 & 0 & .0015 & 0 & 0 & 0 & 0 & 0 & 0 \\
\hline & 0.0 & 0 & 0 & 0 & 0 & 0 & 0 & 0 & 0 & 0 & 0 & 0 & 0 \\
\hline & 0.4 & 0 & 0 & 0 & 0 & 0 & 0 & 0 & 0 & 0 & 0 & 0 & 0 \\
\hline & 0.8 & 0 & 0 & 0 & 0 & 0 & 0 & 0 & 0 & 0 & 0 & 0 & 0 \\
\hline & 1.2 & 0 & 0 & 0 & 0 & 0 & 0 & 0 & 0 & 0 & 0 & 0 & 0 \\
\hline & 1.6 & 0 & 0 & 0 & 0 & 0 & 0 & 0 & 0 & 0 & 0 & 0 & 0 \\
\hline & 2.0 & 0 & 0 & 0 & 0 & 0 & 0 & 0 & 0 & 0 & 0 & 0 & 0 \\
\hline & 2.4 & 0 & 0 & 0 & 0 & 0 & 0 & 0 & 0 & 0 & 0 & 0 & 0 \\
\hline & 2.8 & 0 & 0 & 0 & 0 & 0 & 0 & 0 & 0 & 0 & 0 & 0 & 0 \\
\hline \multicolumn{2}{|c|}{$p_{T}\left(t_{\alpha}\right)$} & .0047 & .0060 & .0046 & .0071 & .0117 & .0060 & .0057 & .0060 & .0060 & .0017 & .0017 & .0018 \\
\hline
\end{tabular}

Note: $\tau_{\alpha}, \tau_{\alpha+1}$, and $t_{\alpha}$ are in minutes. 

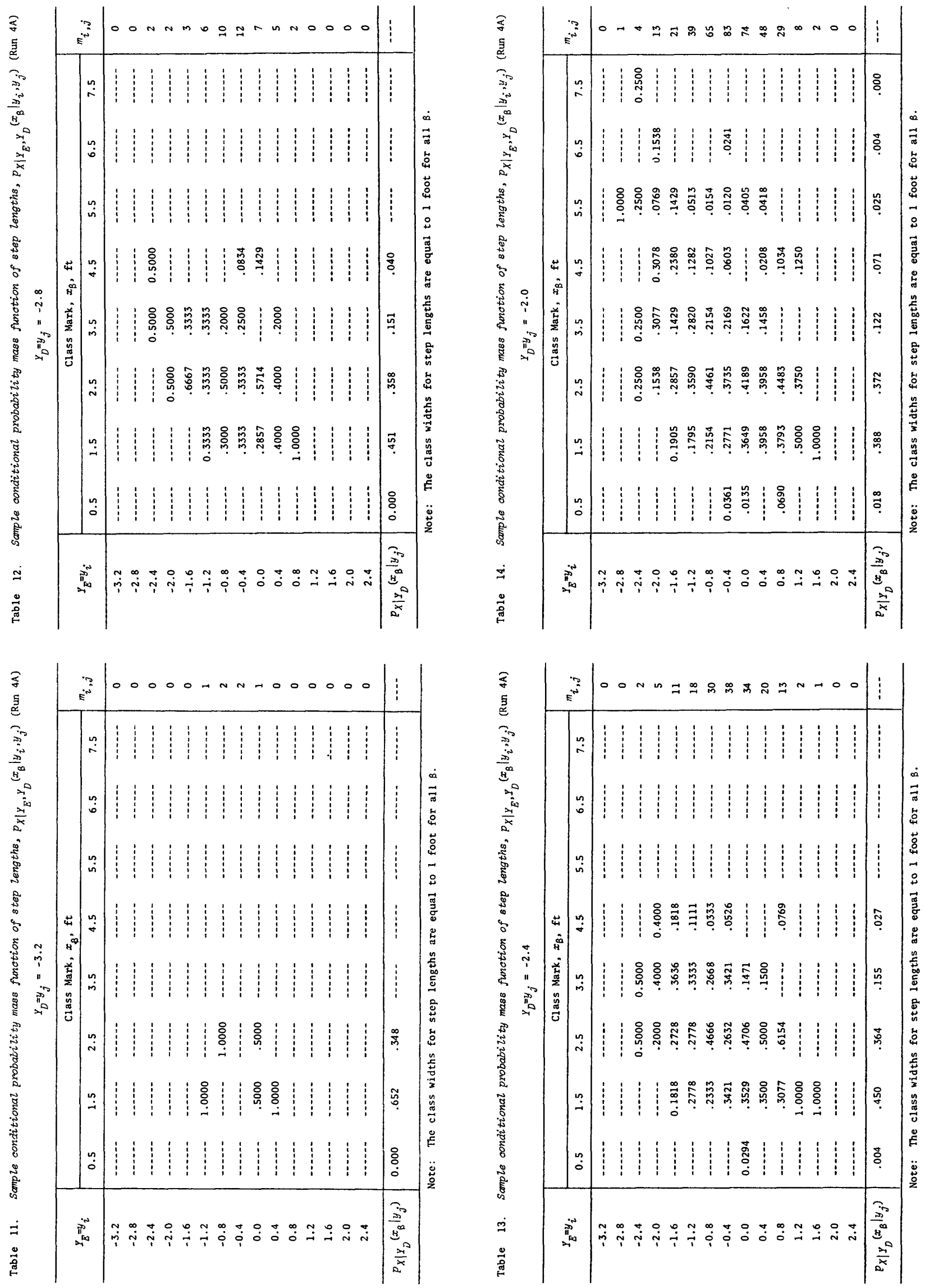

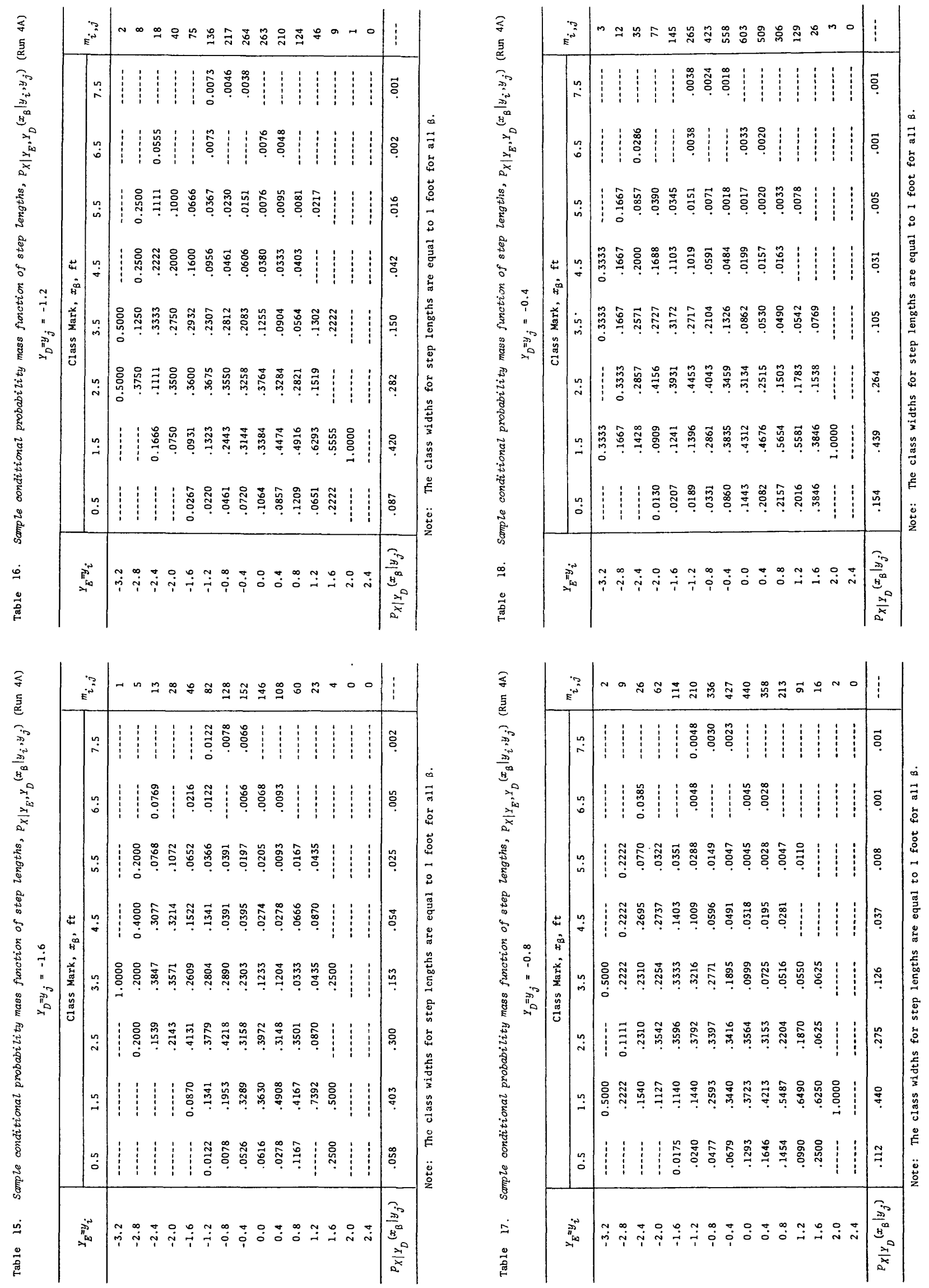

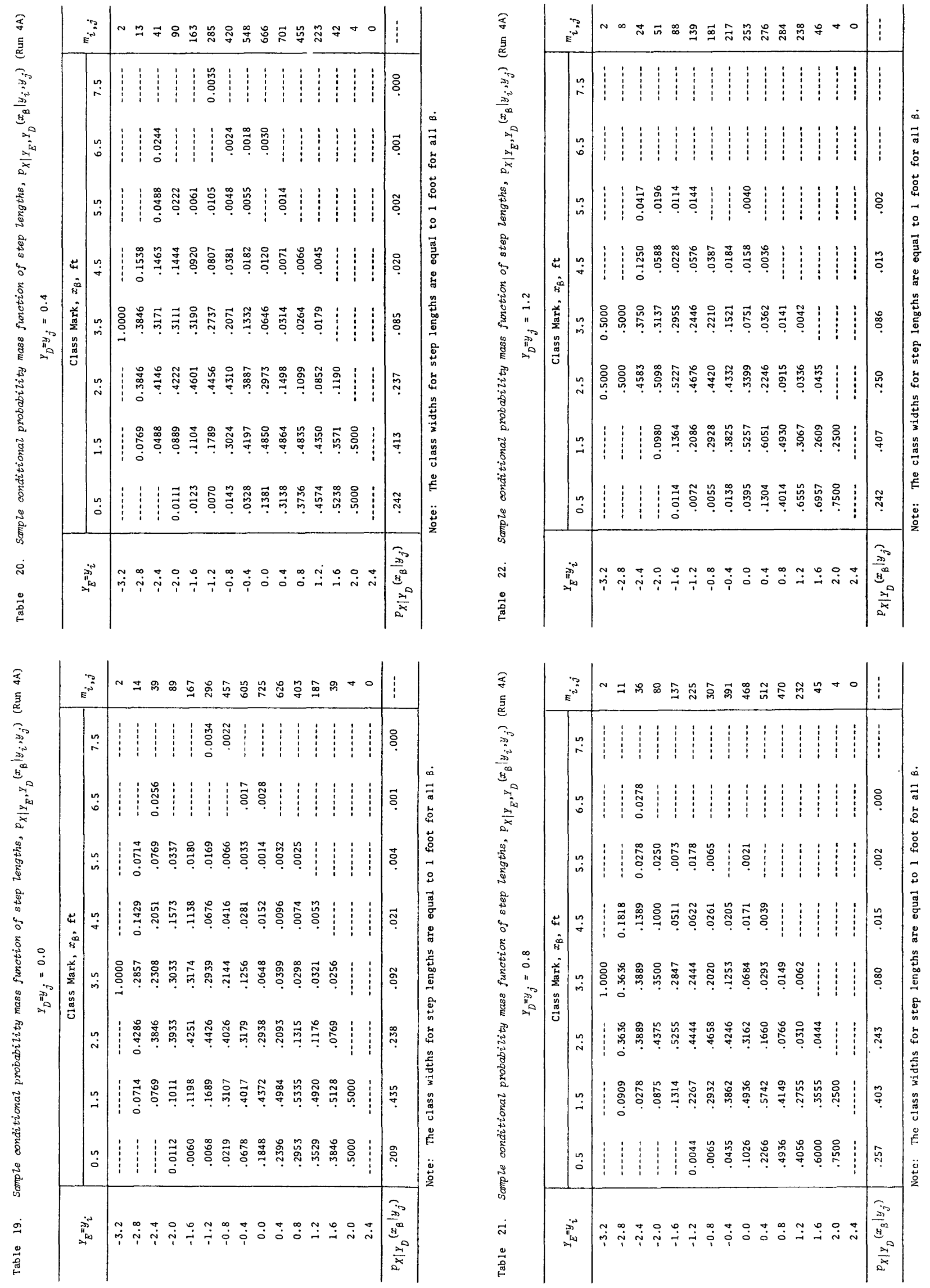

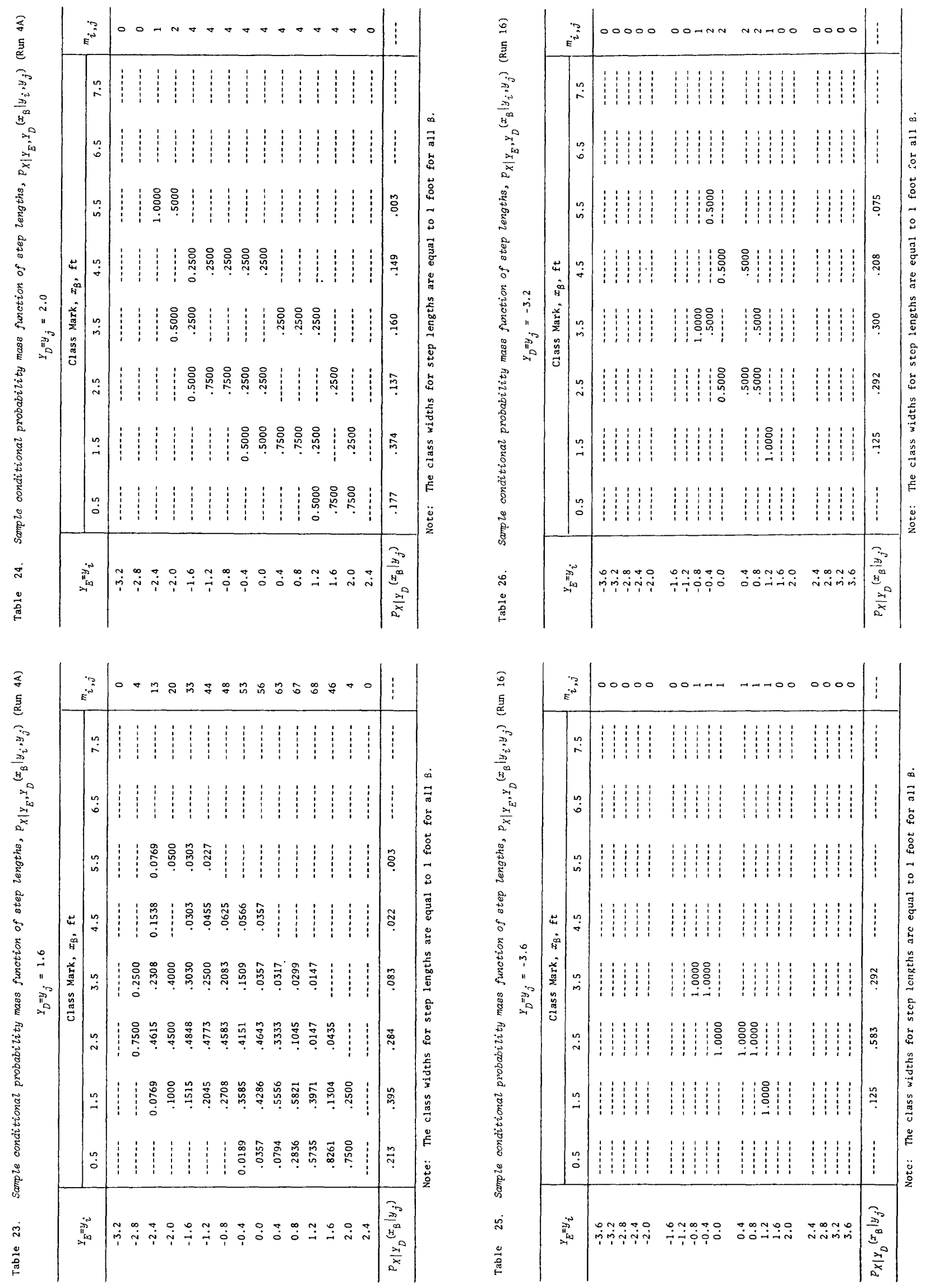

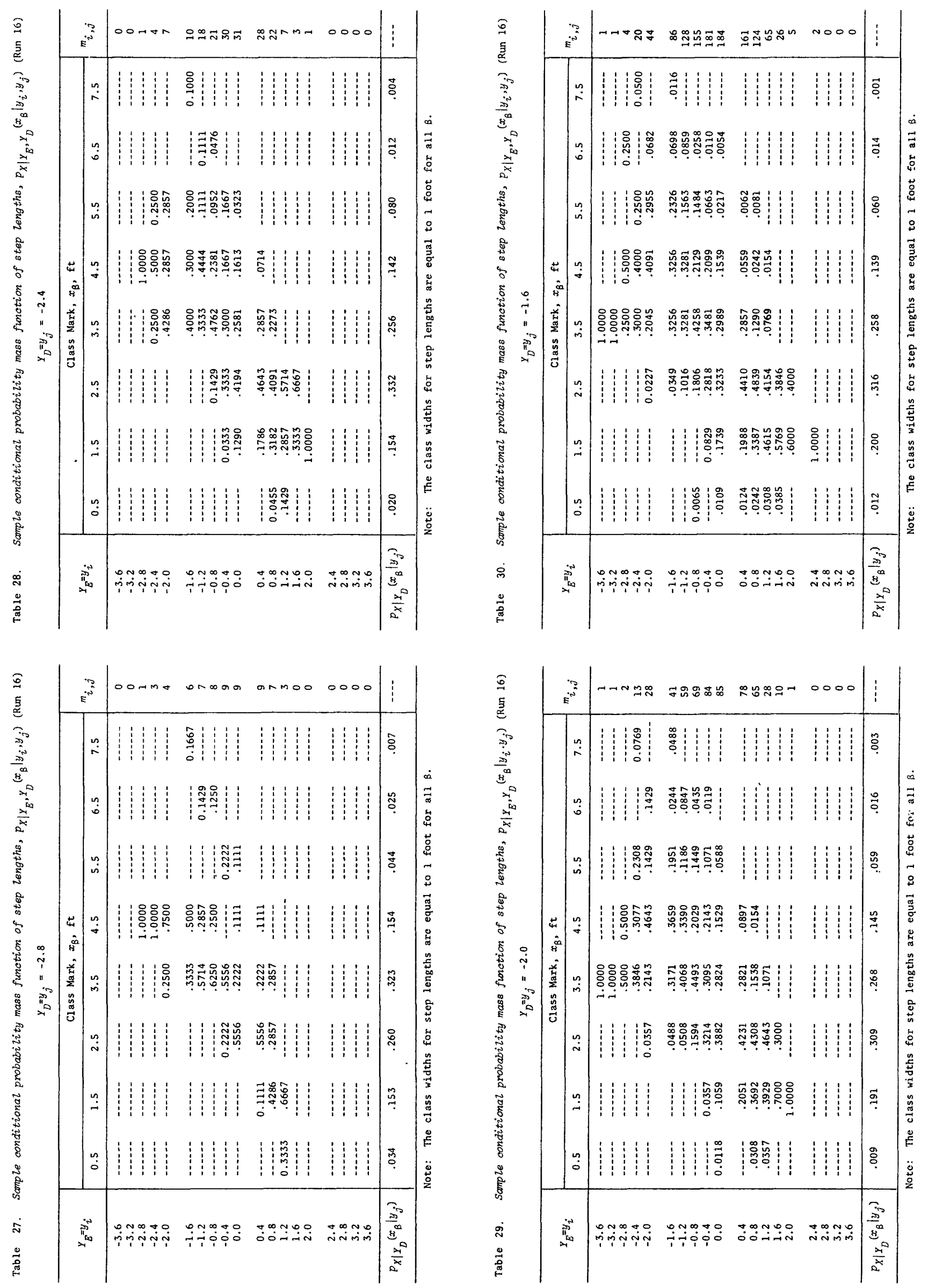

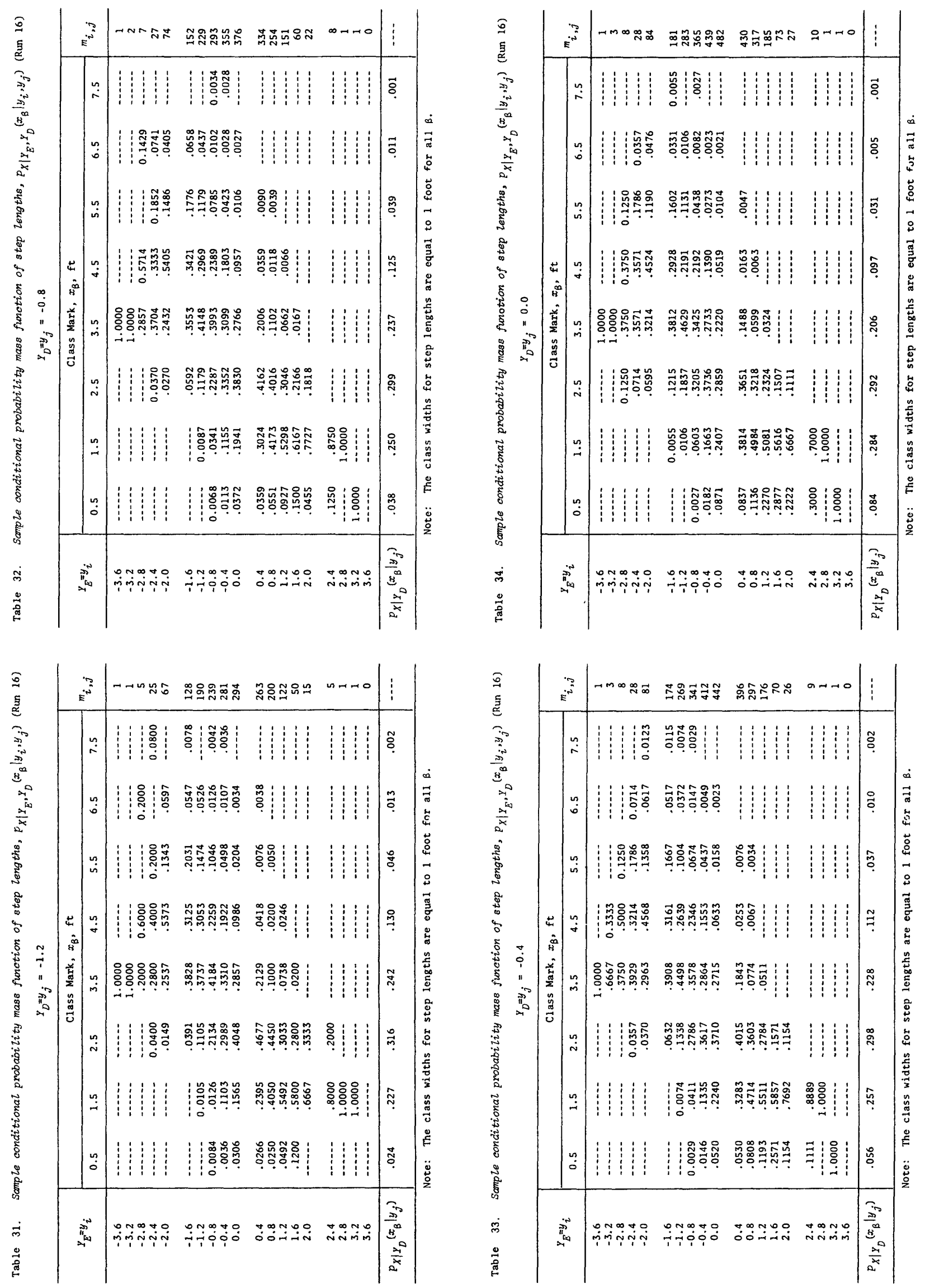

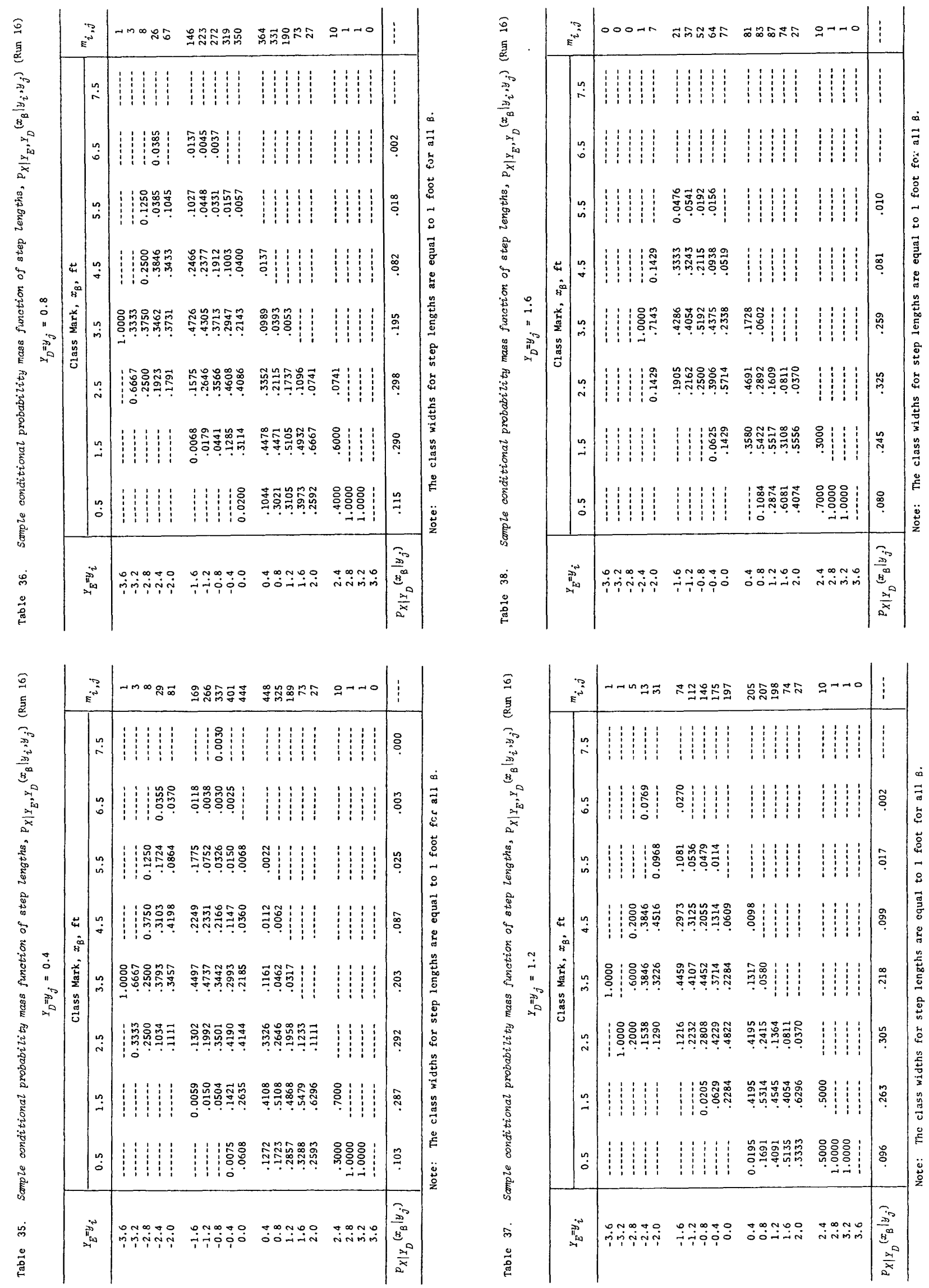

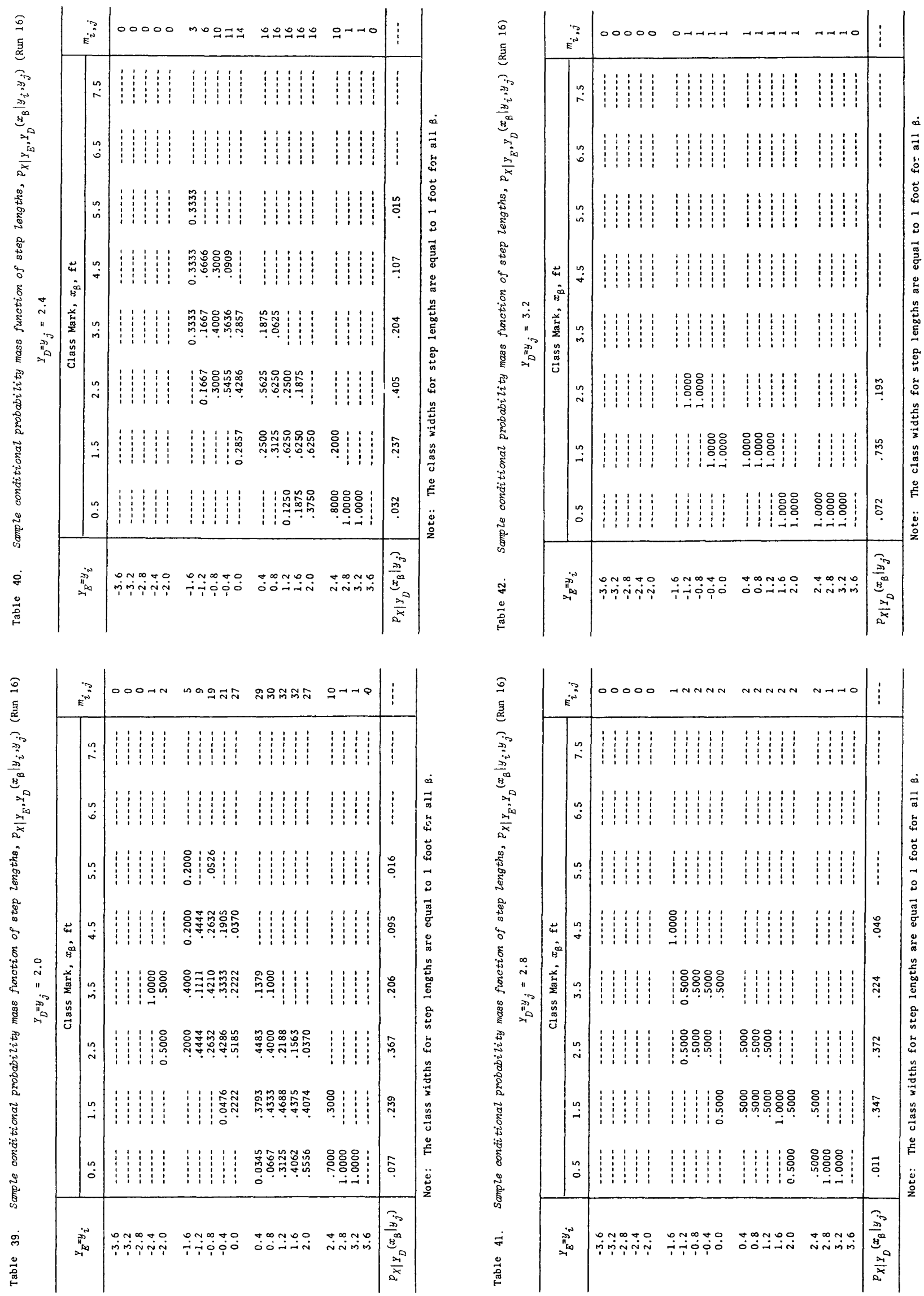

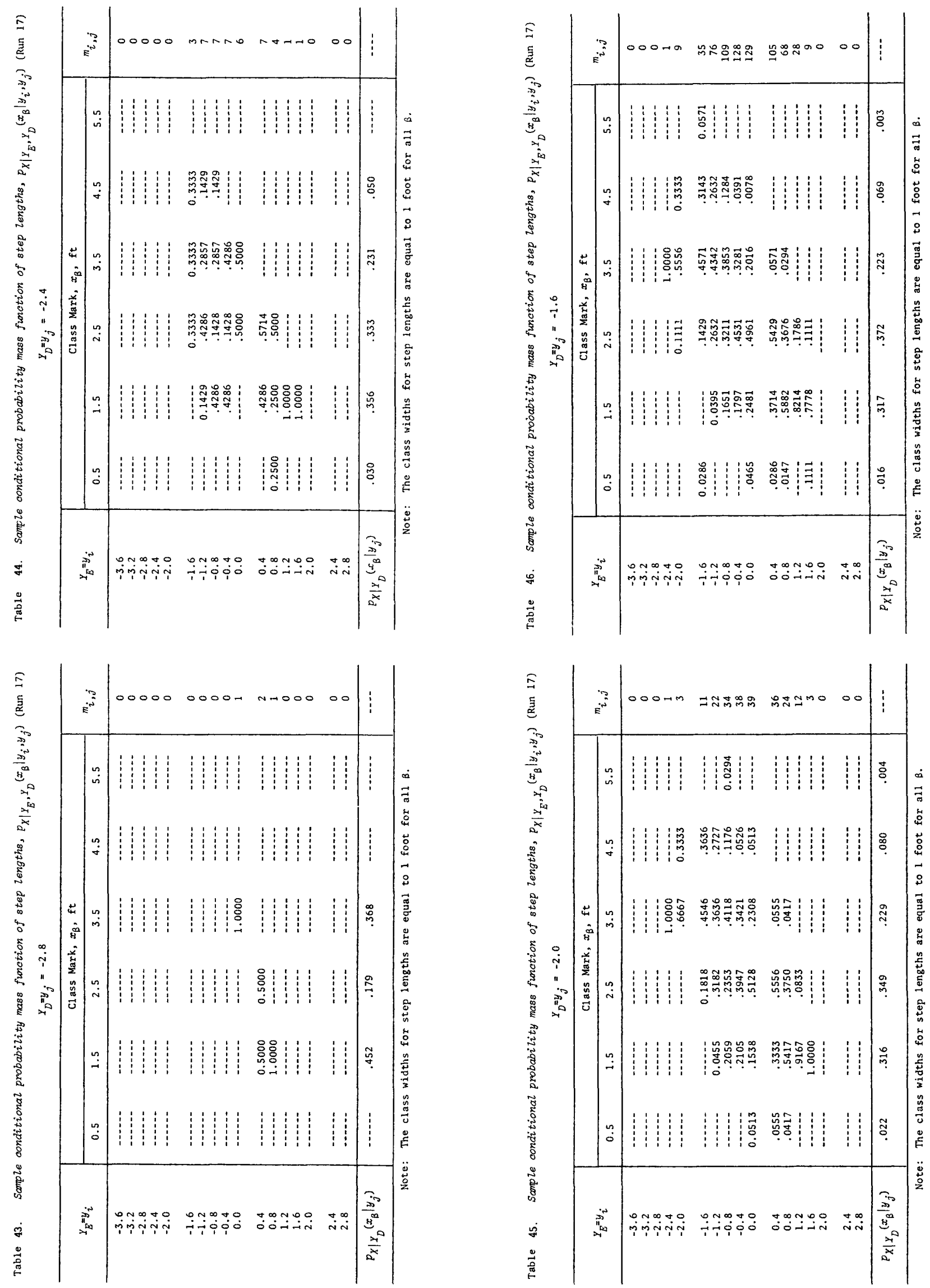

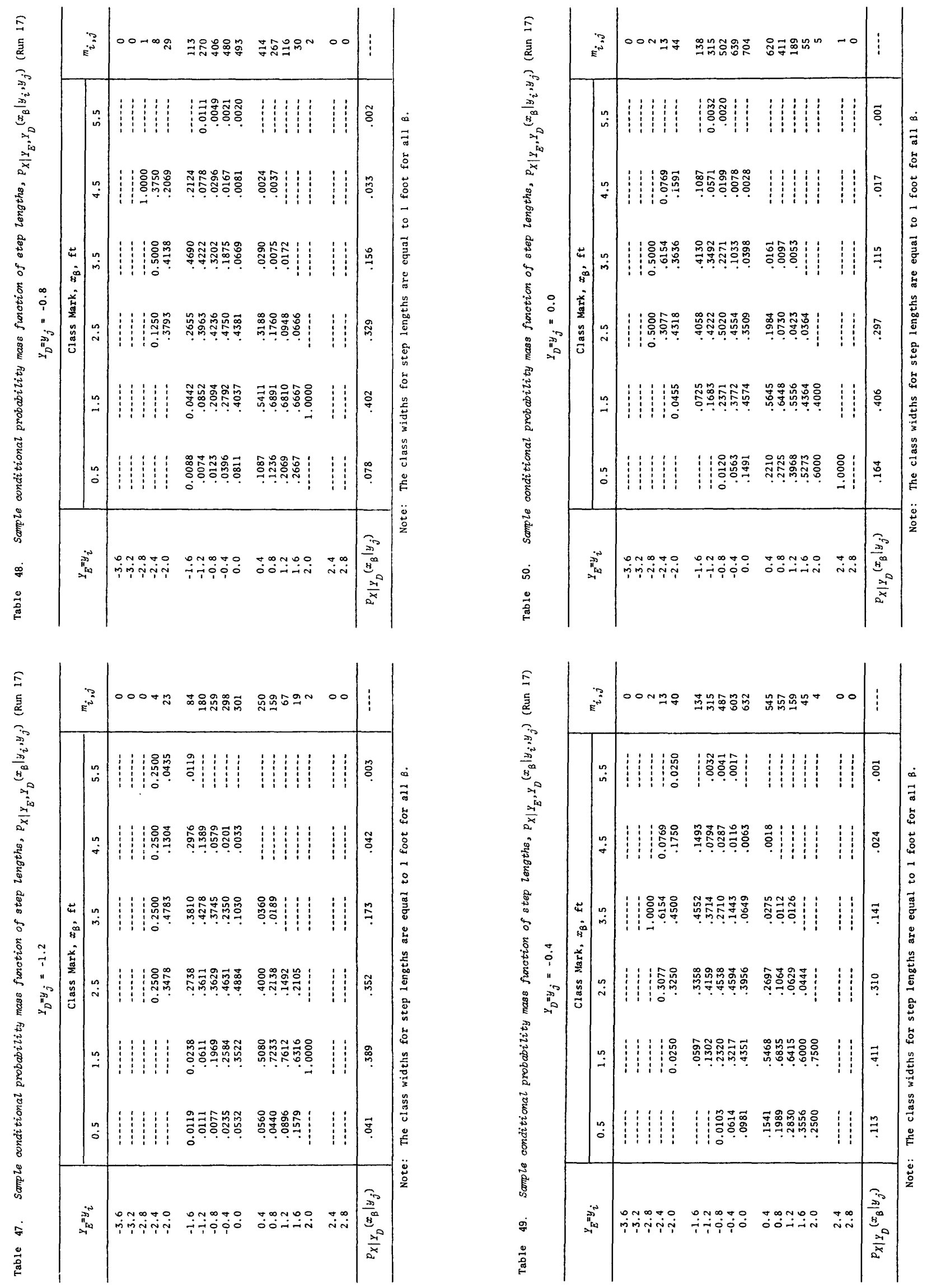

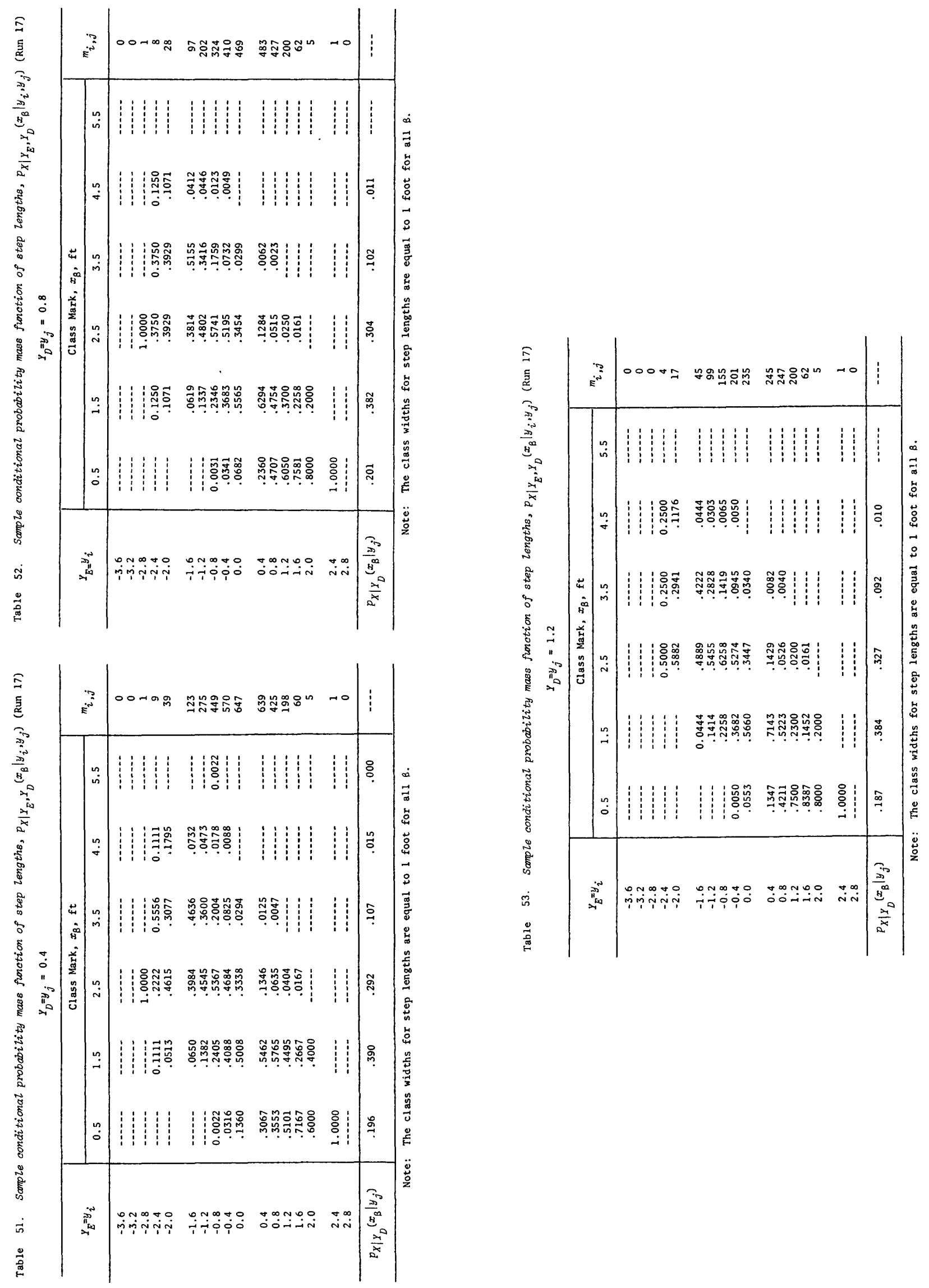

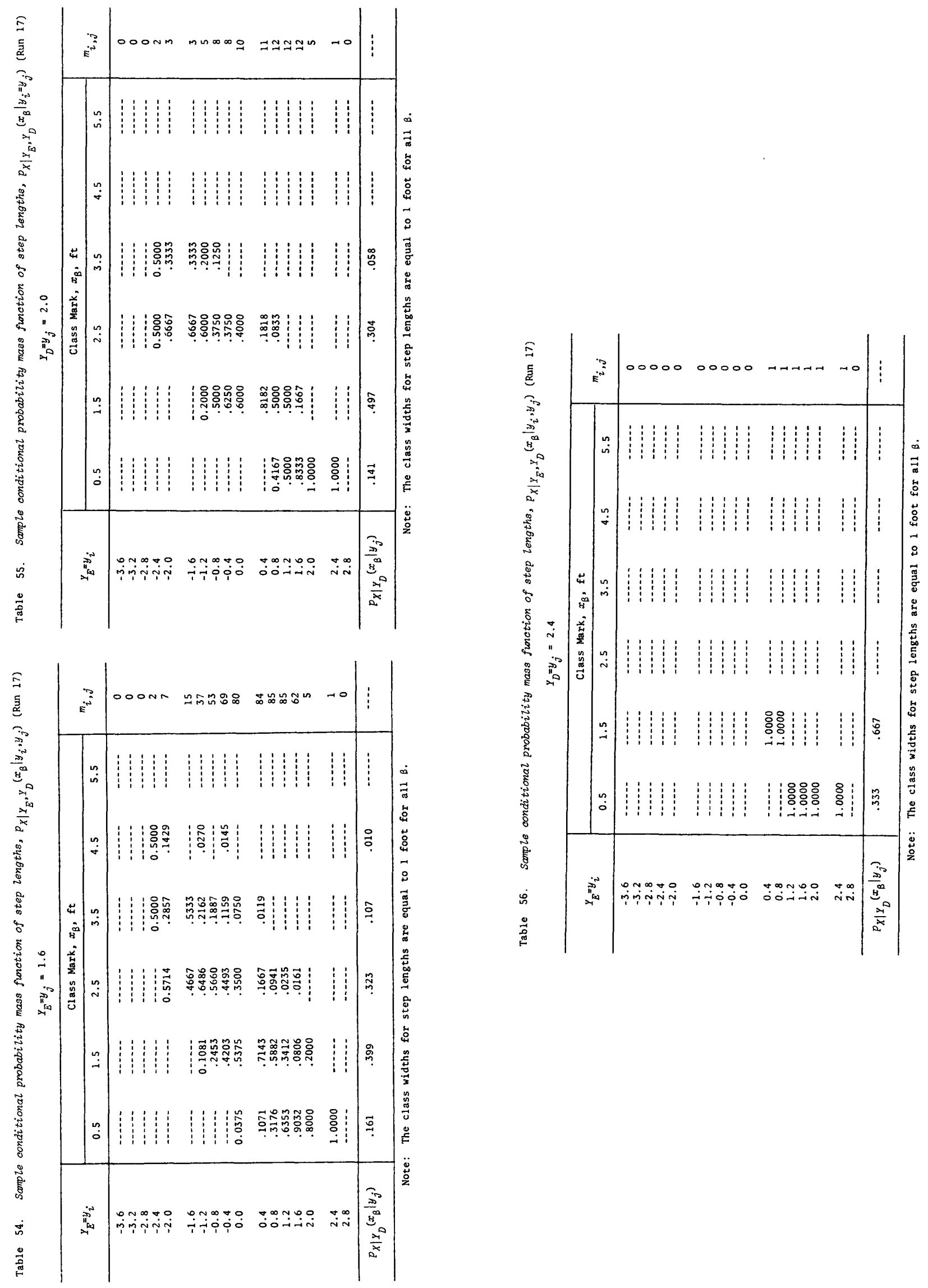
Table 57. Conditional meane and varionces of step lengtho; $\hat{E}\left[x \mid y_{E}=y_{i}, x_{D}=y_{j}\right]$ and $\widehat{\operatorname{Var}}\left[x \mid y_{E}=y_{i}, y_{D}=y_{j}\right]$ (Run 4A)

\begin{tabular}{|c|c|c|c|c|c|c|c|c|c|c|c|c|c|c|c|c|}
\hline$y_{i}$ & -3.6 & -3.2 & -2.8 & -2.4 & -2.0 & -1.6 & -1.2 & -0.8 & -0.4 & 0.0 & 0.4 & 0.8 & 1.2 & 1.6 & 2.0 & 2.4 \\
\hline-3.6 & -.... & $-\cdots$ & -.-.- & $\ldots$ & --- & $\ldots$ & --- & -... & 4.189 & 4.057 & 4.000 & 3.934 & 3.857 & ...... & $-\cdots$ & - \\
\hline-3.2 & $-\cdots$ & $-\cdots$ & ---- & $-\cdots$ & $\cdots$ & $\begin{array}{l}3.974 \\
-\cdots\end{array}$ & $\begin{array}{l}3.038 \\
1.246\end{array}$ & $\begin{array}{l}2.842 \\
1.417\end{array}$ & $\begin{array}{l}3.150 \\
1.235\end{array}$ & $\begin{array}{r}3.647 \\
.101\end{array}$ & $\begin{array}{r}3.549 \\
.141\end{array}$ & $\begin{array}{r}3.440 \\
.191\end{array}$ & $\begin{array}{r}3.283 \\
.302\end{array}$ & $-\cdots$ & - & $\ldots$ \\
\hline-2.8 & --..- & $-\cdots$ & … & a... & $\begin{array}{l}5.792 \\
-\end{array}$ & $\begin{array}{l}4.172 \\
1.570\end{array}$ & $\begin{array}{l}3.823 \\
2.148\end{array}$ & $\begin{array}{l}3.620 \\
1.918\end{array}$ & $\begin{array}{l}3.385 \\
1.529\end{array}$ & $\begin{array}{l}3.239 \\
1.021\end{array}$ & $\begin{array}{r}3.207 \\
.839\end{array}$ & $\begin{array}{r}3.195 \\
.941\end{array}$ & $\begin{array}{r}2.965 \\
.360\end{array}$ & $\begin{array}{r}2.768 \\
.395\end{array}$ & -... & \\
\hline-2.4 & $-\cdots$ & $\cdots$ & $\begin{array}{r}3.636 \\
.373\end{array}$ & $\begin{array}{r}3.215 \\
.132\end{array}$ & $\begin{array}{l}4.730 \\
3.957\end{array}$ & $\begin{array}{l}4.024 \\
1.500\end{array}$ & $\begin{array}{l}3.605 \\
1.849\end{array}$ & $\begin{array}{l}3.476 \\
1.768\end{array}$ & $\begin{array}{l}3.409 \\
1.684\end{array}$ & $\begin{array}{l}3.459 \\
1.357\end{array}$ & $\begin{array}{l}3.357 \\
1.156\end{array}$ & $\begin{array}{r}3.309 \\
.966\end{array}$ & $\begin{array}{r}3.184 \\
.743\end{array}$ & $\begin{array}{r}3.199 \\
.985\end{array}$ & 5.346 & \\
\hline-2.0 & -... & -- & $\begin{array}{r}3.298 \\
.605\end{array}$ & $\begin{array}{r}3.843 \\
.978\end{array}$ & $\begin{array}{l}4.214 \\
1.409\end{array}$ & $\begin{array}{r}3.771 \\
.986\end{array}$ & $\begin{array}{l}3.407 \\
1.133\end{array}$ & $\begin{array}{l}3.261 \\
1.074\end{array}$ & $\begin{array}{l}3.133 \\
1.069\end{array}$ & $\begin{array}{r}3.102 \\
.872\end{array}$ & $\begin{array}{r}3.036 \\
.783\end{array}$ & $\begin{array}{r}2.935 \\
.665\end{array}$ & $\begin{array}{r}2.909 \\
.557\end{array}$ & $\begin{array}{r}3.000 \\
.707\end{array}$ & $\begin{array}{l}4.308 \\
1.503\end{array}$ & \\
\hline-1.6 & 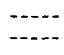 & $\cdots$ & $\begin{array}{r}2.848 \\
.507\end{array}$ & $\begin{array}{l}2.944 \\
1.114\end{array}$ & $\begin{array}{l}3.417 \\
1.665\end{array}$ & $\begin{array}{l}3.239 \\
1.175\end{array}$ & $\begin{array}{l}3.173 \\
1.176\end{array}$ & $\begin{array}{r}3.076 \\
.991\end{array}$ & $\begin{array}{r}2.989 \\
.974\end{array}$ & $\begin{array}{r}2.956 \\
.779\end{array}$ & $\begin{array}{r}2.898 \\
.714\end{array}$ & $\begin{array}{r}2.804 \\
.599\end{array}$ & $\begin{array}{r}2.773 \\
.555\end{array}$ & $\begin{array}{r}2.820 \\
.559\end{array}$ & $\begin{array}{r}3.485 \\
.987\end{array}$ & \\
\hline-1.2 & $\ldots$ & 2.861 & $\begin{array}{r}2.704 \\
.766\end{array}$ & $\begin{array}{l}2.848 \\
1.009\end{array}$ & $\begin{array}{l}3.018 \\
1.125\end{array}$ & $\begin{array}{l}3.136 \\
1.439\end{array}$ & $\begin{array}{l}3.063 \\
1.390\end{array}$ & $\begin{array}{l}2.976 \\
1.210\end{array}$ & $\begin{array}{l}2.854 \\
1.046\end{array}$ & $\begin{array}{r}2.808 \\
.872\end{array}$ & $\begin{array}{r}2.785 \\
.806\end{array}$ & $\begin{array}{r}2.717 \\
.726\end{array}$ & $\begin{array}{r}2.710 \\
.682\end{array}$ & $\begin{array}{r}2.733 \\
.669\end{array}$ & $\begin{array}{l}3.175 \\
1.055\end{array}$ & \\
\hline-0.8 & -.... & $\begin{array}{r}2.611 \\
.054\end{array}$ & $\begin{array}{r}2.478 \\
.392\end{array}$ & $\begin{array}{r}2.588 \\
.620\end{array}$ & $\begin{array}{r}2.747 \\
.942\end{array}$ & $\begin{array}{l}2.785 \\
1.137\end{array}$ & $\begin{array}{l}2.653 \\
1.145\end{array}$ & $\begin{array}{l}2.583 \\
1.063\end{array}$ & $\begin{array}{r}2.505 \\
.887\end{array}$ & $\begin{array}{r}2.498 \\
.759\end{array}$ & $\begin{array}{r}2.507 \\
.683\end{array}$ & $\begin{array}{r}2.466 \\
.623\end{array}$ & $\begin{array}{r}2.503 \\
.603\end{array}$ & $\begin{array}{r}2.562 \\
.669\end{array}$ & $\begin{array}{l}2.879 \\
1.155\end{array}$ & \\
\hline-0.4 & $--\cdot$ & $\begin{array}{r}2.082 \\
.098\end{array}$ & $\begin{array}{r}2.434 \\
.836\end{array}$ & $\begin{array}{r}2.506 \\
.796\end{array}$ & $\begin{array}{l}2.589 \\
1.251\end{array}$ & $\begin{array}{l}2.519 \\
1.229\end{array}$ & $\begin{array}{l}2.455 \\
1.197\end{array}$ & $\begin{array}{l}2.336 \\
1.001\end{array}$ & $\begin{array}{r}2.180 \\
.925\end{array}$ & $\begin{array}{r}2.170 \\
.772\end{array}$ & $\begin{array}{r}2.197 \\
.656\end{array}$ & $\begin{array}{r}2.205 \\
.602\end{array}$ & $\begin{array}{r}2.275 \\
.563\end{array}$ & $\begin{array}{r}2.360 \\
.653\end{array}$ & $\begin{array}{l}2.604 \\
1.225\end{array}$ & --- \\
\hline 0.0 & -...- & 1.892 & $\begin{array}{r}2.557 \\
.609\end{array}$ & $\begin{array}{r}2.300 \\
.584\end{array}$ & $\begin{array}{l}2.400 \\
1.011\end{array}$ & $\begin{array}{l}2.274 \\
1.069\end{array}$ & $\begin{array}{l}2.221 \\
1.084\end{array}$ & $\begin{array}{r}2.083 \\
.950\end{array}$ & $\begin{array}{r}1.929 \\
.854\end{array}$ & $\begin{array}{r}1.797 \\
.813\end{array}$ & $\begin{array}{r}1.843 \\
.666\end{array}$ & $\begin{array}{r}1.916 \\
.581\end{array}$ & $\begin{array}{r}2.006 \\
.542\end{array}$ & $\begin{array}{r}2.081 \\
.540\end{array}$ & $\begin{array}{l}2.350 \\
1.296\end{array}$ & $\cdots$ \\
\hline 0.4 & --- & $\cdots$ & $\begin{array}{r}2.312 \\
.943\end{array}$ & $\begin{array}{r}2.289 \\
.401\end{array}$ & $\begin{array}{r}2.365 \\
.985\end{array}$ & $\begin{array}{r}2.159 \\
.986\end{array}$ & $\begin{array}{r}2.054 \\
.910\end{array}$ & $\begin{array}{r}1.903 \\
.771\end{array}$ & $\begin{array}{r}1.728 \\
.723\end{array}$ & $\begin{array}{r}1.595 \\
.652\end{array}$ & $\begin{array}{r}1.437 \\
.637\end{array}$ & $\begin{array}{r}1.521 \\
.495\end{array}$ & $\begin{array}{r}1.661 \\
.435\end{array}$ & $\begin{array}{r}1.774 \\
.429\end{array}$ & $\begin{array}{l}2.087 \\
1.192\end{array}$ & $-\cdots$ \\
\hline 0.8 & -..- & - & $\begin{array}{r}1.692 \\
.010\end{array}$ & $\begin{array}{r}2.133 \\
.892\end{array}$ & $\begin{array}{l}2.257 \\
1.076\end{array}$ & $\begin{array}{l}2.108 \\
1.091\end{array}$ & $\begin{array}{r}1.933 \\
.837\end{array}$ & $\begin{array}{r}1.775 \\
.690\end{array}$ & $\begin{array}{r}1.604 \\
.634\end{array}$ & $\begin{array}{r}1.439 \\
.550\end{array}$ & $\begin{array}{r}1.306 \\
.485\end{array}$ & $\begin{array}{r}1.127 \\
.416\end{array}$ & $\begin{array}{r}1.244 \\
.367\end{array}$ & $\begin{array}{r}1.394 \\
.357\end{array}$ & $\begin{array}{l}1.829 \\
1.106\end{array}$ & -... \\
\hline 1.2 & -..- & $\cdots$ & -...- & $\begin{array}{r}1.731 \\
.020\end{array}$ & $\begin{array}{r}2.279 \\
.755\end{array}$ & $\begin{array}{l}2.188 \\
1.127\end{array}$ & $\begin{array}{r}1.903 \\
.889\end{array}$ & $\begin{array}{r}1.756 \\
.626\end{array}$ & $\begin{array}{r}1.581 \\
.608\end{array}$ & $\begin{array}{r}1.373 \\
.501\end{array}$ & $\begin{array}{r}1.203 \\
.429\end{array}$ & $\begin{array}{r}1.036 \\
.313\end{array}$ & $\begin{array}{l}.870 \\
.301\end{array}$ & $\begin{array}{l}.968 \\
.297\end{array}$ & $\begin{array}{l}1.508 \\
1.035\end{array}$ & … \\
\hline 1.6 & --.- & - & - & $\begin{array}{l}1.430 \\
-. .\end{array}$ & $\begin{array}{r}1.518 \\
.241\end{array}$ & $\begin{array}{l}1.779 \\
1.693\end{array}$ & $\begin{array}{r}1.687 \\
.942\end{array}$ & $\begin{array}{r}1.558 \\
.539\end{array}$ & $\begin{array}{r}1.503 \\
.646\end{array}$ & $\begin{array}{r}1.288 \\
.424\end{array}$ & $\begin{array}{r}1.142 \\
.397\end{array}$ & $\begin{array}{l}.932 \\
.273\end{array}$ & $\begin{array}{l}.812 \\
.275\end{array}$ & $\begin{array}{l}.595 \\
.270\end{array}$ & $\begin{array}{r}1.081 \\
.829\end{array}$ & -... \\
\hline 2.0 & $-\cdots$ & - & $-\cdots$ & $-\cdots$ & 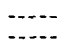 & -..-- & 1.670 & $\begin{array}{r}1.377 \\
.000\end{array}$ & $\begin{array}{r}1.375 \\
.084\end{array}$ & $\begin{array}{r}1.086 \\
.120\end{array}$ & $\begin{array}{l}.954 \\
.125\end{array}$ & $\begin{array}{l}.869 \\
.128\end{array}$ & $\begin{array}{l}.785 \\
.132\end{array}$ & $\begin{array}{l}.687 \\
.147\end{array}$ & $\begin{array}{l}.460 \\
.203\end{array}$ & -... \\
\hline 2.4 & $-\cdots$ & $\cdots$ & -...- & $\cdots$ & $-\ldots$ & $\ldots$ & $-\cdots$ & -...- & $-\cdots$ & -...- & $-\cdots$ & $-\cdots$ & - & $\cdots$ & -...- & $\cdots$ \\
\hline$\hat{E}\left[X \mid Y_{D}=y_{j}\right]$ & $-\cdots$ & 1.194 & 2.172 & 2. 397 & 2.577 & 2.486 & 2.384 & 2.257 & 2.119 & 2.025 & 1.972 & 1.938 & 1.983 & 2.056 & 2.458 & $\cdots$ \\
\hline $\operatorname{Varr}\left[X \mid Y_{D}=y_{j}\right]$ & -.. & 1.396 & 1.232 & .884 & 1.376 & 1.415 & 1.277 & 1.141 & 1.084 & 1.035 & 1.008 & .935 & .892 & .915 & 1.671 & .... \\
\hline
\end{tabular}

Note: Upper values are the means, in feet, and lower values are the variances, in feet squared. 
Table 58. Conditional means and varianoes of step lengthe; $\hat{\varepsilon}\left[x \mid Y_{E}=y_{i}, Y_{D}=y_{j}\right]$ and $\widehat{\operatorname{Var}}\left[x \mid Y_{E}=y_{i}, Y_{D}=y_{j}\right]$ (Run 16)

\begin{tabular}{|c|c|c|c|c|c|c|c|c|c|c|c|c|c|c|c|c|c|c|}
\hline${ }_{y_{E}}=y_{i} Y_{D}=y_{j}$ & -3.6 & -3.2 & -2.8 & -2.4 & -2.0 & -1.6 & -1.2 & -0.8 & -0.4 & 0.0 & 0.4 & 0.8 & 1.2 & 1.6 & 2,0 & 2.4 & 2.8 & 3.2 \\
\hline-3.6 & - & --.- & -... & ---.. & 3.655 & 3.592 & 3.531 & $\begin{array}{l}3.469 \\
-\ldots\end{array}$ & 3.407 & 3.338 & $\begin{array}{l}3.263 \\
-\ldots\end{array}$ & 3.186 & 3.111 & $-\cdots$ & - & -..- & - & $-\cdots$ \\
\hline-3.2 & ----- & $-\ldots$ & -...- & $\cdots$ & 3.442 & $\begin{array}{l}3.379 \\
-\end{array}$ & $\begin{array}{l}3.318 \\
-\ldots\end{array}$ & $\begin{array}{r}3.496 \\
.115\end{array}$ & $\begin{array}{r}3.594 \\
.164\end{array}$ & $\begin{array}{r}3.427 \\
.091\end{array}$ & $\begin{array}{r}3.102 \\
.026\end{array}$ & $\begin{array}{r}3.042 \\
.051\end{array}$ & $\begin{array}{l}2.897 \\
-\end{array}$ & - & -...- & --- & - & -..... \\
\hline-2.8 & - & $-\cdots$ & $\begin{array}{l}4.600 \\
-\end{array}$ & $\begin{array}{l}4.516 \\
-\end{array}$ & $\begin{array}{r}3.852 \\
.678\end{array}$ & $\begin{array}{l}4.551 \\
1.068\end{array}$ & $\begin{array}{l}4.447 \\
1.179\end{array}$ & $\begin{array}{r}4.293 \\
.930\end{array}$ & $\begin{array}{r}4.142 \\
.832\end{array}$ & $\begin{array}{r}4.027 \\
.868\end{array}$ & $\begin{array}{l}3.833 \\
1.047\end{array}$ & $\begin{array}{r}3.696 \\
.983\end{array}$ & $\begin{array}{r}3.830 \\
.573\end{array}$ & - & -...- & $\cdots$ & -...- & ---- \\
\hline-2.4 & ---- & -... & $\begin{array}{r}4.334 \\
.032\end{array}$ & $\begin{array}{r}4.415 \\
.467\end{array}$ & $\begin{array}{l}4.548 \\
1.059\end{array}$ & $\begin{array}{r}4.612 \\
.979\end{array}$ & $\begin{array}{l}4.621 \\
1.077\end{array}$ & $\begin{array}{l}4.480 \\
1.053\end{array}$ & $\begin{array}{l}4.363 \\
1.001\end{array}$ & $\begin{array}{r}4.217 \\
.869\end{array}$ & $\begin{array}{r}4.063 \\
.892\end{array}$ & $\begin{array}{r}3.905 \\
.913\end{array}$ & $\begin{array}{r}3.909 \\
.843\end{array}$ & 3.098 & 3.051 & -... & -...- & --- \\
\hline-2.0 & $-\cdots$ & $-\ldots$ & $\begin{array}{r}4.185 \\
.067\end{array}$ & $\begin{array}{r}4.477 \\
.545\end{array}$ & $\begin{array}{r}4.623 \\
.809\end{array}$ & $\begin{array}{r}4.626 \\
.760\end{array}$ & $\begin{array}{r}4.514 \\
.699\end{array}$ & $\begin{array}{r}4.437 \\
.752\end{array}$ & $\begin{array}{r}4.399 \\
.904\end{array}$ & $\begin{array}{r}4.223 \\
.746\end{array}$ & $\begin{array}{r}4.083 \\
.728\end{array}$ & $\begin{array}{r}3.931 \\
.716\end{array}$ & $\begin{array}{r}4.012 \\
.656\end{array}$ & $\begin{array}{r}3.591 \\
.199\end{array}$ & $\begin{array}{r}3.126 \\
.223\end{array}$ & $\cdots$ & - & $-\cdots$ \\
\hline-1.6 & ---- & --- & $\begin{array}{l}4.649 \\
1.942\end{array}$ & $\begin{array}{l}4.646 \\
1.396\end{array}$ & $\begin{array}{l}4.438 \\
1.074\end{array}$ & $\begin{array}{l}4.524 \\
1.032\end{array}$ & $\begin{array}{r}4.369 \\
.931\end{array}$ & $\begin{array}{r}4.327 \\
.950\end{array}$ & $\begin{array}{l}4.261 \\
1.067\end{array}$ & $\begin{array}{r}4.075 \\
.953\end{array}$ & $\begin{array}{r}3.981 \\
.829\end{array}$ & $\begin{array}{r}3.834 \\
.790\end{array}$ & $\begin{array}{r}3.987 \\
.733\end{array}$ & $\begin{array}{r}3.851 \\
.620\end{array}$ & $\begin{array}{l}3.816 \\
1.163\end{array}$ & $\begin{array}{r}4.430 \\
.858\end{array}$ & $\begin{array}{l}4.379 \\
-\end{array}$ & --- \\
\hline-1.2 & ---- & --- & $\begin{array}{l}4.390 \\
1.397\end{array}$ & $\begin{array}{l}4.513 \\
1.076\end{array}$ & $\begin{array}{l}4.295 \\
1.038\end{array}$ & $\begin{array}{l}4.269 \\
1.079\end{array}$ & $\begin{array}{r}4.113 \\
.960\end{array}$ & $\begin{array}{r}4.039 \\
.918\end{array}$ & $\begin{array}{r}3.942 \\
.978\end{array}$ & $\begin{array}{r}3.783 \\
.880\end{array}$ & $\begin{array}{r}3.694 \\
.748\end{array}$ & $\begin{array}{r}3.562 \\
.705\end{array}$ & $\begin{array}{r}3.685 \\
.678\end{array}$ & $\begin{array}{r}3.689 \\
.665\end{array}$ & $\begin{array}{l}3.568 \\
1.074\end{array}$ & $\begin{array}{r}3.952 \\
.842\end{array}$ & $\begin{array}{r}3.243 \\
.904\end{array}$ & $\begin{array}{l}2.391 \\
---\end{array}$ \\
\hline-0.8 & $\begin{array}{l}3.410 \\
-\ldots\end{array}$ & $\begin{array}{l}3.256 \\
---\end{array}$ & $\begin{array}{l}3.919 \\
1.062\end{array}$ & $\begin{array}{r}4.020 \\
.837\end{array}$ & $\begin{array}{r}3.961 \\
.982\end{array}$ & $\begin{array}{l}3.878 \\
1.077\end{array}$ & $\begin{array}{l}3.726 \\
1.131\end{array}$ & $\begin{array}{l}3.632 \\
1.100\end{array}$ & $\begin{array}{l}3.553 \\
1.082\end{array}$ & $\begin{array}{l}3.399 \\
1.012\end{array}$ & $\begin{array}{r}3.356 \\
.833\end{array}$ & $\begin{array}{r}3.287 \\
.783\end{array}$ & $\begin{array}{r}3.474 \\
.747\end{array}$ & $\begin{array}{r}3.481 \\
.609\end{array}$ & $\begin{array}{r}3.519 \\
.840\end{array}$ & $\begin{array}{r}3.580 \\
.507\end{array}$ & $\begin{array}{r}2.933 \\
.824\end{array}$ & $\begin{array}{l}2.112 \\
-\cdots\end{array}$ \\
\hline-0.4 & $\begin{array}{l}3.197 \\
-\end{array}$ & $\begin{array}{l}4.391 \\
3.638\end{array}$ & $\begin{array}{l}3.823 \\
1.307\end{array}$ & $\begin{array}{l}3.633 \\
1.236\end{array}$ & $\begin{array}{l}3.608 \\
1.108\end{array}$ & $\begin{array}{l}3.443 \\
1.069\end{array}$ & $\begin{array}{l}3.294 \\
1.121\end{array}$ & $\begin{array}{l}3.188 \\
1.126\end{array}$ & $\begin{array}{l}3.079 \\
1.131\end{array}$ & $\begin{array}{l}2.936 \\
1.059\end{array}$ & $\begin{array}{r}2.927 \\
.869\end{array}$ & $\begin{array}{r}2.917 \\
.762\end{array}$ & $\begin{array}{r}3.072 \\
.656\end{array}$ & $\begin{array}{r}3.116 \\
.524\end{array}$ & $\begin{array}{r}3.108 \\
.603\end{array}$ & $\begin{array}{r}3.129 \\
.483\end{array}$ & $\begin{array}{r}2.698 \\
.733\end{array}$ & 1.913 \\
\hline 0.0 & 2.917 & $\begin{array}{l}3.802 \\
2.159\end{array}$ & $\begin{array}{r}3.384 \\
.958\end{array}$ & $\begin{array}{l}3.076 \\
1.092\end{array}$ & $\begin{array}{l}3.132 \\
1.020\end{array}$ & $\begin{array}{l}2.969 \\
1.042\end{array}$ & $\begin{array}{l}2.851 \\
1.028\end{array}$ & $\begin{array}{l}2.731 \\
1.021\end{array}$ & $\begin{array}{l}2.617 \\
1.050\end{array}$ & $\begin{array}{l}2.446 \\
1.032\end{array}$ & $\begin{array}{r}2.436 \\
.851\end{array}$ & $\begin{array}{r}2.457 \\
.714\end{array}$ & $\begin{array}{r}2.638 \\
.585\end{array}$ & $\begin{array}{r}2.674 \\
.462\end{array}$ & $\begin{array}{r}2.582 \\
.584\end{array}$ & $\begin{array}{r}2.657 \\
.502\end{array}$ & $\begin{array}{r}2.459 \\
.611\end{array}$ & $\begin{array}{l}1.726 \\
-. .\end{array}$ \\
\hline 0.4 & $\begin{array}{l}2.534 \\
--. .\end{array}$ & $\begin{array}{l}3.273 \\
1.598\end{array}$ & $\begin{array}{r}2.893 \\
.860\end{array}$ & $\begin{array}{r}2.727 \\
.696\end{array}$ & $\begin{array}{r}2.769 \\
.737\end{array}$ & $\begin{array}{r}2.692 \\
.745\end{array}$ & $\begin{array}{r}2.559 \\
.745\end{array}$ & $\begin{array}{r}2.437 \\
.760\end{array}$ & $\begin{array}{r}2.316 \\
.756\end{array}$ & $\begin{array}{r}2.155 \\
.733\end{array}$ & $\begin{array}{r}1.963 \\
.766\end{array}$ & $\begin{array}{r}1.960 \\
.675\end{array}$ & $\begin{array}{r}2.174 \\
.516\end{array}$ & $\begin{array}{r}2.262 \\
.411\end{array}$ & $\begin{array}{r}2.296 \\
.498\end{array}$ & $\begin{array}{r}2.421 \\
.424\end{array}$ & $\begin{array}{r}2.219 \\
.433\end{array}$ & 1.574 \\
\hline 0.8 & $\begin{array}{l}2.266 \\
-\cdots\end{array}$ & $\begin{array}{l}2.844 \\
1.072\end{array}$ & $\begin{array}{r}2.413 \\
.739\end{array}$ & $\begin{array}{r}2.317 \\
.576\end{array}$ & $\begin{array}{r}2.285 \\
.599\end{array}$ & $\begin{array}{r}2.300 \\
.591\end{array}$ & $\begin{array}{r}2.207 \\
.629\end{array}$ & $\begin{array}{r}2.104 \\
.617\end{array}$ & $\begin{array}{r}1.987 \\
.582\end{array}$ & $\begin{array}{r}1.846 \\
.558\end{array}$ & $\begin{array}{r}1.718 \\
.551\end{array}$ & $\begin{array}{r}1.519 \\
.612\end{array}$ & $\begin{array}{r}1.684 \\
.465\end{array}$ & $\begin{array}{r}1.824 \\
.367\end{array}$ & $\begin{array}{r}1.938 \\
.459\end{array}$ & $\begin{array}{r}2.116 \\
.358\end{array}$ & $\begin{array}{r}1.999 \\
.337\end{array}$ & $\begin{array}{l}1.409 \\
\cdots\end{array}$ \\
\hline 1.2 & $\begin{array}{l}1.728 \\
----\end{array}$ & 1.574 & $\begin{array}{r}1.431 \\
.213\end{array}$ & $\begin{array}{r}2.067 \\
.601\end{array}$ & $\begin{array}{r}2.127 \\
.428\end{array}$ & $\begin{array}{r}2.058 \\
.481\end{array}$ & $\begin{array}{r}1.966 \\
.527\end{array}$ & $\begin{array}{r}1.844 \\
.510\end{array}$ & $\begin{array}{r}1.713 \\
.468\end{array}$ & $\begin{array}{r}1.598 \\
.434\end{array}$ & $\begin{array}{r}1.498 \\
.427\end{array}$ & $\begin{array}{r}1.388 \\
.410\end{array}$ & $\begin{array}{r}1.175 \\
.416\end{array}$ & $\begin{array}{r}1.358 \\
.349\end{array}$ & $\begin{array}{r}1.544 \\
.433\end{array}$ & $\begin{array}{r}1.788 \\
.312\end{array}$ & $\begin{array}{r}1.769 \\
.308\end{array}$ & $\begin{array}{l}1.197 \\
-\cdots\end{array}$ \\
\hline 1.6 & -... & --- & $-\cdots$ & $\begin{array}{r}2.125 \\
.041\end{array}$ & $\begin{array}{r}1.808 \\
.130\end{array}$ & $\begin{array}{r}1.780 \\
.311\end{array}$ & $\begin{array}{r}1.687 \\
.373\end{array}$ & $\begin{array}{r}1.628 \\
.371\end{array}$ & $\begin{array}{r}1.481 \\
.342\end{array}$ & $\begin{array}{r}1.385 \\
.335\end{array}$ & $\begin{array}{r}1.297 \\
.338\end{array}$ & $\begin{array}{r}1.215 \\
.340\end{array}$ & $\begin{array}{r}1.114 \\
.340\end{array}$ & $\begin{array}{l}.946 \\
.383\end{array}$ & $\begin{array}{r}1.195 \\
.390\end{array}$ & $\begin{array}{r}1.438 \\
.252\end{array}$ & $\begin{array}{r}1.512 \\
.223\end{array}$ & $\begin{array}{r}.998 \\
-.-\end{array}$ \\
\hline 2.0 & $-\cdots$ & -...- & -..- & 1.590 & $\begin{array}{l}1.371 \\
\cdots\end{array}$ & $\begin{array}{r}1.811 \\
.160\end{array}$ & $\begin{array}{r}1.718 \\
.297\end{array}$ & $\begin{array}{r}1.676 \\
.229\end{array}$ & $\begin{array}{r}.1507 \\
.242\end{array}$ & $\begin{array}{r}1.419 \\
.232\end{array}$ & $\begin{array}{r}1.340 \\
.232\end{array}$ & $\begin{array}{r}1.269 \\
.234\end{array}$ & $\begin{array}{r}1.198 \\
.232\end{array}$ & $\begin{array}{r}1.109 \\
.237\end{array}$ & $\begin{array}{l}.960 \\
.276\end{array}$ & $\begin{array}{r}1.054 \\
.183\end{array}$ & $\begin{array}{r}1.257 \\
.139\end{array}$ & $\begin{array}{r}.814 \\
---\end{array}$ \\
\hline 2.4 & --- & ---- & -..- & -..- & --- & $\begin{array}{r}1.734 \\
.020\end{array}$ & $\begin{array}{r}1.729 \\
.029\end{array}$ & $\begin{array}{r}1.414 \\
.072\end{array}$ & $\begin{array}{r}1.269 \\
.067\end{array}$ & $\begin{array}{r}1.168 \\
.080\end{array}$ & $\begin{array}{r}1.080 \\
.084\end{array}$ & $\begin{array}{r}1.014 \\
.083\end{array}$ & $\begin{array}{l}.949 \\
.083\end{array}$ & $\begin{array}{l}.879 \\
.083\end{array}$ & $\begin{array}{l}.802 \\
.084\end{array}$ & $\begin{array}{l}.672 \\
.096\end{array}$ & $\begin{array}{l}.923 \\
.017\end{array}$ & $\begin{array}{r}.652 \\
-. .\end{array}$ \\
\hline 2.8 & $\cdots$ & ---- & -...- & +..- & 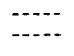 & - & $\begin{array}{l}1.604 \\
\cdots\end{array}$ & $\begin{array}{l}1.291 \\
-\end{array}$ & 1.195 & 1.096 & $\begin{array}{l}1.000 \\
-\cdots\end{array}$ & $\begin{array}{r}.936 \\
.9-\end{array}$ & $\begin{array}{r}.885 \\
-0.5\end{array}$ & $\begin{array}{r}.832 \\
-\end{array}$ & $\begin{array}{r}.780 \\
-\cdots\end{array}$ & $\begin{array}{r}.727 \\
-. . \\
\end{array}$ & $\begin{array}{r}.675 \\
-.-\end{array}$ & $\begin{array}{r}.496 \\
\hdashline-\end{array}$ \\
\hline 3.2 & - & --- & ---.- & $-\cdots$ & ---- & $\cdots$ & 1.284 & $\begin{array}{r}.971 \\
-\end{array}$ & $\begin{array}{r}.875 \\
-.-5\end{array}$ & $\begin{array}{r}.777 \\
-.--\end{array}$ & .681 & .671 & .565 & .512 & $\begin{array}{r}.460 \\
-\end{array}$ & $\begin{array}{r}.407 \\
-\end{array}$ & .355 & .176 \\
\hline$\hat{\mathrm{E}}\left[x \mid y_{D}=y_{j}\right]$ & 2.073 & 2.512 & 3.008 & 2.924 & 3.097 & 3.049 & 2.927 & 2.825 & 2.716 & 2.567 & 2.473 & 2.402 & 2.517 & 2.500 & 2.516 & 2.550 & 2.308 & 1.495 \\
\hline $\operatorname{var}\left[x \mid y_{D}=y_{j}\right]$ & 1.463 & 3.476 & 2.290 & 1.635 & 1.530 & 1.512 & 1.499 & 1.509 & 1.547 & 1.477 & 1.432 & 1.381 & 1.392 & 1.234 & 1.252 & 1.409 & 1.164 & .368 \\
\hline
\end{tabular}

Note: Upper values are the means, in feet, and lower values are the variances, in feet squared. 
Table 59. Conditional mecons and variances of step Lengths; $\hat{E}\left[x \mid Y_{E}=y_{i}, Y_{D}=y_{j}\right]$ and $\widehat{\operatorname{Var}}\left[x \mid Y_{E}=y_{i}, Y_{D}=y_{j}\right]$ (Run 17)

\begin{tabular}{|c|c|c|c|c|c|c|c|c|c|c|c|c|c|c|c|c|}
\hline$Y_{E}=y_{i} D^{-y_{j}}$ & -3.2 & -2.8 & -2.4 & -2.0 & -1.6 & -1.2 & -0.8 & -0.4 & 0.0 & 0.4 & 0.8 & 1.2 & 1.6 & 2.0 & 2.4 & 2.8 \\
\hline-3.2 & - & 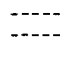 & $\cdots$ & -.-- & ---- & --- & ---- & -....- & --.-- & - & --- & --..- & $-\cdots$ & $-\cdots$ & $-\cdots$ & \\
\hline-2.8 & --- & $-\cdots-$ & $-\cdots$ & ---- & ---- & $-\cdots-$ & $\begin{array}{l}4.657 \\
-\ldots .-\end{array}$ & $\begin{array}{r}3.553 \\
.343\end{array}$ & $\begin{array}{r}3.157 \\
.113\end{array}$ & 2.792 & 2.663 & $-\cdots$ & $-\cdots$ & ---- & ---- & ---- \\
\hline-2.4 & $-\cdots$ & $-\cdots$ & - & $\begin{array}{l}3.984 \\
-.---\end{array}$ & $\begin{array}{l}3.909 \\
----\end{array}$ & $\begin{array}{l}4.026 \\
1.057\end{array}$ & $\begin{array}{r}3.773 \\
.427\end{array}$ & $\begin{array}{r}3.354 \\
.407\end{array}$ & $\begin{array}{r}3.188 \\
.414\end{array}$ & $\begin{array}{r}3.191 \\
.504\end{array}$ & $\begin{array}{r}3.048 \\
.608\end{array}$ & $\begin{array}{r}3.206 \\
.491\end{array}$ & $\begin{array}{r}3.580 \\
.365\end{array}$ & $\begin{array}{r}3.308 \\
.340\end{array}$ & $-\cdots$ & $-\cdots$ \\
\hline-2.0 & -...- & $\ldots$ & n...- & $\begin{array}{r}4.118 \\
.395\end{array}$ & $\begin{array}{r}3.699 \\
.335\end{array}$ & $\begin{array}{r}3.441 \\
.725\end{array}$ & $\begin{array}{r}3.319 \\
.575\end{array}$ & $\begin{array}{r}3.285 \\
.596\end{array}$ & $\begin{array}{r}3.104 \\
.546\end{array}$ & $\begin{array}{r}3.051 \\
.531\end{array}$ & $\begin{array}{r}3.000 \\
.542\end{array}$ & $\begin{array}{r}3.030 \\
.456\end{array}$ & $\begin{array}{r}3.223 \\
.360\end{array}$ & $\begin{array}{r}2.868 \\
.245\end{array}$ & $-\cdots$ & \\
\hline-1.6 & $-\cdots$ & -..- & $\begin{array}{r}3.655 \\
.456\end{array}$ & $\begin{array}{r}3.693 \\
.320\end{array}$ & $\begin{array}{r}3.686 \\
.824\end{array}$ & $\begin{array}{r}3.471 \\
.751\end{array}$ & $\begin{array}{r}3.320 \\
.623\end{array}$ & $\begin{array}{r}3.210 \\
.565\end{array}$ & $\begin{array}{r}3.076 \\
.546\end{array}$ & $\begin{array}{r}3.056 \\
.475\end{array}$ & $\begin{array}{r}2.983 \\
.421\end{array}$ & $\begin{array}{r}2.932 \\
.327\end{array}$ & $\begin{array}{r}2.979 \\
.208\end{array}$ & $\begin{array}{r}2.633 \\
.247\end{array}$ & $-\cdots$ & \\
\hline-1.2 & $\cdots$ & -...- & $\begin{array}{l}3.066 \\
1.202\end{array}$ & $\begin{array}{r}3.369 \\
.700\end{array}$ & $\begin{array}{r}3.408 \\
.632\end{array}$ & $\begin{array}{r}3.117 \\
.611\end{array}$ & $\begin{array}{r}3.008 \\
.629\end{array}$ & $\begin{array}{r}2.922 \\
.589\end{array}$ & $\begin{array}{r}2.818 \\
.552\end{array}$ & $\begin{array}{r}2.816 \\
.477\end{array}$ & $\begin{array}{r}2.769 \\
.453\end{array}$ & $\begin{array}{r}2.704 \\
.411\end{array}$ & $\begin{array}{r}2.707 \\
.416\end{array}$ & $\begin{array}{r}2.515 \\
.706\end{array}$ & $-\ldots$ & \\
\hline-0.8 & --- & $\ldots$ & $\begin{array}{l}2.656 \\
1.053\end{array}$ & $\begin{array}{r}3.013 \\
.935\end{array}$ & $\begin{array}{r}3.017 \\
.733\end{array}$ & $\begin{array}{r}2.790 \\
.638\end{array}$ & $\begin{array}{r}2.662 \\
.681\end{array}$ & $\begin{array}{r}2.574 \\
.610\end{array}$ & $\begin{array}{r}2.499 \\
.530\end{array}$ & $\begin{array}{r}2.476 \\
-.452\end{array}$ & $\begin{array}{r}2.465 \\
.408\end{array}$ & $\begin{array}{r}2.441 \\
.342\end{array}$ & $\begin{array}{r}2.411 \\
.330\end{array}$ & $\begin{array}{r}2.259 \\
.391\end{array}$ & ----- & \\
\hline-0.4 &.- & -..- & $\begin{array}{r}2.516 \\
.833\end{array}$ & $\begin{array}{r}2.772 \\
.664\end{array}$ & $\begin{array}{r}2.709 \\
.613\end{array}$ & $\begin{array}{r}2.461 \\
.583\end{array}$ & $\begin{array}{r}2.354 \\
.616\end{array}$ & $\begin{array}{r}2.232 \\
.608\end{array}$ & $\begin{array}{r}2.141 \\
.529\end{array}$ & $\begin{array}{r}2.129 \\
.445\end{array}$ & $\begin{array}{r}2.151 \\
.383\end{array}$ & $\begin{array}{r}2.187 \\
.354\end{array}$ & $\begin{array}{r}2.219 \\
.407\end{array}$ & $\begin{array}{r}1.998 \\
.287\end{array}$ & 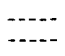 & \\
\hline 0.0 & - & 3.396 & $\begin{array}{r}2.878 \\
.223\end{array}$ & $\begin{array}{r}2.523 \\
.563\end{array}$ & $\begin{array}{r}2.379 \\
.522\end{array}$ & $\begin{array}{r}2.153 \\
.496\end{array}$ & $\begin{array}{r}2.041 \\
.516\end{array}$ & $\begin{array}{r}1.934 \\
.522\end{array}$ & $\begin{array}{r}1.792 \\
.502\end{array}$ & $\begin{array}{r}1.765 \\
.435\end{array}$ & $\begin{array}{r}1.814 \\
.351\end{array}$ & $\begin{array}{r}1.877 \\
.312\end{array}$ & $\begin{array}{r}1.942 \\
.358\end{array}$ & $\begin{array}{r}1.798 \\
.220\end{array}$ & ---- & \\
\hline 0.4 & $\cdots$ & $\begin{array}{r}2.110 \\
.965\end{array}$ & $\begin{array}{r}2.131 \\
.344\end{array}$ & $\begin{array}{r}2.123 \\
.457\end{array}$ & $\begin{array}{r}2.091 \\
.370\end{array}$ & $\begin{array}{r}1.896 \\
.360\end{array}$ & $\begin{array}{r}1.763 \\
.398\end{array}$ & $\begin{array}{r}1.652 \\
.405\end{array}$ & $\begin{array}{r}1.513 \\
.382\end{array}$ & $\begin{array}{r}1.377 \\
.403\end{array}$ & $\begin{array}{r}1.421 \\
.318\end{array}$ & $\begin{array}{r}1.521 \\
.260\end{array}$ & $\begin{array}{r}1.625 \\
.288\end{array}$ & $\begin{array}{r}1.527 \\
.181\end{array}$ & 1.624 & -- \\
\hline 0.8 & -- & 1.108 & $\begin{array}{r}1.636 \\
.439\end{array}$ & $\begin{array}{r}1.888 \\
.238\end{array}$ & $\begin{array}{r}1.846 \\
.237\end{array}$ & $\begin{array}{r}1.696 \\
.245\end{array}$ & $\begin{array}{r}1.573 \\
.289\end{array}$ & $\begin{array}{r}1.464 \\
.279\end{array}$ & $\begin{array}{r}1.332 \\
.257\end{array}$ & $\begin{array}{r}1.219 \\
.256\end{array}$ & $\begin{array}{r}1.069 \\
.272\end{array}$ & $\begin{array}{r}1.135 \\
.241\end{array}$ & $\begin{array}{r}1.291 \\
.247\end{array}$ & $\begin{array}{r}1.396 \\
.182\end{array}$ & 1.234 & ----- \\
\hline 1.2 & - & - & $\begin{array}{l}1.817 \\
---\end{array}$ & $\begin{array}{r}1.584 \\
.090\end{array}$ & $\begin{array}{r}1.621 \\
.220\end{array}$ & $\begin{array}{r}1.526 \\
.253\end{array}$ & $\begin{array}{r}1.400 \\
.245\end{array}$ & $\begin{array}{r}1.280 \\
.248\end{array}$ & $\begin{array}{r}1.146 \\
.214\end{array}$ & $\begin{array}{r}1.048 \\
.210\end{array}$ & $\begin{array}{l}.941 \\
.203\end{array}$ & $\begin{array}{l}.786 \\
.212\end{array}$ & $\begin{array}{l}.891 \\
.202\end{array}$ & $\begin{array}{l}.984 \\
.147\end{array}$ & $\begin{array}{r}.967 \\
-. .--\end{array}$ & $\cdots$ \\
\hline 1.6 & -... & - & $\begin{array}{l}1.226 \\
-\end{array}$ & $\begin{array}{r}1.285 \\
.106\end{array}$ & $\begin{array}{r}1.520 \\
.248\end{array}$ & $\begin{array}{r}1.540 \\
.254\end{array}$ & $\begin{array}{r}1.289 \\
.155\end{array}$ & $\begin{array}{r}1.190 \\
.183\end{array}$ & $\begin{array}{r}1.038 \\
.174\end{array}$ & $\begin{array}{l}.945 \\
.168\end{array}$ & $\begin{array}{l}.841 \\
.161\end{array}$ & $\begin{array}{l}.725 \\
.157\end{array}$ & $\begin{array}{l}.545 \\
.161\end{array}$ & $\begin{array}{l}.639 \\
.133\end{array}$ & $\begin{array}{r}.753 \\
\hdashline-\end{array}$ & -.- \\
\hline 2.0 & - & - & --..- & $\cdots$ & ---- & $\begin{array}{r}1.557 \\
.060\end{array}$ & $\begin{array}{r}1.366 \\
.053\end{array}$ & $\begin{array}{r}1.088 \\
.108\end{array}$ & $\begin{array}{l}.948 \\
.150\end{array}$ & $\begin{array}{l}.866 \\
.148\end{array}$ & $\begin{array}{l}.793 \\
.147\end{array}$ & $\begin{array}{l}.714 \\
.139\end{array}$ & $\begin{array}{l}.629 \\
.123\end{array}$ & $\begin{array}{l}.494 \\
.102\end{array}$ & $\begin{array}{r}.546 \\
-\end{array}$ & \\
\hline 2.4 & $-\ldots$ & ---- & $-\cdots$ & $-\cdots$ & - & $-\cdots-1$ & $\ldots$ &.--- & .941 & $\begin{array}{r}.796 \\
-. .-\end{array}$ & .682 & .577 & .494 & .411 & .328 & \\
\hline 2.8 & - & --- & --- & $\cdots$ & -..-- & ----- & -... & 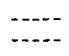 & -.--- & $-\ldots$ & -...- & -...- & - & $-\cdots$ & $\cdots$ &.-- \\
\hline$\hat{E}\left[x \mid Y_{D}=y_{j}\right]$ & -.-- & .989 & 2.311 & 2.473 & 2.440 & 2.271 & 2.153 & 2.042 & 1.925 & 1.866 & 1.841 & 1.847 & 1.899 & 1.777 & .506 & - \\
\hline$\hat{\operatorname{var}}\left[X \mid Y_{D}=y_{j}\right]$ & $\cdots$ & 1.815 & 1.104 & 1.069 & 1.010 & .845 & .861 & .849 & .811 & .818 & .797 & .762 & .765 & .606 & .424 & - \\
\hline
\end{tabular}

Note: Upper values are the means, in feet, and lower values are the variances, in feet squared. 
SUPPLEMENTAL DATA TABLES

Table 60. Estimates of parameters describing two-parameter garma distribution for conditional step lengths (Run 4A)

\begin{tabular}{|c|c|c|c|c|c|c|c|c|c|c|c|c|c|c|c|c|}
\hline$Y_{E}=y_{i}$ & -3.2 & -2.8 & -2.4 & -2.0 & -1.6 & -1.2 & -0.8 & -0.4 & 0.0 & 0.4 & 0.8 & 1.2 & 1.6 & 2.0 & 2.4 & 2.8 \\
\hline-3.2 & & and & 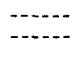 & $\ldots$ & ........ & $\begin{array}{l}2.438 \\
7.407\end{array}$ & $\begin{array}{l}2.006 \\
5.700\end{array}$ & $\begin{array}{l}2.551 \\
8.034\end{array}$ & $\begin{array}{r}36.109 \\
131.689\end{array}$ & $\begin{array}{l}25.170 \\
89.329\end{array}$ & $\begin{array}{l}18.010 \\
61.956\end{array}$ & $\begin{array}{l}10.871 \\
24.818\end{array}$ & -..... & --.- & & \\
\hline-2.8 & & n. & -....... & $\ldots$ & $\begin{array}{r}2.657 \\
11.086\end{array}$ & $\begin{array}{l}1.780 \\
6.804\end{array}$ & $\begin{array}{l}1.887 \\
6.832\end{array}$ & $\begin{array}{l}2.214 \\
7.494\end{array}$ & $\begin{array}{r}3.172 \\
10.275\end{array}$ & $\begin{array}{r}3.822 \\
12.258\end{array}$ & $\begin{array}{r}3.395 \\
10.848\end{array}$ & $\begin{array}{r}8.236 \\
24.420\end{array}$ & $\begin{array}{r}7.008 \\
19.397\end{array}$ & -.... & & \\
\hline-2.4 & & $\begin{array}{r}9.748 \\
35.444\end{array}$ & $\begin{array}{l}24.356 \\
78.305\end{array}$ & $\begin{array}{l}1.195 \\
5.654\end{array}$ & $\begin{array}{r}2.683 \\
10.795\end{array}$ & $\begin{array}{l}1.950 \\
7.029\end{array}$ & $\begin{array}{l}1.966 \\
6.834\end{array}$ & $\begin{array}{l}2.024 \\
6.901\end{array}$ & $\begin{array}{l}2.549 \\
8.817\end{array}$ & $\begin{array}{l}2.904 \\
9.749\end{array}$ & $\begin{array}{r}3.425 \\
11.335\end{array}$ & $\begin{array}{r}4.285 \\
13.644\end{array}$ & $\begin{array}{r}3.248 \\
10.389\end{array}$ & - & & \\
\hline-2.0 & & $\begin{array}{r}5.451 \\
17.978\end{array}$ & $\begin{array}{r}3.929 \\
15.120\end{array}$ & $\begin{array}{r}2.991 \\
12.603\end{array}$ & $\begin{array}{r}3.825 \\
14.422\end{array}$ & $\begin{array}{r}3.007 \\
10.245\end{array}$ & $\begin{array}{l}3.036 \\
9.901\end{array}$ & $\begin{array}{l}2.931 \\
9.182\end{array}$ & $\begin{array}{r}3.557 \\
11.035\end{array}$ & $\begin{array}{r}3.877 \\
11.772\end{array}$ & $\begin{array}{r}4.414 \\
12.954\end{array}$ & $\begin{array}{r}5.222 \\
15.193\end{array}$ & $\begin{array}{r}4.243 \\
12.730\end{array}$ & $\begin{array}{r}2.866 \\
12.348\end{array}$ & & \\
\hline-1.6 & & $\begin{array}{r}5.617 \\
15.998\end{array}$ & $\begin{array}{l}2.643 \\
7.780\end{array}$ & $\begin{array}{l}2.052 \\
7.012\end{array}$ & $\begin{array}{l}2.756 \\
8.929\end{array}$ & $\begin{array}{l}2.698 \\
8.561\end{array}$ & $\begin{array}{l}3.104 \\
9.548\end{array}$ & $\begin{array}{l}3.069 \\
9.173\end{array}$ & $\begin{array}{r}3.795 \\
11.217\end{array}$ & $\begin{array}{r}4.059 \\
11.762\end{array}$ & $\begin{array}{r}4.681 \\
13.126\end{array}$ & $\begin{array}{r}4.996 \\
13.855\end{array}$ & $\begin{array}{r}5.045 \\
14.226\end{array}$ & $\begin{array}{r}3.531 \\
12.305\end{array}$ & & \\
\hline-1.2 & & $\begin{array}{l}3.530 \\
9.545\end{array}$ & $\begin{array}{l}2.822 \\
8.039\end{array}$ & $\begin{array}{l}2.683 \\
8.096\end{array}$ & $\begin{array}{l}2.179 \\
6.834\end{array}$ & $\begin{array}{l}2.204 \\
6.750\end{array}$ & $\begin{array}{l}2.460 \\
7.319\end{array}$ & $\begin{array}{l}2.728 \\
7.787\end{array}$ & $\begin{array}{l}3.220 \\
9.042\end{array}$ & $\begin{array}{l}3.405 \\
9.623\end{array}$ & $\begin{array}{r}3.742 \\
10.168\end{array}$ & $\begin{array}{r}3.974 \\
10.768\end{array}$ & $\begin{array}{r}4.085 \\
11.328\end{array}$ & $\begin{array}{l}3.009 \\
9.555\end{array}$ & 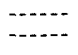 & \\
\hline-0.8 & $\begin{array}{r}48.352 \\
126.247\end{array}$ & $\begin{array}{r}6.321 \\
15.664\end{array}$ & $\begin{array}{r}4.174 \\
10.803\end{array}$ & $\begin{array}{l}2.916 \\
8.011\end{array}$ & $\begin{array}{l}2.449 \\
6.822\end{array}$ & $\begin{array}{l}2.317 \\
6.147\end{array}$ & $\begin{array}{l}2.430 \\
6.276\end{array}$ & $\begin{array}{l}2.824 \\
7.074\end{array}$ & $\begin{array}{l}3.291 \\
8.221\end{array}$ & $\begin{array}{l}3.671 \\
9.202\end{array}$ & $\begin{array}{l}3.958 \\
9.761\end{array}$ & $\begin{array}{r}4.151 \\
10.390\end{array}$ & $\begin{array}{l}3.830 \\
9.811\end{array}$ & $\begin{array}{l}2.493 \\
7.176\end{array}$ & -- & \\
\hline-0.4 & $\begin{array}{l}21.245 \\
44.232\end{array}$ & $\begin{array}{l}2.911 \\
7.086\end{array}$ & $\begin{array}{l}3.148 \\
7.889\end{array}$ & $\begin{array}{l}2.070 \\
5.358\end{array}$ & $\begin{array}{l}2.050 \\
5.163\end{array}$ & $\begin{array}{l}2.051 \\
5.035\end{array}$ & $\begin{array}{l}2.334 \\
5.451\end{array}$ & $\begin{array}{l}2.357 \\
5.138\end{array}$ & $\begin{array}{l}2.811 \\
6.100\end{array}$ & $\begin{array}{l}3.349 \\
7.358\end{array}$ & $\begin{array}{l}3.663 \\
8.076\end{array}$ & $\begin{array}{l}4.041 \\
9.193\end{array}$ & $\begin{array}{l}3.614 \\
8.529\end{array}$ & $\begin{array}{l}2.126 \\
5.535\end{array}$ & . & \\
\hline 0.0 & & $\begin{array}{r}4.199 \\
10.736\end{array}$ & $\begin{array}{l}3.938 \\
9.058\end{array}$ & $\begin{array}{l}2.374 \\
5.697\end{array}$ & $\begin{array}{l}2.127 \\
4.837\end{array}$ & $\begin{array}{l}2.049 \\
4.551\end{array}$ & $\begin{array}{l}2.193 \\
4.567\end{array}$ & $\begin{array}{l}2.259 \\
4.357\end{array}$ & $\begin{array}{l}2.210 \\
3.972\end{array}$ & $\begin{array}{l}2.767 \\
5.100\end{array}$ & $\begin{array}{l}3.298 \\
6.319\end{array}$ & $\begin{array}{l}3.701 \\
7.424\end{array}$ & $\begin{array}{l}3.854 \\
8.020\end{array}$ & $\begin{array}{l}1.813 \\
4.261\end{array}$ & $\cdots$ & - \\
\hline 0.4 & & $\begin{array}{l}2.452 \\
5.668\end{array}$ & $\begin{array}{r}5.078 \\
13.066\end{array}$ & $\begin{array}{l}2.401 \\
5.678\end{array}$ & $\begin{array}{l}2.190 \\
4.727\end{array}$ & $\begin{array}{l}2.257 \\
4.636\end{array}$ & $\begin{array}{l}2.468 \\
4.697\end{array}$ & $\begin{array}{l}2.390 \\
4.130\end{array}$ & $\begin{array}{l}2.446 \\
3.902\end{array}$ & $\begin{array}{l}2.256 \\
3.242\end{array}$ & $\begin{array}{l}3.073 \\
4.674\end{array}$ & $\begin{array}{l}3.818 \\
6.342\end{array}$ & $\begin{array}{l}4.135 \\
7.336\end{array}$ & $\begin{array}{l}1.751 \\
3.654\end{array}$ & 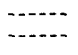 & 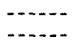 \\
\hline 0.8 & - & - & $\begin{array}{l}2.391 \\
5.101\end{array}$ & $\begin{array}{l}2.098 \\
4.734\end{array}$ & $\begin{array}{l}1.932 \\
4.073\end{array}$ & $\begin{array}{l}2.309 \\
4.464\end{array}$ & $\begin{array}{l}2.572 \\
4.566\end{array}$ & $\begin{array}{l}2.530 \\
4.058\end{array}$ & $\begin{array}{l}2.616 \\
3.765\end{array}$ & $\begin{array}{l}2.693 \\
3.517\end{array}$ & $\begin{array}{l}2.709 \\
3.053\end{array}$ & $\begin{array}{l}3.390 \\
4.217\end{array}$ & $\begin{array}{l}3.905 \\
5.443\end{array}$ & $\begin{array}{l}1.654 \\
3.025\end{array}$ & -... & - \\
\hline 1.2 & - & - & - & $\begin{array}{l}3.018 \\
6.879\end{array}$ & $\begin{array}{l}1.941 \\
4.248\end{array}$ & $\begin{array}{l}2.171 \\
4.190\end{array}$ & $\begin{array}{l}2.805 \\
4.926\end{array}$ & $\begin{array}{l}2.600 \\
4.111\end{array}$ & $\begin{array}{l}2.741 \\
3.763\end{array}$ & $\begin{array}{l}2.804 \\
3.373\end{array}$ & $\begin{array}{l}3.310 \\
3.429\end{array}$ & $\begin{array}{l}2.890 \\
2.515\end{array}$ & $\begin{array}{l}3.259 \\
3.155\end{array}$ & $\begin{array}{l}1.457 \\
2.197\end{array}$ & $\cdots$ & ....... \\
\hline 1.6 & - & $-\cdots$ & - & $\begin{array}{l}6.299 \\
9.562\end{array}$ & $\begin{array}{l}1.051 \\
1.869\end{array}$ & $\begin{array}{l}1.791 \\
3.021\end{array}$ & $\begin{array}{l}2.891 \\
4.503\end{array}$ & $\begin{array}{l}2.327 \\
3.497\end{array}$ & $\begin{array}{l}3.038 \\
3.913\end{array}$ & $\begin{array}{l}2.877 \\
3.285\end{array}$ & $\begin{array}{l}3.414 \\
3.182\end{array}$ & $\begin{array}{l}2.953 \\
2.398\end{array}$ & $\begin{array}{l}2.204 \\
1.311\end{array}$ & $\begin{array}{l}1.304 \\
1.410\end{array}$ & - & $\ldots$ \\
\hline 2.0 & & - & . & . & - & - & $\cdots$ & $\begin{array}{l}16.369 \\
22.507\end{array}$ & $\begin{array}{l}9.050 \\
9.828\end{array}$ & $\begin{array}{l}7.632 \\
7.281\end{array}$ & $\begin{array}{l}6.789 \\
5.900\end{array}$ & $\begin{array}{l}5.947 \\
4.668\end{array}$ & $\begin{array}{l}4.673 \\
3.211\end{array}$ & $\begin{array}{l}2.266 \\
1.042\end{array}$ & ........... & $\ldots$ \\
\hline 2.4 & & $\cdots$ & - & - & - & - & n...- & -.... & - & -..... & - n & $\cdots$ & 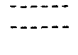 & $\cdots$ & 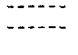 & \\
\hline 2.8 & & $\cdots$ & 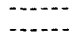 & $\cdots+\cdots$ & $\cdots$ & 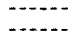 & $\cdots$ & -..... & -...... & --.-- & 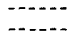 & -..... & - & $\ldots$ & $\cdots$ & \\
\hline
\end{tabular}

Note: Upper values are $k_{1, y, y^{\prime}}$ and lower values are $r_{1, y, y^{\prime}}$. 
Table 61. Estimates of parameters describing two-paraneter gamma distribution for conditional step lengths (Run 16)

\begin{tabular}{|c|c|c|c|c|c|c|c|c|c|c|c|c|c|c|c|c|c|c|}
\hline$Y_{E}=y_{i} Y_{D}=y_{j}$ & -3.6 & -3.2 & -2.8 & -2.4 & -2.0 & -1.6 & -1.2 & -0.8 & -0.4 & 0.0 & 0.4 & 0.8 & 1.2 & 1.6 & 2.0 & 2.4 & 2.8 & 3.2 \\
\hline-3.6 & $-\cdots$ & $-\cdots$ & - & $\cdots$ & $-\cdots$ & $-\cdots-$ & $\cdots$ & n...... & $\cdots$ & $-\cdots$ & - & - & $\cdots$ & $-\cdots$ & $-\cdots$ & - & - & ....... \\
\hline-3.2 & $-\cdots$ & 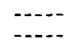 & - & $-\cdots$ & - & - & - & - & -..... & -..- & --.-- & - & 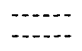 & - & $\cdots$ & ----. & - & 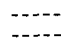 \\
\hline-2.8 & $-\cdots$ & $-\cdots$ & 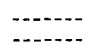 & - & $\begin{array}{r}5.681 \\
21.885\end{array}$ & $\begin{array}{r}4.261 \\
19.393\end{array}$ & $\begin{array}{r}3.772 \\
16.773\end{array}$ & $\begin{array}{r}4.616 \\
19.817\end{array}$ & $\begin{array}{r}4.978 \\
20.620\end{array}$ & $\begin{array}{r}4.639 \\
18.683\end{array}$ & $\begin{array}{r}3.661 \\
14.032\end{array}$ & $\begin{array}{r}3.760 \\
13.897\end{array}$ & $\begin{array}{r}6.684 \\
25.600\end{array}$ & ....... & -..-. & -..... & -...... & 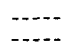 \\
\hline-2.4 & $-\cdots$ & $-\cdots$ & $\begin{array}{l}135.437 \\
586.986\end{array}$ & $\begin{array}{r}9.454 \\
41.739\end{array}$ & $\begin{array}{r}4.295 \\
19.532\end{array}$ & $\begin{array}{r}4.711 \\
21.727\end{array}$ & $\begin{array}{r}4.291 \\
19.827\end{array}$ & $\begin{array}{r}4.254 \\
19.060\end{array}$ & $\begin{array}{r}4.359 \\
19.017\end{array}$ & $\begin{array}{r}4.853 \\
20.464\end{array}$ & $\begin{array}{r}4.555 \\
18.507\end{array}$ & $\begin{array}{r}4.227 \\
16.702\end{array}$ & $\begin{array}{r}4.637 \\
18.126\end{array}$ & -.... & --.- & - & - & -... \\
\hline-2.0 & $-\cdots$ & $\ldots$ & $\begin{array}{r}62.463 \\
216.406\end{array}$ & $\begin{array}{r}8.215 \\
36.777\end{array}$ & $\begin{array}{r}5.714 \\
26.418\end{array}$ & $\begin{array}{r}6.087 \\
28.158\end{array}$ & $\begin{array}{r}6.458 \\
29.150\end{array}$ & $\begin{array}{r}5.900 \\
26.179\end{array}$ & $\begin{array}{r}4.866 \\
21.406\end{array}$ & $\begin{array}{r}5.661 \\
23.906\end{array}$ & $\begin{array}{r}5.608 \\
22.900\end{array}$ & $\begin{array}{r}5.490 \\
21.582\end{array}$ & $\begin{array}{r}6.116 \\
24.537\end{array}$ & $\begin{array}{l}18.045 \\
64.800\end{array}$ & $\begin{array}{l}14.018 \\
43.820\end{array}$ & -...... & -...... & -...- \\
\hline-1.6 & $\cdots$ & ---- & $\begin{array}{r}2.394 \\
11.129\end{array}$ & $\begin{array}{r}3.328 \\
15,462\end{array}$ & $\begin{array}{r}4.132 \\
18.339\end{array}$ & $\begin{array}{r}4.384 \\
19.832\end{array}$ & $\begin{array}{r}4.693 \\
20.503\end{array}$ & $\begin{array}{r}4.555 \\
19.708\end{array}$ & $\begin{array}{r}3.993 \\
17.016\end{array}$ & $\begin{array}{r}4.276 \\
17.424\end{array}$ & $\begin{array}{r}4.802 \\
19.117\end{array}$ & $\begin{array}{r}4.853 \\
18.607\end{array}$ & $\begin{array}{r}5.439 \\
21.686\end{array}$ & $\begin{array}{r}6.211 \\
23.920\end{array}$ & $\begin{array}{r}3.281 \\
12.521\end{array}$ & $\begin{array}{r}5.163 \\
22.873\end{array}$ & -..... & -.... \\
\hline-1.2 & $\cdots$ & $-\cdots$ & $\begin{array}{r}3.142 \\
13.795\end{array}$ & $\begin{array}{r}4.194 \\
18.928\end{array}$ & $\begin{array}{r}4.138 \\
17.772\end{array}$ & $\begin{array}{r}3.956 \\
16.890\end{array}$ & $\begin{array}{r}4.284 \\
17.622\end{array}$ & $\begin{array}{r}4.400 \\
17.771\end{array}$ & $\begin{array}{r}4.031 \\
15.889\end{array}$ & $\begin{array}{r}4.299 \\
16.263\end{array}$ & $\begin{array}{r}4.938 \\
18.243\end{array}$ & $\begin{array}{r}5.052 \\
17.997\end{array}$ & $\begin{array}{r}5.435 \\
20.028\end{array}$ & $\begin{array}{r}5.547 \\
20.464\end{array}$ & $\begin{array}{r}3.322 \\
11.853\end{array}$ & $\begin{array}{r}4.694 \\
18.549\end{array}$ & $\begin{array}{r}3.587 \\
11.634\end{array}$ & $\ldots$ \\
\hline-0.8 & $-\cdots$ & -...- & $\begin{array}{r}3.690 \\
14.462\end{array}$ & $\begin{array}{r}4.803 \\
19.308\end{array}$ & $\begin{array}{r}4.034 \\
15.977\end{array}$ & $\begin{array}{r}3.601 \\
13.964\end{array}$ & $\begin{array}{r}3.294 \\
12.275\end{array}$ & $\begin{array}{r}3.302 \\
11.992\end{array}$ & $\begin{array}{r}3.284 \\
11.667\end{array}$ & $\begin{array}{r}3.359 \\
11.416\end{array}$ & $\begin{array}{r}4.029 \\
13.521\end{array}$ & $\begin{array}{r}4.198 \\
13.799\end{array}$ & $\begin{array}{r}4.651 \\
16.156\end{array}$ & $\begin{array}{r}5.716 \\
19.897\end{array}$ & $\begin{array}{r}4.189 \\
14.742\end{array}$ & $\begin{array}{r}7.061 \\
25.279\end{array}$ & $\begin{array}{r}3.559 \\
10.440\end{array}$ & -... \\
\hline-0.4 & $-\cdots$ & $\begin{array}{l}1.207 \\
5.300\end{array}$ & $\begin{array}{r}2.925 \\
11.182\end{array}$ & $\begin{array}{r}2.939 \\
10.678\end{array}$ & $\begin{array}{r}3.256 \\
11.749\end{array}$ & $\begin{array}{r}3.221 \\
11.089\end{array}$ & $\begin{array}{l}2.938 \\
9.679\end{array}$ & $\begin{array}{l}2.831 \\
9.026\end{array}$ & $\begin{array}{l}2.722 \\
8.382\end{array}$ & $\begin{array}{l}2.772 \\
8.140\end{array}$ & $\begin{array}{l}3.368 \\
9.859\end{array}$ & $\begin{array}{r}3.828 \\
11.166\end{array}$ & $\begin{array}{r}4.683 \\
14.386\end{array}$ & $\begin{array}{r}5.946 \\
18.529\end{array}$ & $\begin{array}{r}5.154 \\
16.019\end{array}$ & $\begin{array}{r}6.478 \\
20.270\end{array}$ & $\begin{array}{l}3.681 \\
9.931\end{array}$ & -..- \\
\hline 0.0 & $\cdots$ & $\begin{array}{l}1.761 \\
6.695\end{array}$ & $\begin{array}{r}3.532 \\
11.954\end{array}$ & $\begin{array}{l}2.817 \\
8.665\end{array}$ & $\begin{array}{l}3.070 \\
9.617\end{array}$ & $\begin{array}{l}2.849 \\
8.460\end{array}$ & $\begin{array}{l}2.773 \\
7.907\end{array}$ & $\begin{array}{l}2.675 \\
7.305\end{array}$ & $\begin{array}{l}2.492 \\
6.523\end{array}$ & $\begin{array}{l}2.370 \\
5.797\end{array}$ & $\begin{array}{l}2.862 \\
6.973\end{array}$ & $\begin{array}{l}3.441 \\
8.455\end{array}$ & $\begin{array}{r}4.509 \\
11.896\end{array}$ & $\begin{array}{r}5.788 \\
15.477\end{array}$ & $\begin{array}{r}4.421 \\
11.416\end{array}$ & $\begin{array}{r}5.293 \\
14.063\end{array}$ & $\begin{array}{l}4.024 \\
9.896\end{array}$ & $-\cdots$ \\
\hline 0.4 & $-\cdots$ & $\begin{array}{l}2.048 \\
6.704\end{array}$ & $\begin{array}{l}3.364 \\
9.732\end{array}$ & $\begin{array}{r}3.918 \\
10.685\end{array}$ & $\begin{array}{r}3.757 \\
10.403\end{array}$ & $\begin{array}{l}3.613 \\
9.727\end{array}$ & $\begin{array}{l}3.435 \\
8.790\end{array}$ & $\begin{array}{l}3.206 \\
7.814\end{array}$ & $\begin{array}{l}3.063 \\
7.095\end{array}$ & $\begin{array}{l}2.940 \\
6.336\end{array}$ & $\begin{array}{l}2.563 \\
5.030\end{array}$ & $\begin{array}{l}2.904 \\
5.691\end{array}$ & $\begin{array}{l}4.213 \\
9.159\end{array}$ & $\begin{array}{r}5.504 \\
12.449\end{array}$ & $\begin{array}{r}4.610 \\
10.586\end{array}$ & $\begin{array}{r}5.710 \\
13.824\end{array}$ & $\begin{array}{r}5.125 \\
11.372\end{array}$ & 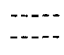 \\
\hline 0.8 & $-\cdots$ & $\begin{array}{l}1.671 \\
4.752\end{array}$ & $\begin{array}{l}3.265 \\
7.879\end{array}$ & $\begin{array}{l}4.022 \\
9.320\end{array}$ & $\begin{array}{l}3.815 \\
8.716\end{array}$ & $\begin{array}{l}3.892 \\
8.951\end{array}$ & $\begin{array}{l}3.509 \\
7.744\end{array}$ & $\begin{array}{l}3.410 \\
7.175\end{array}$ & $\begin{array}{l}3.414 \\
6.784\end{array}$ & $\begin{array}{l}3.308 \\
6.107\end{array}$ & $\begin{array}{l}3.118 \\
5.357\end{array}$ & $\begin{array}{l}2.482 \\
3.770\end{array}$ & $\begin{array}{l}3.622 \\
6.099\end{array}$ & $\begin{array}{l}4.970 \\
9.065\end{array}$ & $\begin{array}{l}4.222 \\
8.183\end{array}$ & $\begin{array}{r}5.911 \\
12.507\end{array}$ & $\begin{array}{r}5.932 \\
11.858\end{array}$ & -.... \\
\hline 1.2 & $-\cdots$ & --- & $\begin{array}{l}6.718 \\
9.614\end{array}$ & $\begin{array}{l}3.439 \\
7.109\end{array}$ & $\begin{array}{r}4.970 \\
10.570\end{array}$ & $\begin{array}{l}4.279 \\
8.805\end{array}$ & $\begin{array}{l}3.730 \\
7.334\end{array}$ & $\begin{array}{l}3.616 \\
6.667\end{array}$ & $\begin{array}{l}3.660 \\
6.270\end{array}$ & $\begin{array}{l}3.682 \\
5.884\end{array}$ & $\begin{array}{l}3.508 \\
5.255\end{array}$ & $\begin{array}{l}3.385 \\
4.699\end{array}$ & $\begin{array}{l}2.824 \\
3.319\end{array}$ & $\begin{array}{l}3.891 \\
5.284\end{array}$ & $\begin{array}{l}3.566 \\
5.506\end{array}$ & $\begin{array}{r}5.731 \\
10.247\end{array}$ & $\begin{array}{r}5.744 \\
10.160\end{array}$ & -...- \\
\hline 1.6 & $-\cdots$ & -... & - & --.-- & $\begin{array}{l}13.908 \\
25.145\end{array}$ & $\begin{array}{r}5.723 \\
10.188\end{array}$ & $\begin{array}{l}4.523 \\
7.630\end{array}$ & $\begin{array}{l}4.388 \\
7.144\end{array}$ & $\begin{array}{l}4.330 \\
6.413\end{array}$ & $\begin{array}{l}4.134 \\
5.726\end{array}$ & $\begin{array}{l}3.837 \\
4.977\end{array}$ & $\begin{array}{l}3.574 \\
4.342\end{array}$ & $\begin{array}{l}3.276 \\
3.650\end{array}$ & $\begin{array}{l}2.470 \\
2.336\end{array}$ & $\begin{array}{l}3.064 \\
3.662\end{array}$ & $\begin{array}{l}5.706 \\
8.206\end{array}$ & $\begin{array}{r}6.780 \\
10.252\end{array}$ & -..... \\
\hline 2.0 & $\cdots$ & $\cdots$ & -..... & ----- & - & $\begin{array}{l}11.319 \\
20.498\end{array}$ & $\begin{array}{l}5.784 \\
9.938\end{array}$ & $\begin{array}{r}7.319 \\
12.266\end{array}$ & $\begin{array}{l}6.227 \\
9.384\end{array}$ & $\begin{array}{l}6.116 \\
8.679\end{array}$ & $\begin{array}{l}5.776 \\
7.740\end{array}$ & $\begin{array}{l}5.423 \\
6.882\end{array}$ & $\begin{array}{l}5.164 \\
6.186\end{array}$ & $\begin{array}{l}4.679 \\
5.189\end{array}$ & $\begin{array}{l}3.478 \\
3.339\end{array}$ & $\begin{array}{l}5.760 \\
6.070\end{array}$ & $\begin{array}{r}9.043 \\
11.367\end{array}$ & -...... \\
\hline 2.4 & $-\cdots$ & $-\cdots$ & --- & --.-- & $\cdots$ & - & -...-- & $\begin{array}{l}19.639 \\
27.769\end{array}$ & - & $\begin{array}{l}14.600 \\
17.053\end{array}$ & $\begin{array}{l}12.857 \\
13.886\end{array}$ & $\begin{array}{l}12.217 \\
12.387\end{array}$ & $\begin{array}{l}11.434 \\
10.851\end{array}$ & $\begin{array}{r}10.590 \\
9.309\end{array}$ & $\begin{array}{l}9.548 \\
7.657\end{array}$ & $\begin{array}{l}7.000 \\
4.704\end{array}$ & $-\cdots$ & (n... \\
\hline 2.8 & & -..- & & & & -..... & -..... & $\cdots$ & & & & & & & & & & \\
\hline 3.2 & $\cdots$ & $-\cdots$ & - & --n- & - & - & 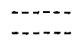 & $-\cdots$ & - & $\cdots$ & -...- & - & --- & $+\cdots$ & $-\cdots$ & 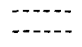 & - & - \\
\hline
\end{tabular}


Table 62. Estimates of parameters describing two-parameter gama distribution for conditional step lengths (Run 17)

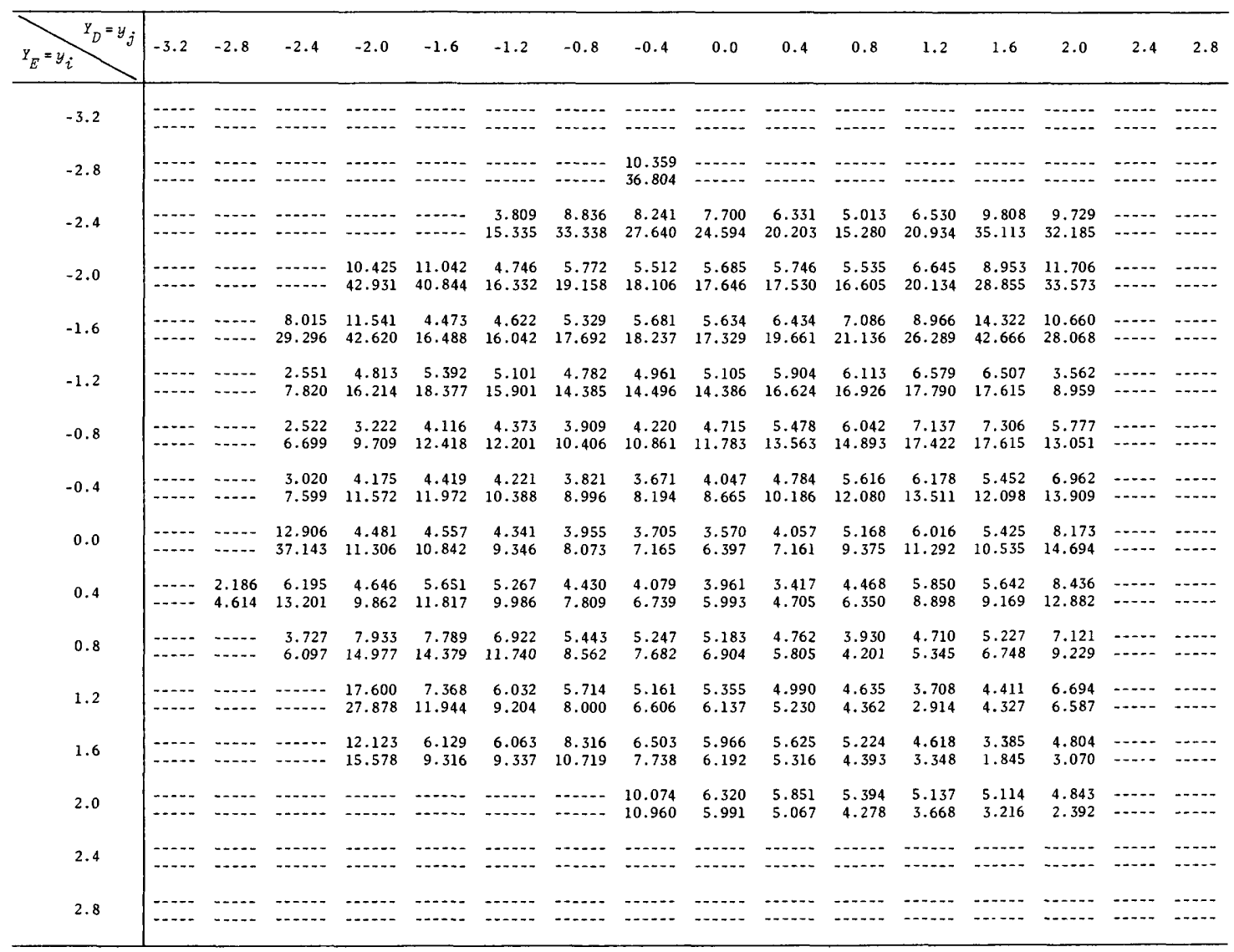

Note: Upper values are $k_{1, y, y^{\prime}}$ and lower values are $r_{1, y, y^{\prime}}$. 
Table 63. Results of goodness of fit test for conditional step lengths (Run 4A)

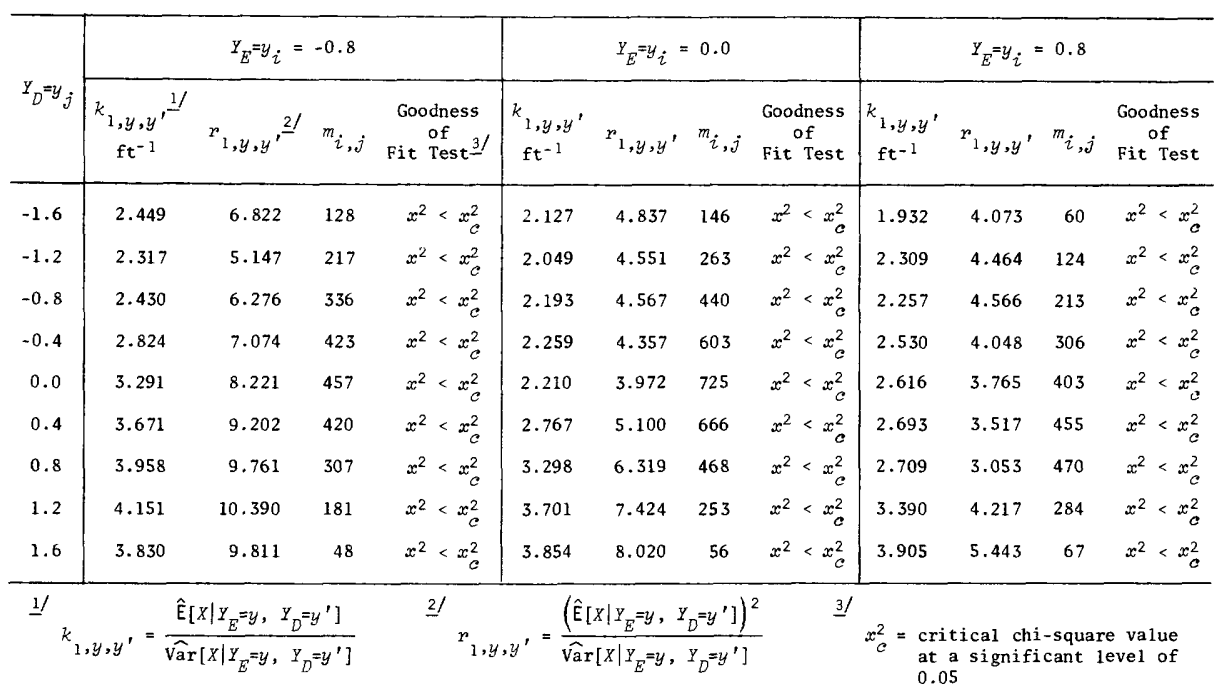

Table 64. Results of goodness of fit test for conditional step lengths (Run 16)

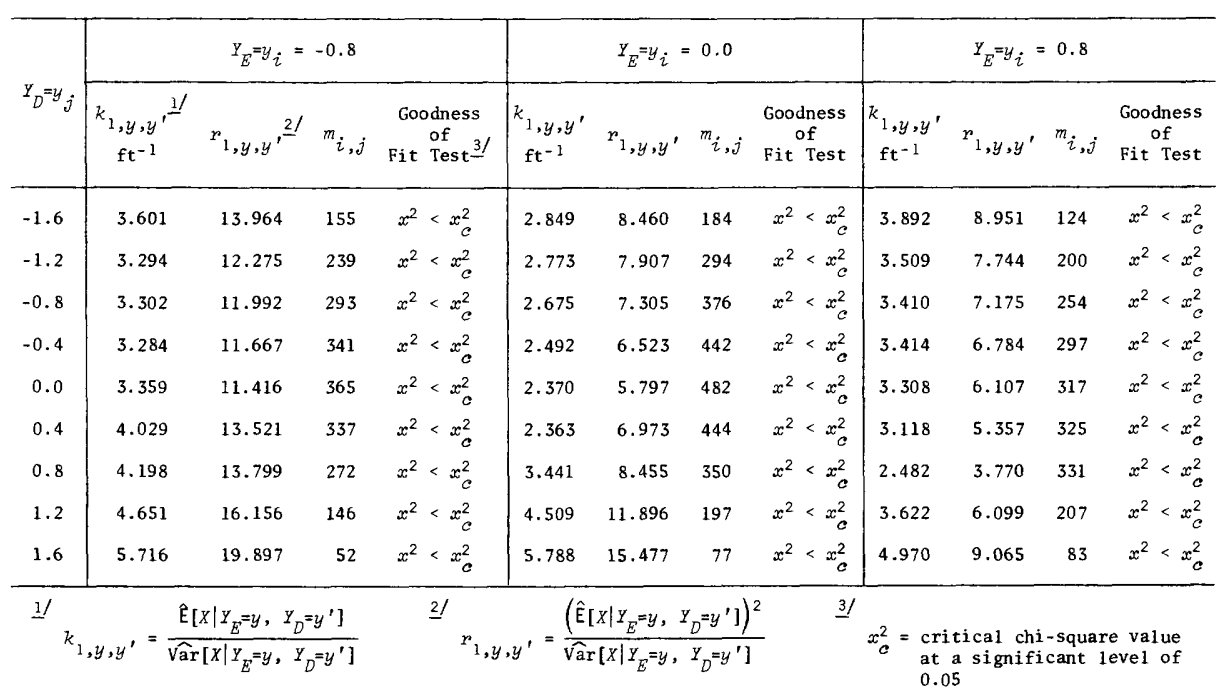

Table 65. Results of goodness of fit test for conditional step lengths (Run 17)

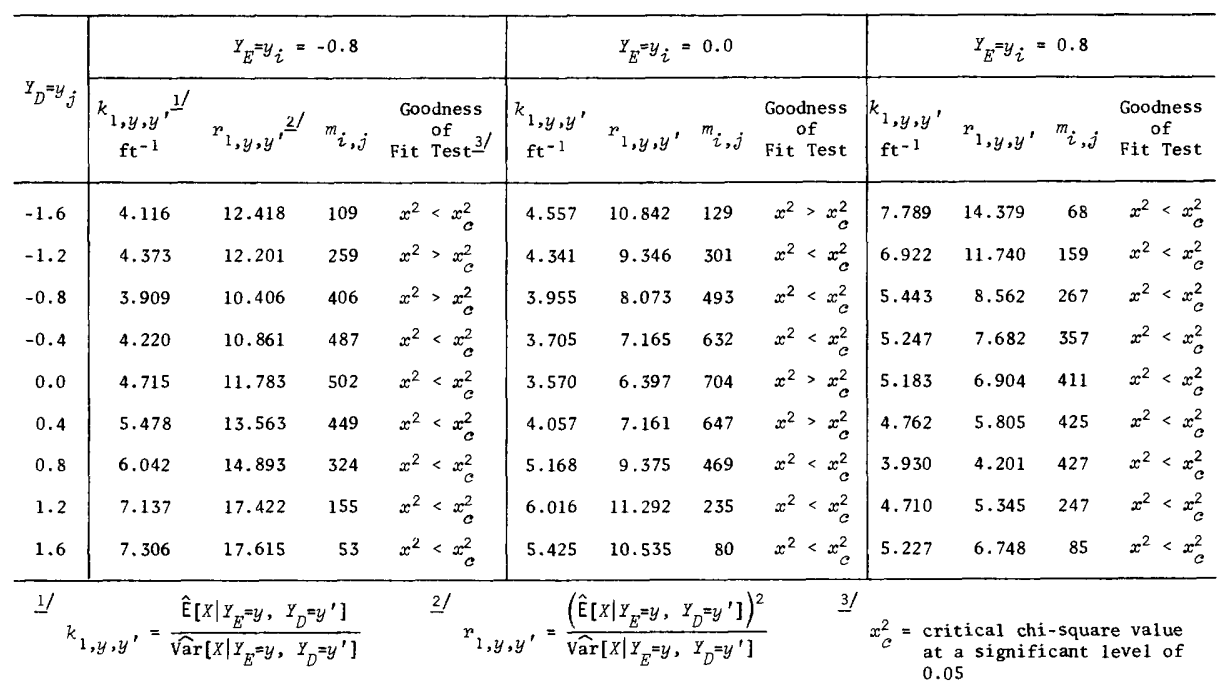



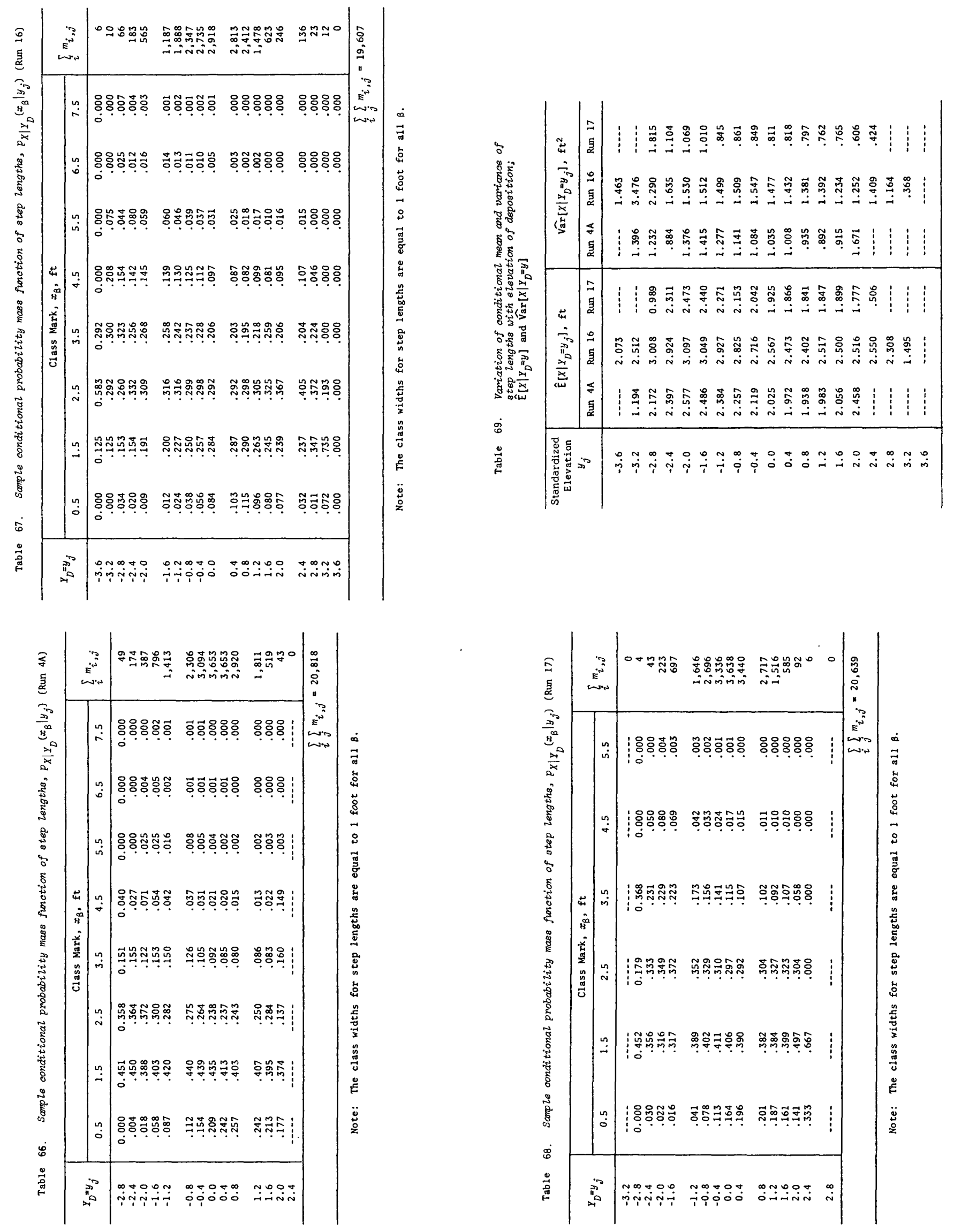

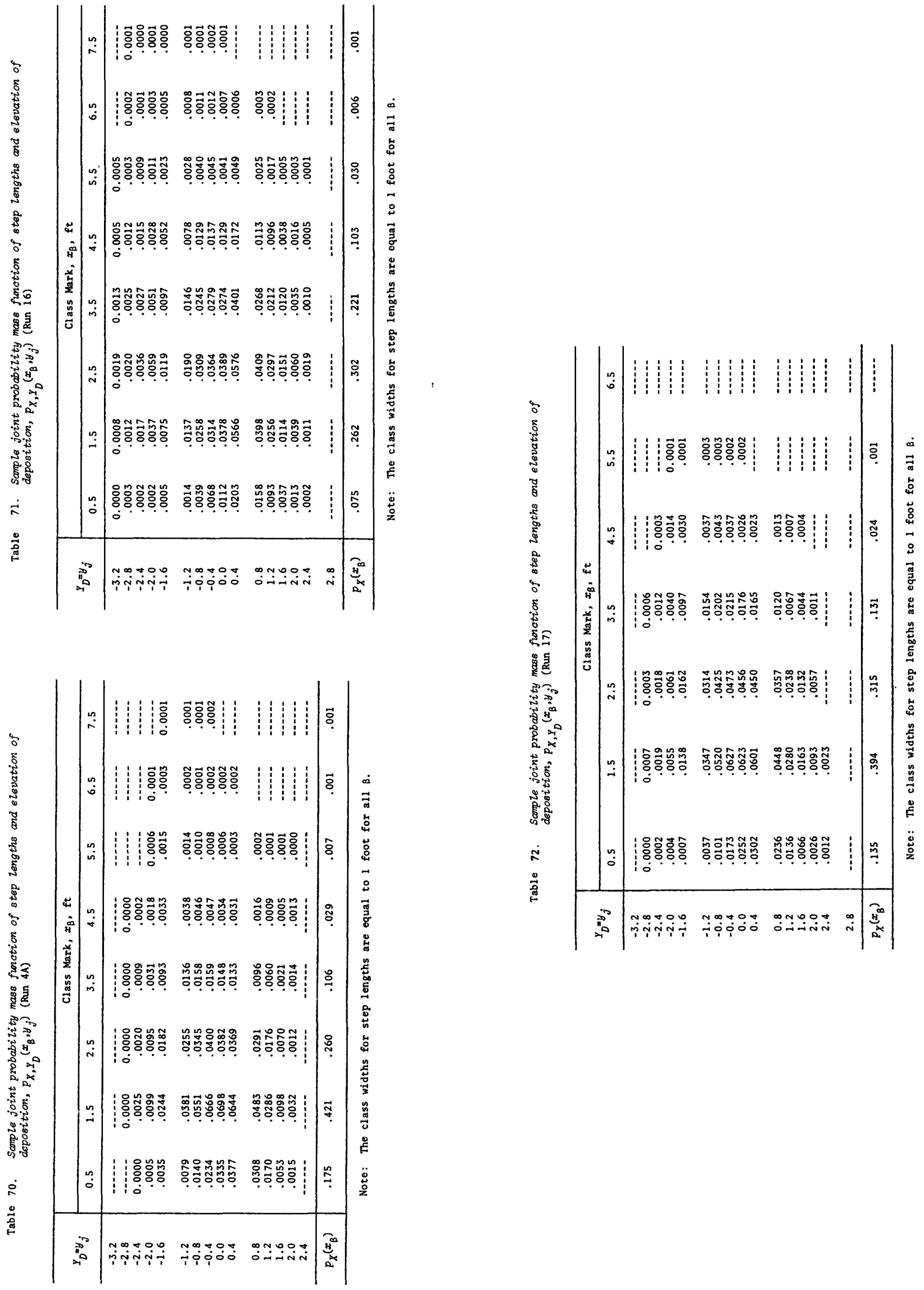

